\title{
Ardian Klosi
}

\section{Mythologie am Werk: \\ Kazantzakis, Andrić, Kadare}

\section{Eine vergleichende Untersuchung am besonderen Beispiel des Bauopfermotivs}

Verlag Otto Sagner München - Berlin - Washington D.C.

Digitalisiert im Rahmen der Kooperation mit dem DFG-Projekt „Digi20“

der Bayerischen Staatsbibliothek, München. OCR-Bearbeitung und Erstellung des eBooks durch den Verlag Otto Sagner:

http://verlag.kubon-sagner.de

( $)$ bei Verlag Otto Sagner. Eine Verwertung oder Weitergabe der Texte und Abbildungen, insbesondere durch Vervielfältigung, ist ohne vorherige schriftliche Genehmigung des Verlages unzulässig. 


\title{
SLAvistische BeIträge
}

\author{
BEGRÜNDET VON \\ ALOIS SCHMAUS \\ HERAUSGEGEGEN VON \\ HEINRICH KUNSTMANN \\ PETER REHDER · JOSEF SCHRENK \\ REDAKTION \\ PETER REHDER
}

Band 277 


\section{Ardian Klosi}

\section{MYTHOLOGIE AM WERK: KAZANTZAKIS, ANDRIĆ, KADARE ; \\ Eine vergleichende Untersuchung am besonderen Beispiel des Bauopfermotivs}

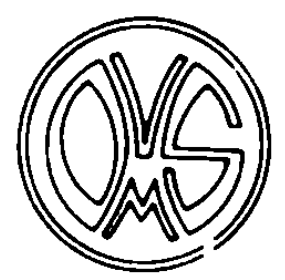

VERLAG OTTO SAGNER - MÜNCHEN 1991 


\section{Diese Arbeit wurde mit einem Förderpreis der Südosteuropa-Gesellschaft ausgezeichnet.}

Bayerische

Staatsbitiliothek München

ISBN 3-87690-494-3

(c) Verlag Otto Sagner, München 1991

Abteilung der Firma Kubon \& Sagner, München 


\section{Vorwort}

Die folgende Arbeit, die zuerst als Dissertation der Leopold-FranzensUniversität in Innsbruck vorgelegt wurde, ist Ergebnis eines 1987 angefangenen Studiums am dortigen Institut für Vergleichende Literaturwissenschaft sowie der Beschäftigung mit den Teilbereichen Mythologie, südosteuropäische Volkskunde, Geschichte und Literatur, u.a. Obwohl sie etliche Gebiete der geisteswissenschaftlichen Forschung anschneidet, liegt ihr Hauptinteresse auf Schwerpunkten, die folgende Fragen beantworten wollen: Was für einen Stellenwert hat die Mythologie im Werk dreier bedeutender Schriftsteller aus dem Südosten Europas, wie schlagen sich mythische Motive in ihrem Werk nieder, und wie hat jeder von ihnen ein bestimmtes, auf dem Balkan sehr verbreitetes Motiv verarbeitet? Diesen Fragen gehen eine Darstellung und ein Interpretationsversuch des Bauopfermythos voraus, die der verglcichenden Analyse als Diskussionsbasis dienen sollen.

Die Südosteuropaforschung weist bis zum heutigen Tag, außer in den Balkanländern selbst, besonders im deutschsprachigen Raum eine jahrzehntelange Tradition auf. Zahlreich sind nicht nur spezielle Studien in den Bereichen Volkskunde, Ethnographie, Sprache, Geschichte, Politik, Literatur u.a., sondern auch jene vergleichenden Untersuchungen, die - einzelne Erscheinungen der Balkanländer auf einer Ebene betrachtend - das gemeinsam Balkanische zu beleuchten versuchen. Ich brauche hier nur an zwei Arbeiten zu erinnern, die schon um die Jahrhundertwende gerade das Motiv des Bauopfers in seiner Verbreitung auf dem Balkan beschrieben haben: an Kristian Schladebachs "Die aromunische Ballade von der Arta-Brücke"l und an Karl Dietrichs "Die Volksdichtung der Balkanländer in ihren gemeinsamen Elementen"2.

Während der Vergleich sprachlicher, volkskundlicher oder geschichtlicher Stoffe bereits Schule gemacht hat, sind komparatistische Arbeiten über die moderne Literatur aus Südosteuropa kaum vorhanden. Ich beziehe mich hier hauptsächlich auf die Stichwörter: zeitgenössische

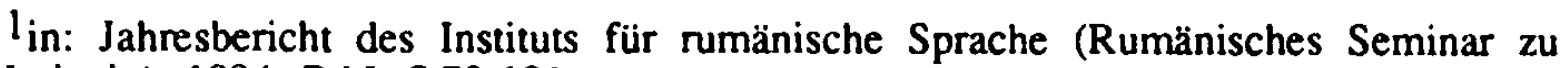
Leipzig), 1894, Bd.I, S.79-121.

2Zeitschrift des Vereins für Volkskunde, zwölfter Jahrgang. Berlin 1902, S.145-155; 272-291; 391-402. 
Prosa; albanische, neugriechische, serbische Literatur; Kazantzakis, Andrić, Kadare. In den Ländem des Balkans sind solche Studien vielleicht deswegen selten, weil die Literatur aus dem Nachbarland oft unzureichend bekannt ist. Im Ausland dagegen war das Interesse vornehmlich auf das Verhältnis der Schriftsteller aus Südosteuropa zu den großen europäischen Literaturen gelenkt ${ }^{\text {. }}$.

Dic moderne Literatur der Halbinsel ist offensichtlich kein unbedeutendes Feld für vergleichende Ansätze. Bei den drei Schriftstellem dieser Arbeit stößt man wiederholt auf Gemeinsamkeiten, Parallelen, Analogien; sie treten nicht nur als Widerspiegelung der gemeinsamen und ähnlichen Geschichte, der ähnlichen Mentalität und geistigen Konstitution der Einwohner dieser Region auf, sondem auch als Parallelen zwischen den Persönlichkeiten der Schriftsteller selbst. In dieser Hinsicht scheint der Vergleich der Schriftsteller in diesem Raum, wenn auch kompliziert, so doch sehr fruchtbar: Im Unterschied zu anderen vergleichenden Gebieten wie Ethnographie oder Sprachwissenschaft bezieht er außer dem Kollektiven auch und besonders das Individuelle in die Analyse ein. Ich werde versuchen, das Gemeinsame im entsprechenden Kapitel (5) zu unterstreichen, bin jedoch sicher, daß manches, besonders partielle Übereinstimmungen, unerwähnt bleiben wird.

Die Porträts in Kapitel 2, 3 und 4 möchte ich nicht nur als eine Präsentation der Schriftsteller, sondem auch als eine Hilfe zum besseren Verständnis des eigentlichen Schwerpunkts dieser Arbeit einführen: Mythologie im Werk des Schriftstellers.

Herzlicher Dank geht an alle, die diese Arbeit unterstützt haben, sowie an die Verleger und Herausgeber des Buches. Für das aufmerksame Lesen des Manuskripts bin ich Herm Prof Dr. Zoran Konstantinovic, Herm Prof. Dr. Hermann Olberg, Frau Dr. Renate Reck und Herm Dr. Gerhard Pail besonders dankbar, für die Betreuung während meines Studiums in Innsbruck bin ich Frau Doz. Dr. Fridrun Rinner und den anderen Kollegen des Instituts für Vergleichende Literaturwissenschaft zu Dank verpflichtet.

Tirana, 1990

\footnotetext{
lJoseph Matl spürt den Mangel schon im Jahre 1962: die südosteuropäische realistische Literatur soll nicht wie bisher nur in ihren Verbindungen mit der französischen, bzw. russischen, sondern auch untereinander in den gemeinsamen Zügen verglichen werden (Sprache und Dichtung als Schicksalsspiegel der südosteuropäischen Völker, in: Die Kultur Südosteuropas, ihre Geschichte und ihre Ausdrucksformen. München 1964, S.188).
} 
Inhalt

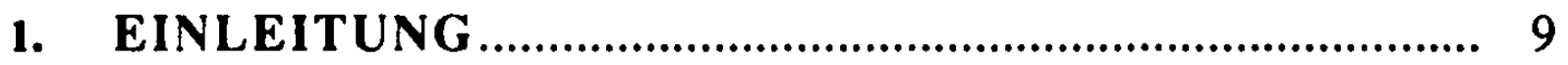

1.1. Zur Terminologie.......................................................... 11

1.2. Über die Ballade........................................................... 13

1.3. Zur Interpretation............................................................ 19

2. NIKOS KAZANTZAKIS - Verflochtene Glaubenswege

2.1. Stationen seines Lebens............................................................ 29

2.2. Ästhetische und philosophische Ansichten.................................... 36

2.3. „Griechische Passion“.............................................................. 42

2.4. „DER BAUMEISTER“...................................................... 48

3. IVO ANDRIC - Zweifaches Verhältnis zum Mythos

3.1. Kurze Biographie............................................................ 55

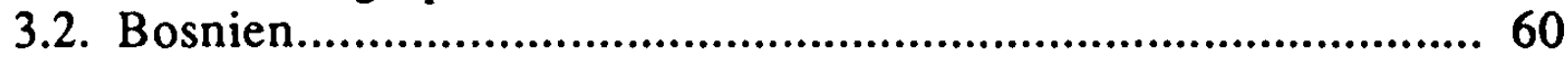

3.3. Orient - Abendland............................................................... 63

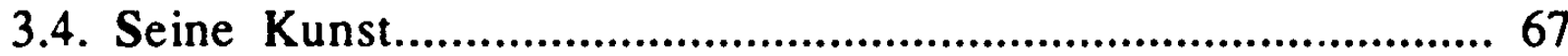

3.5. „DIE BRÜCKE ÜBER DIE DRINA“..................................... 70

4. ISMAIL KADARE - Mythologie als Schauplatz und Inhalt der Fiktion

4.1. Kurze Biographie und Werkregister...................................... 79

4.2. Das Werk.................................................................... 82

4.3. Das Motiv des Widerstandes.................................................. 83

4.4. Das Osmanische Reich, ein Modell des totalitären Superstaates....................................................................... 91

4.5. Im Spiegel der Erinnerungen............................................ 98

Mythologie in der Struktur des Werkes

4.6. „Wer hat Doruntina zurückgebracht"“................................... 102

4.7. „DIE BRÜCKE MIT DREI BOGEN““.................................... 110

5. GEGENÜBERSTELLUNG, ZUSAMMENFASSUNG UND SCHLUSSWORT

5.1. Die Schriftsteller im Überblick.......................................... 117

5.2. Das Motiv im Vergleich................................................. 125

Literaturverzeichnis......................................................... 129

ANHANG 1- Varianten der Ballade...................................... 135

$\begin{array}{ll}\text { ANHANG 2- } & \begin{array}{l}\text { Nikos Kazantzakis: } \\ \text { Der Baumeister - eine Tragödie................................ } 155\end{array}\end{array}$ 


\section{EINLEITUNG}

Also sind die Mauern wie die Bäume eine Geburt der Mutter Ende, und durch die Fundamente, wie die Bäume durch die Wurzeln, mit dem Mutterleibe auch nach der Geburt in fortdauemder fester Verbindung.

J. J. Bachofen

Warum wurde die Mythologie als Stichwort und Vergleichsbasis dieser Arbeit gewählt? Vor allem, weil sie einen Autor in den tiefen Beziehungen zu den Wurzeln seiner Tradition und zugleich zu seinem eigenen Hintergrund zeigt; die Dichtung kann vergessene, überdeckte Situationen einer mythischen Vergangenheit sichtbar machen und dadurch zum besseren Verständnis der Welt und uns selbst führen. Außerdem, weil besonders in unserer Zeit die Skepsis gegenüber traditionellen Werten wie bürgerlicher Moral, reiner Vernunft, christlichen Kategorien, materieller und konsumorientierter Denkweise mehrfach die Auseinandersetzung des Schriftstellers mit mythischen Themen und Werten angeregt hat. Wir brauchen hier nur an G. Hauptmann, Th. Mann, B. Brecht, J. Joyce, D.H. Lawrence, E. O'Neill, J. Anouilh, H. Miller ${ }^{l}$ zu denken, die sich direkt oder indirekt mythischen Stoffen zugewandt haben. Dieses Interesse der Literatur war Teil einer allgemeinen breiteren und regen Forschung auf dem Gebiet der Mythologie; bedeutende Ergebnisse sind hierbei durch die Mythologie- und Religionsgeschichte, die Völkerkunde, die Psychologie, den Strukturalismus, die Anthropologie u.a. erzielt worden. Die Liste der Forscher könnte sehr lang werden; es sei hier nur an Namen wie W. Wundt, C.G. Jung, J.G. Frazer, C. Lévi-Strauss, E. Fromm, G. Devereux, K. Kerényi, M. Eliade, R. Barthes erinnert. Das besondere Interesse, auf das die Mythen in unserer Zeit stoßen, versuchten verschiedene Studierende zu formulieren; einen treffenden Ausdruck finde ich beispielsweise in H.W. Haussigs Vorwort zu: Götter und Mythen im alten Europa. Stuttgart 1973: "Es mag paradox erscheinen, wenn in unserem Jahrhundert, das wie kein fruiheres die Lösung der Welträtsel auf den Wegen der Naturwissenschaften, Mathematik

lErwăhnenswert hier ihre einschlăgigen Werke: "Die Atriden Tetralogie", "Der Erwăhlıe", "Die Antigone des Sophokles", "Ulysses", "Apokalypse", "Mourning becomes Electra", "Antigone" und "Médée", "The Colossus of Maroussi". 
und Technik zu finden hoffte, das Zeichen des Mythos wieder aufgerichtet werden soll... Der Wiedergewinn jener verlorenen Mythen verheißt wie überhaupt jede Rückerinnerung an die Frühzeit der Geschichte Halt und Behauptung gegen den [technisierenden] alles gleichmachenden Strom der Gegenwart".

Das besondere Verhältnis zu Mythologie, Legende und Volksdichtung ist für die Literaturen aus Südosteuropa zweifellos ein Charakteristikum, vergleichbar mit dem Verhältnis der lateinamerikanischen Literaturen zum mythischen Erbe ihrer Länder: Andrić, Kadare und andere machen oft von der mythischen Überlieferung ihres eigenen Landes ebenso tiefgreifend $\mathrm{Ge}$ brauch wie Miguel Angel Asturias oder Garcia Marquez von den lateinamerikanischen Sagen und "magischen" Realitäten. Ein Beweis dafür wäre allein das Echo, das diese Autoren - ebenso wie Kazantzakis mit seinem "Alexis Sorbas" und "Kapetan Michalis" - in Westeuropa gefunden haben, ein Anklang, der zu einem guten Teil mit dem "Ethnologischen" ihrer Werke zusammenhängt. Folklore, Legenden und Sagen des eigenen Volkes in die Literatur zu bringen, das stellt für die Schriftsteller in Westeuropa, aus bekannten Ursachen, eine fast abgeschlossene Vergangenheit dar. Auf dem Balkan war die Volksdichtung dagegen bis in unser Jahrhundert ungewöhnlich lebendig; die Gründe dafür sind ebenfalls bekannt und mehrmals untersucht worden 1 . Die Schriftsteller befanden sich in einer Situation, die es ihnen erlaubte, einerseits den überlieferten Reichtum auszunutzen, andererseits mit den literarischen Entwicklungen bzw. Strömungen in Europa Schritt zu halten.

Das "Ethnographische" ist hier jedoch nicht Gegenstand der Betrachtung. Der Begriff Mythologie wurde auch im Unterschied dazu als Schwerpunkt gewählt. Die Fragen, inwieweit Kazantzakis, Andrić oder Kadare von der Volksdichtung ihres Landes beeinflußt worden sind, wie es mit dem folkloristischen Kolorit in ihren Werken aussieht usw., könnten sicherlich ein Thema für sich sein, die Mythologie hat aber nur begrenzt mit lokalen dichterischen Formen zu tun und weist eher auf allgemeingültige Motive und auf allgemein bekannte Stoffe in den verschiedensten Völkem und Teilen der Welt hin.

Das Besondere bei mehreren Autoren aus dem betreffenden Raum, zumindest bei Kazantzakis, Andrić und Kadare, stellt nun das Phänomen dar, daß ihnen die volkstümliche Überlieferung - Balladen, Legenden, Sagen - als eine Brücke zum mythischen Stoff dient, und das bedeutet sicher eine ungewöhnli-

\footnotetext{
${ }^{1}$ Maximilian Braun beschreibt das Phänomen, wie folgt: "...Es fehlten - mit wenigen, örtich und zeitlich begrenzten Ausnahmen - die Voraussetzungen für eine literarische Entwicklung; die Volksdichtung war als künstlerisches Ausdrucksmittel praktisch konkurrenzlos, wurde zum Sammelbecken individueller Begabungen, konnte somit hohes künstlerisches Niveau und autoritative Geltung erreichen und schließlich sogar die literarische Entwicklung mitbestimmen.

Das hohe Niveau wurde zusätzlich gefördert durch die kulturgeographische Lage der Balkanländer im Schnittpunkt literarisch produktiver Kulturkreise. Aus diesen Nachbarkulturen kamen zahlreiche dichterische Anregungen, die der schöpferischen Phantasie zusätzliche Impulse gaben" (Die geschichtliche Wirksamkeit der Volksdichtung, in: Beiträge zur Südosteuropa-Forschung. München 1966, S 273).
} 
che Bereicherung ihrer Prosa. Dies macht auch einen näheren Blick auf die jeweilige individuelle Art der Verwirklichung sowie die Diskussion auf einer vergleichenden Ebene nützlich.

Warum gerade das Bauopfermotiv? Von einigen Balladen und Legenden, die heute noch immer unter den Völkern des Balkans bekannt sind, birgt diejenige der Einmauerung eines unschuldigen Wesens in die Fundamente eines wichtigen Bauwerkes vielleicht am meisten Erinnerungen an mythische Zeiten in sich. In dieser Hinsicht bin ich meinem Dissertationsbetreuer und Leiter des Instituts für Vergleichende Literaturwissenschaft, Prof. Dr. Z. Konstantinović, dankbar für den Hinweis, dieses Motiv zu untersuchen. Die Ballade war in verschiedenen Varianten auf dem ganzen Balkan verbreitet, sie wurde von mehreren Schriftstellem behandelt ${ }^{1}$. Die drei Autoren dieser Untersuchung haben sie auch in einschlägigen Werken aufgegriffen, auf individuelle Weise dargelegt und interpretiert. Es ist durchaus möglich, daß es unter den erwähnten Werken auch solche gibt, die das Balladenmotiv auf ausführlichere und interessantere Weise als Kazantzakis, Andrić oder Kadare behandelt haben; ich betrachte jedoch die analysierten Werke nicht getrennt vom übrigen Werk der Schriftsteller und von der Mythologie als einem wesentlichen Bestandteil in ihm.

\subsection{Zur Terminologie}

Die Begriffe Mythos und Mythologie brauchen hier eine Erläuterung und Abgrenzung, bevor sie "zu oft" verwendet werden.

Unter Mythologie versteht man im deutschen Sprachgebrauch sowohl die Gesamtheit der Mythen (eines Zeitalters, eines Volkes usw.) als auch die Wissenschaft über die Mythen ${ }^{2}$. Hier soll das Wort fast immer in der ersten Bedeutung verwendet werden; wenn nicht, wird darauf hingewiesen.

Über Mythos, Mythen gibt es bis heute viele Definitionen. Hier ist es wichtig, vor allem den Begriff von dem der Legende, (Sage, phantastischer Erzählung) zu unterscheiden. Eine Legende ist entweder eine Sage von frommen Menschen oder ein verzerrtes, nicht mehr nachweisbares historisches Er-

${ }^{1}$ So zum Beispiel von dem Bulgaren Petko Todorov mit seinem Drama "Zidari"; ebenfalls zwei Theaterstücke aus Rumänien: "Die Erbauung des Klosters Argesch", von Nicolae Jorga und "Meister Manole" von Lucian Blaga. Aber auch im übrigen Europa wurde das Motiv Mittelpunkt literarischer Werke; unter anderem schrieben darüber Theodor Storm die Novelle "Der Schimmelreiter", der Portugiese Julio Dantas das Drama "Catedrala", die Französin Marguerite Yourcenar die Erzählung "Le lait et la mort" in "Nouvelles Orientales".

2 Siehe beispielsweise unter diesem Stichwort: Duden. Das große Wörterbuch der deutschen Sprache. Mannheim,1981. Eine dritte Bedeutung ist: "Person, Sprache, Begebenheit, die (aus meist verschwommenen, irrationalen Vorstellungen heraus) glorifizien wird, legendären Charakter hat". 
cignis sowie eine unglaubwürdige Geschichte. Eine Legende bzw. eine Sage und somit auch eine Ballade - können wohl einen mythischen Inhalt haben, das bedeutet jedoch noch nicht, daß sie einen Mythos darstellen ${ }^{1}$. Der Mythos erzählt immer von der Entstehung der Welt, von Göttern und Dämonen, von kosmischen, chthonischen oder olympischen Kräften, er begründet sie und ist zugleich ein Erlebnis. Daß die Mythen erlebt werden, zeigen uns die Riten, die in Verbindung mit ihnen stehen. Das ganze Wesen des Menschen ist an diesem Erleben beteiligt (Eliade), Legenden und Sagen dagegen spielen sich in dem Bereich der Phantasie und des Dichterischen $\mathrm{ab}^{2}$. Die Grenzen zwischen Mythos und Legende sind oft fließend, so etwa in der spätklassischen und hellenistischen Periode des griechischen Altertums, als das mythische Erlebnis der Realität allmählich abflaute und eine Reihe von alten Mythen nunmehr allein der Dichtung als Stoff dienten. Andererseits enthalten viele Legenden mythische Elemente und mythische Andeutungen inne. Wenn wir die Mythologie als ein Ganzes verstehen ${ }^{3}$, in dem Mythos und Ritual nicht voneinander trennbar existieren, könnten manche Legenden als Erinnerungen an Mythen verstanden werden, in gleicher Weise wie manche Bräuche (siehe Bauopferbräuche, Kap.1.3.) Erinnerungen an Rituale sind.

Unter einigen Legenden (Balladen, Epen, Märchen), die eindeutig Erinnerungen an die mythische Vergangenheit aufweisen, ist bei allen Balkanvölkern, meist in der Form der Ballade, die Legende der eingemauerten Frau besonders bekannt und verbreitet.

1 Siehe unter diesen Stichwörtern: Wahrig, Deutsches Wörerbuch. München 1986.

2 Hier seien nur ein paar Definitionen kurz angeführ, da ich auf das Thema wieder zurückkomme: Karl Kerényi: [Die Mythologie ist] "eine alte, überlieferte Stoffmasse, enthalten in bekannten und doch nicht jede weitere Gestaltung ausschließenden Erzählungen - "Mythologem" ist für sie das beste griechische Wort - über Götter und göttliche Wesen, Heroenkämpfe und Unterweltsfahrten. Die Mythologie ist die Bewegung dieser Materie: etwas Festes und zugleich doch Bewegliches, Stoffliches und doch nicht Statisches, sondern Verwandlungsfähiges" (in: Einführung in das Wesen der Mythologie. Amsterdam 1941, S.11).

Borislaw Malinowski: "Der Mythos in einer primitiven Gesellschaft, das heißt in seiner lebendigen ursprünglichen Form, ist keine bloß erzählte Geschichte, sondern eine gelebte Realităt. Er ist nicht von der Art einer Erfindung, welche wir heute in unseren Romanen lesen, sondern lebendige Wirklichkeit, von der geglaubt wird, sie sei in Urzeiten geschehen, und sie beeinflusse die Welt und die Schicksale der Menschen seitdem fortwährend" ( in: Myth in primitive Psychology. London 1926, zitiert nach Kerényi in: Einfuihrung in das Wesen der Mythologie, S.15)

Erich Neumann: "Der Mythos ist immer die unbewußte Selbstdarstellung derartiger für die Menschheit entscheidender Lebenssituationen" (in: Amor und Psyche. Freiburg 1984, S.72).

Mircea Eliade: "Einer der herausragenden Grundzüge des Mythos besteht darin, in einem für heilig erachteten Urereignis nicht etwas Vergangenes zu sehen, dessen man vielleicht gedenken oder das man irgendwie nachahmen kann, sondern ein ewig Gegenwărtiges oder zumindest beständig identisch Wiederholbares" (zitiert nach Kurt Hübner: Die Wahrheit des Mythos. München 1985, S.109).

3 Jeder Diskurs über Mythologie bleibt zwangsweise im Bereich der Sprache; Mythologie ist ebensosehr Sprache wie auch Realität, daher ähnelt der von außen beschreibende Diskurs eher einer Übersetzung als einer Darlegung oder Erklärung des Mythischen (siehe auch Kun Hübner, Die Wahrheit des Mythos, S.109). 


\subsection{Uber die Ballade}

Ich möchte gleich hier darauf hinweisen, daß die Ballade über das Bauopfer durch eine Reihe von Forschern abgehandelt worden ist ${ }^{1}$. Am Schluß dieser Arbeit befinden sich für den interessierten Leser einige Varianten aus verschiedenen Gegenden Südosteuropas (einschließlich Ungams) in deutscher Übersetzung.

Die Bezeichnung "Ballade der eingemauerten Frau" trifft als Titel für fast alle bekannten Varianten $\mathrm{zu}^{2}$; sie deutet zugleich den Schwerpunkt der Ballade an, d.h. jenes Moment, das den Volkssänger und seine Zuhörer am meisten beeindruckt: jenes Bild - eines unschuldigen, zwischen Mauem und in der vollständigen Dunkelheit eingeschlossenen Menschen - das, wie sich in der Folge zeigen wird, an der ungewöhnlichen Verbreitung der Fabel mitgewirkt hat. Das ist im Lied jedoch nicht ausdrücklich vorgebracht: Der Akzent des Dichters setzt in allen Varianten auf die ujbermenschliche Tragik, die die Entscheidung, in den Fundamenten des Bauwerkes eine lebendige Frau einzumauem hervorruft, zumal diese (wieder in allen Varianten) die Frau des Baumeisters ist.

Ein anderes Moment, das die Notwendigkeit des Opfers eingeleitet hat, bleibt auch in allen Varianten gleich: Die Meister können ihr Werk nicht abschließen, weil das, was am Tag erbaut wird, in der Nacht einstürzt. Und die Notwendigkeit des Opfers wird, außer in ungarischen Varianten ${ }^{3}$, immer auf eine mystische Weise verkündet: durch einen Vogel, durch den Geist des Flusses, durch eine Stimme vom Himmel, in einem Traum des Baumeisters odeer auch durch einen alten Mann.

Die Tragik des verwitweten Mannes übertrifft noch das tragische Entreißen des Kindes von der Brust der Mutter; auch das ist ein Höhepunkt, der die Erzählung des Volksdichters in allen Varianten prägt. Die Frau kommt immer nichtsahnend zum Ort der Aufopferung, wo sie entweder freiwillig oder überlistet im Grundstein des Bauwerkes (Brücke, Festung, Kirche, Kloster ) eingemauert wird.

\footnotetext{
${ }^{1}$ Hier sind außer den bereits erwăhnten einige der wichtigsten Beitrăge: $M$. Amaudoff, Vgradena nevjesta [die eingemauerte Frau] in: Studii vrhu blgarske obredi i legendi, Sofija 1920; S. Baud-Bovy, La chanson populaire grecque du Dodécanaise. Paris 1936; S. Stefanovic, Die Legende vom Bau der Burg Skutari, in: Revue intemationale des études balkaniques, I. Beograd 1934-1935; G. Cocchiara, Il ponte di Arta e i sacrifici di costruzione, in Annali del Museo Pitré, 1. 1950; L. Vargyas, cThessaloniki 1976; H. Diplich, Das Bauopfer als dichterisches Motiv in Südosteuropa. München 1976.

${ }^{2}$ In der bosnischen Volksdichtung ist oft von Zwillingen die Rede (siehe auch G. Gesemann, Gesammelte Abhandlungen, 1. Neuried 1981, S 328; diese Varianten haben auch Andric als Vorlage gedient).

${ }^{3}$ Hier trifft der Baumeister Klemens die Entscheidung auf eigene Faust (siehe u.a. H. Diplich, Das Bauopfer als dichterisches Motiv in Südosteuropa, S.11-13).
} 
Die Motive, die von Gegend zu Gegend, von Zypern und Kappadokien in Kleinasien über den ganzen Balkan bis nach Transsilvanien und der ungarischen Pußta, die Legende der eingemauerten Frau bereichern, vereinfachen, verändern und erweitem, kurzum die Motive, die variieren, sind mehrere und von den Forschem weitgehend aufgezeigt worden. Zusammengefaßt folgen einige Merkmale, die die verbreitetsten Varianten voneinander unterscheiden:

Serbokroatische und albanische Varianten schenken dem Motiv des gebrochenen Wortes besondere Aufmerksamkeit. Die Baumeister sind drei Brüder' und, da das Schicksal verlangt, daß eine von ihren Frauen den Fundamenten geopfert werden muß - und zwar diejenige, die ihnen als erste das Brot überbringt - schwören sie, der jeweiligen Frau nichts von diesem Verhängnis zu verraten. Doch zwei Brüder mahnen ihre Frauen, nur der jüngste hält das Versprechen, und in der Folge muß er seine Frau in den Fundamenten des Baus eingemauert sehen: "Nur der jüngste von den Brüdern/ der der mutigste von allen war/ hielt am Wort und Glauben fest/ an dem Wort der Tapferkeit'2, singt der nordalbanische Rhapsode, dadurch die zwei Begriffe "besë" und "trimëri" ("gegebenes Wort" und "Tapferkeit") hervorhebend, auf die die Albaner immer viel Wert gelegt haben. Die serbokroatische, so wie wir sie von Vuk Karadžićs Sammlung kennen, ist eine für die Volksüberlieferung überraschend poetische Ballade, die den Bau der Festung Skutari in einen historisch-legendären Rahmen setzt: Die drei Brüder sind aus der königlichen Familie der Marljavčević: Vukašin, Uglješa und Gojko. Ein einprägsames Moment in den serbischen und albanischen Varianten ist auch der Wunsch der Frau, man solle an der Mauer ein kleines Fenster offen lassen, damit ihr Knäblein an der Brust saugen kann; weiters die Milch an der Mauer, die auch nach dem Tod der Frau, als wundertätiges Heilmittel "noch heute fließt".

Die rumänische Ballade vom "Kloster am Argesch" erzählt vom Bau eines mittelalterlichen Klosters ${ }^{3}$ durch Meister Manol und seine Gehilfen. Hier, ebenfalls wie in ungarischen Varianten, konzentriert sich die Spannung der Fabel auf das inständige Flehen Manols, daß seine Frau - die um das Brot für die Maurer zu bringen unterwegs ist - doch nicht an die Baustelle kommt. Es spielt sich ein Dialog mit Göttern in ähnlicher Weise wie in den Homerischen Epen ab. Der Meister verlangt von Gott, er solle Stürme vom Himmel freigeben und Berge umwerfen; alles aber ist umsonst, denn das Schicksal der unschuldigen Frau ist unumkehrbar. Als Anhang an die allgemein bekannte Geschichte gibt es in rumänischen Varianten eine Erweiterung; hier werden Manol und seine Gehilfen vom Fürsten zu Tode gebracht, da sie prahlten,

1 "Mit dreihunder Meistern" in serbischen Varianten.

2 Aus: Balada dhe legjenda. Prishtinë 1980, S. 4.

${ }^{3}$ Der rumänische Rhapsode besingt den Wode Negru und seine prächtigen Bauten des orthodoxen Glaubens. Damit reagien er auf die osmanische Besatzung und auf die osmanische Religion, ein Zeichen dafür, wie der Stoff der Legende in verschiedenen Gegenden Südosteuropas mit charakteristischen, eigenständigen Elementen überlagert wurde (siehe auch Diplich, Das Bauopfer als literarisches Motiv in Südosteuropa, S.41). 
einen noch schöneren Bau als das Kloster zu Argesch anfertigen zu können. Dieser Schluß drückt offenbar den Wunsch des Dichters aus, Manol für seine Grausamkeit zu bestrafen.

In griechischen Varianten ist die Frau die unbestritten zentrale Figur des Geschehens; in Einzelheiten schildert der Dichter, wie sie (mit List) an die Baustelle eingeladen, dort übertölpelt (ihr Mann, der Baumeister, beteuert, sein Ring sei in die Fundamenten gefallen, sie möge helfen, ihn zu holen) und im Pfeiler der Brücke zu Arta eingemauert wird. Oft ist die Entscheidung des Baumeisters von der zynischen Uberlegung bestimmt: "ein Weib findest du noch einmal wohl, den Kopf, den findest du nimmer"l. Während die Meister sie einmauem, verflucht die Frau die Brücke: "so wie mein armes Herz erbebt, soll auch die Brücke beben"2; in manchen Varianten nimmt sie den Fluch zurück, da die Brücke doch als ein großes Bauwerk zum Wohle der Gemeinschaft vorgestellt wird. Die Motive des Rings und des Fluchs sind auch in südalbanischen, aromunischen und bulgarischen Varianten bekannt.

Nach diesem kurzen Exkurs über die Haupt- und Nebenmotive der Legende möchte ich wieder auf die umfangreiche Literatur über Verbreitung und verschiedene Motive der Legende in den Balkanländem hinweisen. Hier wird auf die Sichtweise des Folkloristen verzichtet, und daher auch auf die Diskussion über Ursprung, Entwicklung, Entlehnung, Motivwanderung und dichterische Qualität der Balladen. Ein paar Anmerkungen über das Thema Zugehörigkeit möchte ich trotzdem am Rande machen.

Unter den verschiedenen Studien überwiegen bis jetzt jene, die sich der Wanderung der Motive bzw. dem Spezifischen in der einen oder der anderen Variante widmen. Das ist auch verständlich, weil es zu den Hauptinteressen des Volkskundlers gehört. Weniger einleuchtend ist dagegen, daß in einigen Studien die Produkte dieser oder jener Nation vorgezogen werden, der Diskurs meist in terms of nations gefühn wird und das Bemühen bzw. die Versuchung besteht, ein bestimmtes Volk als den ursprünglichen Autor der Ballade unbedingt zu krönen. Diese Art der Analyse ist zum Teil erklärbar, denn sie ist in den romantischen Strömungen der europäischen Volkskunde des vorigen Jahrhunderts ${ }^{3}$ sowie in den Bestrebungen der Balkanvölker verwurzelt, einerseits ihre nationale Unabhängigkeit von den Großmächten des Ostens oder des Westens durchzusetzen, andererseits sich gegen den Chauvinismus der Nachbarn zu wehren. Diese Umstände bedeuten aber nicht immer, $\mathrm{da} B$ die Analyse auch wissenschaftlich sein muß. In der Südosteuropaforschung geht die Wissenschaft bekanntlich davon aus, daß die Völker des Balkans viel

\footnotetext{
${ }^{1}$ Siehe Megas, Die Ballade von der Arta-Brücke, S.117.

2Ebenda, S.183-200.

3Die Diskussion aus dem nationalen Blickwinkel wurde teilweise auch von deutschen Philologen eingeleitet: "Wie wenig autochthon dagegen die (dako-) rumänischen Versionen sein können, ergibt sich schon daraus..." (K. Dietrich, Die Volksdichtung der Balkanlănder in ihren gemeinsamen Elementen, S.152).
} 
mehr nebeneinander oder miteinander gelebt haben als getrennt; feste nationale Grenzen gibt es erst seit den letzten Jahrzehnten. Und zu dieser Zeit war die Entstehung der legendären Volksballaden ein schon abgeschlossener Prozeß.

Z. Konstantinović bemerkt zum Phänomen des Gemeinsamen in der südosteuropäischen Überlieferung:

"Die Gemeinsamkeit realer Tatsachen des sozialen Lebens, der Auffassung des Lebens und das Lebensgefuhhl als solches haben sich aber in der Volksdichtung ausgedrückt und ihre künstlerische Form gefunden(...) Alles dies wird durch gemeinsames geschichtliches Schicksal während der Türkenzeit in einen gemeinsamen Rahmen gebracht, der keine scharf getrennten ethnischen Grenzen kennt, wo Zwei- und Dreisprachigkeit geradezu zur Erforschung der ethnischen, kulturellen und geschichtlichen Beziehungen herausfordern, nebenbei auch zum Vergleich der Volkspoesie der einzelnen Nationen Anregung geben" ( Die Volkspoesie des europäischen Südostens. Begriff und Deutung, in: Die Volkskultur der südosteuropäischen Völker. München 1962, S.14).

$\mathrm{Daß}$ die Völker des Balkans eine gemeinsame oder ähnliche Entwicklung bereits unter Byzanz, aber insbesondere im osmanischen Reich erlebt haben, wird von niemandem emsthaft bestritten. Die Volkskultur weist neben dem Spezifischen auch eindeutige Zeichen der Zusammenzugehörigkeit auf, die die Völkerwanderungen, die Zweisprachigkeit mancher Gegenden, das Völkergemisch mancher anderen, die Hirtenvölker (wie die Aromunen es waren), die Wandervölker (die Zigeuner), die kämpfenden Völker, die Maurervölker ins Leben gerufen und vermittelt haben. Noch einmal beziehe ich mich hier auf Forscher, die die Gründe für die verwickelten, ineinanderfließenden und freien Wanderungen der Folkloremotive überzeugend hervorgehoben haben:

\footnotetext{
"Wie die ethischen Auffassungen der archaischen Sippenkultur in der volksreligiösen Gestaltung der byzantinischen Apokryphen-Tradition von den Höllenstrafen bei den orthodoxen Bulgaren und Serben, eivenso wie bei den katholischen Kroaten gleichen Ausdruck in der Volksdichtung fanden, konnte ich selbst in meinen(...)Studien aufzeigen, gar nicht zu sprechen von den gemeinsamen balkanischen Erscheinungen der Blutrache, des Brautraubes, der künstlichen Verwandtschaft, der Gastfreundschaft.

(...)M. Gavazzi hat aufgezeigt ("Die Kulturzonen Südosteuropas", in Südosteuropa II (München 1958), 11f.), daß sich die Kulturgrenzen am Balkan überhaupt nicht mit den ethnischen Grenzen decken(...) Man kann höchstens von einem Überwiegen in bestimmten Zeitläufen sprechen" (J. Matl, Sprache und Dichtung als Schicksalsspiegel der südosteuropäischen Völker, in: Die Kultur Südosteuropas, S. 177-178)1.
}

\footnotetext{
${ }^{1}$ An einer weiteren Stelle führt der Autor an: "(...)Wir finden am Balkan zwar nicht den Typus des Nationalhelden wie Roland und Cid, sondern den des sagenhaften Volkshelden. Das balkanische sagenhafte Volksheldenideal(...) ist verkörpen in Krajlevic Marko und Starina Novak ebenso wie in dem bulgarischen Indže Vojvoda, in dem albanischen Heros Mujo.(.) In der Epik der bosnischen Muslemanen scheinen christliche Helden wie Katzianer und Petrasch auf, und in der Volkstradition fließen die beiden geschichtlichen Hajdukengestalten des Serben Veljko und des Bulgaren Indže zusammen... Der zum Tode verwundete Kara Mustafa vermacht Flinte, Säbel, Pistole und Rappen dem Hajduken Veljko mit der Begründung, "weil er der bessere Held ist als er"...Es gibt also nicht den primären Gegensatz zwischen Angehörigen verschiedener Völker und Kontessionen - der wurde erst spät geschürt -, sondern zwischen heldischen und nichtheldischen Menschen, zwischen Helden und Händlern [kursiv von mir], ebenda, 186).
} 
Hierbei sind Liederformen zu unterscheiden, die in dem einen oder in dem anderen Volk vorherrschen. So z.B. ist der Kreshnik-Zyklus charakteristisch in Bosnien und in Nordalbanien, die Hajdukenlieder sind es in Bulgarien und Serbien, die Akriten- und die Kleftenlieder in Griechenland und die historischen Lieder (këngë historike) sind typisch für die dichterische Verarbeitung der Geschichte in Albanien. Die Balladen dagegen, die mythische Motive besingen, sind aus jenem Stoff gemacht, der ethnische Grenzen zwischen den Völkem am leichtesten überschreitet, da er sich weder auf historische oder lokale, noch auf kirchlich-religiöse Begebenheiten stützt. Dies erklärt auch, warum die mythischen Motive des Bauopfers und des toten Bruders sowie das odysseische Motiv des heimgekehrten Gatten im ganzen südosteuropäischen Raum verbreitet wurden, andere Stoffe dagegen, etwa die Kreshnik-Zyklen nur dem bosnischen und dem albanischen Gebirge verhaftet blieben. Man denke nur an die vielen Sänger, die mit Armeen, mit Schafherden, mit Baukumpanen oder einfach als wandernde Sänger die Gebiete des Balkans jahrhundertelang durchstreift haben', viele davon, besonders aus Gegenden mit einer Mischbevölkerung wie Mazedonien und Epirus sind zweisprachig gewesen. In angrenzenden Gebieten, von verschiedenen ethnischen Gruppen bewohnt, sind die Ähnlichkeiten der Volkslieder noch auffälliger. Albanische Balladen über die Einmauerung bringen hier ein signifikatives Beispiel: Suidliche Varianten sind oft eher mit den griechischen (Brïckenbau, Motiv des Ringes, Fluch) als mit den nordalbanischen Varianten (Burgbau, wundertätige Muttermilch) verwandt. Solche Umstände haiten trotzdem einige Forscher nicht davon ab, die Balladen als streng nationale Erscheinungen zu betrachten und sie in Wettbewerb treten zu lassen:

"Soweit die griechische Ballade. Ihr verwandt sind die aromunischen und albanischen
Varianten. Diese Gruppe entbehr manche Elemente, die dichterische Phantasie bewegt
sich in anspruchlosen Formen und Kombinationen, die gröblich-primitive Übertölpelung
des Opfers läßt keinerlei differenzierte Gemütsregungen aufkommen"2.

Solche Regungen des Gemütes ("Wir haben uns seit langem daran gewöhnt, das Wesen und den Geist eines Volkes aus seiner Dichtung herauszulesen", S.46) fühlt der Autor dagegen, wenn er die "rumänische Ballade"3 liest:

\footnotetext{
${ }^{1}$ Alois Schmaus berichtet in diesem Zusammenhang: "(...)Wichtig ist jedenfalls das Zeugnis des byzantinischen Metropoliten Arethas von Kaisareia; (850-932) über die 'verfluchten' Paphlagonier, die irgendwelche Lieder dichten (...) und sie, von Haus zu Haus ziehend, gegen einen Obolus singen. Wer die berühmten Helden waren und was für Taten besungen wurden, darüber wird leider nichts gesagt. $\mathrm{DaB}$ es sich aber um fahrende 'Berufssänger' handelte, wie wir sie in neuerer Zeit auf dem Balkan, vor allem als Blinde mit eigenen Sängerschulen und eigener Geheimsprache, vertreten finden, daran dürfte wohl nicht zu zweifeln sein (in: Gesammelte Abhandlungen, II. München 1973, S.29-30).

2Diplich, Das Bauopfer als dichterisches Motiv in Südosteuropa, S. 10.

${ }^{3}$ Um so unbegreiflicher ist diese Bezeichnung, wenn man über rumänische Varianten erfährt, die eher an die westbalkanischen anschließen: "In qualche versione, come quella di Rémnicu-
} 
"Ihre Werke [der anonymen Dichter] gingen nach ihrem Tode nicht unter, sie siedelten sich in der Mutterschicht des Volksgeistes an und werden von der jeweilig lebenden Generation in das BewuBtsein der Sprachgemeinschaft gehoben(...) Dieser Umstand verleiht dem geistigen Bild jener Völker eine innere Geschlossenheit, die wohltut und in der $\mathrm{Zu}$ kunft von unabsehbarer Wirkung sein kann, auch für uns" (S.41-42, kursiv von mir).

Von der "inneren Geschlossenheit" einer "Mutterschicht des Volksgeistes" gehen auch einige andere Autoren auf die Ursprungsdiskussion ein. G. A. Megas kommt am Ende seiner Arbeit, die übrigens einen beachtlichen Beitrag über Verbreitung und Motivmosaik der Ballade im griechischen Sprachraum darbietet, zu diesem Schluß:

"Alle Versuche, die unternommen wurden, die Theorie der Polygenese des Liedes von der eingemauerten Frau zu unterstützen, sind nicht geglückt, da es sich um eine poetische Gestaltung einer Überlieferung handelt, deren Zentral-Thema in den Varianten aller Völker Südosteuropas einheitlich ist; aus diesem Grunde $m u B$ auch ein einziger Ursprung zugrundeliegen. Dieser muß aus den oben angeführten Gründen in den griechischen Raum und in die frühen byzantinischen Zeiten gesetzt werden"l.

Jene Argumente, die die Autoren zu Autochthoniebehauptungen führen, sind oft plausibel, manchmal aber unklar:

"Merkwürdigerweise behamt er auch in der neuen Ausgabe darauf, es sei unverständlich, daß die unglückliche Frau in die feuchten Fundamente der Brücke, in denen sie nach dem griechischen Lied eingemauert wurde, hinabsteigt, und besteht auf seiner Ansicht, daß die Bezugnahme des Themas auf den Brückenbau Nachteile aufweist gegenüber der Verknüpfung des Liedes mit dem Bau einer Burg oder eines anderen Bauwerks, und auf diese seine Auffassung stützt er eines seiner Hauptargumente gegen den griechischen Ursprung des Liedes"2.

Um diesen zweiten Exkurs abzuschließen: Die Diskussion mit Hilfe einer streng nationalen Terminologie verhindert relevante Erkenntnisse; die Polemik über die nationale Zugehörigkeit einer angenommenen Urform der Ballade schafft darüber hinaus unzählige Spekulationsmöglichkeiten. Sie setzt für das "entlehnende" Volk manchmal Phantasielosigkeit oder Gemütsarmut voraus.

sarat (Diaconu), i muratori infrangano slealmente il patto e avverano le proprie mogli, di nascosto" (M. Popescu, Dieci balade romene con rispondenze balkaniche, in: Die Kultur Südosteuropas, S.222).

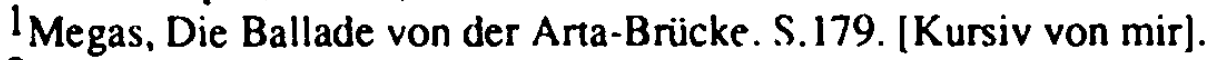

2Ebenda, S.138. Die Polemik richtet suı hier gegen Vargyas und seinen Beitrag über die Ballade (siehe a.a.O.). 
Vor allem aber - ausgenommen für einen rein philologischen Gesichtspunkt - ist die Polemik belanglos, denn jedes Volk, jede Gemeinschaft und jeder Rhapsode haben die Legende der Einmauerung als die eigene empfunden.

Besonders unproduktiv scheint die Auseinandersetzung im hiesigen Fall, in dem mögliche Deutungen der Legende und ihre Beziehungen zu mythischen Vorstellungen das Hauptinteresse ausmachen.

\subsection{Zur Interpretation}

Um mythische Erinnerungen in der Legende der eingemauerten Frau zu erkennen, müßten vorerst manche Motive und Wendungen als später übergelagerte Schichten gedacht werden. Solche Motive sind teils handlungsbezogener, teils märchenhafter Prägung, aber auch moralischer Natur. Typische Beispiele für akzentuierte Handlungsmomente sind hierfür das Abkommen der drei Brüder und der Wortbruch der zwei älteren in albanischen, serbischen oder bulgarischen Versionen sowie das Bemühen des Baumeisters in griechischen, ungarischen oder rumänischen Varianten, seine Frau trotz des unabwendbaren Schicksals fern von der Baustelle zu halten, weiters die Suche nach den Gebrüdern mit den Namen Stojan und Stoja als Vorspiel in der Karadżić'schen Ballade oder die "Verlängerung" am Schluß der numänischen Ballade vom Kloster am Argesch mit dem Flug und Tod der Meister. Hier ist der Ansicht A. Schmaus' zuzustimmen, daß "die Einmauerballade sich zu einer vollen Episierung eignet" 1 . Bei der Suche nach alten Spuren und nach den Wegen der Motivwanderung in der Volksdichtung wird manchmal eine ihrer wesentlichsten Eigenschaften vergessen, nämlich die hedonistische Triebkraft, die Lust am Improvisieren, die besonders in der Gestaltung der Fabel zum Tragen kommt; in diesem Sinne ist wiederum belanglos, wer was als erster erdacht haben soll.

Andere Wendungen, auch wenn sie eine große Verbreitung und daher vermutlich auch ein höheres Alter aufweisen, sind jedoch als spätere Uberlagerungen am mythischen Stoff zu betrachten, so beispielsweise in den meisten griechischen und in mehreren anderen Varianten das Motiv des Ringes. Dieser symbolisiert die Heirat und macht die Tat des Baumeisters um so abstoßender und verurteilenswerter in den Augen des Volkserzählers. Nicht nur der moralische Standpunkt, sondern auch die allegorische Sprache lassen den Bezug zur mythischen Mentalität nur wenig nachvollziehen².

1 In: Beiträge zur Südosteuropa-Forschung, S.303.

2 Die mythische als eine direkt erlebte Realität benötigt kaum die Metaphorik; was später als Symbol empfunden wird, zeigt gerade den Bruch mit solch einer Realität. Claude Lévi-Strauss bemerkt Folgendes über die Hyperbel: "Wenn also die Mythen und Riten eine Vorliebe für die 
Noch einmal, um Mißverständisse zu vermeiden: Es geht hier nicht um das Alter der Legende selbst, die, wie Megas behauptet (S.179), in die frühen byzantinischen Zeiten zu legen wäre; was zählt, ist lediglich die Anwesenheit oder das Fehlen von "Mythologemen" in ihr.

Als Kontamination anderer Fabeln wären auch Elemente der Volksmärchen erkennbar und daher wenig aufschlußreich; so z.B. die schwankende Zahl der Baumeister (von drei bis neunhundert). Auch der Vogel als Verkünder des Opfers in den griechischen Varianten ist wahrscheinlich ein Märchenelement. Über die Zauber-Ereignisse in den nördlichen Varianten der Ballade, die das Kommen der Frau an der Baustelle verhindern sollen, ist ahnliches zu sagen.

Die Ablenkung des Interesses auf das tragische Schicksal der Frau mit den vielen damit verbundenen moralischen Anhaltspunkten bedeutet zugleich eine Uberlagerung der eigentlichen mythischen Botschaft. In vielen Varianten (besonders in ungarischen und rumänischen) wird der Baumeister für seine Unbarmherzigkeit bestraft - obwohl er in der Kernaussage der Legende nichts gegen oder für die Aufopferung seiner Frau tun konnte. "Ging nicht aus dem Hause mehr, sehen wollt er keinen, Nachts trieb ihn vom Lager seines Kindes Weinen" - das ist das Schicksal des ungarischen Maurers Klemens, während in rumänischen Varianten Manol mit seinem Leben büßen muß.

Je mehr eine mythische Begebenheit von ihrer natürlichen Umwelt abgesondert wird, wie es bei vielen Legenden, Sagen, Märchen und darunter auch unserer Ballade der Fall ist, desto deutlicher kommt das DichterischHumanistische zum Ausdruck. Es geschieht, um es mit W. Wundt; zu sagen, "eine zunehmende Selbstunterscheidung des Subjektes von den Objekten(...) und eine sich steigernde intellektuelle Entwicklung(...), die das mythologische Denken hemmt" (in:' Völkerpsychologie, II, Mythus und Religion. Leipzig 1909, S. 579). Es findet eine Bewertung bzw. Verurteilung des mit unserer Moral nicht mehr vereinbaren mythischen Ereignisses statt. Man nehme zum Vergleich das Geschehen um Iphigenie, wie es in den griechischen Mythen, bei Euripides und letztlich bei Goethe vorkommt. Die mythische Iphigenie ist eine matriarchalische Priesterin, die in grausamen Ritualen alle Fremdlinge ihrer Schutzgöttin aufopfert, Euripides bewirkt die Humanisierung des Götterglaubens, Goethe hingegen stellt - entsprechend dem Geist der Aufklärung - eine selbstbewußte und determinierte Frau dar.

Legenden und Balladen stellen in ähnlicher Weise wie die geschriebene Literatur eine Befreiung von den heute als irrational empfundenen Elementen des Mythos dar, sie lassen ihn "absinken" (Eliade), jedoch ohne diese Elemente völlig zu tilgen. Die Mythologieforschung der letzten Jahrzehnte sieht sich oft mit der Aufgabe konfrontiert, gerade solche Spuren ausfindig zu machen, um zu einem besseren Verständis der mythischen Welt der Vorfahren zu kommen.

Hyperbel zeigen, handelt es sich hierbei nicht um einen rhetorischen Kunstgriff. Ihre Emphase ist natürlich, sie drückt unmittelbar ihre Eigenschaften aus, sie ist der sichtbare Schatten einer logischen Struktur, die verborgen bleibt" (in: Mythologica, I. Das Rohe und das Gekochte. Frankfurt a.M. 1971, S.434-435). 
Allerdings haben vorher auch andere wissenschaftliche Richtungen in der Volkskunde und in der Mythologie vorgeherrscht (und die gibt es noch heute), die die aufklärerischen Bemühungen zu extremen Standpunkten gebracht haben. So etwa die anthropologische Schule; sie hatte sich die Aufgabe gestellt, in allen Mythen, die sie oft mit Aberglauben gleichstellte, "das Törichte, Wilde und Absurde zu erklären"'.

Ähnliche Auffassungen, wenn auch nicht vom Positivismus angeregt, sind auch bei Autoren der Klassik zu finden. Ein bezeichnendes Beispiel hinsichtlich der Ballade der eingemauerten Frau ist Goethes Empörung über die "abergläubische-barbarische Gesinnung" der Alten ${ }^{2}$. Hier wird es notwendig, ein paar Bemerkungen zum Verhältnis Ballade - Geschichte mythische Wirklichkeit zu machen.

Das Motiv des Bauopfers ist in der europäischen Volksdichtung außerhalb des südöstlichen Raums, im Unterschied etwa zu dem Motiv des toten Bruders oder des heimkehrenden Gatten, nicht bekannt ${ }^{3}$. Das Ritual des Bauopfers war dagegen und ist noch immer in vielen Teilen der Welt verbreitet. F. Liebrecht brachte schon im Jahre $1875^{4}$ eine Reihe von Beispielen aus mehreren Kontinenten und Ländern: aus China, Japan, Indien, Borneo, von den Semiten in Afrika, aus Neuseeland, Tahiti und von den Chibokas in Südamerika, wobei auch Menschenopfer angeführt sind. Ebenfalls wie Liebrecht weiB A. Wuttke in "Der deutsche Aberglaube der Gegenwart", Leipzig 1925, S.300 über Bauopfer zu berichten. Aus historischem Gesichtspunkt wird beispielsweise angenommen, daß der Tod des Remus bei der Gründung Roms ein Bauopfer war, nach einer keltischen Überlieferung aus Schottland wurde bei der Grundsteinlegung eines Klosters ein Mensch

1Friedrich Max-Müller zitiert nach Marcel Detienne, Die skandaløse Mythologie, in: Faszination des Mythos. Studien zu antiken und modernen Interpretationen. Basel, Frankfurt/M. 1985, S.15; (siehe auch die entsprechende Anmerkung im Zusammenhang mit "Brücke über die Drina"(Kap. 3.5).

2 Z. Konstantinovic berichtet ausführlich über diese Episode in Orbis Litteranum, 1987, 42. Goethe hatte das Lied vom "Bau der Burg Skutari", das der Sammlung Vuk Karadżić entstammte, durch Jakob Grimms Übersetzung kennengelernt. Grimm hatte seinerseits die Ballade "eine der rührendsten Gesänge aller Völker und Zeiten" genannt. In einem Brief vom 30. August 1824 schreibt Goethe jedoch an Grimm: "Das zuletzt mitgetheilte Gedicht ist unter denen die ich kenne wohl das älteste, wenigstens bezieht sich's auf die Erbauung Skutari's, vielleicht schon im achten Jahrhundert, und trägt noch ganz den höheren barbarisch-heidnischen Sinn eines Menschenopfers zu großen unerläßlichen Nationalzwecke." In seinem Aufsatz Serbische Lieder führt er außerdem aus: "...es finden sich Menschenopfer und zwar von der widerwärtigsten An. Eine junge Frau wird eingemauert, damit die Feste Skutari erbaut werden konnte, welches um so roher erscheint, als wir im Orient nur geweihte Bilder gleich Talismanen an geheimgehaltenen Orten in den Grund der Burgen eingelegt finden, um die Unüberwindlichkeit solcher Schutz- und Trutzgebäude zu sichern." Konstantinovic wirft hierbei die Frage auf, ob der Unterschied der Meinungen zwischen Goethe und J. Grimm "nicht vielmehr [als rein persönlicher Geschmack] Ausdruck des Zusammenstoßes von Klassik und Romantik sei, eines Humanitätsideals, das die mythische Welt zum Erlösungsgedanken emporheben wollte und dem Wunsch nach Versinken nicht nur in kosmischen Welten, sondern auch in die Urwelt eines Vor- und Unterbewußtseins".

3 siehe u.a. L.Sainéan, Les rites de la construction d'après la poésie de l'Europe Orientale, in: Revue de l'Histoire des Réligions, Bd.45 (1902), S.359-396, sowie Diplich, Das Bauopfer als literarisches Motiv in Südosteuropa, S.9.

${ }^{4}$ Siehe: Zur Volkskunde. Heilbronn 1879. 
eingemauert, um die Ortsgeister zu besänftigen. Aus Deutschland stammen einige Berichte von Bauopfern im 16. und 17.Jht. Gemäß einer Überlieferung von Schloß Liebenstein in Thüringen wurde die kleine Tochter einer Landstreicherin gekauft; man gab ihr eine Brezel in die Hand und mauerte sie ein. Es wird erwähnt, daß im Jahre 1615 ein solcher Handel von den Behörden verhindert und die Mutter des Kindes bestraft wurde ${ }^{1}$.

Den Brauch des Bauopfers (nicht des Menschenopfers!) hat es bis in neuere Zeiten auch auf dem Balkan gegeben; im Grundstein eines Baues wurden meist Vieh, aber auch hölzerne oder sonstige Abbilder, Talismane, Münzen, ja sogar Schatten von Menschen geopfert ${ }^{2}$.

Stammt die Ballade der eingemauerten Frau aus der Realität der balkanischen Bauopferritualen? Gibt es diese direkte Ableitung, die Goethe zur humanen und ästhetischen Ablehnung der serbischen Ballade führte?

In mehreren der erwähnten Beiträge ist diese Frage entweder nicht angeschnitten oder auf positivistisch-anthropologische Weise beantwortet: Die Legende beruht einfach auf der Wirklichkeit der Bauopferbräuche, die heute zwar Ersatzopfer kennen, sich in früheren Zeiten jedoch der Menschenopfer bedient haben ${ }^{3}$.

Um auf der gleichen Diskursebene zu bleiben, kann man einwenden, daß bis jetzt auf dem Balkan keine sichere Beweise für tatsächliche Menschenopfer im Grundstein großer Bauwerke - zumindest seit dem Altertum ${ }^{4}$ - erbracht worden sind. Im Unterschied dazu gibt es paradoxerweise solche Funde im restlichen Europa, die bis ins 17.Jht. in Deutschland und ins 18.Jht. in England reichen. Warum verbreitete sich denn das dichterische Motiv des Bauopfers

\section{Zitiert nach Megas, Die Ballade von der Arta-Brücke, S.14-15.}

2 Eqrem Cabej teilt aus Albanien mit: "Beim Bau eines Hauses, eines jeden Gebäudes oder einer Brücke wird gewöhnlich ein Widder, aber auch ein Hahn oder eine Henne geschlachtet. Beim Schlachten wird der Kopf des Tieres zu Boden gehalten, und zwar so, daß das Blut auf jene Stelle rinnt, auf der dann der erste Grundstein gelegt wird; dort wird auch der Tierkopf mitvermauert. In Tirana geschieht das zusammen mit Silbermünzen. Hahn berichtet, daß zu seiner Zeit der Gouverneur von Elbasan beim Bau einer neuen Brückc über den reißenden Erzenfluß zwölf Schafe schlachten und ihre Köpfe unter die Fundamente der Brückenpfeiler legen ließ." (Sitten und Bräuche der Albaner, in: Südost-Forschungen XXV. München 1966, S.333-387).

3"Der Handlung der Ballade(...) liegt der weitverbreitete Aberglaube zu Grunde, daß zum glücklichen Gedeihen eines Bauwerks der Ortsgeist durch ein Menschenopfer, und zwar durch Einmauerung eines Menschen, versöhnt werden muß." K. Dietrich, Die Volksdichtung der Balkanländer in ihren gemeinsamen Elementen, S. 151.

"(...)Diese letzten Beispiele und viele andere Angaben überzeugen uns davon, daß die alten Mythen, mittelalterlichen und neueren Überlieferungen von eingemauerten lebenden Menschen beim Bau von Städten und Festungen, bei der Fundamentlegung von Brücken und anderen Bauwerken nicht ausschließlich Phantasiegebilde sind, sondern ihren Ursprung und ihre Entstehung in der Realität haben. In Zeiten der Barbarei und krassen Ignoranz war die Macht des Aberglaubens derart gro $B$, daß viele unschuldige menschliche Wesen auf schreckliche Weise gemordet wurden, um vermeintliche Gefahren abzuwehren". Megas, Die Ballade von der ArtaBrücke, S.17.

"Its subject... no doubt goes back to the heathen times when primitive people believed that the Gods in their jealousy allowed men to build strongholds only in return for the sacrifice of human beings." Dragan Subotić, Yugoslav Popular Ballads. Cambridge Mass., 1932, S.39.

${ }^{4}$ Siehe auch Cocchiara, Il Ponte di Arta e i sacrifici di costruzione, S.35. 
nicht auf diese Teile des Kontinents, zumal mancherorts der Brauch selbst so häufig war, daß man auch Gesetze dagegen erlassen mußte?

Der direkte Bezug Brauch - Legende bzw. Geschichte Mythos reicht nicht sehr weit. Ein Beispiel: Die Legende der eingemauerten Frau war im Skutari des 15.Jahrhunderts wahrscheinlich nicht bekannt. Der albanische Humanist und Historiker Marin Barleti aus Skutari schreibt in seinem Buch "De obsidione Scodrensi" (Venedig 1504) einer anderen Legende die Gründung der Burg Rozafa zu, nach welcher diese Festung Rosa und Fa, die Schwester und Bruder waren, erbaut haben sollen. Das Motiv der eingemauerten Frau könnte sich in den Augen nordalbanischer und serbischer Rhapsoden erst in späteren Zeiten in der Burg zu Skutari niedergeschlagen haben. Die Verbreitung der Legende hatte kein aktuelles Brauchtum von Menschenopfern in den Baufundamenten, nicht einmal Erinnerungen an solche Paganismen nötig. Denn anderenfalls müßten wir auch für andere Motive, z.B. für die Ballade des toten Bruders, die auf dem Balkan eine ähnliche Verbreitung hatte und zum gleichen Liederkreis gehört, eine entsprechende historische Realität aufzeigen können. In einem Parallelverfahren müßte für jeden Mythos - etwa aus der homerischen Welt - das Ritual, von dem er herriuhrt, aufgedeckt werden.

Außer mit der direkten Ableitung Ritual - Mythos haben solche Standpunkte gleichfalls mit der Identifizierung der Magie, des Aberglaubens und des Totemismus mit dem Mythos Schwierigkeiten. Der Bauer, der einen Widder im Grundstein seines neu zu bauenden Hauses schlachtet, glaubt an die Zauberkraft des Blutes, ein anderer an die magische Festigkeit des Schattens, andere wieder, die ihren Schatten "leihen" müssen, haben davor Angst, denn sie betrachten ihn als Totem'. All dies manifestiert sich als Aberglaube, d.h. als Reststuicke eines mythischen Bewußtseins.

Wenn wir uns das chthonische Bauopfer in seinem Selbstverständnis vorstellen wollen ${ }^{2}$, dann dürfen wir es nicht von der mythischen Ganzheit absondem. Zugleich ist an die bedeutendste Eigenschaft des Opferaktes zu denken: er stellt eine innere Verbindung zwischen dem Opferbringer und den chthonischen Mächten der Unterwelt bzw. den olympischen Göttern her ${ }^{3}$. Chthonische Măchte stehen als Gegenstück zu der oberen Götterwelt. Forscher sind der Auffassung, daß die zuerst verehrten Götter jene der Mutter Erde, also die

1 "Ein Mensch, dessen Schatten auf diese Weise eingemauen wird, muß binnen wenigen Wochen an einer schleichenden, geheimnisvollen Krankheit zugrunde gehen." (G. Gesemann, Gesammelte Abhandlungen, I, S.291).

${ }^{2}$ Es sei hier noch einmal an die Übersetzungsrolle erinnert, die die Sprache bei der Mythenbeschreibung spielt "...sacrifice is not a phenomenon that can be reduced to rational terms" ("The New Encyclopadia Britannica", Bd.26, Chicago 1985, S.844).

3"Lebensordnung wird im Opfer durch unwiderrufliche Akte konstituien, eine Ordnung der Gemeinschaft; so selbstverändlich durchdringen sich "Religion" und gewöhnliche Existenz, daß jede Gemeinschaft, jede Ordnung durch ein Opfer begründet sein muß." (W. Burker in: Griechische Religion der archaischen und der klassischen Epoche. Stuttgart 1977, S.380). 
Götter der Unterwelt waren'; hiervon rührt auch der Unterschied zwischen den chthonischen und den olympischen Opfern her, die jeweils dem sanctum (dem Unantastbaren - Prinzip der Göttlichkeit durch die Mächte der Erde) oder den sacra (dem Geweihten - Prinzip der höheren Lichtkraft) dargebracht werden ${ }^{2}$. Die oberen Götter erhielten ihre Opfer meist durch Verbrennen, die tellurischen Mächte durch Eingraben ${ }^{3}$. Die Vorstellung, daß mit dem Tod das Leben in den Schoß der Mutter Erde zurückkehrt. findet ihren Ausdruck auch in der Ähnlichkeit der Rituale um den Tod und um die chthonische Aufopferung. So beschreibt Homer den Ritus, den Odysseus vollzieht, um ins Königreich der Toten zu gelangen:

Und nachdem ich flehend die Schar der Toten gesühnet,

Nahm ich die Schaf' und zerschnitt die Gurgeln über die Grube;

Schwarz entströmte das Blut, und aus dem Erebos ${ }^{4}$ kamen

Viele Seelen herauf der abgeschiedenen Toten.

Jüngling' und Bräute kamen und kummerbeladene Greise,

Und aufblühende Mädchen, im jungen Grame verloren.

Viele kamen auch von ehemen Lanzen verwundet,

Kriegerschlagene Männer mit blutbesudelter Rüstung.

Dicht umdrängten sie alle von allen Seiten die Grube

Mit grauenvollem Geschrei; und bleiches Entsetzen ergriff mich.

Nun befahl ich und trieb aufs äußerste meine Gefährten,

Beide liegenden Schafe, vom grausamen Erze getötet,

Abzuziehen und ins Feuer zu werfen und anzubeten

Hades' schreckliche Macht und die strenge Persephonias.

1 "Nach Bachofens Überzeugung besteht die mythische Grunderfahrung des Menschen darin, in der Erde die große Mutter zu sehen, die das Leben gebier und wieder in ihren Schoß zurücknimmt. Daher sind für ihn Mutterkult und Totenkult dasselbe... Die Vorstellungswelt der Urzeit ist als tellurisch oder chthonisch zu bezeichnen... Das Dunkel des Erdmutterschoßes, die Unterwelt, aus der alles kommt und in die alles zurückkehr, allgemein das Nächtliche prägen Ritus und Kult dieser Epoche, ja, deren ganzes Leben war bestimmt von der mächtigen Gegenwart der Toten.

Einem inneren Entwicklungsgesetz folgend, wandelte sich der Mythos vom ursprünglich chthonischen zum homerischen Mythos, wandelte sich damit das Leben vom Dunkel zum Licht, vom Stofflichen zum Logos. Diese Bewegung vollendete das Christentum, in dem Gott endgültig Geist geworden ist" (siehe K. Hübner, Die Wahrheit des Mythos, S.107).

2 Siehe J. J. Bachofen, Mutterrecht und Religion. Stuttgar 1984, S.45 ff.

3"Für die Olympier mußte das Opfertier weiß sein, schwarz dagegen für die Heroen und die Chthonier. Das Opfertier wurde vollständig verbrannt, kein Lebender durfte davon essen. Der Altartyp für die Olympier war der klassiche Tempel, über der Erde und bisweilen auf einer Anhöhe gelegen, für die Heroen und die Chthonier war es ein niedriger Herd, ein unterirdischer Schlupf winkel oder ein adyton ("Unzugängliches"), das möglicherweise ein Grab darstellen sollte. Die Opfer für die Olympier wurden an sonnigen Vormittagen dargebracht, für die Heroen und Chthonier dagegen am Abend oder um Mittermacht" (E. Rohde, Psyche. Tübingen 1983, S.124f).

${ }^{4}$ D.h. das Totenreich.

5 Die Frau des Hades. 
Aber ich eilt' und zog das geschliffene Schwert von der Hüfte, Setzte mich hin und ließ die Luftgebilde der Toten

Sich dem Blut nicht nah'n, bevor ich Teiresias' fragte.

(Homer, Odyssee XI,34-50)

Durch blutige, aber auch durch unblutige Opfer schließt sich der Kreis zwischen den Menschen und den chthonischen Kräften. Der Mensch sichert so den Zugang zur Fruchtbarkeit, zum Wachstum oder zum Tod. Die meisten Opfer finden wir bei den Agrarvölkem und allgemein in Begräbnisritualen. Ein ähnlicher Kreis wie bei der Beschwörung der Fruchtbarkeit oder der Rückkehr in die Mutter Erde schließt sich auch bei dem mythischen Bauopfer. So wie der Mensch oder die Pflanzen wachsen auch die Mauern aus dem Schoß der Mutter Erde. Mauern gehören $\mathrm{zu}$ den res sanctae, sie sind einmalig und "unverrückbar"2. Eine geeignetere Übersetzung als Mauer auf der Erde bauen (ein Ausdruck, der der heutigen Baumentalität entspricht) wäre für die mythische Auffassung "die Mauer aus der Erde entspringen lassen". So wie die Funktionalität und dabei auch die Bauästhetik die heutige Architektur bestimmen, so dürften vor allem der Glaube und der geschlossene Kreis Mensch Opfer - chthonische Mächte die Bauten des mythischen Menschen eingeleitet haben. Das Ergebnis war, daß wichtige Bauwerke wie Tempel, Brücken, Amphitheater in Ehrfurcht errichtet und immer bestimmten Göttern geweiht wurden. Daraus folgt auch ihre Einmaligkeit, und ein bizarrer Vergleich mit der heutigen Funktionalität kann dies veranschaulichen: Brücken, Autobahnen oder Kinos werden dort gebaut, wo sie am meisten einbringen, und können jederzeit zerstört, renoviert oder ersetzt werden, wenn sie ihre Funktionen verlieren.

Das Problem, ob die Bauopfer ursprünglich Menschen-, Tier- oder Ersatzopfer gewesen seien, ist hier von geringem Interesse. Das Eindringen in das Reich der Dunkelheit und die Verbindung mit den mächtigen irdischen Kräften kann auch durch andere Opfer als Menschenopfer erfolgen, wie das Beispiel von Odysseus zeigt ${ }^{3}$. Außerdem stellte sich kaum ein Zusammenhang zwischen

\footnotetext{
${ }^{1}$ Er sollte Odysseus die Geheimnisse seiner Heimkehr verraten.

2"Platons 'Gesetze' gebrauchen von Sparta den Ausdruck, der Gesetzgeber, der die Stadt mit Mauem zu umziehen verbot, habe wohl daraı getan, dieselben in der Erde schlafen zu lassen(...) Der lateinische Ausdruck excitare muros, die "Mauern erwecken" ruht auf derselben Grundanschauung und beweist, daß sich Platons Darstellung einer hergebrachten Auffassung anschloß. Diese erblickte offenbar in den aus der Erde Tiefen emporsteigenden Mauern eine aus dem Mutterleib hervorgehende Geburt, die in den finsteren Gründen so lange schlief, bis sie die Einwirkung der männlichen Kraft aus dem Schlummer aufweckte." Bachofen, Mutterrecht und Religion, S.43).

3 Allerdings muß die besondere Kraft des Blutes als Hersteller des chthonisch-menschlichen Kreises hervorgehoben werden: "Basic to both animal and human sacrifice is the recognition of blood as the sacred life-force in man and beast. Through the sacrifice - through the return of the
} 
der Legende der eingemauerten Frau und anderen vermeintlichen Einmauerungen im Mittelalter oder in fruheren Zeiten heraus ${ }^{1}$.

Hier seien nun einige Elemente und Motive aus der Legende angeführt, die am meisten als frühe mythische Erinnerungen bzw. als Mythologeme zu deuten wären. Sie zeigen vor allem die Verbindung des Menschen mit der (Mutter)Erde in dem immer beweglichen und fruchtbaren Lebenskreis; weiters lassen sie Einblicke in die alten Denk- und Organisationsstrukturen zu.

- Was am Tage gebaut, stürzt in der Nacht zusammen. Dieses Motiv fehlt niemals. Die Mauem beeindrucken durch ihre Beweglichkeit und durch das Versagen, aufrecht zu bleiben. Durch übermenschliche Kräfte einstürzende Mauern treten in alten Erzählungen immer wieder auf, so beispielsweise die Mauern von Jericho, die beim Schall von Erztrompeten zerstört wurden und die Mauern des römischen Alba, die auch beim Klang eines Blasinsturmentes einstürzten. Umgekehrt können sie auch durch übersinnliche Kräfte entstehen, wie im Mythos von den Mauem Thebens, die sich von selbst, bei den Tönen der Leier Amphions, errichteten².

- Es muß geopfert werden. Wie bereits erwähnt, ist die Aufopferung in der Legende immer eine unbestreitbare Notwendigkeit. Außer in ungarischen Varianten, die den Baumeister an der Aufopferung seiner Frau "schuldig" machen - offensichtlich eine neuere Interpretation - , wird diese Notwendigkeit auf überaus mystische Weise verkündet. Die Art der Verkündung bringt zu interessanten Schlüssen: der typischste Fall ist eine Stimme aus dem Fluß. Die Geister des Flusses (die Vilen) sind in den südslawischen ${ }^{3}$, aber auch in anderen Mythologien immer anwesend, sie gehören den Kräften der Unterwelt oder sind zumindest mit ihnen verwandt. Eine Stimme vom Himmel in griechischen oder ein wandernder Heiliger in albanischen Varianten deuten christliche Konnotationen als neuere Überlagerungen an. Am verbreitetsten ist jedoch die Verkündung im Traum; und ein Traum ist ebenso unwiderruflich wie die Stimme aus der Unterwelt oder vom Himmel. Der Bezug zur mythischen Psychologie ist unverkennbar, der Traum begegnet uns allzu oft als entscheidende Lebenssituation, so etwa in der Literatur des griechischen Altertums und auch in der neueren Überlieferung der Völker. Hübner vermerkt, daß "für den

sacred life revealed in the victim - the God lives, and, therefore, man and nature live" (The New Encyclopædia Britannica, Bd.26, S.839).

${ }^{1}$ Es sei denn, daß bestimmte Bräuche zur großen Verbreitung der Ballade beigetragen haben dürften. Mein Eindruck ist jedoch, daß der Grund für die Verbreitung der Legende ausschließlich auf dem Balkan das Zusammenleben im Osmanischen Reich war. Ein Indiz dafür wäre auch das Fehlen dieses Motivs bei den Albanern Süditaliens, die größtenteils nach der Eroberung ihrer Heimat durch die Türken auswanderten.

2 Siehe auch Bachofen, Mutterrecht und Religion, S.44.

3"...Sie sind den Menschen gut gesinnt und warnen vor verunreinigten Gewässern" ( Wörterbuch der Mythologie, I, 2: Götter und Mythen im alten Europa, Stuttgan 1973, S.207). 
Griechen gleichgültig war, ob ein Gott ihm im Traum erschien oder im Wachen. Beides hatte dieselbe Bedeutsamkeit... Daher sagte der Grieche nicht, er habe einen Traum, sondern er sehe einen Traum"l. Die gleiche Ausdrucksweise gibt es auch in slawischen Sprachen und im Albanischen: shoh një ëndërr bestätigt ebenfalls das Durchdringen von Wirklichkeit und Traum in der mythischen Mentalität.

Das Opfer wird in albanischen Varianten oft auch durch einen alten Mann verkündet. Der alte Mann, der Weise und Befehlende, ist eine zentrale Bastionsfigur des Patriarchats. Bei vielen Völkern war er auch die oberste Autorität in Opferzeremonien ${ }^{2}$.

Es gibt aber Zeichen in der Legende, die an frühere Organisationen oder zumindest an Übergangsperioden anknüpfen.: vor allem der Umstand, daß eine junge Braut getötet und geopfert wird. Hier spielt sich eine Todesheirat ab, so wie wir sie aus vielen Beispielen des Altertums kennen: Antigone - auch sie wurde lebendig eingemauert - Kassandra, Psyche u.a. Die Geschichte der eingemauerten Frau vermittelt noch einmal den Schmerz des besiegten und unterdrückten Geschlechts. E. Neumanri nennt dieses immer wiederkehrende Motiv "das alt-uralte Motiv von der Braut als der Sterbenden, das man auch nennen könnte: 'Der Tod und das Mädchen', wird... eingeschlagen und ein Grundphänomen weiblich-matriarchaler Psychologie wird sichtbar" ("Amor und Psyche", S.69.): das Opfer der Legende kann nie ein Mann sein33. Die Frau des Baumeisters hat gegenüber den erwähnten Heldinnen weniger ausgeprägte amazonische Züge. Mit Ausnahme von griechischen oder südalbanischen Varianten, in denen sie die Brücke verwünscht und verflucht, ist diese eine zarte Braut, die sich wie ein Schaf zur Aufopferung hingibt. Sie ähnelt nicht der Iphigenie, die sich von Geopferter in Aulis zu Opferbringerin in Tauris verwandelt; anders als bei der Ephesus-Artemis, die einen Umhang mit geopferten Brüsten auf matriarchalische Art demonstrativ trägt ${ }^{4}$, konzentriert sich gerade ihre Weiblichkeit auf die Brust und die fließende Milch: dadurch drückt sich an erster Stelle Mutterschaft gemischt mit Resignation aus.

- Das Gefangensein im Dunkeln, das heute eher schreckliche Vorstellungen hervorruft, stellt einen Kempunkt der Legende dar, und ihm ist m.E. die ungemeine Verbreitung dieser Geschichte zuzuschreiben. Das Liegen in den Fundamenten ist eine gleiche Situation wie das Liegen im Schoß der Erde, und zwar bedeutet es keine Tötung, kein Aufhören des Lebens, im Gegenteil, es ist mit einem Embryo-Bild vergleichbar und kündigt das Eintreten in den chtho-

IDie Wahrheit des Mythos, S.125.

2"An old man or the elders of the tribe are in charge of sacrifices among several African peoples... Similarly, among peoples in Australia the leading role in all sacrifical acts is filled by the old men as bearers of tradition and authority." (The New Encyclopædia Britannica, Bd.26, S.839).

${ }^{3}$ Siehe in der Folge das Opfer bei Andric und bei Kadare.

4 (Neumann, ebenda) 
nischen Kreis der Fruchtbarkeit an ${ }^{1}$. Dies bezeugt vor allem die erreichte $\mathrm{Fe}$ stigkeit der Mauem, aber auch - im Legenden-Typ der fruchtbaren eingemauerten Frau - die fließende Muttermilch an den Festungsmauern, die Wunder wirkt. Und diese Milch "fließt heute noch immer...": Dieses Abklingen der Legende erscheint wie eine letzte Erinnerung an jene Zeiten, in denen die Mythen eine sich immer wiederholende Wirklichkeit waren.

${ }_{1}$ Nicht zufällig kommt die beliebteste Figur der albanischen Märchen aus den Tiefen der Erde; $e$ bukura e dheut bedeutet die Schöne (oder die Schönste) der Erde. 


\section{NIKOS KAZANTZAKIS \\ Verflochtene Glaubenswege}

Tiefes Mitgefühl erfaßte mich für die Erde, die uns alle auf sich erduldet und uns emährt. Und unsägliche Trauer legte sich auf mein Herz, weil ich schlecht sprach von dir, o Mutter Erde - ich, der ich deinem Schoße entstiegen bin, aus Lehm und Feuchtigkeit.

\subsection{Stationen seines Lebens}

Nikos Kazantzakis (1883-1957) wurde auf der Insel Kreta, in einer verhältnismäßig wohl situierten kleinstädtischen Familie geboren. Seine Kindheit war - seiner rückblickenden Darstellung zufolgel - geborgen und zugleich gespannt. Kreta befand sich zu dieser Zeit noch immer unter türkischer Besatzung, man lauerte ständig auf den nächsten Aufstand. Kazantzakis' Großvater war von den Türken geköpft worden. Der Vater hatte das Kind darauf vorbereitet, Mutter und Schwestem zu töten, falls die Türken ins Haus eindringen würden². Der Vater wollte, im Zeichen der neuen Zeit, daß sein Sohn eine lange Tradition brechen und eine gute Ausbildung an der Universität von Athen bekommen sollte. Das ambivalente Verhältnis zum Vater, diesem ehrlichen und patriarchalischen Kreter, findet erst nach seinem Tod einen vollständigen Ausdruck: einerseits in den intimsten Aufzeichnungen als Erleichterung von der Tyrannei (siehe in der Folge), andererseits im Roman "Freiheit oder Tod", Ehrfurcht und Bewunderung. Der Vater wird hier vom groben, tollkühnen, fast charismatischen Kapetan Michalis verkörpert. Die ersten

\footnotetext{
${ }^{1}$ Siehe dafür besonders: N. Kazantzakis, Rechenschaft vor El Greco. Berlin 1964. In diesen ersten zwei Kapiteln habe ich mich für die Fakten hauptsächlich auf dieses und das andere autobiographische Buch Kazantzakis gestützt: Einsame Freiheit. Biographie aus Briefen und Aufzeichnungen, herausgegeben von seiner Frau Eleni Kazantzakis; die griechischen Texte sind ins Deutsche von Chlodwig Plehn, das französische Original von Jutta und Theodor Kunst übersetzt worden; erschienen in München 1972.

2Einsame Freiheit, S.34.
} 
Briefe aus Athen schreibt ihm der Student auf diese Art: "Wahrlich, mein hochverehrter Vater, es ist sehr schmerzlich, so weit von Vater, Mutter und Brüdern wegzugehen. Aber es mußte ja sein, da Sie doch wollen, daß aus mir ein Mann wird, der sich nicht schämen muß, Ihr Sohn zu heißen..."(35) Der Mutter und den Schwestern schreibt er dagegen viel lockerer und ehrlicher. Was noch merkwürdiger ist: Die Briefe an den Vater sind in katharevousa, dem starr-literarischen Neugriechischen, geschrieben, und gleich auf der anderen Seite des Blattes gibt es in dimotiki, der gesprochenen Sprache des Volkes, affektionierte Zeilen für die Frauen der Familiel. Sehr schmerzhaft sind einige Bekenntnisse des Schriftstellers aus dem Jahre 1933, als ihm in Madrid die Nachricht vom Tod des Vaters erreichte ${ }^{2}$. Seine Bekenntnisse sprechen von sich selbst, sie bezeugen, daß Nikos zwar mit seinem Vater äußerlich in Frieden lebte und der Familie pflichtgemäß während der Sommerferien Besuche abstattete, sich selbst aber allmählich zu einer sehr starken Persönlichkeit entwickelte, zu stark, als daß er die autoritäre Figur des Vaters erdulden konnte. Er dürfte dauernd Schuldgefühle gehabt haben, als er mit dem Geld des Vaters seine Studien in Paris fortsetzte und längere Aufenthalte in den Kunststädten Italiens machte. Sein eifriges Arbeiten und die Teilnahme an vielen literarischen Wettbewerben während seiner Jugendjahre kann vielleicht auch als ein Bemühen gegenüber dem Vater angesehen werden, damit er sich für den Sohn nicht zu "schämen" brauche. Letztlich hat vielleicht eine solche Erleichterung und Befreiung bei dem Vierzigjährigen wirklich stattgefunden, wenn man z.B. die Tatsache beriucksichtigt, daß Kazantzakis seine Meisterwerke im fortgeschrittenen Alter (zwischen 60 und 70) geschaffen hat. Man denke beispielsweise auch an Franz Kafka, der vermutlich im Schatten der Vater-Tyrannei den größten Teil seiner Manuskripte unvollendet ließ.

Schlechtes Gewissen rief vermutlich auch der Umstand hervor, daß der Vater einen Rechtsanwalt, ja sogar einen Politiker aus ihm machen wollte; der Sohn abeer erkannte und verfolgte seine literarische Neigung schon sehr früh.

\footnotetext{
'Siehe auch P. Bien, "Kazantzakis and the Linguistic Revolution in Greek Literature", Princeton, N.J., 1972, S.152.

2"Die Empfindungen, die mir der Tod meines Vaters verursachte, waren unbeschreiblich... Nur wenn ich schweigen würde, flüchten würde, fasten würde..., würde ich meinen heilen Verstand bewahren können und nicht verrückt werden. Ich wiederhole es Ihnen, es war nicht Liebe, die mich mit meinem Vater, dem Oberhaupt der Familie, verband, aber eine starke, tiefreichende Wurzel, die nun durchschnitten war... Ein Alpdruck hat mein ganzes Leben lang auf mir gelastet: jetzt werde ich anfangen aufzuatmen. Vieles was ich tat, vieles, was mich hemmte, wird jetzt wegfallen... Ich komme mir jetzt vor wie ein Falke, dem man die Fesseln gelöst hat. Der Schatten, der über mir hing, ist weggegangen, hat sich gesenkt, ist in der Erde verschwunden...

Der Verlust meiner Mutter war ein rein gefühlsgebundener Schmerz, das Klagen eines Kindes, das man allein läßt im Finstern, und die geliebte Hand hat sich der kleinen Faust entzogen. Der Tod meines Vaters war eine Erleichterung, schmerzhaft aufwühlend... Das sind schreckliche Worte, und ich sage sie keinem außer Ihnen..." (Einsame Freiheit, S.285. Dieser Brief ist an seine Lebensgefahrtin und zweite Frau Eleni gerichtet, welche trotz seines Wunsches, den Brief zu vernichten, ihn doch nach Kazantzakis' Tod veröffentlichte).
} 
Der Erfolg seiner ersten Werke, der langen Novelle "Schlange und Lilie" (1906) und des Dramas "Es tagt", welches 1907 den Preis der Universität Athen bekam und die Anerkennung einiger Kritiker', bestärkten ihn in seinem gewählten Weg. Der Gebrauch eines neuen Idioms, der griechischen Volkssprache dimotiki, bis dahin von der Schriftsprache fast völlig ignoriert, zeichnet diese ersten Werke, besonders den "Baumeisters" aus. Zwar hat Kazantzakis die meisten seiner Jugendwerke später verleugnet, ihr so anregendes Echo hat ihn jedoch in seiner Ubberzeugung nur gestärkt, er wäre zu etwas Außergewöhnlichem berufen. "Gott, mach einen Gott aus mir!" hatte schon der Knabe auf dem Bauernhof seines Vaters in Kreta geschrien ${ }^{2}$, und die intellektuelle Atmosphäre am Anfang des Jahrhunderts, mit der Philosophie von Nietzsche (Askese, Übermensch) und Bergson (élan vitale, volonté omnipotente) geladen, war für den ambitionierten jungen Mann gerade richtig. Er schrieb gleichzeitig den "Baumeister" und eine Dissertation über Nietzsche ("Nietzsche in der Rechtsphilosophie"), die im Jahre 1909 veröffentlicht wurde. Sein Streben darf aber nicht mit dem Sehnen nach literarischem Ruhm gleichgesetzt werden: "Mein Ziel ist nicht literarische Leisiung, sondern ich will einen neuen Sinn des Lebens zum Ausdruck bringen"3, wird er 1920 schreiben; Literatur also als einer der möglichen Wege zur Selbstverwirklichung.

$\mathrm{Da}$ er eine große Verantwortung sich selbst und in hohem Maß seinem Volk gegenüber empfand, wird auch von der großen Zahl seiner Übersetzungen bestätigt. Die Intellektuellen in Griechenland und anderswo auf dem Balkan, z.B. in Serbien, Rumänien, Albanien oder Bulgarien wollten die kulturelle Rückständigkeit ihres Landes überwinden, indem sie Meisterwerke der antiken und abendländischen Philosophie und Literatur übersetzten. Kazantzakis stand in dieser Hinsicht in der ersten Reihe; zurückgekehrt von Paris und Italien, übersetzte er fieberhaft vier Jahre lang eine Reihe von Werken Platons, Maeterlincks, Darwins, Nietzsches, Bergsons, Büchners, Eckermanns ins Neugriechische.

Außerdem arbeitete er an vielen Schulbüchern, die er unter dem Namen seiner Frau Galathea publizierte, um keinen Neid zu erwecken. (Durch seine Veröffentlichungen hatte er sich auch Abneigung zugezogen. So wurde schon bei der Preisverleihung im Jahre 1907 von seinen Professoren betont: "Wir

${ }^{1}$ So etwa des zu dieser Zeit bekannten Journalisten Gavrielidis : "...Sein neues Werk birgt in sich eine unbändige rebellische Kraft, es ist eine Art Ringen mit der Natur, mit dem Weib, mit der Liebe, mit dem eigenen Ich. Das Bedeutsamste für uns ist: in der Person des Verfassers von "Es tagt" und "Schlange und Lilie" erhält unsere so dürftige griechische Literatur einen neuen Autor, der aller Wahrscheinlichkeit nach aufsteigen wird, bis er in vorderster Linie steht, ja vielleicht über sie hinaus. Wer diese beiden Werke mit Aufmerksamkeit durchgelesen hat, erkennt in ihnen einen literarischen Wendepunkt. Der Autor bringt in unsere Literatur neue Elemente dämonischer, intellektueller, gefühlsmäßiger, sprachlicher Art... Er ist der neue, der junge Schriftsteller; was er schreibt ist Feuer, ist Leben" (ebenda, S.41).

2Einsame Freiheit, S.34.

Ebenda, S.83. 
krönen den Dichter, aber wir stoßen aus unserem züchtigen Tempel den jungen Mann aus, der es gewagt hat, solche Dinge zu schreiben"1). Die Schulbücher sorgten zugleich für seinen Lebensunterhalt, da er vom Vater keine Unterstützung mehr akzeptierte.

Ein dritter Bereich, wo sein soziales und politisches Engagement hin und wieder Ausdruck fand, war die direkte Beteiligung an wichtigen gesellschaftlichen Projekten. In den Jahren 1918-1920 war er Generaldirektor im Ministerium für Soziale Fürsorge, im Jahre 1945 vor dem Ausbruch des Bürgerkrieges für eine kurze Zeit Minister ohne Portefeuille; er hat sich sehr um die Unterstützung der griechischen Flüchtlinge aus dem Kaukasus nach dem ersten Weltkrieg bemüht, um Sozial- und Bildungsreformen auf dem Land, um die journalistische Darstellung der neuen Gesellschaft in Rußland, des Bürgerkrieges in Spanien, bis hin zur Teilnahme an Übersetzungsprojekten der UNESCO nach dem Zweiten Weltkrieg. Dieses Engagement war aber nie dauerhaft, einfach deshalb, weil es bis zur nächsten Enttäuschung nicht lang dauerte; er, der sensible, schaffende Mensch konnte sich mit den poítischen Zänkereien, mit der Mittelmäßigkeit und dem Pragmatismus der politischen Lösungen nicht abfinden.

In den Jahren 1914-1915 unternahm Kazantzakis zusammen mit seinem Freund, dem bekannten Dichter Angelos Sikelianos, den er stets verehrt hat, eine "Pilgerfahrt" durch die berühmten Kultstätten Griechenlands der antiken und der byzantinischen Zeit (Berg Athos, Mykenai, Delphi, Theben, Akropolis). Durch diese Besuche und längere Aufenthalte wünschte sich Kazantzakis "ein Bewußtsein für seine Geschichte und die Synthese zwischen Byzanz und Hellas zu finden"2. Er sehnte sich darüber hinaus nach einem eigenen Glauben, der seinem schöpferischen Werk wie ein Rückgrat dienen sollte. Und obwohl er die religiöse Heuchelei und das mönchische Vegetieren im Kloster wie auf dem Berg Athos zutiefst haßte ("Der Feind bricht schon ein, sein Fuß zertritt unsere Häuser und unsere Herzen. Der Feind ist der Gott der Kutten und der Rosenkränze, der schmutzige Faulpelz im Zölibat..."3), hatte für Kazantzakis die Askese, das Leiden für die anderen, immer eine schöpferische Anziehungskraft; auch die beiden Werke, die anschließend betrachtet werden, sind in gewisser Hinsicht ein Ergebnis davon. Auf seine Glaubenshaltung komme ich wieder zurück, hier sei nur vermerkt, daß er sich nach seinen "Pilgerfahrten", nach den oft stürmischen innerlichen Auseinandersetzungen mit alten und neuen Religionen, der Dichtung zuwandte.

Daneben widmete er sich auch "wirtschaftlichen Unternehmungen". Im Jahre 1917 wollte er ein Braunkohlenbergwerk wiederbeleben, ein Bergwerk, das später berühmt wurde, allerdings nicht durch wirtschaftlichen Erfolg (es scheiterte bald), sondern durch Kazantzakis' Partner im Unternehmen, Jorgos

\footnotetext{
${ }^{1}$ Ebenda. S.40.

2Ebenda, S.59.

${ }^{3}$ Ebenda, S.66.
} 
Sorbas, den Helden seines 1941 geschriebenen Romans "Alexis Sorbas". Allgemein ist hier zu bemerken, daß dem Schriftsteller der Sinn für das praktische "untermehmerische" Leben gefehlt hat, und da $B$ ihn nicht so sehr die Projekte, an denen er beteiligt war, interessierten als die hinter ihnen steckende Philosophie und ihr Idealismus.

Im Jahre 1921, nach drei Jahren fieberhafter Arbeit für die Rettung griechischer Flüchtlinge', trat Kazantzakis aus der Politik aus und begann wieder sein "nomadisches" Leben in den Städten Mittel- und Westeuropas. Wiederholt denkt er über den Sinn seines Lebens und über seine Mission nach. Er kommt dabei zu folgendem Schluß:

"Mein Ziel ist nicht literarische Leistung, sondern ich will einen neuen Sinn des Lebens zum Ausdruck bringen. (Denk an Nietzsche und Tolstoi!) Zur Erreichung dieses Zieles gibt es drei Wege:

1) der Weg Christi - unerreichbar,

2) der Weg des Apostels Paulus - Verbindung von literarischer Leistung (die Briefe!) und Aktion. Doch dazu ist Christus nötig;

3) der Weg literarischer oder philosophischer Leistung (Tolstoi. Nietzsche).

Ich schlage den dritten Weg ein, und darum wird das, was ich schreibe, niemals schlechthin etwas Literarisches sein. Denn meine Absicht zielt weit über die Grenzen des Literarischen hinaus..."2.

Es dürfte wirklich schwierig gewesen sein, in einer Zeit, in der die Rolle des Einzelnen angesichts der großen Massenbewegungen, der modernen Technik, der unaufhaltsamen Aufrüstung oder der bürokratischen Machtausübung immer mehr an Bedeutung verlor, solche Tolstoische Ideale zu nähren. Kazantzakis gab aber nicht auf: er übernahm eine Mammutarbeit, die als Motivation und Vorhaben das Schaffen eines neuen Glaubens hatte, die aber im Endeffeki seine Spannungen und Dilemmas widerspiegelte: dic "Odyssee", ein Epos in 33.333 Versen. Der Autor war damit über zwanzig Jahre hindurch beschäftigt und schrieb dazu mehr als sieben Fassungen. Das Buch wurde 1938 veröffentlicht; in der Zwischenzeit gab es kleinere Werke, die für ihn im Vergleich zur "Odyssee" vielleicht "Sonntagsspielereien" waren ${ }^{3}$, unter ihnen sind jedoch interessante Titel zu finden wie "Askese" (1927) "Toda Raba" (seine Auseinandersetzung mit der Sowjetunion, 1934), oder die Tragödien über Christus (1928) und Prometheus (veröffentlicht 1941).

Es war dies auch die Zeit der großen Reisen und der immerwährenden Wissbegierde. Er besuchte Spanien und beschäftigte sich hier intensiv mit seinem Landsmann El Greco, hielt sich in der Sowjetunion auf und dachte lange Zeit über die sozialistische Ordnung nach, lemte den südsowjetischen Orient, die Einöde Sibiriens und den Femen Osten kennen. Seine Vertiefung in die Bereiche Kultur, Politik, Philosophie, Religion (Mythologie, Christentum,

${ }^{1}$ Siehe auch den späteren Roman Griechische Passion, deutsch von Werner Krebs. Berlin 1963.

2 Einsame Freiheit, S.59.

3Siehe auch: Kindlers Literaturlexikon, Bd.VIIl. Zürich 1970, S.6894. 
Buddhismus), Literatur und Kunst ist ein seltener Fall für Schriftsteller aus Südosteuropa, die meistens, mit der harten Realität ihres Landes konfrontiert, entweder in der Provinz dahinlebten und provinzielle Bücher schrieben, oder das Heimatland, ja sogar manchmal ihre Muttersprache aufgaben. Kazantzakis gelang es, sich völlig zu entfalten und zugleich seine Heimat nicht zu verleugnen, obwohl er mehrere Jahre außerhalb Griechenlands lebte und einige Bücher auf Französisch schrieb.

Zwischen den großen Reisen gab es ruhigere Lebensabschnitte, etwa in der Ägina, der Insel in der Bucht von Pyreus, oder in Gottesgab, einem verschneiten Plateau in Böhmen, wo der Dichter seine "einsame Freiheit" genoß und eine Unmenge Arbeit leistete, vor allem den Kampf mit seinem "Odissia".

Kurz vor Ausbruch des Zweiten Weltkrieges hielt sich Kazantzakis mehrere Monate in England auf. In den Aufzeichnungen aus dieser Zeit fällt besonders seine Abscheu vor der englischen Industrialisierung, vor den Industriestädten Birmingham, Liverpool, Manchester auf. Wie so oft in seinen Schriften nimmt Kazantzakis auch hier den heutigen Zeitgeist voraus: "Der Mensch unserer Zeit, begeistert von seinen neuen eisernen Dienern, hat sich rückhaltlos und mit glühender Hoffnung, mit einfältigem Optimismus, auf die Unterjochung der Materie geworfen. Damit glaubt er das Glück zu gewinnen und den Geist zu befreien... Dies ist das Antlitz unserer industriellen Zivilisation: wild, ohne menschliche Güte, mitleidlos, und schmerzlich. Du siehst das ameisenhafte Gewimmel von Menschen, die mürrisch und eilig in den trostlosen Straßen durcheinanderlaufen, und eine quälende Angst beschleicht dich: vielleicht ist es nur ein Angstraum? Vielleicht lastet auf der ganzen Menschheit ein Alptraum? Wohin gehen sie? warum laufen sie? warum mußte das Leben des Menschen so unmenschlich werden?"1 Ein erster Rückblick in die mythisch-christlichen Wurzeln seines Landes wurde im Geiste der nationalen Begeisterung und der Spätromantik vorgenommen (siehe den "Baumeister"), der zweite, wie etwa in "Griechische Passion", brachte vor allem Pessimismus und Mißtrauen angesichts der modemen Entwicklungen in Europa zum Ausdruck.

Während des italienisch-griechischen Krieges und der darauffolgenden deutschen Besatzung befand sich Kazantzakis in seinem Haus in Ägina; hier arbeitete er trotz seiner Isolierung im gewohnten Rhythmus. Am Rande der Hungernot, manchmal auch in Lebensgefahr, schrieb er eines seiner geistreichsten Werke, "Alexis Sorbas".

Mit der Befreiung wurde Kazantzakis Minister und zugleich Präsident der Griechischen Literaten. Das Nationaltheater in Athen führte mit großem Erfolg Tragödien von ihm auf. Es gab jedoch keinen Anlaß zur Freude. Sein Kreta wurde von den Kriegsoperationen besonders betroffen, Griechenland war vom Weltkrieg verwüstet und stand vor einem neuen Krieg. Bei einem Besuch auf der Heimatinsel mußte der Schriftsteller schmerzvoll feststellen, daß die Orte "nicht mehr wiederzuerkennen sind. Die alten Häuser sind zu

IEinsame Freiheit, S.403. 
Ruinen geworden; neue Menschen; meine Bekannten tot oder Wracks... Ich gehe umher inmitten trauriger Erinnerungen, und jede Freude ist mir vergangen. Es wird schwer sein, ein Buch über Kreta zu schreiben, weil ich vor Schmerz vergehe... Diese Reise ist tragisch, ist sehr bedrückend." (ebenda, S.458)

Im Ministerium arbeitete er leidenschaftlich; es ging für ihn hauptsächlich darum, "Unschuldige zu retten". Bald trat er aber zurück, da er, wie seine Frau Eleni berichtet, die Intrigen und die Einmischung der englischen Gesandten nicht verkraften konnte. Außerdem hatte er, wie erwähnt, kaum ein Talent als Politiker. Er konnte "nicht einmal Schmeichler sein; darüber ärgert sich die Rechte wie die Linke". "Keine Regierung unterstützt mich, und da ist es nur gerecht, daß ich auch keine unterstütze", so drückte er selbst seinen Fall aus $^{1}$. Es begann noch einmal das Leben im Ausland, diesmal ohne große Reue, da der Zustand seiner Heimat mit jedem Tag katastrophaler wurde, und Kazantzakis die Pläne großer Romane in sich trug. Seine Reiselust, "das unstillbare Verlangen" nahm sogar zu. Er reiste trotz Krankheit nach England, Österreich, Holland, China, Japan. Griechenland wollte er nicht mehr besuchen. "Ich will Norditalien sehen, Griechenland trage ich in mir. Ich habe keine Lust, es wiederzusehen"2. Der eigentliche Grund war die Zerrissenheit seines Landes, das von den Wellen des Hasses noch einmal verschlungen war. "Wie ist es möglich, daß ein so vortreffliches Volk solch törichte, verbrecherische und schuftige Führer hat? Das Schicksal Griechenlands ist tragisch, und das letzte Abenteuer kann es tief in den Abgrund stürzen"3.

Er lebte und arbeitete, nach der Beschäftigung bei der UNESCO in Paris, in Antibes, an der Côte d'Azure. Zu dieser Zeit wurde er immer bekannter und anerkannter, seine Bücher "Alexis Sorbas", "Griechische Passion" (1948), "Freiheit oder Tod" (1951), "Die letzte Versuchung" (1952) wurden in mehr als zwanzig Sprachen übersetzt. Der Erfolg hatte auch seine nachteiligen Seiten, weil die Intrigen gegen ihn in Griechenland nie aufhörten (seine Romane wurden insbesondere vom orthodoxen Klerus abgelehnt) und weil die Anerkennung im Ausland sehr "langsam" vor sich ging. So war er von den griechischen Schriftstellern schon im Jahre 1946 für den Nobelpreis vorgeschlagen worden (er hatte diese Idee nur unter der Bedingung akzeptiert, daß Sikelianos auch mit ihm vorgeschlagen werden sollte), später auch von dem Verband der norwegischen Schriftsteller. Diesen Preis hat er aber nie bekommen. Dazu schreibt der bekannte Mythologe Kerényi: "Das nicht immer ganz klare Verhältnis derjenigen zur Humanität und zum Humanismus, die nach dem Tode von Kazantzakis zu Preisträgern wurden, schaltet den Verdacht aus, daß seine eigenartige Beziehung zum Menschen, über den er die verzehrende Flamme

lEbenda, S.493.

2Ebenda.

${ }^{3}$ Ebenda, S. 497. 
setzte, ein Hindernis gewesen wäre. Die unerhörte Substanz, die er war, die einmalige Entelechie, wurde in ihrer Bedeutsamkeit nicht genügend erkannt."1

Nach wiederholten Krankheiten starb Nikos Kazantzakis im Jahre 1957 in einer Klinik in Freiburg. Wie seine Frau Eleni berichtet, bewahrte er bis zum Ende den Stoizismus: Als seine Augen erkrankten, diktierte er, als die rechte Hand steif wurde, schrieb er mit der linken. Solch ein Tod erinnert, wenn er sich selbst auch oft als einen Federfuchser bezeichnet hat ("der einen Dialog mit der großen Seele des Volkes führt"2), an die charismatischen Kreter seiner Bücher.

\section{2. Ästhetische und philosophische Ansichten}

Beim Lesen des dichterischen und autobiographischen Werkes Kazantzakis' fallen bestimmte Motive oder sich wiederholende Themen auf, die sein einzigartiges Porträt gut skizzieren können.

Der griechische Autor hat sich für die Literatur entschieden, denn hier sah er sich am begabtesten, sein höchstes Ziel zu verwirklichen, nämlich "soviel Materie wie möglich zu 'Geist' zu machen"3. Dies war kein leichter Entschluß, er rief sogar, wie schon angedeutet wurde, ständig innere Konflikte hervor. Das Schreibzimmer war ihm, besonders in seiner Jugend, zu eng, den Elan seiner Jugend und die Träume eines "Weltverbessers" mußte er notgedrungen in Dichtung umsetzen: "Schwer und freudlos ist das Schicksal des Dichters; denn er ist gezwungen, Worte zu gebrauchen, das heißt den inneren Antrieb in etwas Starres zu verwandeln. Jedes Wort ist eine harte Schale, die in sich eine große, sprengende Kraft birgt. Um herauszufinden, was es sagen will, mußt du es in dir wie eine Granate explodieren lassen; nur so kann es die Seele freigeben, die es gefangen hält"4; zu dieser Erkenntnis gelangt er gegen Ende seines Lebens.

Bleiben wir bei der Mission des Dichters als erstem wiederkehrenden und wichtigen Motiv für seine Persönlichkeit. Der junge Mann wurde durch seine Veranlagung und durch seine Zeit dazu gebracht, die Literatur als einzigen Ausweg zu wählen, um seine stürmische rebellische Natur in Worte zu bringen. Eine "Notlösung" seiner Jugend ("der Sprung zur Höhe ist nur aus dem Leben heraus, nicht als literarische Kunst möglich... darin ruht die Tragik meines Lebens"5, wurde für den reifen Schriftsteller die einzige Ausdrucks

\footnotetext{
1 Im Vorwort zu Kazantzakis' Tragödie in einem Akt Komödie. Zürich 1969, S.5.

2 Gemeint ist damit Alexis Sorbas, siehe Einsame Freiheit, S.521.

3 Ebenda, S.520.

${ }^{4}$ Rechenschaft vor El Greco, S.86.

5 Einsame Freiheit, S.83.
} 
möglichkeit. Kazantzakis faßt seinen beschwerlichen Weg bis zur Abfindung mit dem geschriebenen Wort folgendermaßen zusammen: "Seit 65 Jahren ziehe ich nun meine Kreise, gehe auf und ab in diesem Gefängnis mit den beiden Fensterchen, diesem finsteren und geheimnisvollen Gefängnis, das 'Mensch' heißt; und ich schaue aus den beiden Fensterchen auf die Welt und werde nicht satt, sie zu sehen. Welch ein Wunder ist doch diese Welt, wie harmonisch entspricht sie unserem Hunger und Durst, unserer Sehnsucht nach Gott! Und seit 45 Jahren mühe ich mich darum, all das Geschaute, all diesen Hunger und Durst umzuwandeln zu Höherem, es einzukleiden in die 24 Buchstaben unseres griechischen Alphabetes, ehe ich sterbe; um so viel Materie wie möglich zu 'Geist' zu machen.

Und sollte ich noch einmal geboren werden, keinen anderen Weg würde ich einschlagen. Mühevoll, rauh ist der Anstieg, den ich mir gewählt habe, doch ich bereue es nicht"1.

Trotz seiner zeitweiligen patriotischen oder revolutionären Abschweifungen konnte Kazantzakis, in schwierigen Zeiten und überall auf der Welt lebend, sein früh anvisiertes Ziel ständig verfolgen. Und hier gehöıt er wieder zu den Ausnahmen aus dem südosteuropäischen Raum. Denn die tumultuöse Entwicklung auf dem Balkan um die Jahrhundertwende und in der ersten Hälfte unseres Jahrhunderts hat meistens, wie es in Albanien hieß, "Dichter der Feder und des Gewehrs" hervorgebracht, Schriftsteller, die sich selten völlig entfaltet haben, weil sie entweder dem Druck der Realität nicht standhielten oder andere Gebiete als die Literatur für ihre Bestrebungen aussuchten. (Währenddessen die meisten Schriftsteller in Westeuropa aufgehört hatten zu glauben, sie hätten andere Mittel als ihre Kunst zur Verfügung). Es drängt sich hier geradezu der Vergleich mit einer albanischen Persönlichkeit auf - Fan Noli (1880-1964), dem Staatsmann, Dichter, Kirchenoberhaupt, Historiker und Komponisten; die Gemeinsamkeiten mit Kazantzakis sind höchst interessant und vielleicht nicht ganz zufällig:

Auch Noli, aufgewachsen in einer halborientalischen Welt und erzogen in dem gleichen abendländischen Klima wie Kazantzakis, war von der Philosophie der Jahrhundertwende beeinflußt und von der Idee des Übermenschen besessen (er nennt sich selbst in einigen Gedichten Christus und Messias, er sei zur Rettung seines Volkes, der Albaner, berufen). Gleichfalls wie Kazantzakis war auch er Politiker, und zwar höheren Ranges: Drei Monate lang im Jahre 1924 war Noli Ministerpräsident, bis er vom "Barabbas", dem späteren König Ahmet Zogu, gestürzt wurde. Gescheiter im politischen, fühlt er sich ebenfalls geschlagen im literarischen Bereich und widmet sich nach den 20er Jahren in den USA der Gründung der albanisch-orthodoxen Kirche, der Geschichte Skanderbegs und Beethoven. Er besaß ebenfalls viele Kenntnisse der Welt, der abendländischen und der orientalischen Kultur; durch sein Schaffen und noch

lEbenda, $S .520$. 
mehr vielleicht durch seine meisterhaften Übersetzungen hat er die junge albanische Literatur um vieles bereichert; zuletzt war auch er gezwungen, durch die Welt zu ziehen und mehrere seiner Bücher in anderen Sprachen zu schreiben.

Hier hören aber die Gemeinsamkeiten auf, vielleicht genau an dem Punkt, der betont wurde: Kazantzakis ließ sich trotz seiner "übermenschlichen" Ambitionen und trotz der Abneigung gegen das Wort "Literatur" nie vom früh gesetzten Ziel ablenken; und je nüchterner seine jugendlichen Größenvorstellungen wurden, desto mehr erlangte seine Literatur Bedeutung. Noli dagegen hatte ein stürmisches Temperament, das nach keiner Synthese zwischen den verschiedenen Tätigkeitsbereichen strebte, sondern vielmehr der Begabung dort Ausdruck verlieh, wo das Zusammentreffen von Ereignissen sie brauchte.

Die Literatur faßte Kazantzakis oft als Mission auf, als seine Aufgabe auf der Erde. "Ich muß den letzten Ansturm unternehmen, um meine Pflichten zu erfüllen, ehe ich unter der Erde verschwinde", schreibt er im Jahre 1929.1 Was er unter Pflichten versteht, erklärt vielleicht die folgende Aussage: "Wachzurufen, die Ruhigen unruhig zu machen, denen, die sich bescheiden glücklich fühlen, zu zeigen, daß sie unglücklich sind, glühende Kohlen ins Innere jeden friedlichen Hauses zu werfen - das ist unsere harte, schwere, höchste Pflicht. Warum? Damit die Welt nicht verrottet im Sumpf der Behaglichkeit, damit die Seelen nicht verrotten in Wohlstand und Lässigkeit" 2.

Diese schwungvolle, selbstverherrlichende Sprache ist vor allem für den jungen Kazantzakis typisch; noch in den 20er Jahren macht er Propaganda unter der Bevölkerung Kretas gegen das herrschende System, schreibt Pamphlete und verkündet 1925 seine "politische Rechtfertigung". Inzwischen reifte aber in ihm der Schriftsteller als eine Synthese seiner früheren Auseinandersetzungen mit sich selbst und der Welt, mit Philosophie, Glauben und Politik. Damit Dichtung im Vergleich dazu nicht als minderwertig und zu "schöngeistig" erscheint, muß er sich ihr vollständig widmen und jede Barriere, die sie vom Leben trennt, zerschlagen. "Ich muß zwei Feinde besiegen: 1. Das um jeden Preis Auffallende, verkrampft Lyrische, d.h. das nur dem Tag Verhaftete, das nicht Essentielle; 2. Das Abstrakte. Jeder Gedanke muß zu einem plastischen Bilde werden", schreibt er 1915. Und wenn er manchmal eine seiner Arbeiten in den Papierkorb warf, sagte er zu seiner Frau: "Es ist zu sehr vom Gehirn diktiert, Lenotschka. Es ist noch nicht aus den Nieren gekommen" 3.

Schreiben bedeutete für ihn also, etwas nicht zu intellektuell und durch den kultivierten Geist mitzuteilen, sondern sich mit Schmerz von etwas zu trennen. Nachdem Kazantzakis den Roman "Freiheit oder Tod" fertig geschrieben hatte,

\footnotetext{
1Ebenda, S.157.

2Ebenda, S.28.

3 Ebenda, S.58, 81 .
} 
notierte er: "Ich bin gewiß: wer dies Buch liest, wird es spüren, wieviel der gelitten hat, der es schrieb, und sein ganzes Volk"1.

Sich seiner Mission und seiner Kunst bewußt sein, bedeutet bei Kazantzakis noch lange nicht, daß er mit seinem "Metier" den Frieden gefunden hat. Die Frage, 'wie weit kann ein Schriftsteller durch seine Tätigkeit bestimmte politische und soziale Entwicklungen beeinflußen, ob er die Massen uiberhaupt erreicht', hat auch ihn gequält, vielleicht noch mehr als andere Zeitgenossen, da er in höherem Maße ein politisch engagierter Mensch war. Seine Antworten auf diese Frage waren vor allem Ohnmacht und Enttäuschung2.

Bezüglich der Mission des Dichters scheint mir noch eine Ansicht, die Kazantzakis in seinen letzten Jahren geäußert hat, erwähnenswert. Sie stellt eine Erkenntnis dar, die offenbar lange Zeit brauchte um gewonnen zu werden: "'Wir können die Wirklichkeit nicht ändern', sagte mir ein bekannter Mystiker. 'Laß uns also das Auge ändern, das die Wirklichkeit sieht.' Das tat ich, als ich Kind war; das tue ich auch heute in den schöpferischsten Augenblicken meines Lebens"3.

Dem Begriff des Schreibens in Schmerzen ist bei Kazantzakis noch ein anderer Begriff verwandt; er verdeutlicht seine "Entelechie" vielleicht noch besser als andere: nämlich die Sinnlichkeit. Seine Bücher vermitteln eine unmittelbare Nähe, eine "Greifbarkeit" der Dinge und Szenen; Farben, Landschaften, Geräusche erreichen den Leser durch stark konnotierte Wörter und Wendungen ${ }^{4}$.

Das Integrieren der Natur, der Farben, Düfte und Töne in die Dichtung, diese "gesättigte" Sinnlichkeit ist ein Charakteristikum, das vielleicht die kontrastreiche griechische Landschaft selbst mitbeeinflußt; wir treffen es auch bei anderen Autoren der neugriechischen Literatur, etwa bei den Lyrikern Seferis, Elitis oder Ritzos ${ }^{5}$. Kazantzakis erläutert dies als reine individuelle

1 Ebenda, S.527.

2 So schreibt er im Jahre 1927 während seiner Reisen quer durch Rußland und die Republiken des sowjetischen Orients: "Alles, was ich geschrieben und getan habe, kommt mir wertlos und provinziell vor - in dem kleinen, armseligen Erdenwinkel haben nur ganz wenige Menschen, und davon die meisten ablehnend und bösartig, meinen Schrei vernommen. Ich schaue auf die Frauen hier, auf die Muschiks, und ich weiß: Niemals wird meine Stimme sie erreichen, weil die Mittel, die ich anwenden kann, zu schwach sind" (Einsame Freiheit, S. 238).

${ }^{3}$ Rechenschaft vor El Greco" S.40.

${ }^{4}$ Ein $\mathrm{x}$-beliebiges Beispiel aus der Fülle solcher Mittel kann diese charakteristische Eigenschaft veranschaulichen: "Zypern ist wahrhaft die Heimat Aphrodites. Nie habe ich eine weiblichere Insel gesehen, nie eine so schr von gefährlicher Wollust gesättigte Luft geatmet. Ich spüre, wie ich weich werde. Am Abend, wenn die Sonne sinkt, wenn der Seewind die kleinen Schiffe wiegt, wenn sich die Frauen am Strand ergehen, gibt sich meine Seele hin, Aphrodite gleich, der heiligen Prostituierten. Hier dringt eine Süße tief in euch ein wie der Duft von Jasmin. Eine Stimme liebkost euer Ohr, und hingerissen hört ihr ihr zu. Das Denken ist ein Elan, der im Gegensatz zum Lebenswillen steht. Die Spannung der Seele, der Aufschwung des Geistes sind die großen Sünden unserer Vorfahren. Eßt, schlaft, liebt, ergeht euch am Ufer des Meeres" (aus einem in Französisch geschriebenen, zu seinen Lebzeiten nicht veröffentlichten Text, in Einsame Freiheit, S.142).

${ }^{5}$ Folgende Verse aus einem zufällig herausgegriffenen Gedicht Seferis' dürften das Phänomen in Erinnerung bringen: [1] Einmal Mittagssonne, ein andermal Händevoll Nieselregen/und die 
Prägung: "Jede Ergriffenheit, jede meiner Ideen, auch die abstrakteste, ist aus diesen vier Urbestandteilen [Erde, Meer, Frau, Stemenhimmel] zusammengesetzt, und selbst das übersinnlichste Problem nimmt in mir natürliche, warme Körperformen an, die nach Meer, nach Erde und nach Menschenschweiß riechen. Das 'Wort' muß, um mich zu berühren, lebendiges, pulsierendes Fleisch werden. Erst dann begreife ich, wenn ich riechen, sehen und berühren kann"1.

Der große Meister heißt für Kazantzakis Natur; der Mensch soll an ihr das Beispiel nehmen, mit ihr in Einklang und in ihrem Rhythmus leben. Das ist ein Ideal, dem die Schriftsteller sowohl im alten Griechenland, in der romantischen Epoche, aber auch in der modernen Zeit nachgestrebt haben. Hier liegt vielleicht einer der Gründe, die Kazantzakis so tief in der Tradition verwurzelt und doch so modern und aktuell erscheinen läßt. Denken wir an "Alexis Sorbas"; dieses Buch hat die Leserwelt mit seiner Einfachheit, mit einem elementaren Helden wie Sorbas ${ }^{2}$ verblüfft - gerade in der Zeit, als Menschen und Regierungen auf die Epoche der Technik ein Loblied anstimmten und sehr viel mit Kriegen und modernen Waffen beschäftigt waren, während die Literatur als Gegengewicht dazu fungierte. Das ist Sorbas, in einem bezeichnenden Ausschnitt aus dem Roman:

\begin{abstract}
"Ich schaute in Sorbas' mondhelles Gesicht und freute mich, wie mutig und einfach er sich mit der Welt auseinandersetzte, wie Körper und Seele bei ihm eine Einheit bildeten, wie sich alle Dinge - Frauen, Brot, Wasser, Zukost und Schlaf - harmonisch und glücklich seinem Fleisch verbanden und zu Sorbas wurden. Nie hatte ich solch ein freundschaftliches Verhältnis zwischen einem Menschen und dem Weltall erlebt" ${ }^{3}$.
\end{abstract}

Fast im gesamten Werk von Kazantzakis treffen wir dieses Rousseauische Ideal - das Leben in Einklang mit der Natur. Es bringt für uns auch seine Einstellung zur mythischen Erbe des Menschen deutlicher an den Tag. In "Alexis Sorbas" ist das Ideal direkt und geradezu programmatisch ausgedrückt: "Heute begreife ich erst richtig, daß es eine Todsünde ist, die ewigen Gesetze zu vergewaltigen. Wir haben die Pflicht, uns nicht zu beeilen, nicht ungeduldig zu werden und dem ewigen Rhythmus der Natur mit Vertrauen zu folgen"(S.103).

Noch kurz einige Hinweise auf Kazantzakis' Verhältnis zur Philosophie und zum Glauben, bevor zum Stichwort Mythologie übergegangen wird. Vielleicht ist eine solche Trennung bei ihm überhaupt nur dadurch möglich, da der Schriftsteller sich intensiv mit Philosophie und Glauben in der ersten

Küste voller Scherben alter Krüge./Unbedeutend die Säulen, nur der Heilige Epiphanios/zeigt dumpf, versunken, die Macht des goldschweren Kaiserreichs. [2] Junge Leiber sind hier vorbeigekommen, Verliebte;/ Pulsschlag im Schoß, rosenfarbene Muscheln und die KnöcheV furchllos auf dem Wasser laufend und offene Arme für die Paarung der Sehnsucht (aus "Kavafis, Seferis. Gedichte", dt., Eridianos-Athen, Ersch.-Jhr. fehlt).

${ }^{1}$ Rechenschaft vor El Greco, S.38-39.

2"(...)whose philosophy is that real man undoes his belt and looks for trouble" (Bien, "Kazantzakis and the Linguistic Revolution in Greek Literature", S.171).

${ }^{3}$ Alexis Sorbas, übertragen von Alexander Steinmetz. Hamburg 1955, S.111. 
"Etappe"1 seines Werdens beschäftigt hat; außerdem gibt es von ihm ein philosophisch-dichterisches Werk, "Askitiki", 1928, mit dem Untertitel "Rettet Gott", das in hohem Maß sein Credo darstellt und auch in seinen späteren Werken Resunanz findet.

In "Rettet Gott" will Kazantzakis seine Ästhetik und soeine Einstellung zu philosophischen Grundfragen formulieren; dies findet in einer wenig "wissenschaftlichen", eher thetorischen Sprache Ausdruck. Als seine Hauptaufgabe bezeichnet der Schriftsteller die Erforschung der Welt und der Seele: "Mich bewegt nur eines: zu erfassen, was sich hinter den Erscheinungen verbirgt, was für ein Geheimnis sie umgibt". Das ist das Motto von "Askitiki", seiner Dialektik, wenn wir es so wollen, und seines Pessimismus. Dialektik, insofern als für Kazantzakis das Leben einen hellen Zwischenraum zwischen zwei Abgründen darstellt, und das menschliche Dasein durch zwei entgegengesetzte Tendenzen bestimmt ist, die unaufhörlich miteinander ringen: a) die Tendenz zur Synthese, zum Leben, zur Unsterblichkeit und b) die Tendenz zur Auflösung, zur Materie, zum Tod. Trotzdem ist das Individuum kein passives Werkzeug fremder Mächte, sondern maßgebendes Wesen des Kosmos, ein tätiger Lebensträger ${ }^{2}$. Im Menschen wirbeln alle kosmischen Kräfte. Darum kann es auch keine Grenzen für ihn geben: "Niemals sollst du die Grenzen des Menschen anerkennen! Durchbrich die Grenzen! Leugne, was deine Augen sehen! Stirb und schrei: 'Es gibt keinen Tod!"'3. Parallel zu diesem Glauben an den menschlichen Elan läuft die Hoffnungslosigkeit: "Ich durchmesse die maßlose, gestaltlose Zeit, mutterseelenallein, hoffnungslos, schreiend in der Öde... Ich wandle, ich strauchle umher unter dem Fleisch wie ein Pilger, den die Nacht überrascht hat. Und ich schreie: $\mathrm{Zu}$ Hilfe! (S.48). Den Körper vergleicht er mit einem Schiff, dessen einzige Bestimmung es ist, zu scheitern. Wozu dann das ganze Ringen? "Frage nicht! Kämpfe!".

Der Untertitel des Buches, 'Salvatores Dei', deutet bereits Kazantzakis Auffassung von Gott an. "Unser Gott ist nicht Allmacht. Er ist nicht Allgüte" (S.85). Gott muß man retten, er soll von der Materie und von unserer Seele, wo er begraben liegt, befreit werden. Der Schrifteller hatte schon im Jahre 1915 auf dem Berg Athos geschrieben: "Wir vermenschlichen so oft Gott, anstatt den Menschen zu vergöttlichen"4.

\footnotetext{
IIm Jahre 1929 schreibt er: "Ich will einmal annehmen, daß alle diese Jahre nur Vorbereitung waren, daß nunmehr die Vorbereitung zu Ende ist. Ich habe noch 40 Jahre zu leben. Das reicht. Es genügt, daß ich nichts mehr auf Dinge verschwende, die taggebunden sind und außerhalb des Zieles liegen" (Einsame Freiheit, S.233).

2 Siehe auch "Kindlers Literaturlexikon", Bd.II, S.1212.

${ }^{3}$ Nikos Kazantzakis, Rettet Gott!, übertragen von Karl August Horst. Wien 1953, S.17.

${ }^{4}$ Einsame Freiheit, S.55.
} 
Sein Antikonformismus in philosophischen und religiösen Fragen hat Kazantzakis ein Leben lang Schwierigkeiten eingebracht, weil sich dadurch besonders die offizielle Kirche herausgefordert fühlte. Einer seiner späten Romane, "Die letzte Versuchung", der seinerzeit auf den päpstlichen Index gesetzt worden war, sorgte noch im Jahre 1987 in der Verfilmung von Martin Scorsese für große Aufregung im Westen. Die Art, wie Kazantzakis Fragen des Glaubens erörterte, war immer zu persönlich und "zu radikal", sie enthielt oft Sprengstoff für alle möglichen festgesetzten Dogmen, wie folgende Aussage verdeutlicht:

\begin{abstract}
"Kurz ist dies Leben, und wir kommen nicht dazu, Freude oder Schmerz so zu empfinden, wie es unserer Seele gemäß wäre. Noch auch zu sündigen, wie es nötig ist. Der Tugendbegriff, definiert von kleinen ängstlichen Menschen, ist im Wege, und die Sünde, definiert auch sie von ängstlichen kleinen Menschen, bereitet keinen Genuß. Und in dem Augenblick, da wir anfangen, unsere eigenen zehn Gebote zu schaffen, sterben wir" (ebenda, S.496).
\end{abstract}

Es ist schwierig, Kazantzakis' lange und einzigartige Auseinandersetzung mit dem Glauben in wenigen Worten zusammenzufassen; mehr dariber bei der Besprechung der "Griechischen Passion". Dem Schriftsteller wurde u.a. oft auch voreilig Mystizismus zugeschrieben, ohne zu erklären, was dieses Wort bedeutet; Ketzerei und Mystizismus als falsche Beschreibung, aus entgegengesetzten Positionen, eines und desselben Phänomens: des komplizierten, radikalen Glaubens. Die Auseinandersetzung mit ihm war immer sehr intensiv gewesen, sie hatte schon in der Kindheit begonnen. So wie andere Kinder Abenteuerbücher lesen und davon träumen, Piraten, Generäle, Staatsmänner zu werden, so hatte der künftige Schriftsteller leidenschaftlich Volksbücher mit Heiligenlegenden gelesen und ein Heiliger werden wollen'.

Auch dieses andere Ideal war für seine Literatur, wie beide zu analysierenden Werke zeigen, von entscheidender Bedeutung.

\title{
2.3. Griechische Passion
}

Diesen Roman (wortwörtlich übersetzt "Christus wird wieder gekreuzigt") schrieb Kazantzakis in seiner reifsten Periode. Durch die Erzählung von Ereignissen, die sich in einem griechischen Dorf irgendwo in Anatolien irgendwann in unserem Jahrhundert abspielen, erzählt Kazantzakis die immer wie-

\footnotetext{
1 "Meine erste Sehnsucht war die nach Freiheit; die zweite, die heimlich noch in mir fortdauert und mich quält, der Trieb, ein Heiliger zu werden. Ein Held und gleichzeitig ein Heiliger, das war das hïchste Vorbild des Menschen; von Kindheit an hatte ich diesem Vorbild über mir in der blauen l.uft feste Gestalt verliehen" (Rechenschaft vor El Greco, S.67).
} 
Jerkehrende Geschichte des Martyriums - der Opferung eines Christus durch eine Gemeinschaft bzw. durch ihre Führer und Priester.

Für ein Mysterienspiel - ein alter aus dem Mittelalter überlieferter Brauch, der alle sieben Jahre im Dorf stattfindet - wählen die Gemeindeältesten einige Bauern aus, die in der Karwoche die Passion Christi darstellen sollen. Als Christus wird Manolios bestimmt, ein armer und schlichter Hirtenjunge, den Herr Patriarcheas, der reichste Mann im Dorf, von einem Kloster geholt und in seinen Dienst gestellt hat, in der Absicht, ihn mit seiner außerehelichen Tochter Lenio zu vermählen. Vier andere halbwegs bizarre Figuren sollen als die drei vertrautesten Apostel Christi erscheinen: Michelis, der junge Sohn des Herm Patriarcheas, als Johannes, Konstantis, der Wirt, der geme schwindelt und den seine Frau verprügelt, als Jakobus und Giannakos, ein Kleinhändler, dessen größter Besitz eine Eselin ist und dem es das größte Vergnügen bereitet, wenn er Briefe, die die anderen ihm anvertraut haben, öffnet, als Petrus und als Judas - Panagiotaros: ein barscher und bösartiger Sattelmacher, der hin und wieder Gips iBt. Die Begrindung dieser Auswahl liegt nicht besonders tief; so ernennt man Giannakos zu Petrus, weil er einfach "eine niedere Stirn, lockiges, graues Haar hat", und Panagiotaros zu Judas hauptsächlich wegen seinem roten Bart. Die Witwe Katarina - schön, verführerisch und für die jungen Männer des Dorfes sehr großzügig - denkt man sich gleich als Maria Magdalena, wenn auch niemand sie dazu tatsächlich bestimmt.

Jetzt haben die Ausgewählten ein Jahr Zeit bis zum nächsten Osterfest, um sich zu bessern und von ihren Sünden zu befreien, damit sie ihrer Rolle gerecht werden. Am ernstesten nimmt seine Rolle Manolios, der Hirte, der im Kloster und später im Dorf immer ein sehr frommer Junge war. So sehr gedenkt er, Christi Beispiel zu folgen, daß er nach und nach auf seine Verlobte Lenio und auf andere kleine irdische Freuden verzichtet. Bei solch schwerer Situation, während er auf dem Berg das Evangelium liest und einen Holzschnitt mit dem Bild Christi anfertigt, wird er plötzlich von einem argen Aussatz, der sein Gesicht völlig entstellt, befallen. Die Witwe Katarina hat sich währenddessen in Manolios verliebt und will ihn ständig verführen. Manolios' Aussatz und seine intensive Meditation auf dem Berg scheinen zu erfolgreichen Mitteln gegen diese Versuchung zu werden. Und in der Folge wird aus ihr eine reine Freundschaft, so etwas wie eine MutterSohn-Liebe.

Eines Tages treffen Hunderte von Flüchtlingen, von den Türken vertrieben, mittellos und ausgehunger im Dorf Likovrisi ein. Durch ihren Anfuhrer, den Priester Fotis, bitten sie die wohlhabenden Bauem von Likovrisi um Unterstützung, um die Vergabe einiger unbebauter Äcker am Dorfrand, wo die Flüchtlinge sich niederlassen und ein neues Leben anfangen könnten. Die christliche Nächstenliebe findet jedoch keinen Widerhall in Likovrisi; der geistige Führer des Dorfes, der Priester Grigoris, verjagt durch eine raffinierte List die Flüchtlinge, indem er angibt, unter ihnen einen Fall von Cholera erkannt zu haben; nun sind die Heimatlosen gezwungen, in Grotten und Hohlen oberhalb des Dorfes ihre kümmerliche Existenz weiterzuführen.

Der türkische Aga findet eines Tages seine schöne Sklavin erdolcht in ihrem Bett. Da er den Mörder nicht entdecken kann, nimmt er erzümt die Gemeindeältesten fest und verkündet seine Absicht, jeden Tag einen von ihnen und noch andere Griechen hinzurichten, falls sich der Täter nicht meldet. Fast fröhlich erblickt hier Manolios die große Chance, sich selbst für die Gemeinde zu opfern: er kommt ins Dorf herab und stellt sich als der angebliche Mörder der schönen Sklavin vor den Aga. Im letzten Moment vor der Hinrichtung wird allerdings der wirkliche Mörder, der Leibwächter des Agas, herausgefunden und Manolios mit den anderen befreit.

Im Schicksal der Flüchtlinge, vom frommen und asketischen Priester Fotis besonders inspiriert, sehen Manolios und seine drei "Jünger" eine große Herausforderung, als ob sie selbst auf die Probe gestellt wären.

Bei einem christlichen Fest findet Manolios Gelegenheit, zu den auf dem Berg versammelten Bauern zu sprechen. Er will sie zu Barmherzigkeit und Mitleid mit den Hei- 
matvertriebenen bewegen, und es gelingt ihm tatsăchlich, zum großen Ärger der Gemeindeăltesten, mehrere Spenden zu sammeln.

Von seinem Herrn gefeuert, findet Manolios bei den Flüchtingen ein neues Zuhause: Giannakos schenkt ihnen sein größtes Eigentum, die Eselin, und nach dem Tod seines Vaters, des Herm Patriarcheas, will Michelis sogar seine ganze Erbschaft unter ihnen verteilen; diese Absicht entrüstet den Priester Grigoris am meisten, denn er hat seine einzige, todkranke Tochter mit Michelis verlobt. Der Priester sammelt seine Gemeinde in der Kirche und legt Manolios "in Acht und Bann", "weil er sich gegen das Vaterland, gegen die Familie und das Eigentumrecht erhoben hat... Er nimmt Befehle von Moskau entgegen, er ist ein Bolschewik!"l. Michelis erklärt er für geistesgestört, er findet genug "Zeugen", um das zu beweisen und um die Verteilung seiner Besitztümer an die Flüchtlinge ungültig zu machen. Jetzt gibt es offenen Krieg zwischen den zwei Gemeinschaften. Die Armen versuchen, die ihnen geschenkten Äcker mit Gewalt in Besitz zu nehmen, die reichen Bauern verteidigen sich und bringen durch den Priester Grigoris den türkischen Aga auf ihre Seite. Panagiotaros-Judas und einigen anderen gelingt es, Manolios festzunehmen. Es findet nun eine öffentliche Hinrichtung in der Kirche statt, wo so gut wie eine ganze Gemeinde Manolios schlägt und niedersticht; einer versucht sogar, ihm mit den Zühnen ein Stück vom Hals auszureißen. Zu spät kommen der Priester Fotis und die anderen Freunde Manolios zum Tatort. Es ist Weichnachtszeit und Manolios wird "in ein weißes Laken gehüllt und wie ein neugeborenes Kind eingewickelt" (S.363). Nach der Bestattung machen sich Fotis und seine Gemeinde, die ihren Kampf aufgegeben haben, wieder auf den Weg.

Das ist die Handlung des Romans, übrigens eine leicht zu erzählende, da sie mehr oder weniger linear und in sich geschlossen ist. $\mathrm{Zu}$ ihr sind mehrere Motive und Ideen verknüpft, vor allem das Motiv des Machtmißbrauchs bzw. des materialistischen Zynismus der Machthaber gegenüber dem Idealismus und der Opferbereitschaft einfacher Christen; weiter das Motiv der Diskrepanz zwischen der offiziellen Kirche und dem ursprünglichen reinen Glauben, sowie auch noch andere. Eine ausführliche Analyse in dieser Hinsicht wäre aber fehl am Platz, da uns hier vor allem die Art interessiert, wie Kazantzakis den legendären, mythischen und biblischen Stoff handhabt.

Die Vorlage für seine Anspielungen, Parallelen, Identifikationen im Roman war das Neue Testament. Um Mißverständnisse zu vermeiden, muß ich hier noch einmal auf jene Definition des Mythos verweisen, die ihn als "eine zeitlose Gegenwart erscheinende Aussage über die Zusammenhänge der Welt, als eine nicht beweisbare Aussage über Göttliches, doch mit Anspruch auf Wahrheit"2 beschreibt. Der so oft betonte Gegensatz Mythologie-biblische Erzählung ${ }^{3}$ würde in dieser Hinsicht zu einem guten Teil nicht so unüber-

${ }_{1}^{1}$ Griechische Passion, S.276-277.

2 Siehe auch "Brockhaus-Lexikon" in 20 Bd. Mannheim 1988, Bd.12, S.276.

3Z.B. von R. Trousson in seiner komparatistischer Studie: Le Thème de Prométhée dans la Littérature Européenne. Genf 1964: "[Les legéndes] font parties d'un patrimoine indoeuropéen et, tout en étant pour chaque peuple parfaitement autochtones, elles se réunissent en des symboles identiques grâce au parallélisme de l'evolution psychologique des differentes nations. En raison de ces ressemblances s'élèveront plus tard les contestations judéo-chrétiennes". "Le mythe du Voleur de feu ne revêt pas au Moyen Age une importance particulière, mais s'inscrit simplement dans l'ensemble de la lutte de la pensée chrétienne contre la mythologie classique" (S.8, 59), usw. 
brückbar erscheinen: Kazantzakis macht gerade von jenen Szenen und Stellen aus der Bibel Gebrauch, die im Bewußtsein einfacher Leute einen mythischen Wert bekonmen haben'; so beispielsweise den Wunderszenen, der Sturm-Episode, dem Abendmahl, der Kreuzigung, der Auferstehung u.a.

Darüber hinaus befindet sich im Kern des Romans - ebenso wie im Jugendwerk "Der Baumeister" - das mythische Motiv des Opfers. Sowohl die Smaragda des "Baumeisters" als auch Manolios sind unschuldige Wesen, die für die Sünden der anderen zu büßen haben. Sie sind das Echo größerer Opfertaten, bei denen der einzelne eine ganze Gemeinschaft oder wie Christus die ganze Welt erlösen sollte. Der Befleckte, der Fehler und Sünden hat, bringt mit seiner Aufopferung höchstens die eigene Erlösung, nicht aber die der anderen: das müssen die Reinen vollbringen. Diesen immer wiederkehrenden Zusammenhang erzählen uns alle Mythen der Welt, in denen es sich um Opfer handelt, bis hin zur Geschichte Christi. Daher beruht die "Griechische Passion" nicht einfach auf einer biblischen Vorlage, so wie Kazantzakis nicht einfach ein christlicher Autor im traditionellen Sinn ist.

Die mythisch-biblischen Elemente im Gewebe der Manolios-Geschichte sind zahlreich, sie erscheinen jedoch hauptsächlich in zwei Arten:

1. Als direkte Zitate aus dem Neuen Testament. Dies sind hier die Erwähnung der Gebote Christi ("Wer nicht haßt seinen Vater, seine Frau und seine Kinder, ist nicht wert, mein Jünger zu sein" \{S.249\}; "Was nützt es dir, die Gebote zu halten, sagt Christus, das reicht nicht aus. Verkaufe dein Eigentum und verteile es an die Armen, wenn du ins Himmelreich kommen willst" (S.272\} usw.), dort Deutungsversuche der Heiligen Schrift, die Manolios und seine Freunde unternehmen, so etwa bei der Bergpredigt Christi (S.147-149). Außerdem gibt es Identifikationsmomente Manolios' mit Christus, bei denen ganze Szenen aus der Bibel in den Roman hineingezogen werden:

"Er stieg mit Christo ins Boot, er verbarg sich unter den Jüngern, sie fuhren auf den See Genezareth hinaus, ein heftiger Sturm kam auf... Christus war müde davon geworden, den ganzen Tag zum Volke zu sprechen. Er hatte sich auf die Netze im Bug des Schiffes gelegt und war eingeschlafen... Doch der Nordwind kam mit rasender Gewalt von den Gebirgen in Galatien herab, er wühlte das Meer auf und warf die Wogen gegen das kleine Fischerboot. Die Jünger wurden erschreckt.

'Wir vergehen' murmelten sie. 'Wir vergehen! Laßt uns den Meister wecken!'

Aber keiner wagte den heiligen Schlaf zu stören. Petrus näherte sich, beugte sich herab und sah beim Aufleuchten eines Blitzes Christi Gesicht ruhig und glücklich lächeln..." usw. (S.188-89).

\footnotetext{
${ }^{1}$ Allein die Tatsache, daß es den Geschichten aus dem Evangelium im frühen Mittclalter gelang, im Bewußtscin der Griechen, der Römer und anderer Völker die mythische Welt des Altertums zu verdrängen, spricht von ihrer Kraft und ihrer Fähigkeit, das mythische Bedürfnis des Menschen zu befriedigen. Einzelne Episoden aus der Passion Christi traten an die Stelle von mythischen Heldentaten, nicht zuletzt, weil diese schon längst ermattet waren (siehe auch Kap.1.2).
} 
2. Es fallen allerdings am meisten die Parallelen mit der biblischen Erzählung in der Gesamthandlung und in einzelnen Episoden auf. Diese sind teils direkte, offensichtliche Analogien (a), teils verzerrte Anspielungen (b), teils Gefüge, in denen sich vertraute biblische Konnotationen mit persönlichen Erlebnissen oder rein fiktionalen Einfällen verschmelzen (c).

Manolios' Geschichte und der Passion Christi sind folgende Stationen gemeinsam: Versuchung und Askese, Gefolgschaft der Jünger, Aufklärung des Volkes, Ächtung durch die offizielle Kirche, Kreuzigung und Auferstehung. Gehen wir auf einige diese Motive näher ein:

Versuchung und Askese. Manolios muß heiraten, verzichtet aber auf seine Verlobte und zieht sich mitten unter Versuchungen in die Meditation auf dem Berg zurück (b) (Christus in der Wüste/auf dem Berg: "Wiederum führte ihn der Teufel mit sich auf einen sehr hohen Berg, und zeigte ihm alle Reiche der Welt und ihre Herrlichkeit"; Matthäus 4,8). Die größte Versuchung stellt jedoch die Witwe Katarina dar, die in der Vorstellung der Bauern für die Rolle Maria Magdalenas höchst geeignet ist: die biblische Analogie vollzieht sich tatsächlich, was die Verwandlung betrifft, d.h. diese Frau, die anfangs eine Sünderin war, folgt später dem Christus-Manolios nach (Lukas 7.36-50), welcher ihr die Sünden vergibt (a). Katarina opfert sogar ihr Leben für Manolios ,und hier hört die Parallele mit der(n) biblischen Handlung(en) auf (c). Die Versuchung Christi durch Maria Magdalena ist dagegen ein in den heiligen Schriften nicht enthaltenes Moment, mit dem aber im Volksmund oft spekuliert worden ist. Maria Magdalena vertritt für den griechischen Autor hier die barmherzige Hure, dort den Zugang zur Fruchtbarkeit. Im Jahre 1915 hatte er in seinen Tagebüchern geschrieben: "...Überall im Erdreich regte es sich von Leben und drängte es sich hervor, ich spürte, wie der Baum, an dem ich mich lehnte, die Säfte in seinen Stamm hinaufzog, wie er sich mühte, Lehm und Stein, Wasser, Luft und das Sonnenlicht zu verwandeln, um Blüten daraus werden zu lassen. Ich sah die dunkle Materie, die große Hure mit den breiten Hüften, sich niederwerfen wie Maria Magdalena vor Christus, um unter Tränen sich umzuwandeln" (Einsame Freiheit, S.66). Maria Magdalena ist irrtümlicherweise mit Maria von Bethanien und mit der namenlosen "Sünderin" (Luk. 7.37-50) gleichgesetzt worden. Kazantzakis macht auch davon Gebrauch, noch einmal bekannte Konnotationen im Unbewußten hervorrufend.

Aus dieser Teilhandlung allein wird sichtbar, wie geschickt Kazantzakis die Figur der Sünderin mit der der Frau, die Christus versucht haben soll, und mit anderen fiktionalen Details vereinigt.

Ein anderes Beispiel für solche vielschichtige Verschmelzung bringt das Motiv des Aussatzes: Dieser bricht in dem Augenblick aus, als Manolios vielen Versuchungen ausgesetzt ist: den Trieben der Jugend, Lenio, dann Katarina, und verschwindet, als er sich auf den Weg zum Henker macht, um das Märtyrertum zu vollziehen. Die Krankheit "Aussatz" bewirkt mehrfach Assoziationen aus der Bibel: "Jesus heilt einen Aussätzigen" (Matth. 8.2-4); "Viel 
Aussätzige waren in Israel..." (Luk. 4.27), usw. In der "Griechischen Passion" sind die Rollen jedoch vertauscht: Manolios ist kein Subjekt, sondem ein Objekt des Wunders. In diesem Motiv haben weiter persönliche Erlebnisse ihren Anteil, denn Kazantzakis war selbst einmal in Wien von einer unerklärlichen Hautkrankheit befallen, die ebenso plötzlich abklang, wie sie aufgetreten war. "Ein Ekzem bedeckte ihm plötzlich das Gesicht und verbot ihm jede Annäherung. Er, der Schönheit so sehr verehrte, der jede Krankheit haßte, war nun von einer abscheulichen Maske entstellt", schreibt seine Frau Eleni (in "Einsame Freiheit", S.84).

Die Figur Manolios' hat im übrigen viel Gemeinsames mit der des Autors, oder zumindest mit dem, was er sich als Kind beim Lesen von Heiligengeschichten oder während seiner Wanderung auf dem Berg Athos sehr oft gewïnscht hat.

Aufklärung des Volkes (b) Manolios' Rede vor den Bauem erinnert mehr als Szenario als in ihrem Inhalt an die Bergpredigt. Sie bringt ihm die Ächtung (a) durch die offizielle Kirche. Hier ist die Parallele mit der Bibel eindeutig und allzu ähnlich. Manolios-Christus und seine Jünger stehen dem Priester Grigoris und den anderen ("Pharisäern, Hohepriestern") gegenüber, die ihn als Bolschewik ("Tempelabbrecher, Gotteslästerer") verdammen und verurteilen. Der Hauptkonflikt im Roman unterscheidet sich auch im Wortlaut nicht so sehr von dem der Geschichte Christi:

\footnotetext{
"Wie ihr ihn gemacht habt, ihr Priester, ihr Herren und reichen Bauem, ist Christus zu einem Wucherer, Heuchler und Lügner, einem jämmerlichen, feigen Lumpen mit Kisten voller türkischen und englischen Pfunde geworden! Euer Christus, er verhandelt und schließt Geschäfte mit all den Mächtigen der Erde ab, um seine Haut und seine Börse zu retten!" ("Gr. Pass.", S.273).

"Weh euch, Schriftgelehre und Pharisäer, ihr Heuchler, die ihr das Himmelreich zuschließt vor den Menschen!... Weh euch, Schriftgelehrte und Pharisäer, ihr Heuchler, die ihr der Witwen Häuser fresset und wendet lange Gebete vor!... Weh euch, Schriftgelehrte und Pharisäer, ihr Heuchler, die ihr die Becher und Schüssein auswendig reinlich haltet, inwendig aber ist's voll Raubes und Fraßes!" (Matth. 23.13,14,25).
}

Die Masse, die Bauern von Likovrisi, ist in ihrer Mehrheit, so wie in dem neutestamentlichen Konflikt, egoistisch, ängstlich und verbrecherisch. Dort waren es die Juden, die "allesamt" für die Hinrichtung Christi sprachen, hier ist "auf der Seite der Bischöfe, Priester, Gemeindeältesten der blinde Haufen" (S.309).

Kreuzigung (c). Der Mord an Manolios ist ebenfalls mit vertrauten biblischen Details geladen. Das Hauptmotiv zerlegt sich in kleinere, meist visuell bedingte Motive: "Er traf Manolios mit dem Stein zwischen den Augenbrauen, und das Blut strömte ihm über das Gesicht" (S.290). Vor dem Tod steht er ähnlich einem mittelalterlichen Heiligenbild - "wie eine Säule des Lichts (S.353) - ("ich bin das Licht des Lebens" usw.); "Als er vortrat, ruhig, ungeschützt, ohne Zaudern und das milde Licht der Lampen auf seine blonden 
Haare fiel, blickte das Volk ihn mit Erstaunen an und machte ihm unfreiwillig Platz" (S.360-361): wieder eine bekannte Situation aus der Bibel, dieses "unfreiwillig Platz machen".

Die Reihe von Analogien und Ähnlichkeiten kann weitergeführt werden; so z.B. sagt der türkische Aga, als er über das Schicksal Manolios' zu entscheiden hat: "ich wasche meine Hände" (S.355), und das macht ihn zu einem mohammedanischen Pontius Pilatus. Die Grundtypen wurden jedoch bereits unterstrichen.

Abschließend: Kazantzakis wendet den biblisch-mythischen Stoff frei an. Seine Parallelen sind oft spontan, originell, ja sogar geistreich und eigenwillig. Biblische Situationen sind in ihrem Großteil undogmatisch und durch eine dem Volksmund eigene Umformung bearbeitet. Auf der anderen Seite gibt es Szenen, wo die Analogien sehr bewußt konstruiert sind, wo die Anspielungen oder Zitate als mechanische Gleichnisse erscheinen. Sie bleiben an einer matten Oberfläche, denn die Botschaft der "Griechischen Passion" ist vielleicht gerade dort am tiefsten, wo der ursprüngliche biblische Stoff künstlerisch frei verarbeitet wurde.

\subsection{Der Baumeister}

Diese Tragödie ist gleichfails wie einige andere Jugendwerke des Autors so weit in Vergessenheit geraten, daß es in den westlichen Sprachen keine Ausgabe gibt. Ich mußte das Stück mit Hilfe zweier griechischer Kollegen - denen ich für ihre Unterstützung sehr dankbar bin - zuerst ins Deutsche übertragen, um überhaupt eine Analyse vorzunehmen. Der übersetzte Text befindet sich für den Interessierten als Anhang am Schluß dieser Arbeit. Selbstverständlich ist seine literarische Qualität bescheiden, auch weil vor allem auf eine möglichst treue Wiedergabe des Inhalts Wert gelegt wurde.

Das Stück besitzt merkwürdigerweise nur eine reiche "äußere" Geschichte'. Es bekam unter dem Titel "Aufopferung" den ersten Preis eines dramatischen Wettbewerbs im Jahre 1910 verliehen, bei dem vom Autor nur die Initialen N. K. bekannt waren. Dies erregte Neugier, nicht aber von der Seite der Kritik,

\footnotetext{
'Es sei denn, die Tragödie hat in Zusammenhang mit dem verwendeten Idiom "Dimotiki" die Aufmerksamkeit einiger Kritiker auf sich gezogen. P. Bien sieht in dem umfassenden Gebrauch des Idioms den genxinsamen Einfluß nationalistischer Strömungen der Zeit, der Schriften des Politikers und Publizisten Ion Dragoumis (1878-1920), Herders und Schlegels romantischer Theorien sowie 'Nietzsches "reine" deutsche Kultur"' (in: Kazantzakis and the Linguistic Revolution in Greek Literature, S.131-132; 168-174).
} 
die auch zu der Veröffentlichung des "O Protomastoras" einen Monat später völlig schwieg. Darauf antwortete der junge Kazantzakis, der zu diesem Zeitpunkt von Paris in die Heimat auf Urlaub zurïckgekomrnen war, mit einem entrüsteten Artikel in "Akropolis", wo er der griechischen Literaturkritik Gleichgültigkeit und Ignoranz vorwarf. Er erhielt in der Athenischen Presse eine noch schärfere Antwort, bei der man ihn u.a. zu Fairness aufforderte: "Zeigen Sie uns dann Ihre Kritiken und Ihre Werke..."1. Im September des gleichen Jahres wurde eine Inszenierung des "Baumeisters" angekündigt, die aber nie stattfand. Ein Jahr danach beschuldigte der Schriftsteller Vouteridis Kazantzakis der Nachahmung seines Stückes "Die Arta- Brücke" und sprach von einem Skandal. Kazantzakis erwiderte, es sei "uberhaupt kein Skandal, das gleiche Thema aufzugreifen. Das haben sogar die Größten gemacht. Es kann passieren, daß zwei Schriftsteller ihr Werk von einem dritten klauen und daß die Ergebnisse nicht im geringsten ähnlich sind"2. Nach einigen Jahren des Vergessens machte der Komponist Manolis Kalomiris 1916 aus dem "Baumeister" eine "musikalische Tragödie", die mit viel Erfolg aufgeführt wurde. Begeistert war diesmal auch die Presse, die von einem "einunaligen Werk" sprach, jedoch keine Analyse unternahm. Kazantzakis selbst erwähnt das Werk erst 14 Jahre später in einem Brief an seinen Freund Prevelakis: "Den 'Baumeister' spielt man noch immer, und dieser Esel von einem Musikant hat mir noch nicht geantwortet. Er gehört bestraft, er verdient es". Kazantzakis' Wut war begründet: der Komponist hatte ihm in der langen Zeit keine Autorentantiemen bezahlt. Zum letzten Mal hören wir vom Stück im März 1943: Kazantzakis erhält endlich Geld von einer Neuaufführung der Oper, und zwar als er und seine Frau Eleni in völliger Armut und Isolation in Ägina lebten ${ }^{3}$.

Nun, es ist nicht ganz zufällig, daß man dieses Stück, d.h. seinen Stoff und seine Botschaft, vergaß. Eine nähere Betrachtung läßt die Gründe dafür und für die bewußte Vemachlässigung des Autors erkennen. Und trotz allem birgt Kazantzakis' Tragödie nicht wenig Interessantes in sich, oder, genauer gesagt, dadurch, daß das Problem in der Auseinandersetzung des Schriftstellers mit dem Opfer-Mythos liegt, erregt es Interesse.

Der "Baumeister" ist eindeutig ein Jugendwerk, was besonders in den darin enthaltenen Einflüßen erkennbar ist:

Elemente des klassischen und des klassizistischen Dramas. Schon der Aufbau des Stückes folgt einem klassischen Muster. Es gibt zuerst eine Darlegung des Konflikts: Zum dritten Mal haben die Maurer unter der Führung des Baumeisters die Brücke gebaut, nachdem sie in der Nacht wieder eingestürzt war, und noch einmal beginnt sie beim Einsetzen des Sturmes zu schwanken; es ist abzusehen, daß in der Nacht wieder ein Zusammenbruch geschieht. Nach der Dar-

\footnotetext{
IVgl. C. Janiaud-Lust: Nikos Kazantzakis - sa vie - son œuvre. Paris 1970, S.119 f. 2Ebenda.

3Siehe "Einsame Freiheit", S.441.
} 
legung folgt die Zuspitzung des Konflikts: Man sucht den Schuldigen, den Verursacher der Katastrophe (das Einstürzen der Brücke ist immer von einer Naturkatastrophe begleitet: Sturm, Überschwemmung des Dorfes, Todesopfer). Die weise Mutter, eine in einer Grotte lebende alte Frau, die die Wahrheit immer erkennt und richtig prophezeit, sieht in der Geliebten des Baumeisters, welche ihn "bezaubert und seine Hände zum Zittern gebracht hat", die eigentlich Schuldige; es heißt daher, daß man diese Frau in den Fundamenten der Brücke einmauern muß. Nun ist diese Geliebte die schöne Tochter des Fürsten (Archonten), namens Smaragda. Der Schluß beschreibt in der Folge den Abschied Smaragdas vom Leben, ihre Aufopferung, die viel Bitterkeit und viel Schmerz für ihren Vater und für den Baumeister, eine Erlösung aber für die Gemeinde sowie die Festigkeit der Brücke bedeutet.

Auch die Chöre sind in der Art des griechisch-klassischen Dramas eingesetzt. Das sind der Chor der Schnitter und der Chor der Maurer, die am Anfang des Stückes als fertig gestaltet auftreten, sich im Laufe der Handlung jedoch neu bilden können (z.B. Chor der Frauen, Chor der Männer). Sie wirken meist aktiv in den Dialogen, erfüllen zugleich, wie im Drama des Altertums, die Kommentar-Aufgabe, indem sie die Ereignisse bewerten und die Meinung einer Mehrheit vertreten. Vom klassizistischen Drama her ist eine bestimmte Rhetorik spürbar: viele Metaphern, eine gehobene Sprache mit vielen Ausrufen, Flüchen, Verwünschungen, usw. Manchmal denkt man an Shakespeare: "Oh, Verzweiflung, wie kannst du schlafen?! Holt sie, ich möchte sie nie mehr sehen! Meine Augen verdunkeln sich. Wach auf, Verzweiflung, du bist jetzt meine einzige Tochter!"1 Oder: "O du, Freude, bleib ruhig in mir, du darfst mich nicht ersticken!" (S.160); manchmal erinnert der Konflikt überhaupt mit seinem heiklen Aufeinanderprallen von Liebe gegen Pflicht oder von Liebe gegen das Wohl der Gemeinschaft, dessen Lösung eine Entscheidung verlangt - an das französische Drama des Klassizismus, an Corneille und Racine.

Die Macht des Schicksals hat, ähnlich wie in der antiken Tragödie, Vorrang. Es gibt eine ganze Szene, wo das Thema Schicksal Objekt des Dialogs ist; hier behauptet der Baumeister, der den aufgeklärten, selbstsicheren Menschen des 19. Jahrhunderts vertritt: "Das Schicksal ist ein weicher Teig in den Händen der Männer". Frauen und Männer des Dorfes bestreiten diese Behauptung entsetzt: "das Schicksal hat eine Sichel und es kommt jeden Tag her, um die Seelen zu mähen" (S.162). Der Lauf der Ereignisse selbst widerspricht dem Glauben des Baumeisters an die Vernunft und an den freien Willen des Menschen.

Auch romantische Auffassungen haben im Drama ihren dramaturgischen Anteil. Schon das Aufgreifen eines Volksliedes in der direkten Form - d.h. wenig Distanz oder Verfremdung vom Geschehenen - bezeugt die romantische Neigung des jungen Autors. Die Frage, ob Kazantzakis das Volksmotiv in der Tradition der Romantik (wie üblich in den Literaturen des neu entdeckten na-

ISiehe: Der Baumeister, ins Deutsche übersetzt von A. Dimou, P. Korovessis und A. K'osi, im Anhang 2 dieser Arbeit, S.176. 
tionalen Bewußtseins auf dem Balkan) oder im Geist der aufkommenden Modeme bearbeitet hat, kann gleich mit einem Ja für die romantische Sichtweise beantwortet werden, unter anderem anhand der gefühlsbetonten Tragik des Stückes. Sie äußert sich in der Emotivität der Sprache; Exklamationen und Beschreibung der Gefühle in Klammern sollen sie noch verstärken: "O weh, o weh! Schweige, schweige!... $O$, sei uns gnädig... Erbarme uns!... Reiß dein Herz heraus und wirf es in den Fluß hinein"; \{beängstigt\}... zzitternd\} ... \{traurig\}... \{empört\}... \{trotzig und neidisch\}... \{bösartig\}... \{verzückt\} etc. Wie in der romantischen Dichtung üblich, spielt auch die Natur stets mit: es wird finster bei bösen Vorahnungen, der Fluß, der Berg, die Wolken sind teilnahmsvolle, ja handelnde Subjekte: "In dem Augenblick, als der Baumeister die Frau zeigen will, die er erwählt hat, fängt es zu donnem an; die Brücke bebt... Der Himmel wird dunkler, das sich aufziehende Gewitter wilder" (S.165); oder: "O Sonne, du schwebst nieder verblutet und hie und da fallst du henunter; o Sonne, was für schreckliche Taten wirst du heute vergolden!" (S.172). Eine besonders romantische Figur ist der Sänger, der Smaragda im geheimen liebt, seine Liebe aber nie verrät; er ist ständig von ihr verzückt, er bricht seine Flöte entzwei, als Smaragda der Hinrichtung entgegengeht, um nie mehr Musik zu machen.

Elemente der volkstümlichen Poesie. Kazantzakis nimmt in seine Tragödie nicht einfach das Volksidiom Dimotiki auf, er macht sich auch stilistische Elemente der überlieferten griechischen Poesie zu eigen; so etwa einige Metaphem, die in der Poesie dieses Raumes als Ausdruck des Schmerzes, Leids oder Todes eine besondere tragische Kraft haben'. Hier sind einige Beispiele: "Der Fluß ist mein Bräutigam, die Erde mein Brautbett", sagt Smaragda vor dem Tod; die Mutter "hält in einer Hand den Tod und in der anderen das Leben, wie zwei zitternde Vöglein" (S.177, 166); "die Krähen haben einen Toten gerochen, sie sind die Boten des Schicksals" (S.157) etc.

Andere Züge, die an die Tradition der Volkspoesie erinnern, könnten noch festgestellt werden, es ist aber nicht immer leicht, eine klare Trennlinie zwischen solchen Quellen und romantischen Auffassungen zu ziehen, um so mehr, als beide zum romantischen Charakter des Stückes beitragen.

lVgl. beispielsweise die albanische Ballade des toten Bruders: "Der Grabstein wird ihm zum frostigen Pferd/ der Ring des Steins zum silbernen Zaum", usw. (Näheres darüber in Kap. 4.5.). Ein besonders anschauliches Beispiel für solche "düsteren" Metaphern stellt auch die bekannte albanische Volkspoesie "Ich blieb bei der Kiabe-Brïcke" dar. Sie erzählt von einem "Nizam", einem Soldaten, der für die türkische Armee in der arabischen Wüste seinen langjährigen Dienst un muß: "Mbeç, more shokë, mbeç/ Përtej urès së Qabesë/ Falëm me shëndet nënesë/ Të dy qetè e zes t'i shesë/ ...Në pyet' nënia për mua/ I thoni që u martua/ Në pyet se ç'nuse mori/ Tre plumba prej kraharori/ Nè thëntë se ç'kalë hipi/ Në dy-tri dhoga meitil Në thëntë se c'krushg $i$ vanë/ Zhgabat e sorrat e hané" ("Ich ging, o Freunde, dahin Bei der Brücke zu Kiabe/ GrüBt meine Mutter/ Bald möchte sie für mich/ Die schwarzen Ochse verkaufen... Und fragt nach mir meine Mutter/Sagt ihr, daB er heiratete/Und fragt sie, welche Braut Drei Kugeln auf der Brust/ Und fragt sie, wie er ritt - Auf drei Sargbretter stieg/Und fragt sie, wer die Gästel - Krähen, die ihn auffressen") (aus: Kënga e popullit". Tiranë 1955, S.91-92, m.Ü.). 
Es ist andererseits ungerecht, im "Baumeister" nur Einflüsse - die meist für ein Jugendwerk selbstverständlich sind - zu unterstreichen. Peter Bien sieht in dem Stück ein Amalgam schlechthin: "To give artistic substance and depth to the new nationalistic movement, Kazantzakis tried to infuse his simple folktale with the religious urgency of the ancient drama, the shocking views promulgated by Dragoumis, and the intellectual excitement of the European theatre of ideas" 1 . Der Opfer-Mythos wird in dieser Aussage zu einem "simple folktale" reduziert. Anderenorts erscheint diese Volksgeschichte als ein mystischer $\mathrm{Pa}$ rameter ("...the entire mystique served him and certain others as a context for language", S.170). Wobei der Kritiker wenig sichere Kenntnisse des Stückes besitzt, denn er stellt eine Handlung dar, die der tatsächlichen genau entgegengesetzt ist: "The play is fiercely voluntaristic: the hero puts his will in the arena with fate itself and wins" (S.169). Wir wissen jedoch, daB der Baumeister eigentlich keinen persönlichen Willen durchsetzen will und daß er am Schluß verliert.

Trotz der verschiedenen Einflüsse, die seine philosophischen und literarischen Studien, sowie die geistige Atmosphäre der Zeit bedingten, ist der typische Kazantzakis bereits da. Die Sprache des Stückes ist farbig, einige Personen reden und handeln wie Halbtitanen, so wie in "Odissia" oder in dem viel späteren Roman "Freiheit oder Tod". Und da sind im Keim auch andere Merkmale, die ich vorher besprach, z.B. die Sinnlichkeit, jene Kazantzakis'sche Mischung aus stark konnotierten Wörtern, in denen Natur, Sehnsucht, sinnliche Wahrnehmung in einem auftreten: "Wie süß ist die Liebe...", sagt der Chor der Frauen, "sie erfüllt unseren Körper, so wie der erste Regen die dürstende Erde" (S.171); "O Sonne! Jetzt in der Stunde der Trennung spüre ich dich noch schwerer und süßer, gleich wie den Körper eines Liebhabers. Du füllst meine Handflächen, meine Haare, meine Augen, ich fühle, wie du meinen warmen Hals fest umarmst" (S.178).

Verhältnis zur Ballade der Arta-Brücke. Die Haupt- und die kleineren Motive sind in ihrer Gesamtheit mehr verändert als gleich geblieben. Von der Ballade hat Kazantzakis folgendes übernommen: das Motiv des Zusammenstürzens der Brücke in der Nacht, das Motiv des vorzüglichen Baumeisters, der für seine Bauten überall bekannt ist ("Alle Städte und alle Brücken kennen mich, sie nennen mich Vater" ( S.162 \}), das Motiv des Einmauems eines unschuldigen Wesens in die Fundamente der Brïcke, obwohl der Autor hier sehr stark vom herkömmlichen Sinn abweicht.

Von den kleinerer. Motiven sind zu erwähnen: die Brücke wird auf Befehl des Archonten gebaut; sie bebt, zittert und bleibt am Schluß eisenhart ${ }^{2}$

Es fehlen hingegen Motive, die für den Mythos auf fast allen Gebieten des Balkans unentbehrlich sind, vor allem das Motiv, das für die überlieferte

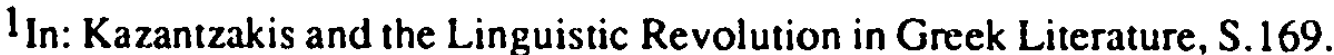

2 Vgl. dazu die Motiv-Liste bei Megas, "Die Ballade von der Arta-Brücke", S.21f.
} 
Handlung am wichtigsten ist: die Familie. Sei es die Mutter, oder seien es die Zwillinge, die man wegen einer mystischen Notwendigkeit einmauern wird, es ist gerade dieses Entreißen des Kindes von der Mutter, das das Schmerzvollste und das Tragischste in jeder Variante der balkanischen Ballade ausmacht. Im "Baumeister" handelt es sich um die Trennung zweier Liebender; das ist gewiß wiederum schmerzvoll, es bedeutet aber eine große Verschiebung der Schwerkraft der Legende, um so mehr als in den griechischen Ballade-Varianten der Verlust der Frau noch lange nicht das Schlimmste ist, was dem Baumeister passieren kann. Diesbezüglich gibt es in ihrer Mehrzahl die zynische Uberlegung: eine neue Frau kann man jederzeit finden. ("Ein Weib findest du wohl noch einmal, den Kopf, den findest du nimmer!" - siehe vorher, Kap.1.2.).

Zur Interpretation des Bauopfer-Mythos. Hier liegt auch die Schwerkraft des Stückes, die viele andere Züge in ihm bestimmt hat. Im ersten Teil der Arbeit wurde eine Deutung bzw. Ubersetzung des Mythos unternommen. Die wichtigste Frage war dabei: Warum wird geopfert?, andere Fragen: Wer wird geopfert? Wie steht die Gemeinschaft zur Aufopferung? u.ä.

In einem gewissen Sinne kann eine literarische wie auch jede wissenschaftliche Interpretation der Opfer-Mythen die Frage "Warum wird geopfert?" nicht umgehen, aus dem einfachen Grund, daß das Opfern den olympischen Göttern oder den irdischen Mächten in unserer Zeit keine Selbstverständlichkeit mehr ist. Dieses Verhältnis zu einer heute verschwundenen Weltauffassung bewirkt bei den Schriftstellern unseres Jahrhunderts die verschiedensten Interpretationen, da sie noch distanzierter zu den alten Mythen stehen als ihre Kollegen aus früheren Zeiten.

Die Frage "Warum wird geopfert?" beantwortet Kazantzakis wie folgt: Die Brücke, die dreimal errichtet wurde und in der Nacht immer einstürzte, war schlecht gebaut worden. Diese schlechte Arbeit hat der Baumeister geleistet das entdeckt die Mutter - und schuld an dieser seiner schlechten, sonst immer hervorragenden Arbeit ist die Liebe. "Seine Hände zittern vor fleischlichem Verlangen", sagt die Mutter, "sie sind nicht keusch genug für große Werke" (S.167). Der Baumeister versucht, sich dagegen zu wehren: "Es ist nicht das erste Mal, daß ich eine Brücke errichtet habe..."; "Ja", antwortet die Mutter, " aber es ist wohl das erste Mal, daß sich der Schoß einer Frau, der Hafen der Vernichtung, dir öffnete" (S.168); oder: "Seht ihn an, der Körper der Frau schillert vor seinen Augen wie ein Schloß aus Elfenbein; sobald es dunkel wird, stolpert sein Körper vor Verlangeil; jeden Tag, wenn er herkommt und die Arbeit beginnt, sind seine Augen dunkel und seine Gedanken schweifen weit ab" (S.167). Das Scheitem des Bauwerkes hat also eine klare Ursache, die man beseitigen muß, will man die Brücke solide bauen. "Die Frau, die ihn bezaubert und ihn in der Nacht um den Schlaf gebracht hat, muß sterben", rät die Mutter, "damit die Hände des Baumeisters wieder frei sind und nicht mehr zittern, wenn er eine Brücke entwirft" (S.169). Diese Forderung ist für alle überzeugend, auch für den Fürsten, der, wie es sich erst später herausstellt, 
seine eigene Tochter in den Tod schicken muß. Smaragda ist also die Frau, die den Baumeister an seiner Arbeit hindert, sie gehört in den Pfeilem der Brücke eingemauert. Nach der Opferung - die eigentlich mehr eine Bestrafung als ein Opferritual ist- baut man die Brücke schnell und sicher, ohne daß sie wieder schwankt. Am Schluß sagt der Chor zum Baumeister: "Als siegreicher Reiter gehst du durch die engen Gassen der Jugend, Baumeister, wo Frauen lauem und töten" (S.189).

Dies sind Darlegung und Deutung des Autors, zumindest die schwerwiegendsten; denn manchmal sind auch sie nicht konsequent - gerade dort, wo der Autor sich vom hergebrachten Sinn der Legende nicht völlig losgelöst hat. In der ersten Hälfte des Stückes ist noch die Rede vom "wütenden Fluß, den man nicht unterjochen darf". Ein alter Mann weist den Baumeister zurecht: "Gott hat unseren alten Fluß auf dieser Welt frei und ohne Brücke erschaffen. Wer bist du, woher kommst du, der du es wagst, ihn zu knechten und zu unterjochen?" (S.161). Das ist eine Auffassung, die der unterschwelligen Aussage der alten Ballade am nächsten steht; der Autor läßt sie jedoch im Laufe der Handlung fallen und verbindet sie mit einem "Gebot": nur derjenige darf den Fluß unterjochen, also ein halbgöttliches Werk unternehmen, der vor Gott rein und sündenfrei ist.

Kazantzakis ist also der vielschichtigen und verwickelten Botschaft des Mythos ausgewichen und hat sie in einen Liebe-Askese-Konflikt verwandelt. Die Notwendigkeit eines Opfers, so wie wir sie von den Mythen kennen, nimmt in der Tragödie die Form einer Sühne für die Unzucht an (um so verfehlter scheint daher die Schublade des Mystizismus). Der Autor interpretiert den Tod an der Brïcke als eine Tötung durch die Gemeinschaft und spricht das Motiv des Opfers sonst kaum an.

Es ist kein Wunder, da $B$ in einer frühen Phase seines Werdens, auf seinem langen und verworrenen Weg durch Religion - durch Christentum, Askese, Atheismus, Buddhismus und wieder Christentum - der griechische Autor bei solch einem alten heidnischen Motiv den Akzent auf ein christliches Dilemma setzt, anders gesagt, den herkömmlichen Sinn des Opfer-Mythos in eine christlich-moralische Frage umwandelt. In "O Protomastoras" ist die Opferung eine oberste Instanz, die die freie Liebe verbietet und gleichfalls dem Wunsch einer Gemeinschaft entspricht. 


\section{IVO ANDRIĆ Zweifaches Verhältnis zum Mythos}

Man muß die Legenden belauschen und aus ihnen, so weit das möglich ist, den Sinn unseres Schicksals enträtseln.

Die Sekundärliteratur zum Leben und Werk von Ivo Andric ist äußerst umfangreich.' Angesichts der reichen und vielfältigen Publikationen ${ }^{2}$ möchte ich nur darauf hinweisen und das folgende Porträt auf einige Stichwörter begrenzen, bevor zum Thema Mythologie im Roman "Die Brücke über die Drina" übergegangen wird.

\subsection{Kurze Biographie}

Ivo Andrić wurde 1892 in Travnik, dem ehemaligen Zentrum der osmanischen Verwaltung in Bosnien, geboren. Sein Vater, ein kleiner Handwerker, starb,

ISo führt eine von der Serbischen Akademie der Wissenschaften für die Zeit bis einschließlich 1970 herausgegebene Bibliographie insgesamt 2538 Titel an (Ivo Andric. Bibliografija dela, prevoda i literature, Hrsg. von R. Lukić. Beograd 1974). Die wichtigsten darin erwähnten sowie später erschienenen Monographien wären: P. Džadžic: Ivo Andrić. Beograd 1957; P. Zoric: Ivo Andric. Beograd 1962; M. Bandić: Ivo Andric - Zagonetka vedrine. Novi Sad 1963; J. Wierzbicki: Ivo Andric. Warszawa 1965; B. Milanovic: Ivo Andric. Zagreb 1966; S. Korac: Andricevi romani ili svijet bez boga. Zagreb 1966; R. Vuckovic: Velika sinteza o Ivi Andricu. Sarajevo 1974; I. Tartalja: Pripovedaceva estetika. Beograd 1979; M. Karaulac: Rani Andrić. Beograd 1980; P. Palavestra: Skriveni pesnik. Prilog kritickoj biografiji Ive Andrica". Beograd 1981 .

Die Beiträge zweier Symposien liegen in Sammelbänden auf: Zbornik radova o Ivi Andricu, Hrsg. von Antonie Isakovic. Beograd 1979 (= Srpska akademija nauka i umetnosti. Posebna izdanja 30) und: Delo Ive Andrića u kontekstu evropske knjizevnosti i kulture, Hrsg. von Dragan Nedeljković. Beograd 1981.

2Manchmal analysieren die Studien das eine und gleiche Thema, z.B. G. Bergman: Turkisms in Ivo Andric" "Na Drini cuprija" examined from the points of view of literary style. Uppsala 1969, und J. Kragalott: Turkish loanwords as an element of Ivo Andric's literary style in "Na Drini Cuprija" in: Balkanistica. Cambridge, Mass.,2,1975. 
als das Kind zwei Jahre alt war. Die junge Mutter war gezwungen, ihren Sohn der Schwester ihres Mannes, Ana, in Wischegrad zu überlassen. So wuchs der zarte, zu Krankheiten neigende Junge bei ihr und bei dem Onkel Ivan, einem Beamter der lokalen österreichischen Polizei, auf'. In Wischegrad wird Andrić die Volksschule besuchen; 1902 geht er nach Sarajevo, um dort in der Mittelschule weiter zu lemen. Dieses Dreieck seiner Jugend: Travnik-WischegradSarajevo wird auch das Dreieck und die Welt seines Werkes sein. Von diesen drei Städten tritt vielleicht Wischegrad am deutlichsten hervor, nicht nur weil sich in diesem Ort Andrić' bedeutendstes Werk "Die Brücke über die Drina", abspielt, sondern auch weil ihn hier eine Mischung von starken, oft entgegengesetzten Gefühlen bewegten, die seinem Charakter die einmalige "bosnische" Prägung verliehen. Andrić schreibt in einer Skizze aus dem Jahre 1940 folgendes über die Stadt seiner Kindheit:

"Am Anfang aller Wege und Straßen, die ich kenne, ragt besonders scharf und unauslöschlich der Weg heraus, wo ich meine ersten, sicheren Schritte machte.

Das war in Wischegrad, auf seinen harten, holprigen Straßen, wo alles trocken und kümmerlich ist, ohne Schönheit, ohne Freude, ohne jegliche Hoffnung auf Freude, ohne das Recht zu hoffen, wo ein bitterer Bissen, den du nie gegessen hast, dich bei jedem Schritt erwürgt, wo Hitze, Wind und Schnee den Boden und die Saat in ihm zerfressen und wo alles, das trotz alledem wăchst, verdom und krumm ist, als ob die Urkrăfte versuchten, es in die Finsternis und in die Gestaltlosigkeit, denen es entkommen war, zurückzuholen...

Auf diesen vom Wind verwehten und vom Regen verwaschenen, von der Sonne infizierten und zugleich geheilten Wegen triffst du erschöpftes Vieh und schweigsame Menschen mit rauhen Gesichtem; auf diesen Wegen habe ich meine Träume von den Reichtümern und den Schönheiten der Welt geträumt. Hier war ich, der ich ungebildet, schwach und mit leeren Händen war, glücklich, glücklich über alles, das nicht hier existierte, das nicht hatte und nie würde existieren können."2

Der Aufenthalt in Sarajevo und später in Zagreb war nicht mehr so "glücklich"; in Wischegrad hatte das Kind neben der Wärme seiner Familie und seiner Spielkameraden auch die einiger Volkschullehrer gespürt, während seiner weiteren Ausbildung dagegen fand der junge Mann keine besondere Freude mehr. Er schreibt darüber: "Alles, was später kam, in der Mittelschule und auf der Universität, war rauh, grob, automatisch, unpersönlich, ohne Glauben, Menschlichkeit, Wärme oder Liebe"3. Das Lehrprogramm war so gestaltet, daß es aus der Jugend tüchtige Verfechter der k.u.k. Monarchie machen sollte. Außerdem war Andrić immer häufiger krank, und es scheint, daß er seine Universität aufgrund von Krankheiten mehrmals wechseln mußte: zuerst Zagreb, dann Wien und später Krakau. Er hatte Tuberkulose, ein Erbe,

${ }^{1}$ Für den biographischen Teil beziehe ich mich vorwiegend auf $C$. Hawkesworth, Ivo Andric: Bridge between East and West. London 1984, M. Njegosi Petrovic, Ivo Andrić. L'homme et l'oeuvre. Ottawa 1969, und die Aufzeichnungen von Andrić in: Staze, lica, predeli, aus: Sabrana dela Ive Andrica, 10 (Bd.10 des Gesamtwerkes, Beograd. 3.A. 1967).

2Staze, lica, predeli, S.9, 10 (m.Ü.)

$3 \mathrm{Vgl}$. C. Hawkesworth, Ivo Andric: Bridge between East and West, S.13, 14. 
das seinem Vater und drei Onkeln von ihm im jungen Alter den Tod gebracht hatte. Aus Krakau schreibt er 1914 zu einem Freund: "...Ich habe mir das Rauchen abgewöhnt... ich glaube, im Mai werde ich entweder wieder gesund oder sterben..."1

In den Städten seines Studiums war Andrić mit anderen jungen Patrioten, Schriftstellern und Künstlern (so etwa bei dem revolutionären Verein "Junges Bosnien") in Kontakt gekommen. Er hatte im Juni 1914 auch seine ersten Gedichte in der Anthologie "Neue kroatische Lyrik" veröffentlicht. Als er im selben Monat vom Attentat auf den österreichischen Thronfolger Franz Ferdinand in Sarajevo erfuhr, reiste er von Krakau in die Heimat zurück und wollte sich in Split bei seinem Freund und Aktivisten Cerina erholen. Cerina war aber aus Angst vor der österreichischen Polizei nach Italien geflohen. In diesem Monat nahm die Polizei mehrere Freunde von Andric fest, und es war kein Wunder mehr, daß auch Andrić selbst am 29. Juli 1914 verhaftet wurde.

Mit Hunderten anderen Verhafteten hielt man ihn in mehreren Gefängnissen, in Split, Sibenik, Rijeka, Maribor, immer nördlicher, inhaftiert, als wollte die Monarchie sie vom Zentrum aus immer näher bewachen. Andrićs Gesundheit verschlechterte sich; er versuchte, seinen schweren Zustand durch die Kameradschaft der Zelle, durch Lesen und Lemen fremder Sprachen zu überwinden. In einem Brief vom Januar 1915 schreibt er: "...Wir haben hier eine wirkliche Universität gegründet"2. Im März 1915 wurde Ivo Andrić mangels Beweisen freigesprochen und nach Ovčarevo, unweit von Travnik, in die Verbannung geschickt. Dort verbrachte er zweiundeinhalb Jahre in einem Franziskanerkloster, in Gesprächen mit den Fratres, im Nachdenken, mit Lektüre aus alten Chroniken, im Herzen einer wilden und düsteren Berglandschaft. Es ist dies eine Zeit, die sein späteres Werk stark prägen wird; man braucht nur an die Fratres seiner Erzählungen, oder an die bedrückende Atmosphäre der Travnička hronika denken.

Nach der Amnestie von 1917 und mit dem Niedergang der österreichischungarischen Monarchie befand sich Andrić in Zagreb, wo er zusammen mit anderen begeisterten jungen Männern für das neue vereinigte Jugoslawien kămpfte. Er und zwei Freunde von ihm gründeten Anfang 1918 die Zeitschrift "Der literarische Süden"; hier erschienen von Andrić verschiedene Artikel, Besprechungen, Gedichte, Übersetzungen (Strindberg und Whitman), sowie der erste Teil seines ersten bedeutenden Prosastücks: "Djerželez in der Herberge".

Die nationalistische Begeisterung hielt nicht lange: Andrić, Vojnović und andere Schriftsteller "realised that the organisation of the new state had simply replaced the old one, more or less unchanged. They were deeply disappointed.."3 Zwar veröffentlicht Andrić weiterhin patriotische Artike' und wird als Sekretär des nationalen Rates in Zagreb gewählt, zieht sich aber im-

\footnotetext{
1Ebenda. S.15.

2Ebenda, S.16.

3 Ebenda, S. 17.
} 
mer mehr in das schriftstellerische Leben zurück. "Ich sehne mich nach einem konkreten Werk, das nichts mit journalistisch-literarischen Cliquen zu tun hat", schreibt er im Juli 19191. Er hatte seine Berufung deutlich erkannt; unter seinen Kollegen wird er auch die verdiente Anerkennung finden ${ }^{2}$.

$\mathrm{Zu}$ einem Zeitpunkt, als sich wieder seine Gesundheit und ebenfalls seine finanzielle Lage - da er jetzt für drei alte Leute zuhause sorgen mußte - verschlechterten, wurde Andrić von seinem einstigen Schullehrer, zu dieser Zeit Minister für Glaubensfragen in Beograd, Tugomir Alaupović - für ihn eine Art Mäzen -, unter die Arme gegriffen. In September 1919 wurde Andric zum Sekretär im Ministerium ernannt, und im Februar 1920 begann er die diplomatische Karriere. Die ersten Städte seines Dienstes waren Rom, Bukarest, Triest und Graz. In Graz konnte er sein unterbrochenes Studium fortsetzen, und hier schrieb er auch eine Dissertation mit dem Titel "Die Entwicklung des geistlichen Lebens in Bosnien unter der Einwirkung der türkischen Herrschaft" (eine Studie, die Andric selbst nie veröffentlichen wollte). Andrić promovierte im Juni 1924.

Bis zum Ausbruch des Zweiten Weltkrieges vertrat Andrić sein Land und seine Regierung in Rom, Madrid, Marseille, Budapest, Genf, Brüssel und zuletzt Berlin. Die freie Zeit nützte er zum Schreiben und zum weiteren Kennenlemen der europäischen Kultur und Kunst ${ }^{3}$. Während dieser Zeit veröffentlichte er drei Sammlungen von Erzählungen: 1924, 1931 und 1936. Sie spielen sich fast ausschließlich in Bosnien ab und können als eine Vorbereitung seiner großen Romane betrachtet werden, zugleich aber weisen sie eine große darstellende und künstlerische Kraft auf, die manche Erzählungen ("Die Brücke über die Žepa", "Der Weg des Alija Djerželez", "Anikas Zeiten", "Olujaci", "Die Rzavaer Berge" usw.) zu vollendeten, reifen Werken macht. Dadurch, daß Andric seine Heimat Bosnien zum Schauplatz der Fiktion macht, ist er noch einmal das Beispiel des Schriftstellers, der seine Weltkenntnisse und die "europäische" Ausbildung völlig zu diesem Zweck in Dichtung umsetzt. Es ist ein Prozeß, der sich bei vielen bedeutenden Schriftstellem des südosteuropäischen Raumes vollzogen hat ${ }^{4}$; bei Andrić ist die Fokussierung

\footnotetext{
lEbenda, S.19.

${ }^{2}$ Vojnovic etwa schreibt um diese Zeit über ihn "Er ist einer der feinsten Geister, denen ich je begegnet bin, und sein Werk wird eines Tages zum Gemeingut aller Völker werden, wenn es übersetzt wird". Ein anderer Schriftsteller, Milos Crnjanski, notient am Ende seiner Besprechung von Andrićs "Ex Ponto" - einem essayistisch-poetischen Werk - "Andrić est arrivé" (ebenda, 18,19).

3"Pendant tout ce temps. il poursuit à travers l'Europe sa quête de l'homme et de l'histoire... Il se familiarise avec les auteurs des pays qu'il visite et apprend à les connaître. Cela se reflète dans les nombreux essais littéraires de cette epoque qu'il consacre aux écrivains russes, italiens, espagnols, allemands, autrichiens, hongrois, roumains et suisses" (Njegoši Petrovic, Ivo Andric. L'homme et l'oeuvre, S.20).

${ }^{4}$ In der albanischen Literatur der Vorkriegszeit läßt sich ein ähnlicher Weg u.a. bei den Autoren Poradeci und Kuteli feststellen.
} 
noch "hartnäckiger", im Vergleich etwa zu Kazantzakis (mehr dazu im letzten Kapitel).

Wenige Tage vor der totalen Niederwerfung Jugoslawiens durch HitlerDeutschland zieht sich Andric völlig ins private Leben zurück; er akzeptiert keine Pension, um jeden Kontakt zur quislingischen Regierung in Belgrad zu vermeiden. Bis zur Befreiung Jugoslawiens im November 1944 wird er in einer Art freiwilligen Gefangenschaft leben und an seinen großen Romanen: "Die Brücke über die Drina", "Wesire und Konsuln" und "Das Fräulein" schreiben. Nicht einmal während der heftigsten Bombardierungen Belgrads verließ er seine Wohnung, eine Haltung, die an den über alle Ereignisse stehenden und zugleich resignierten Chronistenton seiner Romane erinnert.

$\mathrm{Daß}$ seine Isolation keine Flucht vor dem tragischen Geschehen des Krieges, sondern vielmehr eine mittelbare Teilnahme und die ständige Besorgnis um das Schicksal der Menschheit war, beweisen viele Stellen seiner Romane; wobei ein Plädoyer für die verfolgten Juden in "Wesire und Konsuln" besonders auffällt. Der jüdische Kleinhändler Atijas bittet den scheidenden französischen Konsul Daville, daß er scine Regierung auf das iraurige Los seines Volkes aufmerksam mache:

\begin{abstract}
"Seien sie für uns Kronzeuge im Westen, der wissen soll, was man aus uns gemacht hat... Der brudermörderische Sturm, den wir heute noch nicht begreifen können und der sich bis heute selbst nicht begriffen hat, zerstreute uns in alle Welt und machte uns zu Bettlern, denen alles Gold nichts nützt... Unsere Sehnsucht nach einer besseren Welt, nach einer Welt der Ordnung und der Menschlichkeit, wird nie verlöschen, einer Welt, in der man aufrecht geht, ruhig vor sich hin schaut und offen redet. Davon werden wir uns ebensowenig befreien können wie von dem Gefühl, daß wir trotz allem dieser Welt angehören, obwohl wir, verbannt und unglücklich, in der entgegengesetzten Welt leben.

Wir wollen, daß man drüben von uns weiß. $\mathrm{DaB}$ unser Name nicht verschwindet in der helleren und höheren Welt, die sich ständig verdunkelt und einstürtt, sich bewegt und wandelt, aber nie untergeht und stets irgendwo und für jemand da ist"l.
\end{abstract}

Diesen Text, der eine Situation des Jahres 1814 schildem soll, schrieb Andrić im Frïjahr 1942.

Die drei Romane wurden 1945 veröffentlicht. Besonders "Die Brücke über die Drina" fand eine große Leserschaft und wurde mehrmals neu gedruckt. Wieder einmal war Andric zu dieser Zeit gesellschaftlich engagiert, obwohl er immer das Schreiben in der Zurückgezogenheit vorzog. Im November 1946 wurde er Vorsitzender des jugoslawischen Schriftstellerverbandes, 1947 wählte man ihn als Delegierten der Versammlung Bosniens und Herzegovinas, usw. Von den wichtigsten Publikationen bis zu seinem Tod im Jahre 1975 seien hier erwähnt "Neue Erzählungen"(1948) und "Der verdammte Hof"(1954), eine lange Erzählung, die Andrić - mit seiner gewöhnlichen strengen Anforderung an sich selbst - schon im Jahre 1928 angefangen hatte, und die einen anderen Höhepunkt in seinem Werk darstellt. Er veröffentlichte ebenfalls zahlreiche Artikel, Essays und Erinnerungen; ein anderer Roman, "Omer Pascha

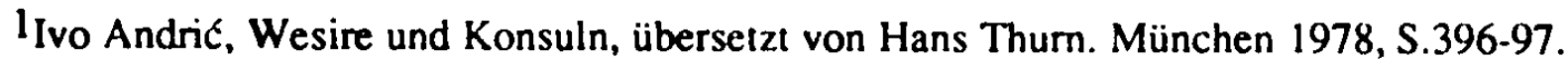


Latas", der Andrić in einigen "schwachen Punkten" zeigt', blieb unvollendet und wurde posthum veröffentlicht.

Allmählich erreichte sein Werk durch mehrere Übersetzungen auch im Ausland Anerkennung; auf Einladungen reiste nun Andrić oft, etwa nach China (1956) oder England (1959). Schlagartig wurde er aber nach der Verleihung des Nobelpreises durch die schwedische Akademie im Oktober 1961 im Ausland berühmt. Sein Werk ist inzwischen in mehr als dreißig Sprachen übersetzt worden und in über vierzig Iändern erschienen. Gleich nach der Nobelpreisverleihung sagte er in einem Interview: "Was werde ich jetzt tun? Ehrlich gesagt, werde ich geduldig warten, bis diese Aufregung rund um mich und diese festliche Stimmung, die ich nicht gewohnt bin, vorbei sind; dann kann ich wieder zu meinem üblichen monotonen Arbeitstag zurückkehren. Und ein Arbeitstag ist für mich immer ein Fest"2.

Er hielt an diesem Arbeitstag bis Ende 1974 fest, bis er nach einer langen Krankheit an 24. März 1975 starb. Mehrere Tausende Bürger nahmen an seinem Begräbnis in Belgrad teil.

\subsection{Bosnien}

Bei R. Minde findet sich eine Definition des Bosnien von Andric, die interessant und zugleich problematisch ist: "Das zentrale Thema der Erzählungen ist die menschliche Einsamkeit, die existentielle zwischenmenschliche Beziehungslosigkeit. Das Böse - 'zlo' - und Sünde oder Schuld - 'greh, krvica' -, deren Untersuchung Džadžić einen wesentlichen Teil seiner Studie widmet, erscheinen immer nur als untergeordnete Aspekte dieses Weltverständnisses. Wenn Bosnien als das Land des Hasses, das Land der unversöhnlichen Gegensätze bezeichnet wird, dann ist das vor allem in diesem Sinne zu verstehen"3. Zuvor hat die Autorin behauptet, dieses Bosnien sei "eine Welt eigener Art und ein eigengesetzliches Ganzes... Was zählt, was allein existent ist, ist diese Welt Bosnien. Sie ist für Andrić das, was für Faulkner Yoknapatawpha ist"4.

Damit ist die Realität Bosniens, so wie sie sich im Laufe der Zeitspanne, die Andric für seine Erzählungen und Romane benützt, darbietet, auf die innerste Realität des Schriftstellers reduziert, als eine Funktion der Schwerkraft seiner

\footnotetext{
${ }^{1}$ Die träge, gemächliche Ar der Beschreibung verlangsamı die Handlung bzw. läßt sie erstarren, die Figuren werden nach einem gleichen Schema gestaltet: Vorstellung - Hintergrund - Privatgeschichte - wieder Gegenwart, etc.

2 Siehe N. Petrovic, Ivo Andric. L'homme et l'ocuvre, S.112.

${ }^{3}$ Regina Minde, "Ivo Andrić. Studien über seine Erzählkunst". München 1962, S.190.

4 Ebenda, S.56.
} 
Prosa - nämlich der menschlichen Einsamkeit. Wozu dann die ganze Sorgfalt des Autors, seine skrupulöse historische Genauigkeit, die geographische, landschaftliche und ethnologische Ubereinstimmung mit dem tatsächlichen Bosnien? Der Schriftsteller zögert nie, bekannte und wenig bekannte Geschehnisse, Orte, Helden mit ihren wahren Namen zu nennen. Schon die Art, wie er eine Landschaft schildert, ruft Bilder hervor, die besonders wirklichkeitstreu anmuten. Dies ist z.B. das Bild Travniks im Roman "Wesire und Konsuln":

\begin{abstract}
"Ihre Stadt, das ist in Wirklichkeit nichts anderes als eine enge, tiefe Schlucht, im Laufe der Zeit von Geschlecht zu Geschlecht aufgebaut und umgestaltet, ein befestigter Durchgang, in dem die Menschen unversehens haltmachen, um für immer darin zu wohnen, den sie allmăhlich ihrem Wesen anglichen. Zu beiden Seiten der Stadt stürzen die Berghänge schroff $a b$ und treffen sich im Tale in einem spitzen Winkel, so daß für den schmalen Fluß und die nebenherlaufende Straße kaum noch Platz übrig ist. So erinnert die ganze Landschaft an ein halb aufgeschlagenes Bilderbuch: die links und rechts liegenden Gärten, Gassen, Häuser, Äcker, Friedhöfe und Moscheen sind die Bilder auf den beiden Seiten des Buches" (S.9).
\end{abstract}

Die Werke Andrićs haben unter anderem einen augesprochenen kognitıven Wert, sie berichten über Bosnien mehr als dokumentarische Darstellungen oft machen könnten. Mindes SchluBfolgerung kann auch in anderer Hinsicht bezweifelt werden: Wenn dieses Bosnien völlig auf einer eigenen existentiellen Realität des Schriftstellers beruht - und die eigene Existenz ist einmalig - wieso weist es so viele Ähnlichkeiten mit anderen Gegenden des Balkans auf, die eine ähnliche Geschichte erfahren haben? Man vergleiche etwa die Atmosphäre in "Wesire und Konsuln" mit der im "Zerrissenen April" von Kadare, und da bedrückt die düstere Realität und die düstere Geschichte zweier ähnlicher Gegenden (bosnisches und albanisches Gebirge) in ähnlichem Maß. Auch folgende Steile ist aufschlußreich:

"Des Fossés wies nach, daß die Gegend, obgleich tot und weltabgeschieden, keine Einode, sondern im Gegenteil abwechselungsreich und in jeder Hinsicht interessant sei und auf ihre Weise dem aufmerksamen Beobachter vieles zu sagen habe. Freilich sei die Bevolkerung in Konfessionen gespalten und ganz dem Aberglauben hingegeben, sie sei der übelsten Verwaltung, die es auf der Erde gibt, unterworfen und deshalb in vielem rückständig und unglücklich, gleichzeitig aber sei sie reich an geistigen Gütem, weise interessante Charaktereigenschaften auf und verfüge über eine Fülle wunderlicher Sitten und Gebräuche; auf jeden Fall lohne es sich, den Ursachen der unglücklichen Lage und Rückständigkeit nachzugehen"1.

Dieses Tableau würde genau zur Wirklichkeit mancher Gegenden in Albanien (womöglich auch in Mazedonien und anderswo) passen, die historisch in verschiedenen Konfessionen und Bräuchen zerspalten und zugleich weltabgeschieden waren. Folglich kann man sagen, daß dieses Bosnien besser zu verstehen und zu interpretieren ist, wenn sowohl die Welt Andrićs als auch die Realität Bosniens erkannt wird. Die existentialistische Erklärung der Autorin ist daher

${ }^{1}$ Wesire und Konsuln, S.111. 
unzureichend, sie spiegelt vermutlich eher eine intellektuelle Stimmung am Anfang der 60er Jahre wider.

V.T. Johnson hat eine genauere Bezeichnung für den Hauptdarsteller in der Prosa Andrićs, Bosnien: "In Andrić's early fiction Bosnia not only functions as a setting for the majority of his stories but also emerges as a major theme, even the main protagonist. In other words, it operates on both a formal and a thematic level. While the historical-ethnographic entity provides the formal setting, a highly subjective, mythical Bosnia becomes a major theme and such a powerful presence that it attains the status of an autonomous being on a par with the characters themselves"!.

Marković interpretiert diesen Punkt aus der entgegengesetzten Position zu Minde: "Der menschliche Körper ist kein Gefängnis des Geistes, sondern der Mensch hat sich und seinen Nächsten überall auf Erden Gefängnisse errichtet. Ist nicht ganz Bosnien ein einziges großes Gefängnis? Und das war anscheinend wohl noch nicht genug, sondem es unterteilte sich in eine Reihe noch kleinerer Gefängnisse, in die der Städte und Städtchen und so fort bis zu den hohen Mauern, die die Häuser und Höfe umgeben, hinter denen jede Familie ihre Geheimnisse, ihre Schande und ihre Krankheiten verbirgt"2. Die Geschichte Südosteuropas wird in dieser Behauptung nur bestätigt, und die Literatur in der ersten Hälfte unseres Jahrhunderts hat dazu entsprechende Erinnerungen hervorgebracht. Andrić mit seinem Bosnien ist der repräsentativste Autor in der serbokroatischen Literatur, in der albanischen etwa war es zu dieser Zeit Migjeni, für den der oben zitierte Satz durchaus sein Haupthema wiedergibt. Qyteti $i$ Veriut, die religiös gemischte Stadt im Norden, hatte ebensoviel Schande und Krankheiten zu verheimlichen, und sie war nicht weniger mit kleinen Gefängnissen übersät als Bosnien. Aber merkwürdigerweise haben die Menschen in diesen Gegenden nicht so sehr unter Beziehungslosigkeit gelitten der Begriff ist eher von der abendländischen Mentalität bzw. vom Geist der Modeme entlehnt; im Gegenteil, Bräuche, Rituale, Traditionen haben das gemeinsame Leben, die patriarchalische Familienverbundenheit, die große Verwandtschaft, die Gastfreundschaft usw. gefördert. Was isolien und entfremdet in der Welt Andrić' ist, daß hat in erster Linie mit der Gemeinschaft als Ganze zu tun. Mindes Behauptung könnte daher umgeschrieben werden: "Eines der zentralen Themen bei Andrić ist die Vereinsamung einer ganzen Landschaft, Bosnien, die Beziehungslosigkeit zwischen sämtlichen Welten in ihr".

Am besten erklärt das Phänomen Bosnien Andrić selbst, z.B. in seinem "Brief aus dem Jahre 1920":

"Nun ja, Bosnien ist das Land des Hasses. Das ist Bosnien. Und auf Grund des seltsa-
men Kontrastes, der in Wirklichkeit gar nicht so seltsam ist, kann man ebenso sagen, daß
es wenig Länder gibt mit so viel festem Glauben, so erhabener Charakterfestigkeit, mit so
viel Zartheit und Liebesglut, mit so viel Gefühlstiefe, Anhänglichkeit und schwankungs-
loser Ergebenheit, mit so viel Durst nach Gerechtigkeit. Aber unter all dem verbergen

In: Fiction and Drama in Eastern Europe. Columbia, Ohio 1980, S.242.

2Tausende und eine Nacht des Ivo Andric. München 1962, S.49. 
sich in undurchsichtigen Tiefen Gewitterwolken des Hasses, ganze Orkane gedrängten, verdichteten Hasses, die wachsen und auf ihre Stunde warten... Wer in Sarajevo nachts wach im Bett liegt, kann die seltsamsten Töne des nächtlichen Sarajevo hören. Schwer und selbstsicher schlägt die Uhr von der katholischen Kathedrale: zwei nach Mitternacht. Es vergeht mehr als eine Minute (genau fünfundsiebzig Sekunden) und erst dann ertönt mit etwas schwächerem aber durchdringendem Klang die Uhr von der orthodoxen Kirche, sie schlägt ihr zwei Uhr nach Mittemacht. Kurz darauf ertönt mit heiserer ferner Stimme die Turmuhr bei der Beg-Moschee, und sie schlägt elf Uhr, elf gespenstische türkische Stunden nach der sonderbaren fernen Zeitrechnung fremder Erdteile! Die Juden haben keine Uhr, die schlägt, und Gott allein weiß, wie spät es nun bei ihnen ist, wie spät nach Sefard und wie spät nach der Zählung Aschkenazis. Die öden Geisterstunden der Mitternacht zählend wacht auch nachts, wenn alles schläft, der Unterschied, der diese verschlafenen Menschen trennt, die, so sie wach sind, nach vier verschiedenen und untereinander zerstrittenen Kalendarien sich freuen, trauem, Feste feiern und fasten, und alle ihre Wünsche zu einem einzigen Himmel in vier verschiedenen Kirchensprachen richten. Und dieser Unterschied ist manchmal sichtbar und heimlich, stets dem Haß ähnlich, oft ihm vollkommen gleich"l.

\subsection{Orient - Abendland}

Sehr oft wurde gesagt, daß Bosnien einen Treffpunkt zweier Welten - des Orients und des Westens - darstellt (das ist übrigens von vielen Gegenden des Balkans, Mittel- und Osteuropas behauptet worden) und daß das Werk Andrićs eine Brücke zwischen beiden Welten und Kulturen schlägt. Das Symbol der Briicke hat eine große Anziehungskraft, man verknüpft es sofort auch mit dem bekanntesten Titel von Andrić; ganze Bücher stehen unter dem Zeichen dieser Assoziation, etwa "Ivo Andrić: Bridge between East and West".

Wir werden sehen, daß die Brücke im Roman "Die Brücke über die Drina" an erster Stelle andere symbolische Bedeutungen enthält als die der Verbindung zweier Welten; auf der anderen Seite, wie schon angedeutet, repräsentiert Bosnien kein ideelles Zusammenkommen (oder auch Aufeinanderprallen) zweier Kulturen: es steht vor allem als Absonderung von der übrigen Welt und deren Ablehnung da.

Andrićs Auffassung des Orients bzw. des Westens führt dagegen zu interessanten Schlüssen über seine Philosophie. In einem gewissen Sinne zieht sich wie ein roter Faden seine Interpretation der Geschichte und der Gegenwart durch die Gegenüberstellung der zwei Welten. Das betrifft letztendlich auch eine der wichtigsten Botschaften der "Brücke über die Drina", verkörpert im Schlußmonolog des sterbenden Ali Hodschas. Hierauf beruht ebenfalls der Konflikt zwischen den europäischen Konsuln und der bosnischen Bevölkerung im Roman "Wesire und Konsuln". Und das ist das Thema vieler Erzählungen,

1Zitien nach Markovic, Tausend und eine Nacht des Ivo Andric, S.50-51. 
beispielsweise der "Rzavaer Berge", "Geschichte des Bauern Simans", "Liebe in der Kleinstadt" usw. Die Kemgeschichte innerhalb der Erzählung "Der verdammte Hof" - die des im Westen gefangengehaltenen Sultans Dschem - zeigt wiederum, wie Andric die geschichtlich-politische Entwicklung im Westen und im Orient projiziert

Wer in diesen Gegenüberstellungen das Gute und das Böse, das Schlechte und das weniger Schlechte auf der einen oder auf der anderen Seite zu finden sucht, der wird enttäuscht sein. Andrić überstürzt sich nie, ein Urteil abzugeben, da er weiß, daß die Geschichte ein sehr viel komplizierteres und verwirrenderes Tableau ist, als es auf dem ersten Blick erscheinen mag. Außerdem erzăhlt er diese Geschichte nicht in Form von historischen Schlußfolgerungen, sondem vor allem durch die Geschichte und das Schicksal des einzelnen Menschen.

Und selbstverständlich durch die Geschichte Bosniens, das abwechselnd vom Reich des Ostens und Reich des Westens verwaltet wurde. In Bosnien sind aber zwei verschiedene Mentalitäten und entgegengesetzte Lebensarten, so wie in Istanbul und in Wien oder Paris vorhanden, nicht anzutreffen. Andrićs Bosnien ist ein eigenes Phänomen, trotz des christlichen und des mohammedanischen Anteils der Bevölkerung. Seine Katholiken und Orthodoxen haben mit seinen "Türken" viel mehr gemeinsam als mit Christen in Europa oder gar mit Katholiken im benachbarten Kroatien'. Andric selbst ist ein Beispiel des Menschen und Schriftstellers, der von seiner (katholischen) Familienreligion sehr wenig bestimmt ist. Mehrere Studierende haben seine gründliche Kenntnis der orientalischen Welt und die orientalische Anmut seiner Prosa betont; es überrascht fast der Umstand, so wenig Sympathien für den westlichen Fortschritt bei diesem Schriftsteller, der einen christlichen Namen trägt und im fortgeschrittenen Europa studierte, finden zu können.

Im Werk Andrićs gibt es verschiedene Bezeichnungen und Metaphem für das "spezifisch Bosnische". Hier drücken sich aus: Trägheit, ruhiges Handeln, Freude am Zusammensitzen, an endlosen Gesprächen und an schadenfroher Nachrede, Mißtrauen gegenüber Ausländern, strenge Moral, Armut, Lebensklugheit, Angst vor den Mächtigen, Rebellion, Märtyrertum. Sowohl Einheimische als auch Ausländer stellen dieses Bosnien zur Schau. Die ersten haben nicht viele Worte darüber zu sagen: das Leben in dieser Gegend, mit ihren guten und bösen Seiten, ist für sie etwas Natürliches, das man am besten nicht ändert, sondern so läßt, wie die Vorfahren es gewollt und gemacht haben. Deswegen bedient sich Andrić oft der Fremden, um ein Bild Bosniens von auBen zu geben. So empfindet am Schluß des Romans "Wesire und Konsuln" der französische Konsul Daville sein jahrelanges Leben in Travnik:

"Von Jahr zu Jahr steigerte sich in ihm die verheerende Wirkung des 'orientalischen Giftes', das den Blick trübte und den Willen ätzte, und mit dem ihn dieses Land vom ersten

${ }^{1}$ Vgl. dazu Omer Pascha, Ledenik und andere Charakteren seiner Prosa. 
Tage getränkt hatte. Weder die Nähe des franzősischen Heeres in Dalmatien noch der Glanz der großen Siege vermochten daran etwas zu ändern"!.

In der Erzählung "Liebe in der Kleinstadt" berichtet der österreichisch-kroatische Offizier Ledenik einem Kollegen in einem Brief folgendes über eine kleine bosnische Stadt (offensichtlich Wischegrad):

"Und alles, was ich Dir von den hiesigen Einwohnem geschrieben habe, ist nicht nur der erste Eindruck, sondern hat sich von Tag zu Tag mehr bewahrheitet. Ich lebe unter wilden, schmutzigen und unwissenden Menschen. Die Menschen hier sind nicht nur unzivilisiert, sie werden sich auch meiner festen Überzeugung nach niemals zivilisieren lassen, weil sie das bißchen Hirn, das sie besitzen, dazu benutzen, um sich gegen jeden Zivilisationsversuch aufzulehnen. Und selbst diejenigen, die ein bißchen Verstand zu besitzen scheinen, sind so zugeknöpft und verschroben, daß man nur mit Stahl einen Funken aus ihnen schlagen könnte. Allerdings zeigen sie sich vor uns nicht, wie sie sind.

Von dem Schmutz, dem Mangel an dem nötigsten Komfor, von Eigenbrötelei und Brutalität, die mich umgeben, habe ich Dir schon genug geschrieben. Hier ändert sich nichts, höchstens zum Schlimmeren"2.

Der Erzähler bzw. Chronist - ein für Andrić beliebter Blickwinkel, jedoch nicht mit dem Autor selbst unbedingt zu identifizieren - hat immerhin ein anderes Bild mitzuteilen als der Abenteuerer Ledenik:

"Die Leute dor [in Wischegrad] kannten keine Fröhlichkeit. Die zurückgestaute Lebensfreude manifestierte sich in zügelloser Leidenschaft und in Ausbrüchen beim einzelnen wie in der Gemeinschaft. Was das schwere Leben und der unbarmherzige Kampf innen noch an Menschlichkeit gelassen hatten, leitete sich in religiöse Zeremonien, in überlieferte, einfache Formen der Anhänglichkeit innerhalb der Familie und in die Ehrenhaftigkeit des Kaufmannsstandes ab. Nur in außergewöhnlichen Situationen zeigten sie unerwartete Solidarität, Wagemut, Dankbarkeit und Größe"3.

Auch wenn Andric keine offenkundigen Interpretationen der Geschichte verlautbart, gelangt man doch zu solchen beim aufmerksamen Lesen seines Werkes. Ein weitreichendes Beispiel stellt in dieser Hinsicht "Die Brücke über die Drina" dar: hier bewegen sich nicht nur unzählige Menschenschicksale, sondern auch das Schicksal eines ganzen Lebensraumes im Laufe der Jahrhunderte. Der Bericht über dieses bosnische Schicksal setzt mit dem Bau der Brïcke ein, und er ähnelt im ruhigen, statischen Stil Andrićs dem Fluß Drina, der zwar auch Unglück in sich birgt, letzten Endes aber das Leben selbst bedeutet - viel Schmerz, manchmal Freude und Gleichgültigkeit. Die Brücke ist ein Wunder der schöpferischen Kraft des Menschen, sie fügt sich wunderbar zur Landschaft und dient zugleich dem Menschen. Das Wischegrader Leben fließt trotz aller Armut, Krankheit. Unterdrückung und Leiden im gewohnten ruhigen Rhythmus durch Jahrhundere, und die Brücke auf seinem Rücken ist

1 Wesire und Konsuln, S.402.

2I. Andric, Sämtliche Erzählungen (in drei Bänden), übersetzt von Milo Dor, Reinhard Federmann und Alois Schmaus. München, 1962-64 II, S.152.

3Ebenda, S. 150 . 
in ihrer Selbstverständlichkeit solch ein Teil der Natur geworden wie der Fluß selbst und die Berge ringsum ${ }^{1}$.

Bis die "Zivilisation" nach Bosnien kommt. Sie wurde mit dem Berliner Kongreß vom 1878, welcher Bosnien und Herzegowina Österreich-Ungarn zusprach, möglich. Urplötzlich änderte sich der Rhythmus des Lebens. Es gab neue Straßen in Bosnien, Eisenbahnen, gut organisiertes Beamtentum, Ordnung. Die Menschen waren nun viel mehr unterwegs, sie sahen viel mehr Geld als früher, die Chancen, zu Geld zu kommen, stiegen. Sogar die Brücke änderte sich, denn die Österreicher brachten elektrisches Licht auf das Kapija; gleichzeitig bauten sie im geheimen, in Voraussicht der kommenden Kriege, Minen in seine Pfeiler ein.

Und der Krieg war unvermeidlich. Die Fremden waren nach Bosnien nicht aus Liebe zu diesem Volk gekommen, zu ihren Bräuchen und ihrer Kultur, oder aus der Sorge, auch hier den sozialen und wirtschaftlichen Fortschritt zu verbreiten, sondem einfach, um das Land auszubeuten, noch grober gesagt, um zu rauben. Der tatsächliche Fortschritt in der Wirtschaft, Kultur, in den Institutionen usw. war eine Nebenerscheinung der Gesamtstrategie der Besatzer und kein Ziel an sich; denn, wenn es anders gewesen wäre, wie könnte er so einfach wieder zerstört, in die Luft gesprengt werden, so wie die Brücke gesprengt wurde? Diese Interpretation der Ereignisse dringt zum Leser mehrfach, besonders aber durch die Figur Ali Hodschas, durch.

Einen konzentrierten Ausdruck für die Zeit der österreichischen Besatzung in Bosnien hat Andrić in der Erzählung "Die Rzavaer Berge" gefunden, die so etwas wie einen Entwurf zum letzten Teil der "Brücke über die Drina" darstellt:

"Da kam Geld unter das Volk. Das Untemehmen wurde erweitert. Man kaufte neue Grundstücke, errichtete ein Sägewerk. An den zugänglicheren Stellen lichtete sich auffällig der Wald. Die hohen Kiefern auf dem Moljevnik konnte man mühelos zăhlen. Dic Kahlschläge breiteten sich aus und griffen von einem Wald auf den anderen, von einem Berg auf den anderen über. Die Dividenden stiegen. Zu Tausenden lagen auf den Stapelplätzen die Kiefemstämme wie gemordet, und neben ihnen erhoben sich Türme von aufeinandergeschichteten Eichenbrettern aus der Suha Gora.

... Und alles, was die Fremden taten, war erfüllt von einem Selbstbewußtsein, das verwunderte und bedrückte, mächtig und schön für das Auge war und dennoch unbegreiflich schön.

Gleich danach kam das Militär....

Und das Ergebnis:

${ }^{1}$ Mehr darüber im folgenden Kapitel. 
"Der Krieg lastete mit ganzer Schwere auf den Bergen. Es war als sollte sich erst jetzt zeigen, warum man all das aufgebaut und herbeigeschafft hatte. Der ganze von außen ins Land gekommene Wohlstand verkehrte sich in Grauen und Entsetzen. Im Laufe von vier Jahren wechselten Truppen und Kämpfe, wurden Dörfer und Wälder niedergebrannt, Herden von Vieh vernichtet, Vermögen zugrunde gerichtet. Die Menschen wurden in alle Winde zerstreut. Und wohin auch immer einer kam und ging, er trug wie einen kalten Stein den Gedanken an das zerstörte Heim und die ermordeten Kinder in seinem Inneren"l.

In "Wesire und Konsuln" ist diese Auffassung noch prägnanter ausgedrückt: "Sehen Sie aufmerksam hin und Sie werden erkennen, daß es stimmt, daß überall wo das christliche Europa seine Herrschaft samt seinen Sitten und Einrichtungen ausbreitet, daß es überall dort auch zum Kriege kommt, zum Krieg zwischen den Christen".

Der Schlußmonolog des sterbenden Ali Hodscha hat in diesem Zusammenhang einen besonderen Stellenwert, da er so etwas wie das Finale der "Brücke über die Drina und zugleich Andrićs Pessimismus und Skepsis gegenüber der bisherigen geschichtlichen Entwicklung vertritt:

\begin{abstract}
"Aber wenn auch hier zerstön wird, denkt er weiter, irgendwo wird gebaut. Irgendwo muß es doch friedliche Gegenden geben, in denen vernünftige Menschen um gute, gottesgefällige Werke wissen... Oh, wenn er doch nur ein wenig tiefer einatmen kðnnte! Wer weiß, vielleicht werden diese Unmenschen, die mit ihrem Tun alles ordnen, putzen, ändern und zurechtmachen, um es sofort danach zu verschlingen und zu zerstören, sich über die ganze Erde verbreiten, vielleicht werden sie aus der ganzen Welt ein wüstes Feld für ihr sinnloses Bauen und henkerisches Vernichten machen, einen Weideplatz für ihren unersärtlichen Hunger und ihre unfaßbaren Gelüste? Alles kann sein, eines aber kann nicht sein: es kann nicht sein, daß die großen mitfühlenden Menschen ganz und für immer verschwinden, die nach Gottes Gebot dauerhafte Bauwerke errichten, auf daß die Erde schöner sei und der Mensch auf ihr leichter und besser lebe"2.
\end{abstract}

Es ist wahr, daß Andrić diese Zeilen in den düstersten Jahren unseres Jahrhunderts geschrieben hat, daß der Zweite Weltkrieg nicht wenig zur Atmosphäre seiner beiden Romane beitrug: Und trotzdem klingt der Monolog Ali Hodschas sehr aktuell, u.a. als Widerlegung gewisser Nostalgiewellen.

\title{
3.4. Seine Kunst
}

Ein paar Hinweise auf künstlerische Charakteristika in der Prosa Andrics können noch der näheren Analyse des Bauopfermotivs helfen:

\footnotetext{
1 Sämtliche Erzählungen, II, S.404, 409.

2 Ivo Andric. Die Brücke über die Drina, deutsch von Ernst E. Jonas. Frankfur a. M. 1960, S.443.
} 
Das Statische. Wenn Handlung und Meditation unterschiedliche Prosatypen kennzeichnen, dann überwiegt bei Andrić sicherlich die meditative Prosal. Obwohl der Erzähler meist vermeidet, den Verlauf einer Episode durch eigene Urteile und philosophische Schlußfolgerungen direkt zu unterbrechen, besteht die Kunst letztendlich in der Kraft des philosophischen Diskurses. Meist bedeutet, daß Andrić hin und wieder auch von den direkten philosophischen Weisheiten Gebrauch macht; hier ein paar Beispiele:

"Von jeher ist es so, daß sich zwei Generationen, die einander berühren und ablösen, gegenseitig am schwersten ertragen und sich eigentlich am wenigsten kennen" ("Wesire und Konsuln", S.74);

"Wenn sich der Mensch in seinen Gedanken mit etwas versöhnt und befreundet, findet er dafür früher oder später auch in der Wirklichkeit eine Bestätigung. Das gelingt um so leichter, wenn sich die Wirklichkeit in der gleichen Richtung wie die Gedanken bewegt, ja sie oft noch überholt hat" (ebenda, S.385);

"Jede menschliche Generation hat ihre Illusionen über die Zivilisation, die einen glauben teilzuhaben an ihrem Aufflammen, die anderen, Zeugen ihres Erlöschens zu sein" ("Die Brücke über die Drina", S.324);

"Wenn Menschen Generationen hindurch tagein, tagaus, jahrein, jahraus für andere arbeiten und dies auch erkennen und fühlen, aber weder die Kraft dazu haben, es zu ändern, noch ihre wahre Gefühle zeigen zu dürfen, sammelt sich in manch einem die Erbitterung von Tausenden und von vielen Geschlechtern an "("Geschichte vom Zinsbauern Siman" in SE, S.84), usw.

Solche Sprüche bestätigen noch einmal die meditative Natur seiner Prosa, die uns an Schriftsteller wie Thomas Mann oder Hermann Hesse erinnert: diese errichten auch "realistische Tableaus" auf eine meditativ-philosophische Art. Gemeinsam ist diesen Autoren u.a. die leidenschaftslose Klarheit, die äußere Ruhe und der resignierte Ton des Erzählens, die mehrfach der historische Pessimismus angesichts gleicher europäischer Entwicklungen bestimmt ${ }^{2}$.

Auch diese Seite seiner Prosa ist weitgehend untersucht worden (Minde, Marković, Džadžić u.a.); hier sei nur erinnert, daß zu diesem Statischen in seinem Werk außer der Meditation der Naturalismus, das "Einfrieren" der Zeit und die Andricsche Melancholie viel beitragen.

${ }^{1}$ Dazu bemerkı S. Grubačic: "Andrić geht nicht von einer Dynamik des Handelns, sondem von der fixierten Situation aus, die cien Charakter enthüllt" (in: Kritisches Lexikon zur fremdsprachigen Gegenwartsliteratur, 10. Nachtragslieferung. München 1983; siehe unter 'Andrić', S.5).

${ }^{2}$ Diesen eher spontanen Eindruck fand ich später bei Z. Konstantinović in: Die Kultur Südosteuropas, a.a.O., S.157 bestätigt: "Mit Thomas Mann lassen sich sicherlich zwei Berührungspunkte feststellen: jener Entwicklungsweg des Künstlers, den Thomas Mann als den Weg vom 'Bürgerlich-Intellektuellen zum Mythisch-Typischen' bezeichnet, sowie Rückkehr und Versinken in die 'Legende der Menschheit'. Und obwohl bei Andric jener Hang zur Parodie fehlt, der einen der Hauptbestandteile bei Thomas Mann bildet, besteht bei beiden zweifellos eine ähnliche künstlerische Ausrichtung. Im Zusammenhang damit ist es interessant festzustcllen, daß Andric von Hermann Hesse außer dessen Lyrik fast nichts gelesen hat. Das ist umso verwunderlicher, da beide durch Abstammung, Themen und Motive viel Gemeinsames haben. Auch was den Stil betrift, scheint Andr: : : "ielem Hesse verwandt." 
Der Naturalismus bringt eine gewisse Bewegungslosigkeit auch in die handlungsreichsten Situationen; man soll diese Eigenschaft in Zusammenhang mit dem erwähnten überlegenen Chronistenton der Prosa betrachten; daraus resultiert auch die "bewegungs- und teilnahmslose" Darstellung erschütternder Szenen. So sind etwa Mordszenen im gleichen Rhythmus wie gewöhnliche Situa • tionen erzählt:

"Einmal sah er, wie in Sarajevo ein Serbe einen Albaner niederstach. Das Messer blieb in der Wunde stecken. Der Verletzte kümmerte sich nicht um den Mörder, den die anderen verfolgten, sondern schritt langsam, gleichsam feierlich und gefaßt, auf die nächste offenstehende Tür zu. Er ging als zählte er die Schritte, sah niemanden an, drückte nur beide Hände auf die Wunde, klar fühlend, daß er so lange leben würde, bis man ihm das Messer herauszog" ("Anikas Zeiten" in SE I, S.266. Siehe in der Folge auch das Mărtyrertum Radisaws).

Die gewählte Ruhe ist jedoch nur ein Schein, denn die Kernaussage bei Andrić triff immer entscheidende, dramatische und tragische Situationen im Leben des Menschen. Außerdem verbergen sich unter dem Mantel des besonnenen logischen Stils oft irrationale Handlungen, Motivationen, Konflikte bei Typen, die ihnen preisgegeben sind; es sei hier nur an einige Figuren seinen Erzählungen erinnert: Mustafa Magyar, den Bauern Siman, Alija Djerželez, den Ehemann von "Olujaci", Djamil aus dem "Verdammten Hof" usw.

Im Vakuum der Aktion und in der Fülle der innerlichen "Bewegungen" in Andrićs meditativer Welt herrschen selbstverständlich eigene Zeitverhältnisse. Ich sprach kurz das Verhältnis dichterisches Bosnien - tatsächliches Bosnien an: ähnliches gilt hinsichtlich der fiktionalen Zeit. Typisch ist bei Andrić, daß die Zeit träge wird, daß sie, auch wenn sie Jahrhunderten entspricht, sogar stehenbleiben kann. Der Schriftsteller friert - so wie in der "Brücke über die Drina" - diese Zeit ein, und gibt sie dadurch als eine "ewig Stehende" wieder. Um so paradoxer und lächerlicher erscheint dann die Illusion der modemen Gesellschaft, die Zeit "beschleunigen" zu können, alles schneller zu machen und schneller zu erreichen. Hier sind aus der "Brücke über die Drina" zwei Beispiele für diese entgegengesetzten Auffassungen:

"So vergeht ihnen die Nacht und mit ihr das Leben, erfüllt von Gefahr und Tod, aber klar, unbeugsam und gerecht in sich. Geleitet von uralten und ererbten Trieben, teilen und zerlegen sie es in vorübergehende Eindrücke und unmittelbare Bedürnnisse und verlieren sich völlig in ihnen. Denn nur so, jeden Augenblick für sich durchlebend, ohne vorwärts oder rückwärts zu schauen, läßt sich ein solches Leben ertragen und der Mensch sich für kommende bessere Tage bewahren"("Die Brücke über die Drina", S.421).

Diese Philosophie seiner Vorfahren kennt Ali Hodscha gut und weiß es zu schätzten. Daher kann er sich nicht mit der neuen, aus dem Abendland kommenden Hetzerei abfinden: 


\begin{abstract}
"Jenen, die sich der Geschwindigkeit rühmten, mit der sie jetzt ihre Geschäfte erledigen, und ausrechneten, wieviel Zeit, Mühe und Geld man spart, erwidert er mürrisch, es sei nicht wichtig, wieviel Zeit der Mensch spare, sondern was er mit der ersparten Zeit beginne; wenn er sie schlecht verwende, dann sei es besser, er habe sie nicht. Er bewies, daß es nicht die Hauptsache sei, daß der Mensch schnell forkomme, sondern wohin er gehe und zu welchem Zwecke, und daB Geschwindigkeit daher auch nicht immer einen Vorzug bedeute. 'Wenn du zur Holle gehst, dann ist es besser, du gehst langsam', sprach er bissig zu einem jungen Kaufmann; 'du bist ein Narr, wenn du glaubst, daß der Schwabe Geld ausgegeben und die Maschine hergeführt hat, nur damit du schneller reisen und deine Geschäfte schneller abschließen kannst. Du siehst nur, daß du fährst, aber du fragst nicht, was die Maschine außer dir und solchen, wie du es bist, noch fortbringt und heranschafft. Denn das will dir nicht in den Kopf. Fahre du nur, Freundchen, wohin du immer willst, ich fürchte nur, daß dir dieses Reisen eines Tages übel bekommen wird. Es wird noch die Zeit kommen, daß dich der Schwabe auch dahin fährt, wohin es dir nicht recht ist und wohin du nicht zu fahren gedachtest" (S.294).
\end{abstract}

Das Gefühl der stagnierenden Zeit verstärkt bei Andrić auch die große Zahl der Verben, die sich wiederholende Handlungen ausdrücken; hier fällt die häufige Anwendung des Präsens für vergangene Situationen auf, beispielsweise in der "Brücke über die Drina": "So verläuft das Leben der Stadtkinder unter der Brücke und um sie herum in ziellosem Spiel" (S.13); "Wie die Nacht weiterrückt - und sie rückt langsam weiter, als sei sie gewaltig und schwelle und wachse unaufhörlich wie das Wasser da unten -, da beginnen die Bürger und Ältesten sich an Kaffee und Raki zu erwärmen" (S.97); "In den regnerischen Herbstnächten versinken die Menschen, die sich in Zarijas Schenke versammelt haben, in Langeweile" (S.260); "Sie kehren wieder auf ihre alte Plätze zurück und setzen sich wiederum nieder" (S.295) usw. usf.

Es gibt sicherlich viele Züge in der Kunst Andrić, die einer Analyse wert sind; trotzdem enträtselt diese eigenartige Zeit, die sich entweder langsam und träge bewegt oder völlig stehenbleibt, mancherlei und bietet einen wichtigen Schlüssel zum Verständnis seines Werkes.

\title{
3.5. Die Brücke über die Drina
}

In der Sekundärliteratur über diesen Roman wird oft die Eigenschaft Andrićs hervorgehoben, Legenden und Realität untrennbar in der Erzählkunst zu vermischen ("Ein Erzählstil quasi mit dem Munde des Volkes, in dem Geschehen und Figur legendär bleiben, wechselt mit auktorialer Erzählung"l; "Die Vertrautheit mit der reichen folkloristischen und volkssprachlichen Tradition... verbunden mit einer objektivierten Betrachtung der Zeit, sichert seinem

${ }^{1}$ Lexikon der Weltliteratur. Stuttran 1968, S.147. 
epischen Werk nicht allein die Fülle und distanzierte Gelassenheit einer Chronik, sondem bedingt auch den konservativen, deduktiv-auktorialen Stil des Romans..."1 usw.). Ich glaube, daß schuld an dieser Ansicht, die eine solche Eigenschaft als maßgebend für Andrićs Prosa darstellt, der Prolog seines Romans "Die Brücke über die Drina" ist. Man liest den Anfang des Buches, der wirklich beeindruckt, und schreibt einer Technik der ersten fünfzehn Seiten, höchstens der ersten drei Kapitel, den ganzen Roman zu.

Und auch diese Technik baut nicht die folkloristische Tradition in die Prosa ein, sondern macht vielmehr das Gegenteil: sie will Legenden, Sagen, Volksglauben über die Brücke "aus dem Wege räumen", um die wahre Geschichte der Brücke erzählen zu können. Indem der Schriftsteller verschiedene Erzählungen aus dem Volksmunde wiedergibt, distanziert er sich von ihnen auf eine leicht ironische, heitere Art. Es herrscht überall die Gegenüberstellung: was erzählt das Volk - wie war es eigentlich. Diejenigen, die heutzutage an die Legenden über die Brücke glauben, sind bezeichnenderweise nur noch die Kinder Wischegrads, höchstens abergläubische Frauen. Hier sind Beispiele für die ironische Distanzierurig von zwei Legenden:

\begin{abstract}
"Als der Wesir Mechmed Pascha es unternahm, eine Brücke über die Drina zu bauen, und Leute entsandte, da beugten sich alle und leisteten Frondienste, nur ein Radisaw erhob sich, wiegelte das Volk auf und ließ dem Wesir sagen, er solle von diesem Unterfangen ablassen, denn es würde ihm nicht so leicht gelingen, eine Brücke über die Drina zu bauen. Und nicht wenig Mühe kostete es den Wesir, ehe er den Radisaw überwand, denn das war ein gewaltiger Held unter den Menschen, kein Gewehr und kein Säbel konnten ihn verwunden, kein Strick und keine Kette ihn binden, er zerriß sie wie dünne Fäden. So einen starken Talisman trug er bei sich. Und wer weiB, was noch geschehen wäre ob der Wesir jemals die Brücke gebaut, wenn sich nicht unter den Männem des Wesirs einer gefunden hätte, der weise und geschickt war und Radisaws Diener bestach und ausfragte. So gelang es ihnen, den Radisaw im Schlaf zu überraschen und mit einer seidenen Schnur zu erdrosseln, denn nur gegen Seide wirkte sein Talisman nicht" (S.12-13).
\end{abstract}

"Im Mittelpfeiler der Brücke, unter der Kapija, ist eine größere Öffnung, eine enge, aber hohe Tür ohne Füllung, wie eine riesige Schießschane. In diesem Pfeiler, heißt es, ist ein großes Zimmer, ein dunkler Raum, in dem der Schwarze Mann lebt. Das wissen alle Kinder. In ihren Trăumen und Schwindelgeschichten spielt er eine große Rolle. Wem er sich zeigt, der muß sterben. Kein Kind hat ihn bis jetzt gesehen, denn Kinder sterben nicht. Aber gesehen hat ihn eines Nachts Hamid, jener kurzatmige, ewig betrunkene oder verkaterte Lastträger mit den entzündeten Augen, und noch in der gleichen Nacht starb er, dort neben der Mauer. Übrigens war er sinnlos betrunken und hatte bei fünfzehn Grad Kälte unter freiem Himmel auf der Brücke genächtigt" (S.10).

Ich habe Behauptungen unterstrichen, die die Wahrheit solcher Legenden humorvoll oder ironisch ausschließen. Ähnlich tut diese Erzählweise im Prolog alle anderen Sagen über die Brücke $a b$; sie schafft somit das Bild eines "verläßlichen" Schriftstellers, der in den folgenden Kapiteln völlig besonnen und aufgeklärt über die wahre Geschichte der Brücke berichten wird. Auf

${ }^{1}$ Kindlers Literaturlexikon, siehe unter "Brïcke..." 
diese Art ist schließlich auch der Mythos über den Bau der Brücke erzählt worden. Ich zitiere hier die ganze Stelle:

\begin{abstract}
"Die Kinder wissen, daß Großwesir Mechmed Pascha die Brücke erbaut hat... Nur der Wesir konnte alles geben, was man braucht, um dieses unvergängliche Wunder aus Stein zu bauen. (Der Wesir - das ist im Bewußtsein der Kinder irgend etwas Herrliches, Gewaltiges, Furchtbares und Ungewisses.) Gebaut hat sie Rade, der Baumeister, der Jahrhunderte hätte leben müssen, um alles zu bauen, was es an Schönem und Ewigem in serbischen Landen gibt, ein legendärer und wahrhaft namenloser Meister, wie ihn sich jede Masse erdenkt und wünscht, denn sie mag nicht viel im Gedächtnis behalten müssen noch vielen etwas schulden, und sei es auch nur in der Erinnerung. Sie wissen, daß die Wassernixe, die Vila, den Bau gestort hatte, so wie schon immer und überall irgendwer jeden Bau stört, und nachts hatte sie das abgerissen, was am Tage aufgebaut worden war. Solange, bis ein "Etwas" aus dem Wasser zu sprechen anhob und dem Baumeister Rade riet, zwei unmündige Kinder, Zwillinge, Bruder und Schwester, namens Stoja und Ostoja (Halte und Bleibe) zu suchen und in den Mittelpfeiler der Brücke einzumauern. Sofon begann man, in ganz Bosnien nach solchen Kindern zu suchen. Eine Belohnung wurde für den ausgesetzt, der sie finden und herbeischaffen würde.

Schließlich fanden die Sejmen in einem entfernten Dorf die Zwillinge an der Mutterbrust und nahmen sie im Namen des Wesirs mit sich, aber als sie sie wegtrugen, wollte sich die Mutter nicht von ihnen trennen und wankte, wehklagend und weinend, unempfindlich gegen Flüche und Stöße, hinter ihnen her bis nach Wischegrad. Dort gelang es ihr, sich vor den Baumeister zu drängen.

Die Kinder wurden eingemauert, denn es konnte nicht anders sein. Aber der Baumeister - so sagt man - empfand Mitleid und ließ in dem Pfeiler Öffnungen, durch die die unglückliche Mutter ihre geopferten Kinder stillen konnte. Das sind die schón ausgehauenen blinden Fenster, eng wie Schießscharten, in denen jetzt die Wildtauben nisten. Zur Erinnerung daran fließt schon seit Jahrhunderten Muttermilch aus dem Gemäuer. Das sind jene weißen Rinnsale, die zu gewissen Jahreszeiten aus den makellosen Fugen heraussträufeln und deren unverwischbare Spur auf dem Stein zurückbleibt"(S.9-10).
\end{abstract}

Distanzierter und mißtrauischer kann man Mythen nicht erzählen! Einen letzten sarkastischen "Schlag" versetzt Andric dieser Legende an einer weiteren Stelle: "Die Brücke zeigt, wie sehr die alten Baumeister, von denen man erzählt, sie hätten mit Vilen und dunklen Mächten Umgang gehabt und sogar Kinder lebendig einmauern müssen, einen Sinn nicht nur für Beständigkeit und Schönheit eines Baues hatten, sondem auch für den Nutzen und die Bequemlichkeit..." (S.15, kursiv von mir). Die drei folgenden Kapitel gehen im Detail auf die Geschichte des Baus ein, wobei sie durch ihre realistische Erzählweise in einem gewissen Sinne als Widerlegung der Sagen über das Bauopfer gelten. Um sie zu entmachten, unternimmt der Autor sogar eine Deutung der Legende bzw. zeigt den Mechanismus seiner Entstehung; dies geschieht auf eine ebenso trockene Art wie die Erzählung der Legende selbst:

"Leicht erdenkt das Volk Geschichten und schnell verbreitet es sie, die Wirklichkeit aber verknüpft und vermischt sich wundersam und untrennbar mit diesen Geschichten. Die Bauern', die des Nachts dem Guslaren zuhören, erzählten, die Fee, die den Bau zerstöre, habe dem Beauftragten des Wesirs wissen lassen, daß sie erst dann mit der Zerstörung aufhören würde, wenn er in die Grundmauern zwei Kinder, Zwillinge, Bruder und

ISie sind Fronarbeiter beim Bau der Brücke. 
Schwester, namens Stoja und Ostoja einmauere. Und einige schworen, sie hätten die Sejmen gesehen, wie sie in den Dörfern ein solches Kinderpaar suchten. (Die Sejmen waren tatsächlich auf die Dörfer gegangen aber sie hatten nicht nach Kindern gesucht sondern im Volke herumgehorcht und gefragt, ob man nicht wüßte, wer die Unbekannten seien, die die Brücke zerstörten.)

$\mathrm{Zu}$ der Zeit ereignete es sich, daß in einem Dorfe oberhalb Wischegrads ein armes, taubstummes und geistesschwaches Mädchen, das in fremdem Hause diente, schwanger wurde, aber sie wollte oder konnte nicht sagen, von wem. Dies war ein seltenes, unerhörtes Ereignis, daß ein Mädchen, und noch dazu ein solches, schwanger wurde und daß der Vater unbekannt blieb. Und das Ereignis sprach sich weit herum. Gerade in diesen Tagen gebar das Mädchen in einem Schuppen Zwillinge, aber beide waren tot. Die Frauen halfen ihr bei der Geburt, die ungewöhnlich schwer war, und begruben die Kinder sofort in einem Pflaumengarten. Aber das Mädchen, dem nicht beschieden war, Mutter zu sein, stand schon am dritten Tage auf und begann, die Kinder überall im Dorf zu suchen. Vergeblich erklärten sie ihr, die Kinder seien tot zur Welt gekommen und beerdigt. Um ihr Herumfragen abzuschütteln, sagten sie ihr oder machten ihr eher mit Gesten verständlich, ihre Kinder seien fortgeschafft in die Stadt, dort, wo die Türken die Brücke bauten. Schwach und verzweifelt, wie sie war, streifte sie weiter bis zur Stadt und begann um das Gerüst und die Baustelle herumzuschleichen, verängstigt den Menschen in die Augen zu sehen und mit unverständlichem Brummeln nach den Kindern zu fragen. Die Leute sahen sie erstaunt an oder verjagten sie, damit sie nicht bei der Arbeit störe. Als sie sah, daß man nicht verstand, was sie wollte, knöpfte sie ihr grobes Bauernhemd auf und zeigte ihnen die wehen, milchstrotzenden Brüste, deren Warzen bereits von der unaufhaltsam herausfließenden Milch aufgesprungen waren und bluteten. Niemand wußte, wie man ihr helfen und erklären sollte, daß ihre Kinder nicht in die Brücke eingemauert seien, denn auf alle guten Worte und alles Zureden brammelte sie nur traurig und durchsuchté mit scharfem, ungläubigem Blick jeden Winkel... So lebte sie dort neben der Baustelle als stille Irre. Mit ihr blieb auch das Gerede, die Türken hätten die Kinder in die Brücke eingemauert. Die einen glaubten daran, die anderen nicht, aber alle wiederholten und verbreiteten es." (S.38-40)

Hier ist nicht einmal mehr von einer Legende die Rede, geschweige denn vom Mythos, sondern nur noch vom Gerede. Die frei erfundene Geschichte des irren Mädchens kann den Sinn und die Wurzeln des Bauopfermythos gar nicht erklären'. Es wird nun deutlich, daß Andrić wenig von diesem Motiv hält; es hat den Schein, als ob er sich mit der Legende von der Entstehung der Brücke auseinandersetze, sie in seinem Diskurs aufnehme, in Wirklichkeit schließt er diese Legende von seinem Roman ebenso gelassen aus, wie er sie in ihn eingeführt hatte, die Literaturkritiker damit verunsichernd.

Warum beschäftigt sich dann der Schriftsteller überhaupt mit dieser Legende? Dafür gibt es offenbar mehrere Gründe: erstens, weil er sie nicht unbeachtet lassen kann: Balladen oder Legenden über den Bau einer Brücke, einer Festung usw., kurzum Bauopfermythen sind in diesen Gegenden, wo sich

\footnotetext{
${ }_{1}$ Andrics "Entblößung" des Motivs erinnert an die anthropologische Erklärung der Mythologie. Tylor, ein Vertreter dieser Schule, behauptete u.a.: "Die Ethnographie hat schwere, manchmal sogar mühsame Pflichten; sie muß nämlich an den Tag bringen, was die rohe Zivilisation des Altertums in Form von jämmerlichem Aberglauben an unsere Gesellschaft weitergegeben hat, und sie muß diesen Aberglauben der sicheren Zerstörung übergeben. Dieses Werk, sei es auch nicht besonders angenehm, ist denn (zitiert nach Marcel Detienne, a.a.O 1).
} 
der Roman abspielt, wie gezeigt wurde, sehr verbreitet, und man muß ihnen einfach Rechnung tragen, wenn man über den Bau einer Brücke im Nebel der Geschichte erzählt; zweitens bringen diese Erzählungen für den außenstehenden Leser des 20. Jahrhunderts, der den Mythos schon vergessen oder nie gekannt hat, sicher viel Farbe, d.h. "Lokalkolorit", in den Roman. Und zuletzt machen sie eben den Weg frei für die wirkliche, realistische Erzählung.

Wer die Ballade in den von Karadžić und von anderen veröffentlichten Varianten kennt, der wird von Andrićs trockener Darstellung bestimmt enttäuscht. Da ist nichts mehr von der Notwendigkeit und Tragik der chthonischen Opferung, nichts mehr von der finsteren Poesie des Mythos geblieben, nicht einmal ein Hinweis, daß es sich hier um ein sehr altes Motiv handelt; es ist, wie wenn alte Mythen Griechenlands in Form von zusammengefassten Märchen erzählt würden.

Das ist zu bedenken, wenn man den "Bericht" über die Bauopferlegende von jenem Teil absondert, der sich mit dem Bau der Brücke befaBt, und ihn abgetrennt vom Kontext des ganzen Romans liest. Das wäre aber eine ungerechte und ungerechtfertigte Art der Betrachtung; denn Andric hatte sich schon, obwohl nicht in der Wiedergabe der Legende selbst, mittelbar und auf eine eigenwillige Weise mit dem Bauopfermotiv auseinandergesetzt ${ }^{1}$.

Der Bau der Brücke ist ein riesiges Untemehmen, bei dem Hunderte von Menschen ihre Arbeit unter extrem harten Bedingungen, in der ersten Phase sogar als Fronarbeit, leisten; dies ist zu einem GroBteil von der Strenge und Unmenschlichkeit des Beauftragten des Wesirs, Abidaga, bestimmt. Unter den Arbeitern beginnen sich aber allmählich Zeichen der Auflehnung bemerkbar zu machen. Am kühnsten ist Radisaw (jener gewaltige Held der Legende, den kein Gewehr und kein Säbel verwunden konnte), ein untersetzter, starrköpfiger Bauer, der seine Kumpels in Aufruhr bringen will; sie sollen Schaden an der Brücke anrichten, und dabei das Gerücht verbreiten, "daß eine Fee den Bau zerstön und keine Brücke über die Drina will" (S.37). Radisaw und andere gehen mehrmals in der Nacht zu dem Gerüst über dem Fluß und reißen von den Fundamenten der Brücke so viel sie können ab; einmal erwischen aber die Sejmen Radisaw, und nun wartet auf ihn narh grausamen Foltern die grausamste Hinrichtung, die sich die osmanische Verwaltung je erdacht hat: Pfählen bei lebendigem Leibe. Der Autor schildert seitenlang, erbarmungslos und in allen Einzelheiten die Vollstreckung dieses Urteils. Hier ist ein Ausschnitt davon:

"Radisaw senkte den Kopf noch tiefer, während die Zigeuner an ihn herantraten und sich
anschickten, ihm Joppe und Hemd abzustreifen. Auf der Brust zeigten sich, gerötet und
voller Blasen, die Brandwunden der glühenden Ketten. Ohne noch ein Wort zu sprechen,
legte sich der Baucr, wie ihm befohlen, nieder, das Gesicht zum Boden gekehrt. Die Zi-

I In Zusammenhang mit dem Erzählstil von Andričs bosnischen Geschichten bemerkt S. Grubačic: "Doch in der Maske eines angeblich 'naiv' unmittelbaren Erzählens entfaltet sich ein artistisch sehr anspruchvolles und durchdachtes Erzählverfahren" (Kritisches Lexikon zur fremdsprachlichen Gegenwartslite. . .r"10,S.5). 
geuner traten hinzu, banden ihm zunächst die Hände auf den Rücken und befestigten dann an jedem FuB, am Knöchel, einen Strick. Sie zogen, jeder von einer Seite, und spreizten seine Beine weit auseinander. Inzwischen legte Merdschan den Pfahl auf zwei kurze Rundhölzer, so daß die Spitze dem Bauem zwischen die Beine zeigte. Dann zog er ein kurzes, breites Messer aus dem Gürtel, kniete vor dem ausgestreckten Verurteilten nieder und beugte sich über ihn, um ihn den Stoff der Hose zwischen den Beinen zu zerschneiden und die Öffnung zu erweitem, durch die der Pfahl in den Körper eindringen sollte. Dieser furchtbarste Teil der Henkersarbeit blieb glücklicherweise für die Zuschauer unsichtbar. Man sah nur, wie der gefesselte Körper unter dem kurzen, unbemerkten Messerstich erschauerte, sich bis zur Hüfte aufbäumte, als wolle er aufstehen, aber sofort wieder zurückfiel und dumpf auf die Bretter aufschlug. Sobald er dies beendet hatte, sprang der Zigeuner auf, nahm den hölzernen Hammer vom Boden und begann mit ihm auf das untere, stumpfe Ende des Pfahles langsam und gleichmäßig zu schlagen. Nach jedem zweiten Schlag machte er einen Augenblick halt und betrachtete zunächst den Körper, in den er den Pfahl trieb und dann die beiden Zigeuner, die er ermahnte, langsam und gleichmäBig zu ziehen. Der Körper des ausgespreizten Bauern krampfte sich von selbst zusammen; bei jedem Hammerschlag krümmte und buckelte sich das Rückgrat, aber die Stricke zogen ihn auseinander und streckten ihn" (S.56-57).

Radisaws Hinrichtung ist jene Episode, die vom ersten Teil des Romans, vom Bau der Brücke, am meisten beeindruckt und in Erinnerung bleibt. Weswegen hat sie solch einen großen Anteil? Radisaw vertritt an und für sich nicht so viel: er lehnt sich sowohl gegen die türkischen Befehlshaber als auch gegen den Bau der Brücke als etwas Fremdes auf - diese ist aber letztendlich ein sehr nützliches Bauwerk und, wie sich herausstellen wird, auch ein großes Kunstwerk; daher steht Radisaw einerseits für Widerstand gegen die schwere Fronarbeit, andererseits jedoch auch für Ignoranz und Bauernbosheit da. Beide sind Ideen, die zur Botschaft und zum Symbol der Brücke über die Drina wenig beitragen und die das Gewicht, das die Szene von Radisaws Hinrichtung zugeteilt bekommt, nicht rechtfertigen; im ersten Blick ist es nicht verständlich, warum Andrić, in vollem Naturalismus, die vielleicht grauenhaftste Schilderung seines ganzen Werkes hier untemimmt.

Radisaw bleibt, gepfählt, den ganzen Tag am Leben; sein qualvoller Tod muß laut Befehl des türkischen Kommandeurs sehr langsam eintreten. Damit wird eine ganze Stadt in Schrecken versetzt, keiner kann seine Gedanken vom Pfahl wegbringen und in der Nacht ein Auge zutun. Und in der Morgendämmerung:

"...kletterten die Zigeuner erneut auf das Gerüst und betrachteten den Verurteilten von allen Seiten; sie sprachen etwas untereinander, hoben den Blick und schauten nach oben in das Gesicht des Bauern; einmal zog ihn Merdschan an den Hosen. Schon an der Art, wie sie zum Ufer hinunterstiegen und schweigend zwischen den geschäftigen Menschen hindurchgingen, begriffen alle, daß der Bauer ausgelitten hatte. Und alle Serben empfanden etwas wie eine Erleichterung, wie einen unsichtbaren Sieg.

Jetzt blickten sie alle mutiger hinauf zum Gerüst und zum Verureilten... Der Tod war der schwerste Pfand. Die bis dahin von Furcht geschlossenen Münder offneten sich von selbst. Schmutzig, naB, unrasiert und bleich, mit Kiefernstangen große Blöcke Banjaer Steine wälzend, machten sie für einen Augenblick halt, um in die Hände zu spucken und mit unterdrückter Stimme, einer zum anderen, zu sagen:

'Gott sei seiner Seele gn:: 
'Ach, der Gram! Leid unseres Herzens!'

'Siehst du denn nicht, daß er ein Heiliger geworden ist? Ein Heiliger, verstehst du!'

Und jeder warf dem Verstorbenen, der sich aufrecht hielt, als schreite er einer Abteilung voran, einen verstohlenen Blick zu. Oben, in seiner Höhe, schien er ihnen nicht mehr entsetzlich oder bedauemswert. Im Gegenteil, allen war jetzt klar, wie sehr er sich abgesondert und erhöht hatte. Er stand nicht auf der Erde, er hielt sich nicht mit den Händen, er schwamm nicht, er flog nicht; er trug seinen Schwerpunkt in sich selbst; befreit von irdischen Bindungen und Lasten, spïrte keine Qual mehr, keine Macht konnte ihm etwas anhaben, weder Gewehr noch Säbel, weder menschliches Wort noch türkisches Gericht. So, nackt bis zum Gürtel, mit gebundenen Händen und Füßen, aufrecht, den Kopf zum Pfahl zurückgeworfen, erinnerte dieses Bild nicht so sehr an einen menschlichen Körper, der wächst und zerfällt, als vielmehr an ein hoch erhobenes, festes und unvergängliches Standbild, das dort für immer bleiben würde.

Die Fronarbeiter wandten sich ab und bekreuzigten sich verstohlen." (S.63-64)

So hat sich in wenigen Stunden die Umwandlung Radisaws von einem üblichen, bomierten Bauern zu einem Heiligen bzw. zu einem Abbild Christi vollzogen. Bereits vorher, zum Hinrichtungsplatz,

"...ging Radisaw zwischen den Henkem, barfüßig und barhäuptig... er hüpfte fast auf den verstümmelten Füßen, die blutige Löcher statt der Fußnägel zcigten, auf der Schulter toug er einen langen, weißen, zugespitzten Pfahl" (S.54-55).

Das ist ein Bild, das keiner mißverstehen kann; Christi Hinrichtung sickert sogleich durch mehrere ikonische Zeichen' ins (Un)bewußtte ein; er war auch barfuB, und das Kreuz auf der Schulter tragend begab er sich zur Kreuzigung, wo man ihn an den Händen und Füßen nageln und verbluten lassen sollte.

Laut Befehl sollte man den Körper Radisaws den Hunden vorwerfen, einige Bauern tragen ihn jedoch, nachdem sie den Henker bestechen, heimlich weg und begraben ihn abseits von der Stadt. Hier ist der Ort, über den einmal im Jahr ein Licht vom Himmel fallt.

Es handelt sich hier nicht einfach um eine Kreuzigung oder das Märtyrertum eines Christen durch Andersgläubige, sondern vor allem um ein Bauopfer. Auch nur der Umstand, daß nach Radisaws Tod (welcher einen Höhepunkt und das Ende der türkischen Terror-Bauweise darstellt, denn in der Folge wird Abidaga entlassen und ein menschlicherer Aufseher angestellt) die Bauarbeiten sicher voranschreiten, ohne Auflehnung der Arbeiter, Beschädigung der Fundamente usw., also auch dieser Umstand bezeugt, daß die Aufopferung Radisaws quasi eine Notwendigkeit für den Bau der Brücke war. Wie sehr es auch paradox erscheinen mag, daß ein realistischer, besonnener Schriftsteller wie Andrić, nachdem er Sagen und Legenden entkräftet hat, unterschwellig einen neuen Bauopfermythos erzählt, so ist das doch der eigentliche Diskurs, der das zweifache Verhältnis des Schriftstellers zum Bauopfermythos erblicken läßt. Er stimmt mit den allgemeinen, hergebrachten Wahrheiten des Mythos nicht ganz überein: Radisaw ist kein unschuldiges Opfer (seine Hinrichtung ähnelt vielmehr der pragmatischen Aufopferung von Feinden und Kriegsgefangenen

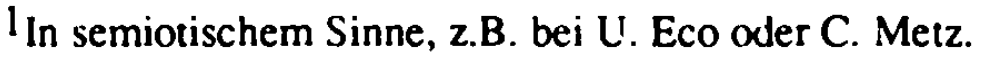


bei vielen alten Völkem), niemand denkt bei seiner Tötung an ein Bauopfer, er wird nicht eingemauert, er wird vielmehr gekreuzigt usw.

Und trotzdem stellt dieser Augenblick den Wendepunkt in der Geschichte des Brückenbaus dar; man vergißt fast, wer Radisaw war, der Leser weiß nur, daß nach seinem Tod eine Arbeit, die anfangs die Hölle war und nur Rückschläge brachte, langsam aber reibungslos fertiggestellt wird. Es gibt nur einen erwăhnenswerten Zwischenfall: eines Tages fällt ein großer Steinblock vom Kran auf den Mohr, den Gehilfen des Baumeisters Antonio, und quetscht seine untere Körperhälfte an dem mittleren Pfeiler der Brücke ein; obgleich sie versuchen, können die Arbeiter ihn vom großen Block nicht befreien und sein Leben retten. Andrić erzählt also eine neue Variation des Bauopfermythos, diesmal auf eine offensichtlichere Art. Davor schreibt er: "Am Ende dieses dritten Jahres ereignete sich einer jener Unglücksfälle, ohne die große Bauwerke selten errichtet werden können" (S.76), wobei es keine Ironie oder Distanzierung mehr gibt wie in Zusammenhang mit der volkstümlichen Iegende.

Endlich ist die Brücke da: ein Wunderwerk des menschlichen Könnens, sie übertrifft an Größe, Harmonie und Baukunst alles, was die Wischegrader sich je vorgestellt hatten. Die Brücke erfüllt nicht nur ihre praktische Funktion, sie wird zu einem Mittelpunkt des Lebens jener Gegenden; in ihr und rund um sie spielen sich Jahrhunderte durch die wichtigsten Ereignissen ab, mit denen der Autor sich befaßt. Ich will hier aber nicht ausführlich auf die Symbolik der Brïcke und ihre organisierende Bedeutung für den Roman eingehen, denn diese Punkte hat die Literaturkritik über Andrić sicherlich mehrfach angesprochen. Sein Glauben an Meisterwerke, die im Glauben und in voller Harmonie mit der Natur errichtet werden, ist hier jedoch zu unterstreichen.

Bis jetzt wurde gezeigt, wie ein Schriftsteller - der sowohl Künstler als auch Philosoph ist - eine wichtige Botschaft mit nicht weniger dichterischer Kraft als eine alte, hergebrachte Ballade vermitteln kann; er lehnt dabei sogar ihre Dienste $a b$, indem er eigene Wege einschlägt. Denn in beiden Fällen, in dem der Ballade vom Bauopfer und in Andrićs Roman klingt eine ähnliche Botschaft: hier entsteht ein großes Bauwerk, das seine Festigkeit, Schönheit und Harmonie von den chthonischen Kräften der Erde schöpft:

"Die Menschen gingen zahllose Male über die Brücke, von einem Ufer auf das andere... Jeder, auch der kleinste Städter, fühlte, als hätten sich seine Fähigkeiten mit einem Male vervielfacht und seine Stärke vergrößer, als sei eine wunderbare, übermenschliche Heldentat in das $\mathrm{MaB}$ seiner Kräfte und in die Grenzen seines Alltagslebens gerückt, als sei neben den bisher bekannten Elementen, Wasser und Himmel, mit einem Male noch ein weiteres entdeckt worden..." (S.81-82).

"Ein jeder ... wußte, daß es in seinem Leben etwas gab, das jedem Element widersteht und das wegen der unfaßlichen Harmonie seiner Formen und der unsichtbaren weisen 
Kraft seiner Fundamentel aus jeder Prüfung unzerstörbar und unverändert hervorgeht" (S.102-103).

Diese Eigenschaften der Brücke kann der Schriftsteller nicht genug betonen; sie dienen ihm als Refrain für seinen Roman und sind fast immer am Ende und in Kontrast zu einer Episode zu finden, die von vergänglichen menschlichen Schicksalen berichtet:

"Ihre lichte Linie im Bild der Stadt änderte sich ebensowenig wie die Konturen der umliegenden Berge an Himmel... ${ }^{2}$ Ihr Lebensalter glich der Ewigkeit, denn sein Ende war nicht abzusehen" (S.88).

"Dort nahm sie die unbewußte Philosophie der Stadt auf: daß das Leben ein unfaßbares Wunder ist, denn unaufhörlich verbraucht und verströmt es, und dennoch dauert es an und steht fest 'wie die Brücke über die Drina' (S.103).

"So erneuerten sich die Geschlechter neben der Brücke, sie aber schüttelte wie Staub alle Spuren von sich ab, die vergängliche Launen und Einfälle auf ihr hinterlassen hatten, und blieb nach wie vor unverändert und unveränderlich" (S.120).

"Man kann überhaupt sagen, daß alle diese Änderungen auf der Brücke unbedeutend,
oberflächlich und von kurzer Dauer waren. Zahlreiche und weittragende Veränderungen
im Geist und in den Gewohnheiten der Bürger und im äußeren Bild der Stadt verliefen,
als gingen sie an der Brücke vorüber, ohne sie zu berühren. Es schien als würde die
weiße, alte Brücke, über die drei Jahrhundere ohne Spur und Narben hinweggegangen
waren, auch unter dem neuen Herrscher unveränder bleiben und auch dieser Flut von
Neuheiten und Veränderungen widerstehen, wie sie immer auch den höchsten Über-
schwemmungen widerstanden hatte, und aus den wütenden, trüben Wassermassen, die
sie überfluteten, unberührt und weiß, wie wiedergeboren, aufgetaucht war" (S.191-192).

Diese Unvergänglichkeit der Brücke, die zur Andrićschen stagnierenden Zeit so gut paßt, geht aber einem Paradox entgegen: es wird eine Zeit kommen, in der der Mensch "an das Festeste und Dauerhafteste rühren und von dem nehmen wird, was Gottes ist" (Monolog Ali Hodschas, S.443). Es scheint, als ob diese einzige Gewalttätigkeit, die Zerstörung der Brücke durch das Militär im Ersten Weltkrieg, als Gegengewicht für all das, was schön, harmonisch und unvergänglich in der ganzen Geschichte Bosniens war, fungiert: sie bringt daher intensiver als jedes andere Moment Andrićs Pessimismus, sein Mißtrauen gegen die glaubenlose Vernunft und modeme Technik zum Ausdruck. Denn der Gewaltakt hat gerade an die unsichtbare Kraft der Fundamente, an die mythischen Vermächtnisse unserer Vorfahren gerührt.

\footnotetext{
${ }^{1}$ Allein dieser Satz bestätigt das Gewicht, das der mythische Hintergrund im Roman hat. 2 Bachofen hatte geschrieben "...seinen stofflichen Urgrund hat der murus aus der Erde, weshalb die Mauerkrone der großen Naturmütter Haupt ziert... Mit den Mutterleibe der Erde in fester Verbindung, ist er unverrückbar" (Mutterrecht und Religion, S.45).
} 


\section{ISMAIL KADARE \\ Mythologie als Schauplatz und Inhalt der Fiktion}

Es war wohl eine Zeit, in der, so sagt man, Lebende und Tote, Menschen und Götter zusammenlebten, sie sollen sogar unter sich geheiratet und eigenartige Mischungen zur Welt gebracht haben, das war aber eine andere, heidnische Zeit, die nie mehr wiederkommt.

Im Unterschied zu Kazantzakis und Andrić gibt es über Ismail Kadare, dessen Werk erst in den zwei letzten Jahrzehnten vielfach übersetzt worden ist, wenig Sekundärliteratur im Ausland. Die meisten Besprechungen seiner Bücher sind als Kurzrezensionen in Zeitschriften erschienen, und auch sie beschäftigen sich zu einem guten Teil mehr mit der Geschichte und der aktuellen Politik Albaniens im allgemeinen als mit den konkreten Büchem des Autors'. Daher schien es mir angebracht, über ihn hier etwas mehr als über die anderen Autoren zu berichten und seine literarische Persönlichkeit so weit wie möglich unter mehreren Blickwinkeln zu betrachten.

\subsection{Kurze Biographie und Werkregister}

Ismail Kadare wurde 1936 in Gjirokastra, Südalbanien, geboren. Sein Vater war Postangestellter, die Mutter Hausfrau. Den zweiten Weltkrieg erlebte das Kind in seiner Heimatstadt, die mehrmals von der italienischen und der griechischen, später von der deutschen Armee besetzt wurde. Eine ausführliche, wenn auch von der Metaphorik und von der kindlichen Traumwelt verzerrte Autobiographie jener Zeit ist im Roman "Chronik in Stein", 1971, zu finden (siehe unten).

${ }^{1}$ Dies ändert sich jedoch. Im "letzten Moment" erfuhr ich von einer Monographie der Französin Anne-Marie Mitchell mit dem Titel "Un thapsode albanais: Ismail Kadare". Paris 1990, die ich leider nicht mehr verwenden konnte. 
Nach dem Krieg besuchte Kadare in Gjirokastra die Volksschule und das Gymnasium; sehr früh begann er, Gedichte zu schreiben und zu veröffentlichen (ein Teil davon ist Gegenstand seiner Satire in der späteren Erzählung "Zeit des Schreibens", 1985). In der Folge inskribierte er an der neugegründeten Universität Tirana die Studienrichtung Albanische Sprache und Literatur. 1954 erschien seine erste poetische Sammlung, "Jugendliche Inspiration", drei Jahre danach die zweite, "Träume"; später distanzierte er sich jedoch von seiner fruihen Lyrik, indem er sie größtenteils nicht in die Ausgabe seines $\mathrm{Ge}$ samtwerkes ${ }^{1}$ aufnahm.

Nach Abschluß des Studiums in Tirana setzte Kadare 1959 seine literarischkünstlerische Ausbildung am Gorki-Institut in Moskau fort. Hier kam er umfassend mit der zeitgenössischen, bzw. modernen europäischen Literatur in Kontakt ${ }^{2}$. Mit dem Abbruch der Beziehungen zwischen der Sowjetunion und Albanien, 1961, mußte auch Kadare sein Studium abbrechen und nach Tirana zurückkehren.

Er arbeitete zunächst als Joumalist und Redakteur für literarische Zeitschriften Albaniens. 1963 gelang ihm mit dem Roman "Der General der toten Armee" der Durchbruch; angesichts des philosophischen Ansatzes und den stilistischen Innovationen erkannte man in dem jungen Autor einen bedeutenden Schriftsteller, wie er in der albanischen Literatur nicht oft vorkommt. Der Roman löste gleichzeitig Polemiken aus, ein Zeichen, daß ein wichtiges Werk entstanden war ${ }^{3}$.

Allerdings war Kadare in den 60er Jahren in Albanien mehr als Lyriker bekannt. Seine Sammlungen "Mein Jahrhundert", 1964, "Worüber denken diese Berge nach", 1965, "Hoch fliegen die Adler", 1966, "Sonnige Motive", 1968 gekennzeichnet von Begeisterung für den Sozialismus, Abstraktionen und poetischen "Verblüffungen" - wurden damals unter der Jugend sehr populär. Die bisher letzte poetische Sammlung, "Die Zeit", vielleicht sein Abschied von der Lyrik, erschien 1976. Sie besteht aus einer ausgesprochenen politischen Poesie, die Albaniens eigenen Weg zum Kommunismus besingt.

"Die Festung" und "Chronik in Stein" waren nach dem "General der toten Armee" Kadares wichtigste Prosawerke der 60er Jahre.

Vom Anfang der 70er Jahre bis zum Jahre 1990 lebte Kadare als freier Schriftsteller in Tirana. Er war mehrmals Abgeordneter der Volksrepublik und Vorstandsmitglied des Schriftstellerverbandes.. Im Jahre 1988 wurde er als Vizepräsident der Demokratischen Union Albaniens gewählt. Er war auch Chefredakteur der literarischen, in französischer Sprache erscheinenden Zeitschrift "Les Lettres Albanaises". Ende 1990 floh Kadare mit seiner Familie

1"Vepra letrare". Tiranë 1980-81.

2 Bereits sein erster Roman, "Der General der toten Armee", weist gute Kenntnisse von Autoren wie Kafka, Hemingway, Buzzati u.a. auf.

${ }^{3}$ Er ist inzwischen in mehr als zwanzig Sprachen übersetzt worden und gilt im Ausland meines Erachtens imümlicherweise und zum Nachteil späterer komplexerer Romane, als sein Hauptwerk. 
nach Frankreich und distanzierte sich somit von seiner Partei und der Politik der albanischen Regierung. Die neue Situation in Osteuropa und in Albanien hatten seine Stellung als prominenterster Schriftsteller des offiziellen Albaniens und zugleich als Verfechter der Demokratisierung des Landes in ein neues Licht gerückt.!

Als Prosaautor war Kadare besonders in den 70er Jahren produktiv. 1973 erschien "Der Winter der großen Einsamkeit" (1976 erweitert als "Der große Winter"); 1974 der andere Roman "November einer Hauptstadt"; 1976 "Das alte Emblem", eine Sammlung von Erzählungen und längeren Prosatexten; 1978 drei Romane in einem Band: "Die Brücke mit drei Bogen", "Die großen Paschaliks" und "Die Dämmerung der Steppengötter"; 1979 zwei Romane, "Wer hat Doruntina zurückgebracht", "Der zerrissene April" und drei Romanausschnitte in einem Band. In den 80er Jahren erschienen der Roman "Ein Dossier für Homer", 1981, die Prosasammlung "Zeit des Schreibens", 1986, und sein umfangreichste Roman, "Konzert am Ende eines Winters", 1988.

Kadare ist außerdem als Essayist und Übersetzer bekannt. Erwähnenswert sind sein Beitrag über die Tradition der albanischen Volkspoesie "Autobiographie des Volkes in Versen", 1975, und die Essays über Äschylus, 1986 (als Vorwort seiner Übersetzung von "Orestie" veröffentlicht) und über den albanischen Dichter Migjeni, 1988.

\section{Kadare im Ausland}

Auf Anregung des bekannten Autors und Kritikers Robert Escarpit und mit dessem Vorwort verlegte 1970 Editions Albin Michel in Paris den "General der toten Armee". Dieses Datum hat eine zweifache Bedeutung: einerseits übersteigt ein Autor die Grenzen seines Landes, andererseits veröffentlicht ein großer ausländischer Verlag zum ersten Mal überhaupt Literatur aus Albanien. Vielleicht waren die Sechziger und die Siebziger eine günstige Zeit für die "kleinen" Literaturen; in den traditionellen Kulturmetropolen wie Paris wandte man den Blick vom Abendland zu den Literaturen in Lateinamerika, Afrika und anderswo hin; es wurden dabei Autoren wie G. García Marquez, J. Cortásar u.v.a. entdeckt. Die Unbekanntheit des Landes Albanien, seine "Exotik" spielten (ähnlich wie in den Zeiten von Lord Byron und "Childe Harold") gleichfalls keine geringe Rolle in dem Anklang, den das Buch sofort fand.

Bald wurde Kadare unter Literaten, Journalisten und Lesern in Frankreich zum Synonym für Albanien. "Ein Albaner birgt ganz Albanien in sich"2. "Le

1 Die Frage, ob Kadare politisch ein Regimekritiker oder ein Regimeunterstützer war, wird zur Zeit in Albanien heftig diskutiert. Meiner Ansicht nach war er beides. Viele von seinen besten Romanen bringen indirekt seine Ablehnung des totalitären Staates zum Ausdruck. Andererseits haben Werke, wie seine Gedichte der '60er Jahre oder Romane wie "Der große Winter" und "Der November einer Hauptstadt" beträchtlich dazu beigetragen, den Kommunismus in Albanien zu verschönern und den Personenkult von Enver Hoxha zu befestigen.

2R. Escarpit im Vorwort von "Le General de l'armée morte". Paris 1970. 
General de l'armée morte" erreichte eine Auflage von über 100.000 Exempliren, nach einigen Jahren wurde er, mit M. Piccoli und M. Mastroianni in den Hauptrollen, verfilmt.

Dem Roman folgten andere Werke von Kadare. In Frankreich sind inzuischen bei Editions Fayard die meisten Romane, die wichtigsten Erzählungen sowie auch ausgewählte Lyrik herausgekommen, insgesamt 14 Titel. In den skandinavischen Ländern, in Holland, Italien, Spanien und in den Ländern Osteuropas sind neben dem "General der toten Armee" hauptsächlich die Romane "Chronik in Stein und "Die Festung" erschienen. Im englischen- und im deutschsprachigen Raum sind neuerdings mehrere Bücher verlegt worden. Mit der neuen Situation nach Kadares Flucht wird sein Werk sicher auch eine veränderte Rezeption im Ausland finden, die noch abzuwarten bleibt.

\subsection{Das Werk}

Kadares Werk umfaßt bisher 13 Romane, etwa 10 Novellen $^{1}$, zahlreiche Erzählungen und acht lyrische Sammlungen. Trotz der Vielfalt der Themen und Ideen und obwohl Kadare seit über drei Jahrzehnten eine beachtliche Entwicklung erfahren hat, kann man in seinem umfangreichen Werk einige Schwerpunkte feststellen, die zur Skizzierung seines literarischen Porträts verhelfen.

In diesem Sinne habe ich in seinem Gesamtwerk, ohne Anspruch auf Vollständigkeit, folgende Schwerpunkte festgestellt: 1. Geschichte Albaniens - Widerstand als Zentralmotiv, 2. Sozial-politische Aktualität des Landes; 3. Das Osmanische Reich, ein Modell des totalitären Superstaates; 4. Die Welt im Spiegel der Erinnerungen; 5. Mythologie in der Struktur des Werkes.

Die 'Grenzen' dieser Einteilung sind oft fließend, sie ist sinnvoll, insofem als sich beispielsweise Werke der ersten von denen der zweiten Gruppe klar unterscheiden: während die zweiten einen näheren Bezug auf die gegenwärtige Realităt nehmen und historische Tatsachen weitgehend berücksichtigen, sind Romane wie "Der General der toten Armee" vielmehr auf die Symbolik als auf eine genaue Widerspiegelung der Geschichte angewiesen. Romane und Erzählungen der dritten Gruppierung haben dagegen den Anschein, historische Literatur zu sein, sind aber freie Streifzüge durch die Geschichte, mit einem eindeutigen aktuellen Hintergrund, wobei die fiktiven "Tatsachen" gegenüber den

\footnotetext{
'Unter 'Novelle' versteht man in Albanien längere Prosatexte, die üblicherweise 50-100 Seiten betragen. Die Gattung wird formal und inhaltlich zwischen dem Roman und der Erzählung angesiedelt. In der Regel sollte die Novelle eine mehr oder weniger geradlinige Handlung und begrenzte Zahl der Charaktere aufweisen. In der Praxis entscheidet jedoch das Formale, d.h. die Zahl der Seiten. So nennt man einen Prosatext wie Kadares "Das verhängnisvolle Jahr" Novelle, obwohl dieser angesichts der Vielschichtigkeit der Handlung und der Anzahl der Handelnden z.B. mit Garcia Marquez' "Chronik eines angekündigten Todes" vergleichbar wäre.
} 
historischen überwiegen. Die autobiographische Prosa läßt sich leichter absondem, auch wenn hier die anderen Themen hin und wieder auftauchen.

Das Stichwort Mythologie wird in zwei eigenen Kapiteln untersucht, als Betrachtung des Romans "Wer hat Doruntina zurückgebracht" und des anderen Werkes, das sich auf das Bauopfermotiv stützt, "Die Brücke mit drei Bogen".

Diese Darstellung des Werkes von Kadare, wenn auch ausführlicher als bei den anderen Autoren, hat keinen Anspruch auf Vollständigkeit. Ich habe hier vor allem Werke, die repräsentativ für den Autor sind, und Schwerpunkte, die zum Verständnis seiner Handhabung des Themas Mythologie führen, herangezogen. In dieser Sichtweise fehlen einige in Kadares Werk wichtige Romane wie "Der große Winter", "Konzert am Ende eines Winters" oder "November einer Hauptstadt", die hauptsächlich politische Romane sind und unter Schwerpunkt 2 fallen; es fehlt ebenfalls eine Betrachtung seiner Lyrik, in welchem Bereich der Autor in den Sechzigem sehr produktiv war; ich neige allerdings dazu, diese Lyrik eher als eine "Vorbereitung" oder als Ausgangspunkt für die späteren bedeutenderen Romane anzusehen. Es gibt dementsprechend manche Gedichte, die prägnant die Ideenkonstellationen der künftigen Prosatexte enthalten und diesen Texten als Epigramme dienen könnten.

Eine Einteilung Kadare-Prosaautor und Kadare-Lyriker wäre auf jeden Fall unzutreffend. Es wird dem Lyriker kein Unrecht angetan, wenn man hauptsächlich seine Prosa analysiert. In dieser Prosa sind nämlich fast alle Elemente des künstlerischen Diskurses enthalten, die den Poeten früher kennzeichneten. Kadare war kein 'Sonetten-Poet'; außer in seinen Anfängen hat er klassische Formen immer abgelehnt. Er war auch kein Poet der spontanen Gefühle, der Innerlichkeit, usw. Die dichte, den Leser verblüffende Metaphorik, der rationale Gedankengang, das weitreichende Nachdenken waren die eigentlichen Hauptmerkmale seiner Poesie. In wenigen Fällen nur hat der Autor versucht, Spontaneität und Vorgänge der überlieferten albanischen Poesie nachzuahmen. Jedoch mit wenig Erfolg, denn Kadare steht sicher nicht in der "bodenständigen" Tradition der albanischen Lyrik im Sinne von N. Frashëri, Çajupi, Asdreni, Poradeci, die die folkloristische Tradition entweder unmittelbar übernommen oder auf natürliche Weise verarbeitet haben.

\subsection{Das Motiv des Widerstandes}

Felder mit Köpfen von Paschas, Wesiren,

Grafen und Obersten bebaut.

Der Wind pfeift über sie.

Ein schwebendes Blatt, ein Pferdeschwanz, Vögelfelder

Verwandeln sich plötzlich in Zeichen, Orden, Ränge. 
Die Einöde der Felder lockte alte Schatten her.

(Wie oft brachten sie hier mitten im Sommer den Winter!)

Das Korn wird aber bald aufgehen,

Die Geister werden zeitweise veschwinden,

Um nach den Emten und den ersten Niederschlägen

Wiederaufzutauchen

Und werden wieder herumgehen, ihre Köpfe suchen,

Von vergeblicher Suche beunruhigt. Wo? Wo? Was?

Über den winterlichen Feldem

Werden ihre Alpträume schweben.

(I.Kadare, "Die winterlichen Felder")

Das Motiv des Widerstandes ${ }^{1}$ hat Ismail Kadare intensiv beschäftigt. Es steht vor allem in seinen bedeutendsten Gedichten und in den ersten Romanen, aber auch in der späteren Prosa im Mittelpunkt. Der Autor hat damit das Zeichen für eine neue Entwicklung in der albanischen Literatur ${ }^{2}$ gesetzt, die keineswegs als eine rein persönliche Tendenz eines Schriftstellers zu sehen ist: die Geschichte Albaniens und die der Albaner war vor allem mit dieser qëndresë zu identifizieren. Die neue Literatur stand vor einer Schlüsselfrage, die Antworten und Interpretationen benötigte: Wie konnte ein Volk ohne einen eigenen Staat, ohne eigene Kulturzentren und ohne eine einheitliche Religion, trotz wiederholter Besatzungen, seine Sprache und Identität bewahren? Eigentlich hatte die albanische Literatur diese Frage schon seit ihren Anfängen aufgeworfen, die romantischen Antworten der Dichter der nationalen Wiedergeburt boten aber keine sachliche Interpretation der Geschichte. Um ein nationales BewuBtsein zu erwecken und die Unabhängigkeitsbewegung anzuregen, hatten Schriftsteller wie De Rada ("Milosao", 1836) und Naim Frashëri ("Geschichte Skanderbegs", 1882) die Geschichte Albaniens vor der türkischen Eroberung im 15. Jahrhundert als eine blühende Zeit der vereinigten Nation, mit einem eigenen Staat (auf dessen Tradition man jetzt zurückgreifen könnte) idealisierend dargestellt.

Der Widerstand der Albaner gegen die Türken, das erste Bündnis der albanischen Fürsten und Führer unter Skanderbeg war tatsächlich der größte Aufbruch der Albaner im Mittelalter. Für eine Staatstradition vor diesem Zeitpunkt fehlen aber die Beweise. Die Geschichte dokumentiert vielmehr, wer die Gebiete auf dem westlichen Balkan in seiner Macht hatte, ob Byzanz oder die Anjous von Neapel, ob Venedig oder das serbische und das bulgarische Reich. Und trotzdem steht die Existenz des albanischen Volkes zumindest seit der Zeit des römischen Reiches außer Zweifel.

Meinungsunterschiede gibt es dagegen über die Frage, ob die fünf Jahrhunderte nach Skanderbeg als eine Zeit des dauernden Widerstandes oder des $\mathrm{Zu}$ -

\footnotetext{
${ }^{1}$ Das albanische Won "qëndresë"ist zugleich mit Widerstand und Überleben zu übersetzen.

2Ebenfalls in der Literatur aus Kosovo.
} 
sammenlebens innerhalb des osmanischen Reiches (etwa drei Viertel der Bevölkerung wurden islamisiert) aufzufassen sind. "Die Albaner spielten in der Geschichte des Osmanischen Reiches eine Rolle, die die der anderen nichttürkischen Nationalitäten bei weitem übertraf. Sie bekleideten führende Posten in der Armee und Verwaltung; selbst im höchsten Staatsamt bei den Großwesiren, war ein hoher Prozentsatz albanischer Abstammung." 1 Der zitierte Autor erwähnt aber nicht, daß Albaner nicht nurl hohe Ämter bekleiden, sondern auch Kriege für die Türkei führen mußten. Sie starben überall auf der Welt, sei es vor den Toren Wiens oder in den Wüsten Asiens und Afrikas. Das Land blieb unsagbar arm und rückständig. Die separatistischen Bestrebungen einiger Paschas und Aufstände der Bevölkerung im 18. und 19. Jahrhundert nahmen mit den neuen Reformen der türkischen Verwaltung (Tansimat) und mit dem langsamen Verfall des Reiches immer mehr zu. Große Sorgen für dieses erwachende nationale Bewußtsein bereiteten die Beschlüsse des Berliner Kongresses 1878, der albanisch bewohnte Gebiete Montenegro zusprach. Die Albaner muBten ihre Gebiete selbst verteidigen, ebenfalls nach 1913, als mit der Gründung des neuen Staates, aufgrund von Entscheidungen der Botschafterkonferenz in London, große ethnische Gebiete außerhalb der Grenzen blieben.

Die Unabhängigkeit änderte auch nicht viel an dem Schicksal der von dauemden Kriegen geprägten Nation. Der neue Staat stand im Brennpunkt der Interessen der Nachbam und der Großmächte. Während des ersten Weltkrieges operierten in Albanien Streitkräfte Italiens, Österreich-Ungarns, Hollands, Frankreichs, Serbiens, Montenegros, Griechenlands und Bulgariens ${ }^{2}$. In den $20 \mathrm{er}$ und 30er Jahren geriet das spätere Königreich Albanien immer mehr unter italienischen Einfluß, bis das Land 1939 durch Mussolinis Truppen besetzt wurde. Mit der italienischen Kapitulation im Herbst 1943 marschierten die Truppen des NS-Reiches in Albanien ein. Beide Besatzungen stießen auf massiven Widerstand bis zur Befreiung des Landes im November 1944.

Dieser kurze Exkurs in die Geschichte vermag vielleicht zu erklären, warum das Widerstands- und Überlebensmotiv so stark ins Blickfeld der Literatur rückte. Der Bruch mit der Sowjetunion in den frühen sechziger Jahren war ein zusätzlicher Grund für diese Einstellung und für die emeue Behauptung der Unabhängigkeit. Was auf den Bereichen der ,hohen Politik“ gespielt wurde, stimmte mit den Unabhängigkeitsgefühlen der Albaner überein. Die offizielle Propaganda fand eine breite Unterstützung auch unter den Schriftstellern. Beim Rückblick in die Geschichte empfand man sowohl Trauer für den schmerzvollen Weg einer Nation als auch einen offenkundigen Stolz, daß die Albaner die Geschichte trotz allem überlebt hatten. Ein solcher vertiefter Blick, befreit von romantischen Vorstellungen jedoch nicht ganz von der $\mathrm{Pa}$ -

\footnotetext{
I Peter Bard, "Anmerkungen zu einigen Problemen der albanischen Geschichte" in SüdostForschungen. München 1987, S.680.

2Kadare hat jene chaotische Zeit in der Novelle "Das verhängnisvolle Jahr" (1985) thematisiert.
} 
thetik, kommt prägnant in Kadares längerem Gedicht "Worüber denken diese Berge nach" zum Ausdruck:

So gingst du immer, Albanien,

Auf hohen Beinen und mit langem Gewehr.

Gingst du und wuBtest nicht wohin,

Einem nebligen, trüben Morgen entgegen,

So dunkel, wie ihn die Nacht hinterließ.

...Wilde Feinde hackten auf deine Grenzen,

Hackten auf die nackten bleichen Schultern des Landes.

Vor Hunger schwindelte dem Land

Und trotzdem stand es auf, ging es schwankend in die Nacht,

Die Grenzen zu messen. Mit Yard,s mit Metern?

Nein,

Mit dem langen Gewehr.

Deine ersten Kontakte zu Erfindungen,

Zur Zivilisation und seiner neuesten Technik

Waren neue Waffenmarken und -kaliber,

Die auf deiner durchsiebten Brust geprüft wurden.

Einsame Gräber von Bergbauern

Hinterließ der Krieg.

Traurige Grabsteine,

Einsilbige Namen

noch bis vor kurzem.

Und auf aufgetürmten Steinen

Ein eintöniges Lied...

...Legenden kautest du in frostigen Nächten,

Aus Hunger aßest du deine Lieder wieder auf.

Albanien,

Gebeugt in der Dämmerung auf einem Pflug, schliefst du ein

Unter dem düsteren Himmel

Und träumtest von so wenig Glück,

Wie niemand je geträumt hat.

Träumtest von einem Stückchen Brot

Und einem Löffel Salzwasser mehr,

Träumtest von beiden

Und von nur wenig, nur wenig Öl,

Es mit dem Gewehr zusammen zu essen.

...Der Gewehrlauf

Auf dem Rücken Albaniens

Ist wie ein scharfer Knochen in ihn gesät.

Durch das schwere Schicksal in ihn gestoßen,

Der Fortsatz seines Rückgrats,

Dieser eiserne schreckliche Stumpf,

Stolzer Atavismus aus einstigen Zeiten.

(aus I. Kadare, "Motive me diell", Prishtinë 1978, S. 160 f, eigene Übersetzung.) 
Die beiden angeführten Gedichte könnten emblematisch zu Kadares Roman "Der General der toten Armee" gelten, den ich hier als repräsentativ für den ersten Schwerpunkt näher besprechen möchte. Auf der einen Seite das Motiv des Widerstandes und der Kriege, auf der anderen die Mentalität einer besetzenden Großmacht, beide bilden zusammen das Objekt seines Nachdenkens. Besonders anregend war in diesem Rahmen die Handlung des Romans.

Ein General und ein Priester kommen zwanzig Jahre nach dem Zweiten Weltkrieg (offensichtlich aus Italien) nach Albanien, um die Überreste ihrer Soldaten, die im Land begraben geblieben waren, auszugraben und in die Heimat zurückzunehmen. Es ist eine äußerst schwierige Mission, denn diese Gebeine sind überall im Land verstreut, für einen Teil davon fehlen die Hinweise und außerdem verfolgt die Mannschaft die ganze Zeit ein schlechtes, geradezu feindliches Wetter durch das gebirgige Land. Ihre albanischen Hilfsarbeiter sowie die Einwohner selbst sind meist korrekt zu den beiden, eine unterdrückte Feindseligkeit und das Nichtvergessen sind jedoch immer wieder zu spüren.

Peinlichkeit und Groteske begleiten den General und den Priester in all den Episoden ihrer traurigen Mission. Die Auseinandersetzung mit den Albanem, ein stummer aber hartnäckiger Konflikt, wird letzen Endes von der inneren Einstellung der beiden veranlaßt: sie sind nicht nach Albanien gekommen, um etwa um Entschuldigung für die damaligen Verbrechen zu bitten. Ganz im Gegenteil, sie verachten dieses Volk, der General, weil er wegen der Kriegsniederlage noch immer verbittert ist, der Priester, weil er eine eigene Theorie hat, nach der "der Krieg ein normaler Zustand dieses Volkes ist, darum wird es im Krieg so gefährlich wild und richtet so viel Schaden an". Dementsprechend versuchen sie, sich selbst als überlegen und ihre Mission als "edelmütig" zu empfinden. Die Vollstreckung ihres Auftrages wird aber immer absurder, die Ausgrabungsarbeiten ziehen sich in die Länge, und der General ist zunehmend deprimiert. Am Ende steht er vor einer unübersehbaren, in Nylonsäcken verpackten Armee und hat Alpträume wie aus einerKafka-Welt:

"Ich habe von jener Prostituierten geträumt...Sie lag tot im Sarg. Draußen aber, vor der Tür des Bordells, warteten viele Soldaten in einer Schlange, und auch sie lagen in Särgen... Ich ging dort vorbei und fragte: 'Die Soldaten, die hier warten, kommen die von der Front, oder sind sie auf dem Wege dorthin?' Einige antworteten, sie kämen von dort, andere, daß sie dorthin gingen, und da sagte ich; 'Diejenigen, die an die Front müssen, brauchen nicht mehr zu warten, sie sollen einmal kämpfen, bevor sie ein Recht auf Vergnügen haben. Wer aber von der Front kommt, kann in der Reihe bleiben... Und dann habe ich vom Oberst $Z$. [nach seinen Gebeinen wird umsonst gesucht] geträumt. 'Sie denken, daß ich ein Meter zweiundachtzig groß bin?' sagte er zu mir und lachte hämisch. 'Da irren Sie sich, meine Herren, so groß bin ich nicht.' - 'Wie groß sind Sie denn?' fragte ich ihn. Er lachte wieder und sagte eigensinnig: 'Das verrate ich nicht'"'.

Dieser schwarze Humor vermischt sich oft mit dem Ernst des Schriftstellers, denn es geht ihm nicht ausschließlich um die Auseinandersetzung Albanien Großmächte, sondern auch um den Krieg im allgemeinen, um die absurden und grotesken Situationen, die aus einem agressiven Krieg unvermeidlich entstehen. Dies vermag die schnelle Aufnahme zu erklären, die der Roman auch

1 "Der General der toten Armee", übersetzt von O. Buchholz und W. Fiedler. Kiel 1988, S. 154-155. 
bei ausländischen Lesem, die mit der Geschichte Albaniens nicht vertraut sind, gefunden hat. Kadare verstand es sehr früh, aus dem Stoff "Geschichte Albaniens" - indem er nationale Komplexe, Rhetorik, etc. vermied - allgemeingültige und aktuelle Wahrheiten herauszufiltern.

Die künstlerischen Verfahren, die ihm dabei zu Hilfe kommen, sind vielfältig, drei Typen aber sollte man herausstreichen, da sie kennzeichend für das gesamte Werk sind:

Die Metaphorik: Kadares "Stärke". Sie ist meist assoziativ, d.h. sie wird spontan und überraschend eingesetzt und hat oft einen "unlogischen" Anschein. Diese Metaphorik besteht aus Tropen, Sinnbildern, Symbolen, Parallelismen, Vergleichen, Phantasiegebilden (meist des Typs "als ob" ), usw. Einige Kritiker haben behauptet, daß die metaphorische Sprache bei Kadare den eigentlichen Poeten hinter dem Prosaautor verriete; dieser Standpunkt geht aber von der falschen Überzeugung aus, Metaphorik sei vor allem von der Poesie zu erwarten. Bei Kadare ist die Bildlichkeit der Sprache seine Art der Annäherung an den dargestellten Gegenstand, ja sogar der natürlichste Ausdruck seiner kreativen Persönlichkeit.

Hier sind aus der Fülle ihrer Art ein paar Beispiele der Metaphern im "General der toten Armee":

"Gegen Abend nahm dann die Reihe merklich ab, bis schließlich auch der letzte Soldat gegangen war, dann wurde die Tür geschlossen, und überall herrschte Stille. Gewöhnlich sahen SIE [die Prostituierten] nach solchen anstrengenden Tagen erschöpft und bleich aus, und ihre Augen wirkten verstört wie nie zuvor. Es schien, als hätten die von der Front zurückgekehrten Soldaten den ganzen Kummer, den Regen, den Schlamm und die Niederlagen in den Schützengräbern auf diese armen Mädchen abgewälzt, um selbst erleichtert und befriedigt abzuziehen, als hätten sie eine schwere Last von ihren Schultern abgeworfen, während SIE in unserer Stadt zurückblieben, in der Nähe der Front, um wieder auf andere Soldaten zu warten und auf diese Weise den bitteren Kelch des Rückzugs bis zur Neige zu leeren" (S.85-86).

"Der Bauer hatte erzählt, wie das "Blaue Bataillon" durch die Gegend zog, wie sie alle über die Niederlage wütend waren, wie sie eines Nachmittags die Mühle überfielen, sicherlich weil irgendjemand ihnen verraten hatte, daß dort ein Deserteur arbeitete, wie sie dann den Soldaten fanden, der sich zwischen den Mehlsäcken versteckt hatte, über und über weiß, voller Mehlstaub, als wäre er schon im vorhinein mit dem Leintuch bedeckt" (S.144).

"Diese Menschensammlung [Hochzeitsgäste], die ihm zu Beginn wie ein bunter, rauschender Hain erschienen war, hatte sich für ihn auf einmal in einen finsteren Winterwald verwandelt ${ }^{1}$. Da bewegten sich Köpfe, Schultern, Arme und knochige Finger, die wie vom Sturmwind entlaubte Zweige hin und her schwankten, und dann flatterte über das Ganze mit einem trockenen Krächzen die Unruhe hinweg" (S.246).

"'Das ist der Krieg selbst", sagte der Generalleutnant. "Diese Knochen sind die Quintessenz des Krieges, sie sind das, was zurückbleibt, wie die Salze, die bei einer chemischen Reaktion auf dem Boden des Gefäßes zurückbleiben"'" (S.284).

${ }^{1}$ Shakespeares' "Macbeth" ist für Kadare immer eine faszinierende Inspirationsquelle gewesen. 
Bildung einer bestimmten Atmosphäre: Dies ist ein komplizierter, vielschichtiger Vorgang, der eigentlich eine umfangreiche Analyse benötigte. In einigen Rezensionen über "Den großen Winter" oder "Chronik in Stein" in der deutschsprachigen Presse wird oft im Zusammenhang das Wort 'Sinnlichkeit'1 verwendet. Es stimmt zwar, daß Kadare die Sinne intensiv anspricht ${ }^{2}$, das Wort erklärt jedoch nicht viel. Hinsichtlich des "Generals" sei hier nur vermerkt, daß die Atmosphäre des Romans größtenteils durch die Anhäufung und Wiederholung bestimmter Konnotationen entsteht. Sie vermitteln in ihrer Gesamtheit eine deprimierte Stimmung rund um den General (Sinnlosigkeit seiner Mission), eine triste um die Landschaft (ein für die Fremden abweisendes Land) und eine melancholisch-wehmütige vom Autor selbst ausgehend (Nachdenken über die Geschichte u.a.). Hier beispielsweise einige solche stark konnotierte Wörter und Ausdrücke, die sich regelmäßig wiederholen: Gebeine, Uberreste, Knochen, Ausgraben, Nylonsäcke, klebriger Schlamm, anhaltender Regen, finstere, drohende Berge, kalter, schneidender Wind, grauer Nebel, usw.

Anwendung mythischer Symbole - Dies ist ein hervorstechender Zug im gesamten Werk von Kadare: die albanische, die balkanische, die altgriechische, aber auch die slawische oder die orientalische Mythologie sind mehr oder weniger in fast jedem seiner Bücher anwesend; oft treten die mythologischen Figuren nicht nur als partielle Metaphem, Andeutungen und Anspielungen auf, sondern sie wirken strukturbildend auf das Werk selbst. Davon wird mehr in den betreffenden Kapiteln die Rede sein; in bezug auf den "General" ist hervorzuheben, daß die Mythologie meist als Teil der Metaphorik erscheint, wie die folgenden Beispiele zeigen. Zuerst ein Ausschnitt, in dem geschildert wird, wie die Albaner auf die italienische Invasion im Jahre 1939 reagierten:

(a) "Bruchstückhaft und von verschiedenen Leuten hatten sie erfahren, was sich an jenem Tag an den Küsten der beiden Meere im Westen Albaniens ereignet hatte. Die Nachricht, $\mathrm{daB}$ der Feind das Meer überquerte, hatte sich im Lande verbreitet, und aus allen Gegenden waren die Albaner in Gruppen zu fünf, zu zehn oder zu zwanzig Mann gekommen, mit dem Gewehr über der Schulter. Sie kamen von sich aus, ganz von selbst und spontan, sie kamen von weit her, über Berge und Täler, und in der Art, wie sie daherkamen, war etwas Altehrwürdiges, etwas Uraltes, etwas, was vielleicht instinktiv von Geschlecht zu Geschlecht vererbt worden war, seit den legendären Zeiten des Gjergj Elez Alia, als das Bose immer wie ein Seeungeheuer aus dem Meere stieg und gleich an der Küste des Meeres vernichtet werden mußte, damit es nicht ins Land eindringen konnte. Das war ein

"Siehe etwa im Umschlag der "Chronik in Stein", übersetzt von Joachim Röhm. Salzburg 1988.

${ }^{2}$ Dies geht auf eine andere, "intellektuellere" An vor sich als bei Kazantzakis, der Farben, Aroma usw. direkt in seine Bilder integriert; beim Lesen von Kadare fallt es schwer zu behaupten, daB man Aromen spürt und Ähnliches, vor allem aufgrund der metaphorischen Funktion, die auch Naturelemente immer erfüllen, so z.B. der ständige Regen und die allgemeine Feuchtigkeit, die den Leser auf jeder Seite des "General der toten Armee". "Chronik in Stein" oder "Brücke mit drei Bogen" begleiten. 
alter Ruf zu den Waffen, eine aus ferner Vergangenheit überkommene Furcht vcor den blauen Wassern und vor dem Tiefland überhaupt, denn das Böse drang immer übeer das flache Land ein, und während sie von ihren Bergen herabstiegen, um sich mit den RResten der königlichen Armee zu vereinigen, die noch Widerstand leisteten, fühluem sie, aals sie den Geruch und die Weite des Meeres wahmahmen, zugleich die Gefahr, unid das TTosen der Wellen erschien ihnen wie die Musik des Krieges" (S.191).

(b) "Die Arbeiter zogen die Heringe heraus, und als das erste Zelt abgebaut war, bliieben in dem von der Feuchtigkeit hartgewordenen Sand merkwürdige Spuren zurüick, als ; wäre ein Untier mit großen Klauen dont vorbeigelaufen" (S.182).

(c) "Unterdessen würden unbekannte Sargtischler diese Tausende von kleimen Särgen nach den vertraglich vereinbarten Maßen fertiggestellt haben. Punkt 14 des Verturags: Särge aus doppeltem Sperrholz. Mit weißer Lackfarbe zu streichen. Die Nummser in Schwarz.

Und schließlich wird in jener Baracke inmitten des einsamen Ödlandes am Stadıtrand von Tirana Charon in seinem weiten, abgetragenen Mantel zum letztenmal sein diickes Heft aufschlagen, und sich dabei die Finger anhauchen..." (S.224).

(d) "Unter den Stiefeln des Generals knarten die Dielenbretter.

'Hören Sie es denn nicht? Horren Sie nicht die Trommel? Dort drüben geht es immer noch weiter, ich habe eine böse Vorahnung.'

'Fürchten Sie sich etwa?' fragte der Priester.

'Ja', erwiderte der General. 'Mir ist, als würden sie sich jeden Moment zusammenrotten, vor unser Haus ziehen und die Trommel schlagen, um uns zu vertreiben, $\$ 0$ wie man bei manchen Völkern die bösen Geister vertreibt"' (S.258).

(e) "Ein grauenvoller Anblick. Wir mußten große Särge bestellen, wie für Leute, die' gerade erst gestorben sind. Aber nicht genug damit, die ganze Gegend bekam Wind daivon. Ein paar Tage darauf hat ein Bauer ein Lied darïber gemacht.'

'Ein Lied?'

'Ja, ein Lied. Ich hab mir den Text aufgeschrieben, er liegt oben in meinem Zimrner. die Grundidee des Liedes war etwa so: Nicht einmal die Erde will die Leichen der Fei nde aufnehmen, die uns angegriffen haben, oder so ähnlich. Die Albaner scheinen das wirklich zu glauben. Denn von Chemie verstehen sie nichts'" (S.290-291).

Diese Beispiele verdeutlichen:

- eine Vorliebe für Anspielungen auf bekannte Mythologeme. Sie können "intemationaler" (b,d,e), altgriechischer (c) oder albanischer (a) Herkunft sein. Gjergj Elez Alia ist eine Zentralfigur des nordalbanischen Heldenzyklus, der als Gegenstuick zu den mythischen Ungeheuem des Meeres wirkt.

Charon steht in einer Reihe mythischer Figuren aus dem alten Griechenland, die Kadare immer gern in seine Literatur einsetzt: das Hölzeme Pferd, Laokoon, das Delphische Orakel, der Kentaur, Hypnos u.a. gehören zu dem Kreis und dringen wiederholt sowohl in die Lyrik als auch in die Prosawerke ein. Hier würde ich ebenfalls Shakespeares legendäre Figuren aus "Macbeth" 
und "Hamlet" einreihen, Hexen, Wahrsagerinnen, Geister, die den Autor vermutlich schon als Kind tief beeindruckt haben'.

Das zweite, vierte und fünfte Beispiel zeigen einen anderen Typ mythischer Anspielungen; diese stammen weniger aus klassischen oder sonstigen Stoffen, sondem vielmehr aus einer überlieferten Mythologie. Das Ungeheuer, das Vertreiben böser Geister oder der ablehnende Schoß der Erde sind bei vielleicht allen Völkem bekannte Mythologeme.

- Das Ungeheuer ("përbindëshi": formlos, unbestimmt wie im zweiten Beispiel) erscheint in fast jedem Werk von Kadare ${ }^{2}$ als Teil der Metaphorik, aber auch als Hauptdarsteller - in Form des Hölzernen Pferdes - in seiner frühgeschriebenen Novelle "Përbindëshi" (1965).

- Im letzten Beispiel treffen wir eine für Kadare typische Anwendung der Mythologie: einerseits beruht das mythische Symbol auf dem tief verwurzelten Glauben, daß "die Erde gebiert, um in ihren Schoß wieder zurückzuholen", andererseits bildet der Schriftsteller einen krassen Gegensatz zu diesem Glauben, indem er die Unwissenheit der Albaner in Sachen Chemie sachlich erörtert. Diese Neigung, die ich "Verzerrung des myrhischen Bildes" nennen möchte, ist besonders in seinen auf mythischen Motiven basierenden Werken anzutreffen.

\subsection{Das Osmanische Reich, ein Modell des totalitären Superstaates}

Das Dekret des Sultans ist bereits auf dem Weg.

Auf dem langen Weg nach Albanien, Allah.

Der Halbmond leuchtet über die Straßen.

Kaum sind die Siegel angekommen,

Da gerinnt aus ihnen Blut.

Allah, das Dekret des Sultans kommt.

(I. Kadare, "Das Eintreffen des Dekrets")

Wenn auch die Werke von Kadare, die diesem Themenkreis zuzuordnen sind, in der Zeit der Zugehörigkeit Albaniens zum osmanischen Reich spielen, lassen sie sich doch nicht einfach unter die Bezeichnung "Albanien und das Osmanische Reich" einordnen. Es gibt typologisch zwei polare Arten, die Geschichte

ISiehe "Chronik in Stein".

2Hier ein Beispiel aus dem Roman "Die Festung": "Das Geschrei und der Lärm der Schlacht verwandelten sich jetzt in einen dumpfen und leisen Wirrwarr, der dem Flüstem von Giganten glich. Es schien als würde sich ein tausendfüßiges Untier langsam und unaufhörlich auf dem Boden kratzen" ("Kështjella", Tiranë, 1971, S.62, m.Ü.), usw. 
literarisch zu verarbeiten: sie entweder so weit wie möglich zu respekttieren oder von ihr nur den AnstoB für einen freien Spielraum der Fiktion zu nehmen. In dieser groben Einteilung, wobei es zwischen den beiden Extremen gewiß hunderte andere Möglichkeiten der freieren oder der weniger fireien Gestaltung der Geschichte gibt, bewegt sich Kadare eher in die ziweite Richtung. Das geht auch aus einem einfachen Vergleich seiner "historiscihen" Prosa mit Werken anderer Autoren hervor, die ebenfalls die Zeit der türkischen Herrschaft auf dem Balkan in den Mittelpunkt stellen, so auch mit Andrićs "Die Brücke über die Drina" oder Kazantzakis' "Freiheit oder Tod". In diesen beiden Romanen ist der historische Stoff und die Berücksichti!gung der Geschichte maßgebend'. In den Werken Kadares dagegen, die hier in Frage kommen - nämlich zwei Romane: "Die großen Paschaliks"2 und "Der Angestellte der Traumbehörde", zwei Novellen: "Die Kommission der Fieierlichkeiten" und "Die Schleierkarawane", sowie einige Kurzgeschichten - ist die Geschichte eher Ausgangspunkt für eine völlig neue Konstruktion als vorgegebene Struktur für den fiktiven literarischen Stoff. Kein Wunder, daB eine solche Prosa oft Einwände provoziert, und zwar seitens jener Historiker, die darin eine Veränderung der historischen Tatsachen feststellen. Das war hin und wieder auch bei Kadare der Fall, weil in den genannten Werken unier anderem historische Tatsachen angesprochen wurden, die nicht mehr ais 200 Jahre zurücklagen, d.h. überprüfbar waren, oder Persönlichkeiten, w.e Ali Pascha Tepelena, porträtiert wurden, über die es schon Biographien gibt. Viele erkannten also nicht, daß der Autor nicht so sehr an der Geschichte ar. sich, sonderm, um der Aktualisierung willen, an der freien Gestaltung und Interpretation dieser Geschichte interessiert war.

Aktualisierung ist eigentlich eine auffallende Tendenz im Gesamtwerk von Kadare, in den genannten Texten entwirft er darüber hinaus allmählich das Modell eines Superstaates, das sich gleichzeitig auf die historischen Reicle, auf die modernen totalitären Staaten aber auch auf andere Muster ${ }^{3}$ bezieh. Der Schriftsteller bildet ein eigenes "Reich", einen bekannten und doch neuen Ort, der sich einerseits an die Geschichte anlehnt, sich aber andererseits von ihr unterscheidet. Solche Orte hat es in der Literatur immer wieder gegebin (T. Hardy, W. Faulkner usw.), sie beweisen neben der Einbildungskraft eire besondere Konsequenz des Schriftstellers, der, scheinbar unabhängig vor den zeitgenössischen Ereignissen, ein Zentralthema durch mehrmalige Variaionen desselben bereichert.

\footnotetext{
1Z.B. bleiben allgemein bekannte Tatsachen unverändert, es werden historische Daten, ahreszahlen u.a. erwähnt. Kadare vermeidet aber immer, eine genaue Zeit für die jeweiligenHandlungen anzugeben. Sogar die Jahrhunderte werden nicht genannt.

${ }^{2}$ Seit kurzem beim Residenz-Verlag in Salzburg unter dem Titel "Der Schandkasten" eschienen.

${ }^{3}$ Eine Untersuchung, die nur historisch-politische Parallelen zieht, ist ungenügend, dem psychologische Muster bleiben dabei außer acht, aber solche sind auch in diesen Werken vorhanden. Einen ähnlichen Fehler beginge eine Analyse, die 2.B. Kafkas "ProzeB" und "Schli3" nur unter dem sozialen Aspekt betrachten würde.
} 
Was die erwähnten Werke von Kadare auf einen gemeinsamen Nenner bringt, ist das Nachdenken über den gewaltigen, unübersehbaren Staat. Als repräsentativ dafür bespreche ich in der Folge die zwei Romane sowie die Erzählung "Die Schleierkarawane".

Die großen Paschaliks bringen eine zweifache Zielsetzung des Schriftstellers zum Ausdruck: die Interpretation der Geschichte Albaniens unter dem türkischen Reich sowie erweiterte Einblicke in die Struktur, Hierarchie und Tätigkeit des Schreckenstaates.

Im Zentrum der Hauptstadt des Reiches steht auch der "Schandkasten", ein wichtiges Symbol des allmächtigen Staates. Dort werden die Köpfe der großen Separatisten, aber auch der "Verräter des Staates", wie Paschas und Wesire, ausgestellt. Eine große Masse von Neugierigen, Fremde. Touristen und sonstigen betrachten auf dem Platz diese Köpfe der einst màchtigen, jetzt in Ungnade gefallenen Personen. Und der Kasten bleibt fast nie leer, mit ihm auch der Platz, wo es von dem Gerede der Leute summt. Das überall herrschende Gemunkel ist wie eine zweite Presse, die über neue Aufstände, über Aufstieg coder Fall der hohen Funktionäie u.a. berichtet.

Der Roman besteht aus zwei Ebenen, die miteinander verflochten sind: Die Niederschlagung der Rebellion von Ali Pascha, dessen und Hurschid Paschas Enthauptung (Handlung) und, in einem breiteren Rahmen, die Organisation des Superstaates (Kontext).

Handlung. Anstelle des gescheiterten und inzwischen enthaupteten Bugrahan wird der aufsteigende Hurschid Pascha den Feldzug gegen den albanischen Pascha Ali Tepelena führen. Die Aufmerksamkeit der Reichshauptstadt ist auf ihn gerichtet, dieser Feldzug soll eine Lehre fuir alle Separatisten werden.

Eine Zentralfigur des Romans ist der kaiserliche Bote Tunxh Hatai. Er überbringt die wichrigsten Fermane des Sultans und sorgt zugleich für den vorschriftsmäßigen Transport der abgeschlagenen Köpfe. Der makabre Transpon - alles, was man dafür braucht: Salz, Honig, Eis, Schnee - wird detaillier geschilder. Für Hurschid Pascha hat jetzt Tunxh Hatai zwei Fermane: der erste, öffentliche, macht die Begnadigung Ali Paschas und die Versöhnung mit ihm bekannt, der zweite, streng vertrauliche, ordnet dessen Enthauptung an. Ali Pascha gerät tatsăchlich durch diesen Versobnnungsferman in die Falle und, während man ihm das wertose Papier überreicht, wird er niedergeschossen und gekopft.

Ein Kapitel widmet der Autor der Rolle und Bedeutung dieser komplexen Figur in der Geschichte Albaniens. Der blutrünstige Pascha hatte mit 80 Jahren eine ungewöhnliche Macht errungen und eine unabhängige pragmatische Politik führen können, als der Sultan ihm den offenen Krieg erklärte. Obwohl seine Besitztümer beinahe ganz Südalbanien umfaßten, war Albanien nie ein Schlagwor seines politischen "Programms". Als er dann beim Sultan in Ungnade fiel, versuchte er durch politische Parolen - so Kadare - das Volk auf seine Seite zu ziehen, aber niemand kam inm mehr zu Hilfe. Trotz seiner Ambition "ein zweiter Skanderbeg" zu werden, blieb der alte Greise vereinsamt in seiner belagerten Festung.

Tunxh Hatai kann in der Folge den Kopf des Paschas, wie vorgesehen, nach Istanbul bringen. Der triumphierende Hurschid Pascha ist jetzt zwar Held des Tages, sein Name wird in allen Zeitungen groß geschrieben, das bedeutet aber nicht, daß er sich ruhig und sicher fühlen kann. Aus der Hauptstadt kommt eine Kommission, die die Frage des "begrabenen Schatzes"l von Ali Pascha klären soll. Ohne einen konkreten Grund befallen Hurschid Pascha dustere Ahnungen, bis er durch einen Brief von seinem Freund, dem

${ }^{1} B$ is hin in unsem Jahrhunder ist das Gerücht gegangen. da $B$ irgendwo in der Festung von loann:na Ali Paschas Schatz vergraben worden sei. 
Minister Gizer, erfähr, daß der kaiserliche Bote wieder unterwegs ist, diesmal mit einem Ferman für seinen Kopf. Kurz darauf bringt sich Hurschid Pascha um und wird laut Testament tief in der Erde begraben. Nicht tief genug aber für den wütenden Tunxh Hatai, der die Leiche fünf Tage nachher ausgräbt, sie köpft und rasch in die Hauptstadt fährt. Nach anfänglichem Zögern nimmt die dafür zuständige Kommission den Kopf an und präparier ihn für die Präsentation im Schandkasten.

Kontext: "Die Mechanismen des Staates ähneln riesigen Rädem, die... aus den achthunderjährigen Grundimauem schwarzes Wasser hinausschütten."l Solche Überlegungen macht der niedrige Angestellte Abdullah, der Überwacher des Schandkastens. Tief ist der Kluft zwischen inm und den mächtigen dieser Welt: "der Staat entzückte und erschreckte ihn gleichzeitig" (S.197). Aber auch die hohen Funktionäre führen kein sorgenfreies und gesichertes Leben. In dem verbitterten Kampf um die Macht schweben sie dauernd in Gefahr, die Gunst des Herrschers eines Tages zu verieren. "Abdullah hatte gemerkt, daß je glänzender und schöner ihre mit goldener Stickerei geschmückten Kragen waren - was vom Rang ihrer Träger in der Staatshierarchie abhing - desto beharrlicher tendierte der Kopf, sich vom Leibe abzutrennen." (S.140). Hurshid Pascha, Abdullah, u.a. verkörpern die metaphysische Angst vor der Unberechenbarkeit der zentralen Macht.

Zwischen den Unterdrückten, zu denen die Rajas, die niedrigen Angestellten u.a. gehören, und den hohen Funktionären stehen die mituleren Funktionäre, die allmächtige Bürokratie des Staates. "Tunxh Hatai gehörte jener Unzahl von Angestellten an, die, obwohl sie keine prominente Stellung in der Hierarchie des Staates bekleideten, unantastbar und ewig wie die Săulen der Regienungsgebäude waren. Die 'schrecklichen, mirtleren Funktionäre', so hatte sie einmal der Minister Gizer bezeichnet" (S.264).

Eine andere Dimension des Superstaates stellen die Unterdrückung und die Entnationalisierung der vielen im Reich lebenden Völker dar. Das ist eine gewaltige Maschinerie. die nach sehr alten Doktrinen arbeitet. Sie beruht auf Institutionen wie:

Sheh-UI-Islam: Das Innenministerium, mit seiner gefürchteten Ersten Direktion, die Streitereien und Zwiespait in den "unmöglichen" Gebieten hervorrufen soll;

Das Zentral-Archiv. Seine Aufgabe ist die Voll-oder Teilassimilienung der Volker, die durch fünf Phasen geht: 1. physische Vernichtung der Rebellion, 2. Austottung der Idee des Widerstandes, 3. Ausrottung der nationalen Kultur, Kunst und Bräuche, 4. Ausrottung oder Verstümmelung der nationalen Sprache, 5. Auslöschung oder Schwächung des nationalen Gedächtnisses, etc.

In vielen Details beschreibt der Autor den langwierigen Prozeß der Entnationalisierung. Die Hauptdoktrin hier heißt Kra-kra und erinnert somit an das Krächzen der Raben. So ähnlich klingt die Sprache jener Volker, bei denen der Prozeß sich vollzogen hat. Die Menschen haben kein Gedächtnis mehr, "...die Untertanen vergaßen die Daten, die Jahre, vergaßen alles, bis für sie eine Zeit kam, wo die Steuerabgabe an den Staat zu einem physiologischen Bedürnis wurde... Ihre Sprache fing allmählich an, unbeholfen wie ein Stottern zu werden. Eine solche Sprache war praktisch ungefährlich, weil sie, ähnlich der Frau, bei der die Gebärmutter operien ist, keine Lieder, Geschichten, Legenden mehr hervorbringen kann." (S.273, 253).

Lieder, Geschichten, Legenden sind für Kadare eine ebenso bedeutende Wirklichkeit wie historische und politische Ereignisse. In dem anderen Roman Der Angestellte der Traumbehörde ${ }^{2}$ wird nun auch Träumen diese gleiche Bedeutung beigemessen.

1 "Ura me tri harqe", Tiranë 1978, S 196, e. Ü.

2 Wortwörtlich übersetzt: "Der Angestellte des Traumpalastes". 
Die Traumbehörde ist eine der einfluBreichsten Institutionen des Staates. War die Geschichte in "Die großen Paschaliks" immerhin ein Hintergrund für die Handlung, so dient sie in diesem Roman höchstens dem Kolorit des Erzählten.

Handlung. Ebu Qerim ist ein junger Mann, der Karriere im Dienst des Staates machen will. Dies ist zumindest der Wunsch, bzw. der Druck seiner Familie, denn Ebu Qerim gehörn den Köprülüs an, jener bekannten Familie albanischer Herkunft, die dem Osmanischen Reich u.a. fünf Großwesire gegeben hat (das ist eigentlich eine historische Tatsache). Dem Vorschlag des mächtigen Onkels Ebu Qerims, des Reichsaußenministers, folgend, entscheidet sich die Familie für die Traumbehörde. Ebu Qerim beginnt die Arbeit als bescheidener Angestellter in der Abteilung für die Traumauslese, nimmt :edoch in relativ kurzer Zeit einen kometenhaften Aufstieg in der Hierarchie des Palastes. Nach der Auslese-Abteilung kommt er in die der Traumdeutung, und kurz danach wird Ebu Qerim in die Großtraum-Abteilung versetzt. Dennoch verläuft diese Karriere keineswegs gelassen: mit jeder neuen Stufe, die Ebu Qerim emporsteigt, wachsen zugleich seine Bedrükkung und die Angst vor dem Unbekannten. Denn die eigentlichen Gesetze der Traumbehörde und, in einem breiteren Rahmen, die der osmanischen Verwaltung sind das Unberechenbare und das Rätselhafte. Das bekommt Ebu Qerim ofters zu spüren, z.B. als die Familie Köprülü einen schweren Schlag hinnehmen muß. Ebu Qerims jüngerer Onkel, Kur Köprülü, der Bruder des Außenministers, lädt in die Hauptstadt Rhapsoden aus Albanien ein. da er das albanische Epos als einen wichtigen Träger der nationalen Kultur betrachtet; er will, daß die ganze Familie den Rhapsoden beim Singen zuhört, in der Absicht, vernachlässigte patriotische Gefühle in den Anwesenden zu wecken. Das Haus des Außenministers, wo die Auffuhrung stattfindet, wird aber umstellt, Soldaten dringen ein, schlachten die Rhapsoden und nehmen Kurt Köprülü fest Später wird er hingerichtet. Gerade zu diesem Zeitpunkt, als die Köprülüs dem totalen Sturz scheinbar nahe stehen, als Ebu Qerim die schlimmsten Konsequenzen für sich selbst erwartet, wird er in die höchsten Gremien der Behörde beförder. War das ein Gegenschlag der Köprülüs? Wo hat sich der Machtkampf abgespielt? Nie gelingt es Ebu Qerim zu verstehen, was an diesen Tagen wirklich vor sich ging, wie der Machtmechanismus überhaupt funktioniert.

Eines Tages emennt man ihn zum ersten Mann der Behörde. Jetzt zittern sogar Minister vor ihm. "Mochten sie im täglichen Leben auch einflußreich und respektiert sein, so war das doch nicht ausreichend. Denn es war ebenfalls wichtig, was sie in den Träumen der anderen waren, was für unbegreifliche Zeichen ihre mysteriösen Kutschen darin begleiteten... Mitten im höflichen Lächeln steckte in ihren Augen immer die gleiche Frage an Ebu Qerim: 'Gibt es einen Traur für uns?"'1.

Trotzalledem steigen in Ebu Qerim düstere Ahnungen auf, daß irgendwo eine Gefahr auf ihn lauert. Er hat eine sensible Natur, er kann sich in dem harten Machtkampf nur schwer einleben, undurchschaubare Kräfte lenken sein Schicksal. Der angesehene Leiter der Traumbehörde denkı paradoxerweise bereits an seinen Tod. Als er von seiner Kutsche aus an einem Mandelbaum bemerkt, daß der Frihling schon lange gekommen sei, geht es Ebu Qerim durch den Kopf: "Da würde er schon jetzt einen blühenden Mandelbaumzweig für seinen Grab bestellen" (S.440). So klingt der Roman aus. aus:

Die Organisation der Traumbehörde, soweit Ebu Qerim über sie erfahr, sieht wie folgt

\section{REZEPTION}

Annahme der Träume über tausende von ZWEIGSTELLEN, die sich über das ganze Reich ausdehnen.

\section{ABTEILUNG FÜR DIE TRAUMAUSLESE}

l"Emblema e dikurshme", zweite Ausgabe, Tiranë 1981, S.435. e.Ü. 
Sämtliche Träume müssen hier selektioniert werden. Die Kriterien, die das Weiterleiten zur Deutungsabteilung bestimmen, sind hauptsächllich zwei: (a) Die Träume sollen echt sein, d.h. nicht erfunden, und (b) sie sollen irgendwie Angelegenheiten des Staates betreffen. Träume, die von privaten Ursachen wie z.B. Hunger, Mangel an Frauen usw. veranlaßt sind, scheiden aus.

\section{ABTEILUNG FÜR DIE TRAUMDEUTUNG}

Die selektionierten Trăume waren hier auf die einschlägigen Deutungen. Eine äußerst schwierige Arbeit, wobei Deutungsmuster von früheren Meistern jedoch helfen können. Diese sind im ZENTRALARCHIV zu finden. Hier bewahr man alle seit den Anfängen des Reiches interpretierten Träume auf.

\section{GROSSTRAUM - ABTEILUNG}

Aus den gedeuteten Träumen wählt man hier den Großtraum aus, der jeden Freitag dem Sultan übergeben werden muß. Der Sultan kann im schlimmsten Fall den Großtraum zurïckweisen.

\section{DIREKTION}

Außerdem gibt es VERHÖRRÄUME, wo der Absender eines Traums, der dem Staat große Sorgen bereitet hat, "gründlich" verhört wird.

Hunderte von Angestellten arbeiten in dieser Behörde; schweigsam und fleißig zerbrechen sie sich über undurchdringliche Träume stundenlang den Kopf (sogar eine Tiefenpsyschologie wäre an der Aufgabe gescheitert, einfach weil man nichts Weiteres als den Namen und den Beruf des Traumabsenders weiß.) Die labyrinthischen Gänge des Palastes sind fast immer leer, nur für eine halbe Stunde werden sie belebt, wenn die Angestellten während der Kaffeepause ins Kellerbüffet einströmen. Ebu Qerim bemerkt hin und wieder auch Soldaten oder Menschen, die einen Sarg aus den Verhöräumen wegtragen. Es herrscht eine gedruickte Stimmung, vielleicht auch deswegen, weil jeder mehr oder weniger in Gefahr schwebt, z.B. falls er einen Traum übereilig ausgeschieden, einen anderen Traum falsch oder zu kühn gedeutet hat usw. Als der Souverän einmal einen Großtraum zurückwies, kurz nach dem Schlag gegen die Köprülüs, da wurde die Hälfte der Angestellten der Großtraum-Abteilung verhaftet.

Warum mißt der Staat Träumen eine so große Bedeutung bei? Bevor Ebu Qerim die Arbeit anfängt, gibt ihm ein hoher Funktionär der Behörde folgende Erklärung dazu:

"Zum ersten Mal in der Weltgeschichte hat unser Staat die Traumdeutung auf eine hohe Stufe gestellt, indem er sie bürokratisier hat... Diese Traumbehörde hat sich zur Aufgabe gestelli, die Träume aller Staatsbürger methodisch zu ordnen und zu überprüfen... Gott wirft den ermahnenden Traum so unbefangen auf die Erde wie er seine Blitze einschlagen lässt... Und es kommt uns zu, diesen Traum auffindbar zu machen, ihn unter Millionen und Milliarden anderer Träume zu entdecken, ähnlich dem Mann. der eine Perle mitten in der Sandwüste findet... Solch ein Traum kann das Unglück des Staates oder des Souveräns verhüten, er kann Kriege und Katastrophen vermeiden, neue Ideen entfalten lassen. Darum ist die Traumbehörde eine der Stützen des Staates." (S.280-281) 
Die äußere Organisation und das Funktionieren der Traumbehörde scheinen in ihrer, wenn auch seltsamen Logik, einigermaßen erfaßbar zu sein. Das eigentliche Rätsel beginnt aber mit den Träumen selbst. Sie sind keine einfachen, mit dem Alltag in Zusammenhang stehenden, sondern höchst verworrene Träume und Delirien, wie etwa der Traum, der das Unglück von Kurt Köprülü "hervorrief". Er wurde von einem ganz unbedeutenden Gemüseverkäufer eingereicht: "Ein verlassener Platz bei einer Brücke, ähnlich einer Müllkippe. Unter den Abfällen befindet sich auch ein altes, unbekanntes Musikinstrument, das selbst tönt. Bei dem Brückenpfeiler schnaubt ein Stier wütend, scheinbar wegen des Klanges des Instruments." Dieser verhängnisvolle Traum wurde folgendermaßen gedeutet: "Die Brücke = Köprülï (von Köprü - Brücke); das Instrument = albanisches Epos. Das Epos spornt den Stier an, den Staat zu überfallen."

Glaubt man wirklich an solche Deutungen? Werden sie von den Machthabern emst genommen? Oder ist es möglich, daß die Deutungen der Großträurne willkürlich von der Obrigkeit verfaßt werden und daher eine ganze Bürokratie umsonst arbeitet?

Obwohl der Autor diese letzte Möglichkeit mittelbar andeutet, wird der Leser in Roman keine fertige Antworten bekommen. Er kann hier vor allem spüren, und zu spüren sind die Angst, das Geheimnis, die Willkür, die dem Schreckenstaat innewohnen. In diesem Sinne spiegelt dieser Roman mehr als jedes andere Werk von Kadare die düstere politische Atmosphäre Albaniens in den 70er Jahren wider.

Die Moral-Politik des Reiches zeichnet sich als ein ergänzender Aspekt des Gesamtbildes in der Erzählung Die Schleierkarawanel ab. Die Zentralmacht kümmert sich nicht nur um die vollständige politische Herrschaft über die Völker und Nationen des Reiches, sondem auch um das Privatleben, bzw. die Moral seiner Bürger. Diese Moral muß der staatlichen Religion, dem Islam entsprechen. Eines der wichtigsten Gebote des Islams fordert, daß alle Frauen in der Offentlichkeit ihr Gesicht verschleiem müssen.

Einem großangelegten Erlass dès Sultans zufolge müssen alle "mohammedanischen" Frauen und Mädchen ab dem 13. Lebensjahr einen schwarzen Schleier, das Ferexha, über ihr Gesicht tragen, wann immer sie das Haus verlassen.

Die erste Karawane mit einer halben Million dieser Schleier führt Haxhi Milet, ein niedriger Angestellter des Reiches, an. Er möchte seine Pflicht im Dienst des Staates wie immer tadellos und mit gutem Gewissen erfüllen; diesmal aber wird er unruhig und nachdenklich, sobald er die Halbinsel betritt und zum ersten Mal in seinem Leben unverschleierte Frauen im freien Licht ansieht. Der Schock, den er bei einem Brunnen erlebt, wo mehrere Frauen mit bloßen Kopfen ihn anlächeln, ist einfach zu groß: "'Allah', murnelte er, 'es gibt Tage mit Sonnenlicht und Nächte mit Mondschein, es gibt aber auch etwas anderes: Tage mit Frauenaugen."'2 Bald folgt die Erleichterung, wenn er an die Richtigkeit der Sultans- und Staatsentscheidungen denkt, bald kommt wieder die Unruhe, das schlechte. fast verbrecherische Gewissen. "Welchen Teil des Himmels würden die Ferexhas seiner Karawane bedecken, wenn man sie zusammennähen würde?" phantasier er unwillkürlich, und dann kommt ihm vor, als ob er "eine schwere, schwarze Decke hinter sich ziehen, Wiesen und Seen damit umhüllen, und die Welt hinterher ihn wie den Teufel verfluchen würde" (S.133).

\footnotetext{
lUnter diesem Titel im Verlag "Volk und Welt", Berlin 1988, erschienen. Titel des Originals "Sjellësi i fatkeqëisisë": "Der Unglücksbringer".

2"Koha e shkrimeve", Tiranë 1986, S.135, m.Ü.
} 
Allerdings erfüllt Haxhi Milet seine Aufgabe, indem er den Balkan durchquert und die Bündel mit Ferexhas in den wichtigsten Städten Albaniens, Bosniens, Rumäniens usw. abliefert. Bei der Rückkehr wird ihm noch trauriger zumute, als er merkt, daß die Frauen auf den Straßen der Großstädte selten geworden sind, ebenfalls auf dem Lande: bei dem Brunnen, wo er einmal so schockier-glücklich gewesen war, weilt jetzt keine Menschertseele mehr. "Verschleiere die Sonne und den Mond, du großer Souverän, aber nicht die Frauen', flüsterte er." Und dann: "'Verdammtes Dekret', sagte er plötzlich. Es war das erste $\mathrm{Mal}$ in seinem Leben, daß er über ein Dekret schimpfte." (S.152)

In einem Chan, wo alle Dienstreisenden vor ihrer Einreise auf den Balkan und auf dem Weg zurück eine Nacht verbringen müssen, kann er vor lauter Verzweifelung und Weinen nicht mehr schlafen. Am Morgen wird er verhaftet, nachher monatelang gefoltert und verhorr. Man will wissen, warum er geweint hat, was er "dort unten getrieben hat", usw. Eines Tages wird Haxhi Milet in seiner Zelle tot aufgefunden, mit einem schwarzen Tuch erwürgt.

Zu gleicher Zeit verkündet Sheh-Ul-Islam, der Innenminister, dem Sultan feierlich, daß "alle Frauen und Mädchen des größten Reiches der Welt jetzt mit Ferexhas bedeckt sind".

Mit der Erzählung "Die Schleierkarawane", die übrigens den Untertitel Die islamische Nacht trägt, bringt Kadare noch einmal seine Überzeugung zum Ausdruck, daß die Zeit der osmanischen Besatzung des Balkans in jeder Hinsicht, auch in moralischer, eine Fehlentwicklung war, bzw. Rückständigkeit im Leben der Balkanvölker bedeutete. Wenn man die Erzählung vom historischen Kontext absondem will, dann stellt sie eine mehrdeutige Allegorie dar, vor allem die des Verhältnisses zwischen dem totalitären Staat und dem kleinen Mann, der, indem er seine "Pflicht" erfüllt, ein Teil des verbrecherischen Mechanismus wird: wenn er einmal zum Bewußtsein des Verbrechens kommt und sich innerlich auflehnt, dann steht er hilflos und mit der Aussicht auf schlimme Folgen da.

\subsection{Im Spiegel der Erinnerungen}

Die Finger meiner Kindheit mit Tinte beschmiert,

Am Morgen die Glocken,

Am Abend der Muezzin.

SammlungenvonZigarettenschachteln und von alten Briefmarken.

Man tauschte eine "Ceylon"

Gegen zwei "Luxemburg".

So verging sie,

Die Zeit meiner Kindheit.

Staub wirbelnd und schreiend lief sie einem Ball nach

EinemFetzenball,

Aus den ergrauten Fetzen Albaniens gebastelt.

(I. Kadare, "Die Kindheit") 
Da Kadare lange Zeit als Journalist tätig war und im Laufe der Jahrzehnte viel Publizistik, insbesondere Reiseberichten geschrieben hat, pendelt sein biographiebezogenes Schaffen zwischen der autobiographischen Fiktion und der Publizistik. Neben eine Reihe von Reportagen, Reiseberichten, Skizzen gehören hierher Kurzgeschichten und Erzählungen, wie etwa "Europa der Könige", "Der winterliche Zug", u.a.. Was hier aber am meisten interessiert, um das Porträt des Schriftstellers weiter zu ergänzen und seine originellen stilistischen Verfahren im ständigen Wechselspiel zwischen Realität und Fiktion, Geschichte und Fiktion, Mythologie und Fiktion zu unterstreichen, ist der Roman "Chronik in Stein", der, zusammen mit der "Dämmerung der Steppengötter", als einziger in seinem Werk in der Ich-Form geschrieben ist und eindeutige autobiographische Züge aufweist. Es folgt eine kurze Betrachtung dieses Romans, der einen Höhepunkt im Werk Kadares darstellt.

Chronik in Stein ist die Chronik der steinemen Heimatstadt des Autors, Gjirokastra', in der Zeit des Zweiten Weltkrieges, eine Chronik, die in der phantastischen.Welt des Kindes wahrgenommen wurde und die viel später der bewußte, sehnsüchtig-rückblickende Schriftsteller verarbeitete. Der Blick, bzw. die Position des Chronisten ist originell und eigenwillig, ähnliche Beispiele sind in der Literatur nur selten ${ }^{2}$. Man glaubt, im Buch spreche ein Kind, das seine Welt und Umwelt in einer drolligen Logik erzähle, doch steht hinter ihm der reife Chronist, dem es durch diesen verzerrenden und verfremdenden Blick gelingt, eine wahre Chronik seiner Stadt festzuhalten. Solche Technik schafft der wilden Phantasie, den lyrischen Stimmen, dem Humor usw. viel freien Raum, ohne den realen Hintergrund der Ereignisse zu verstellen.

Der Roman hat keine eigentliche Handlung, er respektiert nur eine zeitliche Folge, die mit der Besatzung der Stadt während des italienisch-griechischen Krieges anfängt und gegen Ende des Krieges ausklingt, als die Stadt noch von den deutschen Truppen besetzt ist. Anstatt der fehlenden Handlung gibt es jedoch eine Fülle von Episoden: grausame, groteske, heitere, schmerzvolle, die die innere Welt des Kindes und sein Wachsen in der vom Krieg erschütterten Stadt aneinanderreiht und zusammenhält. Die Hauptpersonen dieses Mosaiks sind bizarre Figuren der seltsamen Stadt: alte Frauen, die dauernd Kaffee trinken, durch ein Fernglas auf die Stadt draußen blicken und alle möglichen Ereignisse

${ }^{1}$ In Südalbanien; die Stadt befindet sich auf dem Hang eines Berges; überall herrscht der Stein, sogar die Dächer sind mit großen steinernen Platten bedeckt. "Es war dies eine steile Stadt, vielleicht die steilste auf der ganzen Welt... Weil sie derar steil war, konnte es vorkommen, daß sich die Fundamente des einen Hauses auf der Höhe des Daches eines anderen befanden, und gewiß war dies der einzige Ont auf der Welt, wo jemand, der am Straßenrande ausglitt, nicht in den Graben stürzte, sondem womöglich auf das Dach eines hohen Hauses" ("Chronik in Stein", S.5-6).

2"Als ich anfing. die Chronik dieser Stadt zu schreiben, machte ich mir keine Sorgen, daß ich durch diesen Roman über Kindheitserinnerungen mit Hunderten von Schriftstellern dieser Welt, die das gleiche getan hatten, in Wettbewerb trat." (I. Kadare in einem Interview; siehe "Vepra letrare", Bd.11, Tiranë 1981, S.325, e.Ü.). 
auf ihre eigene, zugleich unwissende und weise Art kommentieren ${ }^{1}$; ein "Flugzeugkonstrukteur", der, um das schwere Bombardement der Stadt zu verhindern, ein Flugzeug aus Holz, Typ "perpetuum mobile", bastelt; ein pensioniener Artillerist, der, von den Stadtbewohnern gedrängt, mit einer alten Kanone auf die fremden Flugzeuge schießt; ein Lehrer, der in seinem Unterricht immer wieder Katzen schlachtet; ein mit dem Gefängnis so sehr vertrauter Landstreicher, daß er über die offenen Tore des Gefängnisses zur Zeit des Machtwechsels grübelt und schimpft; Resistance-Teilnehmer, Kollaborateure, fremde Soldaten, usw. Eine ganze Stadt tritt im Roman mittels ihrer bunten Gestalten durch die metaphorische Sprache des Autors aber auch selbst als Person auf. Solche Metaphern, die die verschiedensten "Stimmungen" der Stadt wiedergeben, sind durchaus hăufig: "Die Stadt wand sich in Krämpfen, drohte zu stürzen... Sie starte hinauf zum weiten Himmel, der sich für seine Neutralităt zu entschuldigen schien." "Die Stadt gab sich den kleinen, unbedeutenden Ereignissen hin."; "Nach der Niederlage des Vortags lag die Stadt betreten da, die tropfenden Dächer und Giebel geduckt.": "Da es für die Stadt so schwierig war, in ihren steinernen Gliedern und unter ihrer steinernen Schale menschliches Leben zu bewahren, fügte sie diesem oft ungewollt Schmerzen zu, Kratzer und Wunden, und das war doch nur natürlich, denn es war dies eine Stadt aus Stein, und jede ihrer Berührungen war hart und kalt"2, usw.

Die bildreiche Sprache, die aus dem Stein ein lebendiges Wesen macht, rundet die einzelnen Episoden zu einem Gesamtbild ab: das Bild zeigt eine uralte Gemeinschaft in einem Zeitpunkt großer Umwălzungen, als die ständig wechselnden Besatzungsmächte und ihre Verwüstungen fast dabei sind, sie aus der Fassung zu bringen, und als die neue kommunistische Ordnung vor der Tür steht. In diesen Wirren weiß aber die Stadt, ihre souveräne Haltung zu bewahren und "unter dem festen Panzer das weiche Fleisch des Lebens" dauernd zu erneuern. Das ist eine der wichtigsten Mitteilungen dieses Romans, durch den sich das Motiv "Widerstand" wieder unverkennbar zieht.

Der Roman lebt weniger in einer Gesamthandlung als in den mosaikartigen Episoden und in seiner Sprache, deswegen ist es äußerst schwierig und auch wenig sinnvoll, eine "Inhaltsangabe" davon zu geben. Alle Ereignisse verzerrt und vermittelt diese Sprache, manchmal kann ihre Kraft das Kind, bzw. den Autor tyrannisieren, wie das folgende Beispiel zeigt:

"Ein kalter, trockener Wind wehte beständig von den Schluchten des Nordens her. Liegend vernahm ich sein Seufzen und grundlos fiel mir der Satz wieder ein "Worte sind flüchtig wie der Wind", den ich am Morgen gehör hatte. In letzer Zeit ging etwas Merkwürdiges mit mir vor. Worte und Wendungen, die ich hundertmal gehört hatte, erklangen nun plötzlich in einem neuen Sinn. Worte begannen sich unversehens von ihrer alltäglichen Bedeutung zu befreien. Wendungen, die aus zwei oder drei Wörtern bestanden, fingen auf ganz quälende Weise an, sich in ihre Bestandteile aufzulösen. Hörte ich jemanden sagen:"Mir brodelt der Kopf", so setzte sich in meinem Him unwillkürlich das Bild eines Kopfes fest, in dem es wie in einem Topf voll Bohnen brodelt. In ihrem normalen, erstarten Zustand besaßen die Wore eine ganz bestimmte Energie. Nun, da sie zu zerfallen, sich aufzulösen begannen, setzten sie eine erschreckende Dynamik frei. Ich fürchtete mich vor ihrer Auflösung. Mit allen Mitteln versuchte ich, sie zu verhindern, doch es ge-

${ }^{1}$ Der Autor schreibt später: "Ich empfand es als glücklichen Umstand, die erste Kommentare über die Welt aus dem Mund jener klugen, schwarzgekleideten Frauen vernommen zu haben... Mir wurde immer klarer, daß diese Gespräche nicht nur das eine waren: Unterrichtung über den Lauf der Welt. Für mich, der ich mich später mit dem Metier des Schreibens befaßte, waren sie... dieser alte, ewige Chor... vor allem Dingen Kunst. Verallgemeinerung, Stil"(ebenda, S.324-25).

$2 \mathrm{Zu}$ beobachten noch einmal das mythische, unbestimmte Wesen des Ungeheuers. 
lang nicht. In meinem Kopf entstand ein wahres Chaos, in dem sich die Worte jenseits von Logik und Realität in einem grausigen Tanze drehten. Aussprüche wie "Ich freB' meinen Kopf, wenn nicht..." machten mir übel zu schaffen. Die Qual, mir vorzustellen, wie jemand seinen eigenen Kopf in den Händen hält und verschlingt, wurde noch gesteigert durch die Schwierigkeit zu begreifen, wie jemand seinen eigenen Kopf aufessen kann, wo doch jeder weiß, daß man zum Essen Zähne braucht und daß diese Zähne sich in dem bestraften Haupt selbst finden.

Die Sprache des Alltags, die sich bisher als so ruhig und zuverlässig erwiesen hatte, war plötzlich wie durch ein Erdbeben ins Wanken geraten. Alles zerfiel, zerbrach, zerbröckelte. Ich hatte mich in das Königreich der Wörter verimt. Dort herrschte eine erbarmungslose Tyrannei. Die Welt füllte sich auf einmal mit Menschen, die Birnen anstelle von Köpfen hatten, deren Köpfe ganz verdreht waren, die ihren Augen auf etwas warfen; manchen war das Blut eiskalt in den Adern erstarr, etliche liefen mit verdorrter Zunge herum...; hier gingen einige entwurzelt umher, dort stellte man sich ganz närrisch sinnlose Fragen, etwa, wo man denn seine Augen oder Ohren habe; manch einer versuchte, jemanden nicht mittels der Zähne, sondern mit den Augen zu verschlingen..." usw., (S. 8385).

Die Mythologie und die Legenden leisten der Metaphorik wiederum ihren Beistand, indem sie, mit ihren irrealen Dimensionen in die reale Umwelt projiziert werden und gleichen Stellenwert haben wie sonstige Tatsachen. Aus dem Fenster seines Hauses betrachtet das Kind Kreuzritter, die nach dem Süden ziehen, kurz darauf folgt ihnen ein hinkender Dichter", der "nicht das Grab Christi, sondern sein eigenes suchte"; ein blinder Bettler, der Liedermacher der Stadt, ist für das Kind Homer; ein Nachbar, der in einem schloßartigen Haus wohnt, kommt ihm wie Macbeth vor, und es erwartet, daß ein anderer Bürger (Duncan), der ins "Schloß" zu Besuch gegangen ist, ermordet wird: es sieht tatsächlich Macbeths Frau, wie sie das Blut von ihren Händen abwischt. Ein anderer Nachbar bringt täglich, wenn er vom Markt nach Hause kommt, ein Brot oder einen Kohlkopf mit; für das Kind hat er allerdings immer einen Kopf unter dem Arm. Das Kind hat Türkengeschichten über die einstigen Enthauptungen gehört, sie haben es erschreckt, zugleich aber verzaubert, und jetzt erlebt es diese Geschichten in der Realität. Wie eine Zusammenfassung des späteren Romans "Die großen Fürstentümer" steht in der "Chronik in Stein" das Gespräch zweier alten Leute, dem das Kind entsetzt zuhorcht. Die Enthauptung der Wesire, Paschas, die Ausstellung der Köpfe im Schandkasten usw. ist offensichtlich ein Motiv, das den Autor schon in seiner Kindheit beeindruckt hat; auch deswegen wurde vorher auf mögliche psychologische Muster hingewiesen.

\footnotetext{
1Byron. Während seiner Besuche bei Ali Pascha Tepelena hatte der Dichter seinerzeit diese Gegenden in Südalbanien durchquert.
} 
Mythologie in der Struktur des Werkes

Ihr seht, wic die Schlangen mich erwürgen,
In den Museen von Louvre, Madrid, New York,
Seit hunderte Jahren quälen mich eure Augen,
eure Touristenkameras,
Ich leide, weil ich nicht sprechen kann.

Wie könnte ich sprechen? Wie kann

Ein Kiefer aus Marmor etwas artikulieren?

Ihr müBt meine Augen genau betrachten:

In den Löchem liegt ein Rätsel,

Wie eine ausgetrocknete Amöbe.

(I.Kadare "Laokoon")

\section{6. "Wer hat Doruntina zuruckgebracht"}

Die Ballade vom toten Bruder, der, um sein gegebenes Wort - die besa - zu halten, vom Grab aufsteht und seiner Mutter die einzige, fern verheiratete Tochter, Doruntina, zurückbringt, ist auch außerhalb Albaniens und des Balkans bekannt; in anderer Form und Handlung hat es sie in vielen Gebieten Mittel- und Nordeuropas gegeben. Im deutschsprachigen Raum waren volkstümliche Bailaden verbreitet, in denen es um die Auferstehung des geliebten, im Krieg verstorbenen Mannes geht, der seine Braut wieder trifft und sie nach einem gespenstischen Ritt mit in den Tod nimmt. Gottfried August Bürger holte Anregung von einer plattdeutsche Variante der Ballade, um die erste Kunstballade der deutschen Literatur, seine berühmte "Lenore", zu schreiben. Bewegende Kraft dieser rührenden Geschichte über Tod und Auferstehung ist in den Völkem Europas die tiefe Sehnsucht nach dem geliebten, nun verlorenen Menschen, ein Gefühl, das so stark sein kann, daß es sogar den Toten vom ewigen Schlaf zu erwecken vermag.

In den albanischen Varianten über Konstantin und Garentina (oder Doruntina) rückt die besa in den Mittelpunkt der Handlung; dies ist das gegebene Wort, das, im Kanun festgehalten, durch Jahrhunderte zur Organisation des albanischen Stammeslebens, ja fast zur Gesetzgebung gehörte. Konstantin war unter den neun Brüdern derjenige, der der Verlobung Doruntinas in einem fremden fernen Land zustimmte. Die Mutter gab erst nach, nachdem sie von ihm seine besa erhielt; sie verpflichtete ihn, seine Schwester Doruntina auf Verlangen der Mutter jederzeit zurückzubringen. Der Krieg verschlang alle neun Brüder; und eines Tages ging die verzweifelte Mutter in den Kirchhof 
und beim Wehklagen am Grab erinnerte sie den toten Konstantin an sein gegebenes Wort: in der Nacht stand der Tote vom Grabe auf, "der Grabstein wird ihm zum frostigen Pferd", "der Ring am Stein zum silbernen Zaum"; er zog nach dem fernen Land, wo Doruntina mit ihrem Mann lebte. Kurzerhand holte er sie auf sein Pferd, und beide ritten durch die Nacht zurück in ihre Heimat. Unweit vom Hause sagte Konstantin zu seiner Schwester, er müsse noch in der Kirche ein Gebet sprechen, und verschwand danach in seinem Grab. Als Doruntina ihrer Mutter an der Türschwelle sagte, daß Konstantin sie zurückgebracht hätte, von ihr aber erfuhr, daß Konstantin längst verstorben wäre, fielen beide Frauen einander in die Arme und waren auf der Stelle tot.

In der albanischen Überlieferung ist diese Ballade auch als "Die Ballade des gegebenen Wortes" bekannt, gerade wegen der besonderen Betonung des BesaMotivs. Die Mutter verflucht den verstorbenen Sohn und erinnert ihn so eindringlich an sein gegebenes Wort:

"Unheil möge dich befallen!

Wo ist dein gegebenes Wort?

Tief im Grab liegt es begraben",

so daß der Tote im Grab keine Ruhe mehr finden kann und in der Nacht aufersteht.

Bei Bürger bewirkt jedoch der tiefe Glaube und das inbrünstige Beten an Gott das Wunder, die Auferstehung des verlorenen Mannes:

"Hilf Gott! Hilf! Sieh uns gnädig an!

Kind, bet' ein Unser Vater!

Was Gott thut, das ist wohlgethan,

Gott, deines Heils Berater" -

"O Mutter, Mutter, eitler Wahn!

Gott hat an mir nicht wohlgethan!

was half, was half mein Beten?

Nun ist's nicht mehr von nöten!"...

"Hilf Gott! hilf! Geh' nicht ins Gericht

Mit deinem armen Kinde!

Sie weiß nicht, was die Zunge spricht;

Behalt' ihr nicht die Sünde!

Ach Kind, vergiß dein irdisch Leid

Und denk an Gott und Seligkeit.

So wird doch deiner Seelen

Der Bräutigam nicht fehlen!"...'

${ }^{1}$ G.A. Bürger, Gedichte. Leipzig und Wien 1928, S.66. 
Es ist jedoch $\mathrm{m}$. E. die Behauptung unzutreffend, daß die albanische Ballade überwiegend das Besa-Motiv zum Ausdruck bringe (siehe weiter), und daß sie dadurch den Anspruch auf ein höheres, vorchristliches Alter im Vergleich zu Varianten von Mittel- und Nordeuropa hätte!.

Die Geschichte von Konstantin und Doruntina kann auch aus einem anderen Blickwinkel erzählt werden:

"Was mir Doruntina in ihrem verworrenen Zustand mitteilen konnte, war im großen und ganzen Folgendes:

Eines Abends wurde sie in der kleinen mitteleuropäischen Stadt, in der sie mit ihrem Ehemann wohnte, benachrichtigt, daß ein unbekannter Wanderer nach ihr verlange. Als sie aus dem Hause ging, sah sie auf einem Pferd den soeben Eingetroffenen, der ihr wie Konstantin erschien, obwohl er, verstaubt vom langen Weg, kaum zu erkennen war. Als allerdings der Reiter vom Pferd zu ihr herab sagte, er sei kein anderer als Konstantin, der zu ihr gekommen sei, um sie ihrer Mutter, wie bereits vor der Hochzeit versprochen, zurückzubringen, schwanden alle ihre Zweifel. (Hier muß man schon Einiges ins Gedächtnis rufen: die damalige große Aufregung, die die Verlobung Doruntinas so weit entfernt von ihrer Heimat verursachte, die Ablehnung der übrigen Brüder, insbesondere aber der Mutter, andererseits die Entschiedenheit Konstantins, dieser Verlobung doch einzuwilligen und letztlich sein Versprechen und das gegebene Wort, die Tochter nach Hause jederzeit zurückzubringen, wann immer die Mutter sie brauche.)

Doruntinas Geständnis zufolge kam ihr das Benehmen ihres Bruders sehr merkwürdig vor: er wollte weder das Haus betreten noch vom Pferd steigen, er beharte zudem darauf, daß sie gleich mit ihm aufbrechen solle; auf ihre Fragen, wozu denn die ganze Eile sei, und ob es um etwas Gutes ginge, damit sie sich festlich anziehen, oder ob um ein Unglück, damit sie ihre Trauerkleidung anlegen könne, antwortete er ohne Umschweifung: komm so, wie du bist. All das war für sie unnatürlich und jedem guten Benehmen zuwider, aber, von der Sehnsucht dieser drei Jahre, in denen sie weit weg vom Elternhaus lebte, verzehrt, machte sie keine Umstände mehr und, nachdem sie ihrem Gatten einen Zettel hinterlieB, schwang sie sich aufs Pferd zu ihrem Bruder.

Die Reise dauerte - immer laut ihren Geständnissen - geraume Zeit, nähere Bestimmungen konnte sie jedoch nicht machen. Sie behauptete, sie vermöge sich nur an eine unendliche Nacht und an unzählige Sterne zu erinnern, die scharenweise am Himmel liefen; dieses Bild könnte allerdings vom ständigen Galoppieren und von ihrem Schlummer auf dem Pferde hervorgerufen sein. Dazu ist es noch interessant zu vermerken, daß sie sich an einen Ritt bei Tageslicht nicht erinnem könne. Diese Überzeugung dürfte von zwei Gründen herrühren: entweder hat sie während der Reise am Tag geschlafen, oder beide haben sich in der Morgendämmerung niedergelegt, um sich auszuruhen und bis zum Einbruch der Dunkelheit zu schlafen, um sich dann wieder auf den Weg zu machen. Diese Umstände haben vermutlich Doruntina dazu veranlaßt - sie war übrigens äußerst erschöpft und schockier - die zehn oder fünfzehn Tage ihrer Reise als eine einzige endlose Nacht im Ritt zu empfinden.

Während der Reise hat sie - so dicht neben dem Bruder sitzend - gut beobachten können, da $\beta$ auf seinem Haar eher Schlamm als Staub des Weges lag und daß seine Schultern nach feuchter Erde rochen: zwei- oder dreimal hat sie ihn danach gefragt, seine

\footnotetext{
1 Zef Catapano stellt z.B. fest: "Bürger hat seine Handlung offensichtlich der alten albanischen Legende entnomnien, die durch die albanischen Auswanderer schon im 15. Jahrhundert in Italien bekannt wurde. (Z. Catapano, Constantino e Garentina. Rom 1947, S.7). Auch Kadare, wenn auch humorvoll, behauptet in seinem Roman "Die Dämmerung der Steppengötter": "Bürger und Jukowskij haben die Ballade von den Balkanvölkern übernommen; sie haben sie dabei der eine noch fader als der andere bearbeitet." ("Ura me tri harqe", S.367, e.Ü.)
} 
Antworn hat aber nur gelautet, der Regen hätte ihn mehrmals auf dem Hinweg erreicht und so sei der Staub am Haar und auf dem Körper zu nassen Erdklumpen geworden.

Als am 11. Oktober, gegen Mitternacht, der Unbekannte (ein besseres Wort für jenen Mann, den die Schwester für ihren Bruder hielt, gibt es nicht) endlich in der Nähe des Hauses ihrer Mutter Halt machte, sagte er zu Doruntina, sie solle vom Pferd steigen und nach Hause gehen, denn er selbst würde sich etwas verspäten, da er im Kirchhof zu tun hätte. Ohne auf eine Antwort von ihr zu warten, ging er in die Richtung des Kirchhofes, während sie, beinahe laufend, zur Tür des Hauses eilte und anklopfte. Die alte Frau fragte hinter der Tür, wer dort so spät sei, und, als Doruntina sagte, wer sie wäre und, daß Konstantin sie zurückgebracht habe, erfuhr sie von der Mutter, daß Konstantin schon seit drei Jahren unter der Erde liege; in diesem Augenblick wurden beide Frauen von tiefer Erschütterung getroffen, die sie bis jetzt ans Bett gefesselt hat."1

Das ist der für seine Vorgesetzten verfaßte Bericht des Kapitäns Stres aus Kadares Roman "Wer hat Doruntina zurückgebracht". Stres, eine Art Polizeipräsident in einem mittelalterlichen albanischen Bezirk, hat über die mysteriösen Umstände der Rückkehr Doruntinas in ihr Elternhaus zu ermitteln. Hier sind nun im Vergleich zu diesem Text einige Ausschnitte aus einer der bekanntesten Varianten der albanischen Ballade, "Konstantini the Garentina", die bei den Albanem Süditaliens sehr verbreitet war:

"..."Konstantin, mein lieber Bruder!"

Rief Garentina, als sie ihn sah.

"Komm, Schwester, wir müssen fort,

Wir müssen uns nach Haus' beeilen".

"Erst aber sagst du, Bruder, zu mir,

$\mathrm{Ob}$ ich zur Trauer reise -

Dann lege ich die Trauerkleidung an,

Oder zur Freude -

Dann kann ich meinen Schmuck umtun".

"Komm so, wie du bist".

Und er hob sie aufs Kreuz des Pferdes,

Und sie ritten einen langen Weg,

Bruder und Schwester zusammen.

...Da fragt Garentina plötzlich:

"Konstantin, mein teurer Bruder,

Böses Zeichen sehe ich,

Warum scheint mir dein lockiges Haar

Als wäre es aus Staub und Schlamm?"

"Vom Staub des Weges siehst du

Gespenster, meine gute Schwester".

11. Kadare, "Kush e solli Doruntinën", in "Gjakftohtësia". Tiranë 1980, S.61-63. Die Übersetzungen in diesen beiden Kapitel stammen von mir. 
..Sie ritten an der Kirche vorbei:

"Schwester, in die Kirche muß ich, beten".

Garentina ging allein die Treppe hinauf

$\mathrm{Zu}$ ihrer Mutter.

"Mach mir die Tür auf, Mutter".

"Wer bist du denn?"

"Garentina bin ich, Mutter,

Sperr mir, bitte, auf".

...Und die Mutter sperrte die Tür auf.

"Wer hat dich heimgebracht, meine Tochter?"

"Konstantin war es,

Konstantin hat mich heimgebracht"

"Konstantin?!... Wo ist er jetzt?"

"Dort trennte er sich von mir

Und, um zu beten, in den Kirchhof ging".

"Mein Konstantin ist aber längst tot!..."

Mutter und Tochter fielen einander in die Arme,

Starb die Mutter, starb mit ihr die Tochter." !

Die modeme Ausdrucksweise der Berichterstattung kennzeichnet durchwegs Kadares Roman. Der Schriftsteller macht nicht den geringsten Versuch, den Leser in eine mittelalterliche Atmosphäre einzustimmen. Daher vermeidet er es, Details über Land und Leute, über die Organisation der Gesellschaft jener Zeit, über die er berichtet, zu geben; wenn man will, kann man hier die entgegengesetzte Position zu Andric und andere Schriftsteller feststellen, die eine vergangene Zeit malerisch wiederbeleben und damit glaubwürdig machen können. Die Personen in Kadares Roman denken, sprechen und handeln wie Menschen unserer Zeit: der krasse Gegensatz, der hier zwischen einer legendären Handlung und einer modernen Sichtweise entsteht, ist leicht vorstellbar. Stres' Berichterstattung an die "Kanzlei des Fürsten", seine langwierigen Ermittlungen im Fall Doruntina, die die Handlung des Romans ausmachen, sind sehr bezeichnend für die erwähnte Verzerrung des mythischen Bildes. Es scheint, als ob der Schriftsteller mit seiner Prosa bemüht wäre, jede mögliche, durch den "legendären" oder romantisierenden Blickwinkel stimulierte Illusion zu entkräften; dieser Erzählstil würde auch als ein Beweis dafür gelten, wie weit unser heutiges, aufgeklärtes Weltbild sich von den mythisch-legendären Auffassungen losgelöst hat. Charakteristisch ist in dieser Hinsicht eine Szene im Roman, in der Kapitän Stres der Totenklage alter Weiber des Dorfes um die verstorbene Mutter und Tochter - und zugleich auch der "Entstehung der Ballade" - beiwohnt.

${ }^{1}$ Aus Constantino e Garentina, S.18-20. 
"Mit zitternder Stimme brachte eines der Klageweiber die Hochzeit Doruntinas und ihre weite Hochzeitsreise in Erinnerung. Ein anderes beklagte mit einer noch bewegteren Stimme die neun Söhne, die bald nach der Hochzeit im Krieg umkamen. Ein drittes berichtete von der Trauer der alten Frau, die mutterseelenallein zurückblieb:

"Unheil möge dich befallen, Wo ist dein versprochenes Wort?

Tief im Grab liegt es begraben",

sang ein viertes über den Besuch der alten Mutter im Kirchhof, bei dem sie den Wortbrüchigen verwünschte...

Die Beauftragten von Stres, die er speziell für den Anlaß abgeschickt hatte, zeichneten alle Worte der Klageweiber auf und überreichten sie ihm sofor. Er selbst, am Fenster stehend, blickte erstarrt die Blätter an, nahm dann die Feder und unterstrich einzelne Wörter oder ganze Zeilen.

"Wir können uns Tag und Nacht den Kopf darüber zerbrechen, was sich in Wirklichkeit abgespielt hat", sagte er zu seinem Gehilfen, "die Klageweiber machen trotzdem das ihrige unentwegt weiter" $(\$ .88,90)$.

Noch an einer anderen Stelle klingt diese Idee der undurchschaubaren, für immer vergangenen mythischen Zeit mit. Es ist, wie oft bei Kadare, verblüffend und humorvoll mitgeteilt:
"Das meinte ein Teil der Leute. Andere schüttelten den Kopf... Die Menschen, wie immer kurzsichtig, dachten nicht einmal daran, wie schrecklich das war, wonach sie sich sehn- ten; es ist schon wahr, daß allen die Toten abgehen und jeder sie noch einmal ins Leben zurückbringen möchte, das wünscht man sich aber nur für eine kurze Zeit. Denk mal nach, was wäre, wenn die Toten zu uns kämen und es sich bequem machten? Du kannst dich oft mit einem Neunzigjährigen nicht gescheit verständigen, wie würdest du das mit einem Neunhundertjährigen tun? So steht es auch mit Konstantin oder mit jedem anderen, den man noch einmal ins Leben bringen möchte, das kann nur für eine kurze Zeit so sein, weil sein Totenleben nur don hingehört, wo es ist, ins Grab. Es war wohl einmal eine Zeit, in der, so sagt man, Lebende und Tote, Menschen und Götter zusammenlebten, sie sollten sogar unter sich geheiratet und eigenartige Mischungen zur Welt gebracht haben, das war aber eine andere, heidnische Zeit, die nie mehr wiederkommt" (158-159).

Das Gefühl der Verzerrung und Entmythologisierung vermitteln auch die Untersuchungen des Kapitäns Stres, bei denen die verschiedensten Hypothesen für eine Klärung des Rätsels gehegt werden: Doruntina sei von einem Betrüger heimgebracht worden, der Überbringer sei eigentlich ihr Liebhaber gewesen, Doruntina und Konstantin hätten in der Blutschande gelebt und Konstantins gepeinigtes Gewissen habe nun das Ganze veranlaßt, usw.; geschickt macht der Schriftsteller anfangs diese Vermutungen für den Leser glaubwürdig, um sie später allmählich zu demontieren und fallen zu lassen. Auf diese Weise, durch eine Art Kriminalgeschichte, entsteht aber andererseits ein neuer Glaube, bzw. es bestätigt sich der alte Glaube an die Legende, daß nämlich Doruntina wahrhaftig von ihrem toten Bruder - durch die unermessliche Kraft der Liebe heimgebracht worden sei. Vor dem versammelten Volk und vor den Vertretem der Kirche und der Staates teilt Stres am Schluß seiner Ermittlungen mit: 


\begin{abstract}
"Ich kündige hier an und wiederhole es, daß Doruntina von keinem anderen als von ihrem Bruder, Konstantin, von seinem gegebenen Wort, der Besa, zurückgebracht wurde. Jene Reise hat keine andere Erklärung und kann auch keine andere haben. Es ist nicht wichtig, ob der Tote wirklich vom Grab auferstand... Jeder von uns hat an dieser Reise seinen eigenen Teil, denn die Besa von Konstantin, gerade jene, das Doruntina heimbrachte, entstand hier, unter uns..." (S.174).
\end{abstract}

Die Besa gilt als eine Erläuterung, bzw. Rechtfertigung des Diskurses: solche Erläuterungen gibt es hin und wieder in den Werken Kadares ${ }^{1}$, sie spiegeln vermutlich eine Art Autozensur wider, sie geben einem vermeintlichen, befürchteten Zensor einen einfachen Schlüssel zur Interpretation des Werkes. Denn sonst ist es unerklärlich, warum dieses Bedürfnis in einer Prosa besteht, die die innersten Bereiche der Gefühls- und Abstraktionswelt des Lesers durch eigene, unkonventionelle Mittel erreichen kann und selbsterklärend ist, ohne Antworten zu brauchen, die oft an der Oberfläche liegen. Im letzten Teil des Romans entwickelt sich eine ausführliche Erklärung des bis dahin Geschehenen rund um die Besa. Kapitän Stres entdeckt, daß Konstantin in seinem Leben ein begeisterter Verfechter des gegebenen Wortes, dieser neuen Form des Rechtswesens, gewesen sei; es sollte, nach seiner Ansicht, eines Tages alle gewalttätigen Institutionen des Staates überflüssig machen. "Und damit verstand er nicht einfach etwas Seelisches, das mit dem Gewissen zu tun hätte; nein, so ein Tagträumer war er nicht, daß er an die Regierbarkeit der Menschen allein durch gute Vorsätze glauben würde. Das, an das er dachte, war schon zu spüren und $\mathrm{zu}$ fassen, die Saat dessen hatte er bereits hie und da im Leben der Albaner verstreut gesehen, und nun, meinte er, müsse man sie weiterentwickeln, und zu einem System werden lassen" (S.162), usw. Konstantin als lebender Anhänger dieses neuen Glaubens und Konstantin als Auferstandener seiner Überzeugung wegen, gerät somit in Konflikt mit der Kirche; der Erzbischof des Landes ist um die mysteriöse Rückkehr Doruntinas und um die eventuelle Verbreitung eines neuen Glaubens sehr besorgt. "Das ist eine schreckliche Ketzerei, eine Oberketzerei... Nur einer ist bis heute auf dieser Welt vom Grabe auferstanden, Jesus Christus, verstehen Sie mich, Kapitän?" (101). Es wird also versucht, die Besa-Konstruktion in einen geschichtlichen und antireligösen Rahmen zu bringen. Einerseits bestätigt der Autor dadurch die atheistische Ideologie Albaniens, andererseits werden die heutigen Landsleute, sozusagen, mit einer Ersatzreligion getröstet.

Stres' Rede vor dem versammelten Volk am Schluß des Romans ist ebenfalls ein Plädoyer für die Besa; die bis dahin subtil geführte Prosa verwandelt sich in eine publizistische Darlegung, die das beweisen will, was die Erzählung auf anderen Wegen schon "bewiesen" hat; und sie hat interessanterweise etwas anderes als das Besa-Problem vermittelt:

Wie bereits erwähnt, gibt die albanische Ballade von Konstantin und Doruntina zwar das gegebene Wort als Leitmotiv an, es trifft aber nicht unbedingt das tiefste Anliegen der Legende; so wie bei anderen Völkern Europas ist

1'Siehe u.a. "Die Brücke mit drei Bogen" oder "Die Dämmerung der Steppengötter". 
die Triebkraft der Auferstehungsballade auch hier gerade jene ruhelose Sehnsucht nach dem verlorenen, geliebten Menschen, dem Bruder oder dem Ehemann, ähnlich dem alten Traum der Menschheit von der Auferstehung, den das Christentum so nachhaltig aufgriff. Die Erscheinung des Bruders, das unheimliche Reiten der Lebenden mit dem Toten, ihr Dialog, diese erschütternden Urszenen sind zweifellos übernational; es ist kein Zufall, das sie in griechischen, norddeutschen, albanischen, slawischen oder englischen Gebieten in ähnlicher Form vorkommen. Andererseits ist die Motivierung des Geschehens durch das gegebene, bzw. gebrochene Wort auch bei anderen Völkern, z.B. in der deutschsprachigen Überlieferung, wie bei Bürger, von Bedeutung:

\section{..."Laß fahren Kind, sein Herz dahin! \\ Sein Herz hat's nimmermehr Gewinn! \\ Wann Seel' und Leib sich trennen, \\ Wird ihn sein Meineid brennen!"}

Von der wichtigsten Botschaft der Ballade hat sich auch Kadare trotz allem nicht getrennt, im Gegenteil, er hat neue Wege gefunden, um gerade über jene Sehnsucht nach dem verlorenen Menschen zu dichten, der zwar dem Tod, für den volkstümlichen Glauben jedoch einem widerruflichen Tod, gehört. In dieser Hinsicht sagt der Roman viel über die zwischenmenschlichen Beziehungen aus; dadurch wird der Stoff der Ballade in einer neuen, immer gegenwärtigen Weise verarbeitet; in Aussagen, die wie nebenbei erscheinen, läßt sich die Allgemeingültigkeit einiger legendärer oder mythischer Wahrheiten erkennen. Für Kapitän Stres stellt die Rückkehr Doruntinas einen Augenblick lang kein Rätsel mehr dar:

"Die Geschichte Doruntinas schien ihm plötzlich einfach und sonnenklar zu sein: da war ein Stück Erde unter dem Schnee, in der einige Menschen begraben lagen, die sich gegenseitig sehr geliebt, und zugleich versprochen hatten, den anderen nie zu verlassen und, wenn nötig, ihm beizustehen. Sie waren von der langen Trennung, von der verzehrenden Sehnsucht und von der unerträglichen Einsamkeit gepeinigt. Sie hatten zu dem anderen tendiert, um sich im Leben oder im Tod, in einem toten Leben oder lebenden Tod zu vereinen. Sie hatten versucht, die Naturgesetze, die allen Toten die Rückkehr ins Leben unterbinden, zu durchbrechen..., für einen Augenblick hatten sie geglaubt, dies erreicht zu haben, so wie es oft im Traum vorkommt, wenn du glaubst, du hättest den geliebten, verstorbenen Menschen wieder angetroffen, das ist aber nur eine flüchtige Einbildung gewesen ("ich konnte ihn nicht umarmen, irgendwas hielt mich davor zurück"), und im Dunklen, verlegen, hatten sie sich wieder getrennt, die Lebende hatte sich zum Hause begeben, der Tote zu seinem Grab ("geh weiter, ich muß noch in die Kirche"), und obwohl sich das tatsächlich nicht zugetragen hatte, obwohl Stres nie an eine Auferstehung des Toten glauber. würde, war das, in einem gewissen Sinne, doch vorgekommen..." (S.133-134).

Der schnelle Zugang, den auch Leser, etwa im Ausland, die mit der kanonischen Institution der Besa nicht vertraut sind, zu dem Werk finden, oder die Bedeutungslosigkeit der Besa für die heutige albanische Gesellschaft sprechen 
noch einmal dafür, daß Kadare die Auferstehungsballade, außer in seinen essayistischen Erläuterungen, im Sinne ihrer Allgemeingültigkeit behandelt hat.

\section{7. "Die Brücke mit drei Bogen"}

Die Handlung des Romans spielt sich in Albanien im Mittelalter, vor der türkischen Invasion auf dem Balkan, ab. Es ist die Geschichte eines Brückenbaus, zugleich aber die Geschichte der zunehmenden türkischen Gefahr und der allmählichen Kapitulation der albanischen Fürsten davor. Diese Chronik zeichnet ein Mönch auf, der vom Anfang an um die jüngsten Ereignisse sehr besorgt ist, sowohl um die bevorstehende türkische Besatzung als auch um die Errichtung der Brücke, da beide Entwicklungen als gleich negativ empfunden werden.

Die Brücke baut die Firma "Straßen und Brücken", die sich die Baugenehmigung des lokalen Grafen nur nach einem erbitterten Kampf gegen die rivalisierende Firma "Boote und Flöße" verschaffen konnte. Die Bauarbeiten verlaufen planmäßig, bis eines Nachts plötzlich, von Unbekannten angerichtet, Schaden an den Brückenpfeilem entsteht. Gleichzeitig singen Rhapsoden vom Geist des Flusses, der angeblich keine Brücke über sich erdulden könne. Wie es sich später herausstellt, hat die rivalisierende Firma "Boote und Flöße" (weil eine Brücke die Flößerei in der Gegend stillegen würde) den Schaden verursacht. Nun will die "Straßen und Brïcken" ein abschreckendes Beispiel geben, wofür ihre Vertreter ihren Willen wieder bei dem albanischen Grafen durchsetzen. Der Graf vertritt die Kurzsichtigkeit der albanischen Herrscher jener Zeit, die angesichts der raffinierten Annäherungsversuche der Türken (Verschwägerungen, Bodenkäufe, usw.) nachgeben, aber ebenso auch dem Druck fremder Ausbeuter nicht standhalten;diese wollen die Brücke bauen, hauptsächlich um das albanische Bitumen leichter transportieren zu können. An einem Brückenpfeiler mauern die Konstrukteure einen Arbeiter ein und verbreiten gleichzeitig das Gerücht, da $B$ er, um den Geist des Flusses zu beruhigen, sich selbst freiwillig aufgeopfert habe (vorher hatten anderen Herren dienende Rhapsoden die Notwendigkeit eines Bauopfers besungen). In der Tat handelt es sich um einen Mord; der aufgeopferte Arbeiter, Murrash Zenebisha, wurde offensichtlich, als er Schaden an der Brücke anrichtete, ertappt und in der Folge erdolcht. Nach der Einmauerung baut man die Brücke glatt weiter. Das fertiggestellte Bauwerk ist zwar schön ("Es war kaum zu glauben, wie hatten jenes fremde Gesindel, jene schmutzigen Stotterer und Krüppel, jene streitsüchtigen Geier und Mörder solch ein steinernes Wunder zur Welt bringen können"1) es wirkte aber trotzdem unheimlich und lange Zeit getraute sich niemand sie zu betreten. Ihre Fertigstellung fältt mit der Annäherung der türkischen Gefahr zusammen und am Schluß des Berichtes des Mönchs spiegelt sich vor allem Pessimismus wieder.

Es versteht sich also sogleich die Stellung, die die Legende des Bauopfers in Kadares Roman einnimt: im Spiel der Mächtigen wird der Mythos verwendet und mißbraucht, um aus ihm materiellen Profit zu ziehen. Es ist eine Zeit -

11. Kadare, "Ura me tri harqe", in der gleichnamigen Ausgabe, S.96-97. 
obwohl, wie schon angedeutet, in der Prosa Kadares, die die Vergangenheit als Schauplatz der Fiktion auswählt, selten von einer bestimmten Zeit gesprochen werden kann - in der, so wie im Fall der "Brücke über die Drina", die Mythen, bzw. die Legenden in der ländlichen Gesellschaft noch immer eine gewisse Rolle spielen und ihre Glaubwürdigkeit nicht ganz verloren haben. Bei Kadare ist eine noch "fortgeschrittenere" Phase der Entmythologisierung anzutreffen, wenngleich Andrićs Brücke nach und Kadares Brücke vor der türkischen Invasion errichtet werden: in der "Brücke mit drei Bogen" stützen sich die Ereignisse um das Bauopfer nicht so sehr auf Reste des Aberglaubens, sondem sie leihen vom Mythos vielmehr die Typologie aus, d.h. das Modell. Dieses Modell ermöglicht den Brückenkonstrukteuren, mit modernen Methoden und geschäftlicher Kaltblütigkeit ihren Mord zu verüben.

Gleich am Anfang des Romans nimmt der Erzähler Stellung zu der Verbreitung einer neuen Bauopfer-Legende und kündigt an, daß bei der Brücke über den Fluß Ujana e Keqe kein Bauopfer, sondern in Wirklichkeit ein Verbrechen vollzogen wurde:
"Nun wird überall auf dem großen Land Balkan die Legende der Aufopferung verbreitet, die angeblich im Pfeiler der Brïcke soll stattgefunden haben. Nur wenige aber wissen, daß es kein Opfer für die Wassernixen war, sondern ein ganz normales Verbrechen, des- sen Zeuge aus unserem Jahrhunder ich sein werde" (S.8).

Ein Erzählen im legendären Rahmen oder in Anlehnung daran, was den Leser in eine vermeintlich mittelalterliche Welt versetzen würde, wird somit von vomherein ausgeschlossen. Hier geht es um die Chronik eines angekündigten Todes - und die Sprache der Prosa ist nicht weniger zeitgenössisch als in der gleichnamigen Erzählung von García Marquez. Über das Leben im Dorf, über die Bauern und ihre Mentalität wird so gut wie nichts gesagt, die Erzăhlung konzentriert sich auf die fremden Konstrukteure, d.h. auf ihr Verbrechen und den Mißbrauch der Legende. Geschickt haben sie vor der Ausfuihrung ihrer Tat Informationen über die alte albanische Ballade gesammelt. Thr Zynismus gegenüber dem Volksglauben, bzw. die Distanzierung der Prosa von der Bauopfer-Legende erreicht einen Höhepunkt in $\operatorname{der} A r$, wie Zenebisha eingemauert wird:

"Die kleine Menschenschar bewegte sich langsam, um mir Platz zu machen...

"Da ist er", sagte jemand leise zu mir.

Er war tatsächlich don, weiß wie eine Maske, mit Kalk bespritzt, und von ihm waren nur das Gesicht, der Hals und ein Tei! der Brust sichtbar. Der übrige Körper und die Glieder verloren sich in der Mauer.

Ich konnte nicht von der Mauer wegblicken. Überall waren frische Spuren vom Mörtel zu sehen. Die Mauer war zusätzlich erweitert worden, damit sie das Opfer umfassen könne (Ein Körper, der in den Pfeiler hineingemauert wird, beeinträchtigt die Konstruktion der Brïcke', hatte zu mir jener Erbauer gesagt, der Balladen und Märchen sammelte). Zwei Balken, die unterhalb des toten Mannes befestigt waren, dienten der er-

${ }^{1}$ Kursive von mir. Siehe auch "die Chemie und die Albaner" im Kapitel 4.3.. 
gănzten Mauer als Fundament" (S.67-68; vgl. dazu die nordalbanische Variante im Anhang 1 der Arbeit).

Eine andere Form der Mythos-Entzauberung, die in "Wer hat Doruntina zurückgebracht" zur Struktur des Romans gehört, ist auch hier von Bedeutung: durch die Bildung verfremdender Hypothesen distanziert sich die Prosa noch mehr von den mythischen Vorstellungen. Der Legendensammler macht die bizarrsten Interpretationen über die Ballade: die jüngste Braut wußte eigentlich alles, sie wollte aber selbst in den Tod gehen, weil ihre Schwägerinnen und die Schwiegermutter ihr das Leben zur Hölle gemacht hätten; der jüngste Bruder hătte seine Besa nur deswegen gehalten, weil er von seiner Frau die Nase voll gehabt hätte, die Aufopferung bot ihm nun Gelegenheit, sie loszuwerden" (S.67-68), usw.

Es ist hier noch einmal der essayistische Diskurs über die Legende auffallend. Wenn man beachtet, daB dem erzählenden Mönch wenig Distanz vom Schriftsteller zuzurechnen ist ${ }^{1}$, klingen seine Ansichten über die Bauopferballade als Darlegungen des Autors, zumal sie sich auch von Kadares Essays, beispielsweise im Buch "Autobiographie meines Volkes in Versen"2, nicht zu sehr unterscheiden. Der Mönch ist über die Hypothesen des fremden Erbauers empört:

"Ich wollte ihm sagen, daß seine Versuche, jene alte Tragödie in den Schmutz zu ziehen,
vergeblich wären, weil der wirkliche Kern der Legende die Idee war, daß man in den
Fundamenten einer großen Arbeit oder Handlung immer etwas opferm müsse; diese Idee
war in der Mythologie mancher Volker zu finden. Was in der Ballade unseres Volkes aber
als neu und originell erscheint, das ist der Umstand, daß die Aufopferung sich nicht an
den Beginn eines Krieges, eines Feldzuges oder an ein religiöses Ritual anschließt, son-
dern einfach mit einer Mauer, mit einem Bauwerk zu tun hat. Dies erklär vielleicht die
Tatsache. daB unsere Vorfahren, die Pelasger, die ersten Maurer der Welt gewesen wa-
ren" (S.68).

Diese Behauptungen sind gewi $\beta$ fragwürdig, um so mehr als die albanische Ballade eine Variante des balkanischen Paradigmas ist, in dem es ausschließlich um ein Bauwerk geht, ob das eine Festung, eine Brücke oder eine Kirche ist. Allerdings ist es nicht gerechtfertigt, den Mönch unbedingt als direkte Stimme des Autors zu betrachten; in diesem Sinne sind ihm mangelnde Kentnisse auf dem Gebiet der südosteuropäischen Folklore und ein bißchen Nationalismus zuzubilligen. Auch seine eigene Interpretation des Mythos läßt zu wünschen übrig, da sie lediglich eine poetische ist:

"Ich wollte ihm sagen, daß die Bluttropfen in der Legende eigentlich für den Arbeitsschweiß stünden, denn es ist wohl bekannt, daß der Schweiß eine Art Diener im Verhältnis zum Blut darstellt, da $\beta$ er anonym bleibt; deswegen hat niemand über ihn Lieder oder Balladen geschaffen. So ist es nur natürlich, da $\mathrm{B}$ im Lied eine Handvoll Blut stellvente-

\footnotetext{
${ }^{1}$ Es ist eine Ich-Form, die nicht nur vergangenen Geschichten, sondem auch "momentane" innere Wahrheiten vermittelt.

2"Vepra letrare", Bd.12, S.27-30.
} 
tend für einen Fluß von Schweiß steht. Und selbstverständlich opfert jeder mit seinem Schweiß etwas von sich selbst, so wie der jüngste Bruder sein Glück aufopferte" (S.69).

Ähnlich wie in "Wer hat Doruntina zurückgebracht" fällt auf, daß, wenn Kadares Prosa ins Essayistische übergeht, wenn er sozusagen "die kreativen Wege" verläßt, weniger überzeugt, ja sogar verwirrt; denn das, was offen und deklamativ verkündigt wird, trägt andere Bedeutungen als die übrige Prosa. Die zitierten Aussagen könnte man mit der Botschaft des Romans schwer gleichsetzen, weil solche Interpretationen, wie 'das Blut der Legende bedeutet Schweiß der Arbeit', oder 'die albanische Variante ist die älteste, weil sie an die Pelasger anschließt', kaum Bedeutung in einem Roman haben, der unterschwellig anderes vermittelt.

Es wurde bereits darauf hingewiesen, daß bei einer Analyse der Werke Kadares vor allem oder besonders die Sprache zu untersuchen wäre. Es hat wenig Sinn, sich dabei auf Inhaltsangaben und ausgesprochene Ideen zu stützen; anhand von Konnotationen, bzw. besonderen Stimmungen, die sie übertragen, kann man auf die eigentliche innere Krafi der Prosa schließen. In der "Brücke mit drei Bogen" vermitteln der Bau der Brücke, ihre Konstrukteure, die Umgebung rund um die Baustelle, das Wetter, eine im Roman herrschende niedergedrückte Stimmung. Nur für den deprimierenden Regen, der so wie im "General der toten Armee", fast ununterbrochen anhält, gibt es eine Reihe von Beschreibungen:

"Es fing ein feiner, monotoner Regen an, der schien, als ob er besorgt wäre, keinen einzigen Winkel der Erde trocken zu lassen. In ihre schwarzen, ungeheuerlichen Regenmäntel eingehüllt, setzten die Erbauer ihre Arbeit im Regen fort" (S.40).

"Es war ein regnerischer Dezembertag. Der Wolkenhimmel hatte sich ganz nieder gesenkt, als wollte er die Erde ersticken. Es war ein dünner, langsamer, trostloser Regen" (S.46).

"Der Regen hielt bereits seit einer Woche an, so lästig wie an jenen Tag der Gespräche. Man sagt, daß solch ein Regen nur einmal in vier Jahren vorkomme. Es schien, als wolle der Himmel sein hohes Alter auf die Erde herabschütten" (S.60) usw. 1

Die Erzählung über die Konstrukteure und ihre Brücke beinhaltet eine Reihe von bösen, unheilvollen Zeichen: die Krise eines Epileptikers bestimmt, wo die Brücke zu errichten ist, ein Verrückter ist der einzige Mensch aus dem Dorf, der sich den Arbeitem nähert, das Floß setzt in seinen letzten Fahrten Särge über, die Konstrukteure sprechen eine widerliche, unverständliche Mischsprache, etc. Die Brücke, auch wenn am Schluß der Arbeiten ein nützliches Bauwerk, so wie bei Andrić, "ein Wunder aus Stein", steht vielmehr als Symbol einer innerlichen, verzehrenden Einöde. Grundstimmung ist im Roman eine "verregnete Bedrücktheit"; sie wäre durch die bevorstehende türkische Besat-

${ }^{1}$ Fast sprichwörlich ist in Albanien der Ausdruck aus dem Buch geworden: "Es fiel ein alter Regen". 
zung Albaniens oder durch die Machenschaften der "Straßen und Brücken" allein nicht zu erklären. Die Brücke wird als eine beklemmende Angst, manchmal geradezu als ein Alptraum empfunden:

"Der Märchensammler sagte etwas über Brücken und die Schwierigkeit ihres Baues, und bei seiner Rede ergriff mich ein Gefühl, als befände ich mich unter den Trümmern einer Brücke, die er über mich stürzen ließ" (71).

Die Brücke erscheint also bei Kadare auch als Symbol von Angstgefühlen. Die Mauern haben keine wohltuende Wirkung, sie sind keine "Frucht" der Erde und Glied des chthonischen Kreises, im Gegenteil, sie schließen ein, sie bedricken und ersticken:

Jenen ganzen Tag und auch in den nächsten war ich wie von Sinnen. Seine offenen, unter der Kalkschicht erstarrten Augen tauchten überall auf den Mauern rund um mich auf. Die Mauern jagten mir Angst ein, ich versuchte sie überhaupt zu meiden, das war aber kaum möglich. Erst dann sah ich ein, was für einen gewaltigen, wichtigen Platz die Mauem in unserem Leben einnehmen. Ihnen, so wie dem Gewissen, konnte man nicht ausweichen. Ich ging aus meinem Pfarrhaus, aber auch draußen, fern oder nahe, gab es Mauem (S.83).

$\mathrm{Daß}$ die Mauern bei Kadare etwas zum hergebrachten Sinn Entgegengesetzten bedeuten, ist schon in der Art der Aufopferung begruindet. Bereits hier ist der Mythos "vergewaltigt" worden; ein Mann tritt als Opfer auf, dort wo sich immer eine Frau, und zwar eine unschuldige, findet. Mit jedem Schritt seiner Legendengestaltung bewegt sich Kadare in einer zum Mythos fremden, zum Leser verfremdenden Richtung: man opfert aus nüchtemen, geschäftlichen Gründen, man läßt eine Offnung im Bereich der Augen, statt Milch haftet am Brückenpfeiler Kalk, usw. So können die Mauern auch keine wohltuende, vielmehr nur eine beklemmende Wirkung haben.

Damit ist der Roman jedoch nicht erschöpfend interpretiert; außer den widersprüchlichen Behauptungen im Hinblick auf die Legende, steht man oft vor einer rätselhaften Prosa, die vielleicht, etwa wie bei Franz Kafka, am besten ist, wenn man sie wie ein Rätsel rezipiert und annimmt. Kennzeichnend für diese Eigenschaft wäre u.a. folgendes Beispiel:

"Das schlechte, schneeregnerische Wetter hielt an. Die Umwelt war na $B$ und grau. Über der Niederung verflochten und lösten sich wieder müde Wellen von Nebelbänken auf. Manchmal schien es, als ob der Nebel auf einem Fleck erstarne. Alles verschwand halbwegs in ihm: die Flußufer, die kleinen Dörfer in der Umgebung, der rauhe Flußsand, die Brïcke. Der Eingemauerte in ihrem Schoß schien weit und doch nah zu sein. Es kam einem vor, als würde er in Kürze seinen doppelten Zustand verlassen und auf uns zukommen, wie ein Lebender zu den Lebenden, oder von uns weggehen, wie ein Toter zu den Toten" (117).

Noch einmal zusammenfassend das Verhältnis des Schriftstellers zu Mythos, Brücke und Mauem: 
- Das Modell der Legende dient ihm dazu, eine moderne Kriminalgeschichte mit mythologischem Hintergrund zu gestalten.

- Die Bauopfer-Legende wird darüber hinaus in einen nicht-fiktionalen Diskurs einbezogen. Die in diesen Abschnitten gegebenen Interpretationen sind publizistischer Natur und stimmen mit Bedeutung und Funktion, die der Mythos in der fiktionalen übrigen Prosa innehat, nicht überein, wirken sogar verwirrend; dies war auch im Roman "Wer hat Doruntina zurückgebracht" ein Charakteristikum.

- Der hergebrachte Mythos ist vorwiegend in seiner umgekehrten, d.h. entmythologisierten Seite dargelegt worden.

- Die Brücke, das Einmauem, die Mauern besitzen einen symbolischen Wert, der vielfach der Grundstimmung des Romans entspricht. Eine nähere Analyse der verschiedenen Konnotationen und Zeichen, die diese Symbole manchmal rätselhaft in sich verbergen, bleibt hier offen. 
Ardian Klosi - 9783954791729

Downloaded from PubFactory at 01/10/2019 03:33:12AM

via free access 


\section{GEGENUBERSTELLUNG, ZUSAMMENFASSUNG UND SCHLUSSWORT}

Ich ziehe hier den Begriff Gegenüberstellung vor, da dieser nicht unbedingt gemeinsame Nenner fordert, die im Falle von Kazantzakis, Andrić und Kadare etwas künstlich zusammenzustellen wären. Nichı nur ihre Persönlichkeit, Ümwelt und ihre literarische Prägung sind sehr verschieden, sondem, wie wir sahen, insbesondere die Werke, die das Bauopfermotiv behandeln. In Form einer Zusammenfassung des bisher Analysierten können dagegen einige Schwerpunkte wie Lebensverlauf, Zeitrahmen, sozial-politisches Engagement, Philosophie, Glaube, literarische Grundzüge, Verhältnis zur volkstümlichen Überlieferung, u.a. gegenübergestellt werden, um dadurch das wirklich Vergleichbare in dieser Arbeit zu erleichtern. Die Vergleichsmomente in den jeweiligen Kapiteln waren: Wie steht jeder Autor zum mythisch-legendären Stoff im allgemeinen und speziell zu den Opfer-Mythen? Was für neue philosophische, symbolische und psychologische Werte nimmt ein altbekanntes Motiv in ihrer Literatur ein?

\subsection{Die Schriftsteller im Uberblick}

Nikos Kazantzakis und lvo Andrić haben als Ausgangspunkt noch das 19. Jahrhundert bzw. die Jahrhundertwende, eine Zeit, die für Südosteuropa die nationale Selbstbehauptung der Nationen bedeutete und den Versuch, den kulturellen Anschluß zum übrigen, fortgeschritteneren Teil des Kontinents wieder zu finden. Beide stammen aus Gegenden, die im Aufruhr gegen eine fremde Macht begriffen waren: gegen alteingesessene Türken in Kreta und eine neue österreichische Verwaltung in Bosnien. Beide gehen von der Provinz in die Kulturzentren Europas, um sich ausbilden zu lassen, jedoch mit sehr verschiedenen Erfahrungen. Kazantzakis fand in Europa, in Paris, London, in Moskau, Berlin und Madrid eine zweite Heimat; in diesen großen Kulturzentren "deckte" er seinen "Nachholbedarf" an Philosophie, Religion, Literatur und setzte dies bald durch Übersetzungen, Schulbücher, usw. in geistige Nahrung 
für seine Landsleute um; hier führte er ein sehr reges politisches und journalistisches Leben. In Griechenland arbeitete er, nach den Enttäuschungen seiner politischen Tätigkeit, nur wenn er gezwungen war, in etwa während der Nazi-Okkupation. So sehr die Themen seiner Theaterstücke, Lyrik und Prosa (fast ausschließlich) griechisch waren, so europäisch und kosmopolitisch erscheint er in seiner Lebensweise und in den essayistischen Schriften. Andrić hingegen ging mit weniger Begeisterung in die Großstädte Europas (Wien und Krakau), auch weil er sich seiner Heimat Bosnien vielleicht verbundener fühlte und weil er in den Jahren seines Studiums oft von Krankheiten heimgesucht war. Besonders einprägend wirkten sich jedoch auf ihn die Ereignisse vor dem Ersten Weltkrieg und nach seiner Verhaftung in Juli 1914 aus. Das Gefängnis, die darauffolgende Verbannung im bosnischen Hinterland, haben seine künftige Literatur beträchtlich vorausbestimmt, man denke nur an den "Verdammten Hof", an seine Fratres-Erzählungen oder an "Wesire und Konsuln". Die Gewalt der Machthaber und der Bürokratie, die Isolation und Abgeschiedenheit einzelner Menschen und ganzer Gebietel: diese gehören zu den großen Themen Andrić'. Die "innere Verbannung" dauert auch in der Zeit zwischen den beiden Weltkriegen an; was er damals schrieb, hat augenscheinlich wenig Bezug zu den verschiedenen Stationen seiner langen diplomatischen Karriere als Funktionär des jugoslawischen Außenministeriums. Diese Karriere wurde hier eigentlich wenig besprochen, eben, weil sie kaum im Zusammenhang mit dem Werk des Schriftstellers steht. In der Tat war Andrić doch kein unbedeutender "Politikmacher" des damaligen Außenministeriums. So ist beispielsweise im Jahre 1977 durch eine Zagreber Zeitschrift ein von Andrić für seinen Minister Stojadinović bearbeiteter Entwurf bekannt geworden, der die Invasion weiter Teile Albaniens durch Jugoslawien und die Assimilierung bzw. Deportation der Kosovo-Albaner vorschlägt. ${ }^{2}$ Diese Schrift ist im Januar 1939 verfasst worden; sie zeigt bis zu welchem Ausmaß auch der "humanistischste" Schriftsteller in die Politik verwickelt werden kann. Dies trägt heute unter den albanischen Lesem sicherlich zu keinen besonderen Sympathien für Andrić bei.

Im Kapitel 3.2. wurde jedoch die extreme Behauptung bestritten, die zwischenmenschliche Beziehungslosigkeit sei das Andrićsche Thema schlechthin.

2 Andric empfiehlt unter anderem: "Die Annektierung von Skutari hätte große wirtschaftliche und moralische Vorteile eingebracht. Das hätte urs die Gewinnung fruchtbaren Landes ermöglicht, das Montenegro ernähren könnte. Nordalbanien wäre als Teil Jugoslawiens sehr günstig für den Bau neuer Straßen, damit das nördliche und südliche Serbien die Verbindung zur Adria erreiche. Mit dem Ergreifen Albaniens würde auch ein für die Albaner Kosovos anspornendes Zentrum vernichtet; diese könnte man dann leichter assimilieren. Wir würden eventuell auch 200-300.000 Albaner annektieren; sie sind jedoch größtenteils Katholiken und haben zu den moslemischen Albanem nie gute Beziehungen gehabt. Die Deportation moslemischer Albaner in die Türkei würde dann unter neuen Umständen stattfinden und es würde dafür keine große Hindernisse mehr geben." (Siehe: Casopis za suvremeno povijest, Nr.2. Zagreb 1977. Das Dokument ist von Bogdan Krizman veröffentlicht worden). 
Der Begriff "innere Verbannung" wäre ein passendes Motto für Andrić drei zu dieser Zeit veröffentlichten Novellensammlungen; sie erreicht einen Höhepunkt mit der selbstgewählten Isolation und der Abfassung seiner wichtigsten Romane in den Jahren 1940 - 1944.

Heimat - Abendland - Orient ist kein besonderes Thema beim Griechen Kazantzakis, zumindest nicht in einem so hohen Maße wie in der Prosa Andrić, bei dem sich die Berührung, bzw. das Zusammenprallen, das sich zwischen diesen Welten ereignet, schicksalhaft für ganze Völker und Gebiete auswirkt. Bei dem dritten Autor der Analyse bekommt dies wieder das große Gewicht, das es in der Geschichte der Balkanvölker tatsächlich gehabt hat: Ismail Kadare, ein Autor, der in die Literatur ein halbes Jahrhundert später einging als Kazantzakis und Andrić, macht die Motive des Einbrechens der "islamischen Nacht" über den Balkan, des albanischen Widerstandes dagegen und des totalităren Unterdrückungssystems des Reiches zum Hauptgegenstand seiner Romane und Erzählungen "Die Festung", "Die Brücke mit drei Bogen", "Die Komission der Feierlichkeiten", "Die großen Paschaliks", "Die Schleierkarawane", u.a. Es ist auch nicht zufällig, daß Andrić und Kadare so intensiv das Schicksal ihrer Heimat an den Kreuzungen zwischen Westen und Osten, zwischen alten und neuen Eroberem behandeln. Das war gewiß der Hauptzug in der Geschichte Albaniens und Bosniens, Gegenden, die so viele Gemeinsamkeiten aufweisen. Griechenland, Kazantzakis' Kreta, haben wohl ähnliche Erfahrungen in den letzten Jahrhunderten gemacht, man darf jedoch nicht vergessen, $\mathrm{da} B$ dort die Lager immer scharf voneinander getrennt waren, da $\beta$ der griechisch-orthodoxe Glaube und die Kirche die Vermischung der Völker verhinderten und so durch die Jahrhunderte zur Bewahrung der Identität der Griechen beitrugen. Bosnien und Albanien dagegen waren gerade jene Gegenden Südosteuropas, deren Bevölkerung am meisten islamisiert wurde (50-70\%), und wo, vielleicht mehr als in jedem anderen Gebiet Europas, religiöse Toleranz geübt wurde. 1

Auch wenn Andrić und Kadare ähnliche historische Konstellationen thematisieren, finden wir in ihren Werken diverse Auffassungen der Geschichte: Für

${ }^{1}$ Ein auch in angrenzenden Gegenden bekanntes Phänomen. J. Matl kommt anhand von Beobachtungen aus Jugoslawien zu folgenden Schlüsse: "Einige weitere Beispiele dieser Fluktuationserscheinungen: Im jugoslawischen Mazedonien mit seinem Mosaik von Verflechtungen christlicher, muslimanischer, mazedoslawischer, griechischer, albanischer, aromunischer, türkischer Volksteile finden wir, z. B. in der Metohija albanische Hausgemeinschaften, deren einer Teil der katholischen, der andere der muslimischen Religion angehör, bei weitgehender konfessioneller Toleranz. Nach der Forschung von P. Sobajic kommt es auch im herzegovinischen Stamm der Korjenc vor, daß der eine Teil der christlich - orthodoxen, der andere Teil der muslimischen Religion angehört... Alle diese Beispiele zeigen genügend die Unhaltbarkeit der in der Publizistik wie auch häuf!g in der wissenschaftlichen Literatur noch immer verbreiteten Dualismus-These von dem Auseinanderfall Ost- und Südosteuropas in eine katholisch - abendländische und eine orthodoxe byzantinisch - orientalische, angeblich typologisch in den Grundlagen und in der Entwicklung getrennter und verschiedener Kulturkräfte"; siehe: Sprache und Dichtung als Schicksalsspiegel der südosteuropäischen Völker, in: Die Kultur Südosteuropas, ihre Geschichte und ihre Ausdrucksformen, S. 180 - 181; 182). 
Andric waren die Konflikte zwischen den bosnischen "Türken" und den christlichen "Rajas" zwar immer vorhanden, sie bestimmten allerdings nicht die Geschichte Bosniens; in der "Brücke über die Drina" oder in "Wesire und Konsuln" kommt es oft in diesem "Land des Haßes", Bosnien, zur notwendigen Verständigung und zu gemeinsamem Handeln der geistigen Führer der vier lokalen Religionen. Andrić nimmt die osmanische Besatzung als eine längst geschehene Gegebenheit und das Zusammenleben von Menschen mit verschiedener Vorgeschichte als selbstverständlich, was angesichts der verheerenden Konflikte der modemen Zeit positiv zu bewerten ist. Für Kadare aber bedeutet die türkische Besatzung Albaniens, der Zeitpunkt, in dem Albanien von der Entwicklung des christlichen Europa abgeschnitten wurde, viel Schmerz, viel Verlorenes, einen neuen Kalender, die Hidschra, die die Zeit um "600 Jahre zurückdrehte"1, die Unterwerfung durch "eine Nation, die ihre eigene Quelle, die Frauen, verborgen hielt" (ebenda, S. 37), usw. Beispielhaft stehen für solch einen Blickwinkel die Erzählung "Die Schleierkarawane" und noch andere Werke, wie "Die Festung" oder "Die Brücke mit drei Bogen", die anmuten, als sei Albanien zum Zeitpunkt des Geschehens dabei gewesen sich entzweizuschneiden; der Konflikt spiegelt sich auch in Werken, die eine nähere Vergangenheit rekonstruieren, wider, wie etwa in der Novelle "Viti i mbrapshtë" ("Das verhängnisvolle Jahr"). Wobei aber der Kontrast nicht schematisch als Osten gegen Westen zu verstehen ist, weil sich dazwischen Albanien und Albanertum als der eigentliche Gegenstand des literarischen Dreiecks zeigen. Kadare schwärmt immer wieder von einem "vortürkischen" Albanien; es soll dem damaligen fortschritlichen Teil des christlichen Europas sehr ähnlich gewesen sein.

Die blinde, unberechenbare Gewalt des Staates und die oft undurchsichtigen Strukturen der Bürokratie, verkörpert im osmanischen Reich, bilden ein anderes wichtiges Motiv, das Andric und Kadare einander nahe bringt. Dafür sind bei Andrić "Der verdammte Hof" (1954), bei Kadare "Die großen Paschaliks" (1978) oder "Der Angestellte der Traumbehörde" (1979) typische Werke. Wesire, die in Ungnade fallen, kleine Menschen wie der Zinsbauer Siman der gleichnamigen Erzählungen und Haxhi Milet der "Schleierkarawane", Idealisten wie Džem im "Verdammten Hof" und Kurt Köprülü der "Traumbehörde", alle geraten rettungslos unter die Räder der willkürlichen und undurchschaubaren staatlichen Maschinerie: sie sind trotz so verschiedener Autoren sehr verwandte Figuren; sie entspringen den dunkelsten Kerkem der Geschichte Südosteuropas.

Nun einige philosophische Einstellungen der drei Autoren:

Als Grundstimmung vermittelt die Literatur Kazantzakis' und Andrić' den Pessimismus bzw. die Skepsis gegenüber der neueren Geschichte der Menschheit. Dies kommt nicht nur als Reflexion über die sinnlos-tragischen modemen Entwicklungen in Europa und auf der Welt, sondem überhaupt als Antwort

l"Brücke mit drei Bogen", S.110. 
auf einen gesuchten Sinn der menschlichen Existenz heraus. Andrić schreibt schon 1927 in einem Aufsatz über Goya: "No se pue saber porqué". Hier sind wir am Ende. Auf dem Boden des Abgrunds. Man kann nicht wissen, warum es das Böse auf der Welt gibt; denn alles, was besteht, hat keinen Sinn und keinen Grund"1, und in "Ex ponto": "Die Erde ist stark, der Himmel ewig, der Mensch aber schwach und vergänglich... Unsere Welt ist das Reich der materiellen Gesetze und des tierischen Lebens, sie hat keinen Sinn und kein Ziel, und alles endet mit dem Tod"2. Für Kazantzakis ist der Mensch gleichfalls "ein ephemeres und schwaches Geschöpf, gemacht aus Schlamm und Träumen" ("Rettet Gott"); er geht mit dieser Aussage noch weiter als Andrić: "nichts existiert... Ich durchmesse die maßlose, gestaltlose Zeit, mutterseelenallein, hoffnungslos, schreiend in der Ode" (ebenda). Jedoch gerade dieses "schreiend" unterscheidet Kazantzakis von Andrić am meisten. Im Gegensatz zum ruhigen, resignierten Ton des bosnischen Philosophen, hören wir von Kazantzakis immer wieder den Ruf nach dem Kampf - auch wenn es absurd scheint - für die Freiheit, für die "Befreiung der Materie", für die "Rettung Gottes" oder einfach um des Kampfes willen: "Wozu dieses ganze Ringen? Frage nicht, kämpfe!"

Kazantzakis' Rhetorik läßt auch gewissen Optimismus erkennen Ihm ist die Neugier, die Suche nach dem versteckten, mysteriösen Sinn des Lebens eigen; diese Suche kennt keine Grenzen, sie verlangt sogar die Überwindung des Todes $^{3}$. Viele seiner Helden kennzeichnet dieser "alogische Optimismus", er führt sie zu großen, hoffnungslosen Taten (Manolios, Kapitän Michalis) und folglich zum Märtyrertum. Solche Figuren werden oft zu reinen Ideenträgem, sie spielen vorbestimmte Rollen - etwa einen Christus, einen Hohenpriester, einen Judas. Hier macht sich also noch ein Unterschied zu Andrić bemerkbar, der, anstatt sich auf tragisch-heldenhafte Figuren voll zu konzentrieren, es eher vorzieht, den Sinn des Lebens und des Todes im Mosaik und in der Vielfalt menschlicher Schicksale zu suchen, die oft bizarr und "unheldenhaft" sind. Auch wenn sie zum Heroischen und Außerordentlichen neigen, wie Alija Djerželez, Mustafa Madžar oder Džem, fallen sie ins Tragikomische und Psychopathische. Ruft Kazantzakis nach dem Durchbruch der Grenzen, so nimmt Andric bereits in seiner Jugend die entgegengesetzte Richtung ein, indem er behauptet: "Anfang und Bedingung jedes Handelns ist die Beschränkung"4.

Von Kadare sind keine direkten Bekenntnisse, bzw. eindeutige Aussagen über Fragen wie Materie, Existenz, Tod, u.a. vorhanden (ähnlich wie in politischen, ist seine Figur auch in philoscphischen Fragen höchst verworren und verwirrend); das bedeutet aber selbstverständlich nicht, daß ihm diese Themen

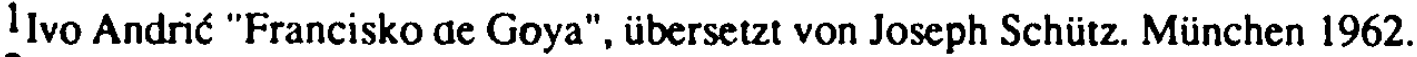

2 Zitient nach Grubacic, in: Kritisches Lexikon zur fremdsprachigen Gegenwartsliteratur.

3"All meine Arbeit soll als Ziel und als Devise haben: come l'uomo s'eterna" ("Einsame Freiheit", S.63); "Nie sollst du die Grenzen des Menschen anerkennen!... Stirb und schrei: "Es gibt keinen Tod"'" ("Rettet Gott", S.17) usw.

${ }^{4}$ Zitien nach Grubacic, Kritisches Lexikon zur fremdsprachigen Gegenwartsliteratur, S.3.
} 
fremd wären. In der Analyse z.B. des Romans "Wer hat Doruntina zurückgebracht" sind wir einem Schriftsteller begegnet, der die Grundfragen der menschlichen Existenz, wie das Leben des Toten unter den Lebenden, Sehnsucht nach den Toten, usw. auf seine Art erforschte. "Der zerrissene April" stellt auch eine existenzielle Frage in einer aufschlußreichen Form auf: Was erlebt ein zum Tode verurteilter Mensch, verkörpert im Bauemsohn Gjorg Berisha (der nach den Regeln der Blutrache im albanischen Kanun an die Reihe gekommen ist $\mathrm{zu}$ sterben), wie wird alles andere relativiert, auch das Leben anderer Leute, die in der Handlung keine besondere Berührung zu Berisha haben?!

Das Motiv "zwischen Tod und Leben", oder wie es Kadare ausdrücken würde "i vdekjejetës", spielt auch in der "Brücke mit drei Bogen" mit. Von den "offenen Augen, mit der Kalkschicht darauf, die das Schweigen, die Antwortlosigkeit und das 'nie und nie wieder' des Todes ausdrückten" (S.188) wird noch einmal die Rede sein.

Die Einstellung zur Religion erwies sich nur bei Kazantzakis als besonders wichtig. Außer in den vielen essayistischen Schriften, in seinen Aufzeichnungen und Tagebüchern, aus denen hier öfters Zitate angeführt wurden, rücken Fragen des Glaubens, der kirchlichen Berechtigung, der Suche nach Gott u.a. auch in der fiktionalen Literatur, besonders in den Romanen "Griechische Passion" und "Die letzte Versuchung Christi" in den Brennpunkt. Diese Fragen werden undogmatisch behandelt, oft entgegen der offiziellen orthodoxen Kirche, was dennoch nicht heißt, daß Kazantzakis christliche traditionelle Werte als Außenstehender in Frage stellte. Dafür war er zu sehr im religiösen Geist aufgewachsen, in einem Land, um es noch einmal zu betonen, wo Religion als wichtiger Faktor der nationalen Selbstbehauptung galt. Bei der Analyse der "Griechischen Passion" war zu beobachten, wie der vorzügliche Kenner des Christentums und der christlichen Schriften viele altbekannte, starre Episoden bei einer literarischen Transposition des biblischen Geschehens neu gestaltet und interpretiert, manche andere jedoch unverändert beibehält.

Andrić fühlt sich von religiösen Themen, zumindest in seinen wichtigsten Werken, nicht herausgefordert. Seine Charaktere haben sicher ihre jeweiligen Religionen, sie tragen sie jedoch so, wie man ein Kleid trägt, weil ihr Charakter von anderen Faktoren bestimmt wird; sie sind sehr selten auf der Suche nach einem "anderen Gott". Religion wird wichtig unter den Bosniaken nur, wenn es zu kritischen Situationen kommt, zu Kriegen. Verfolgungen, Annexionen, oder einfach, wenn es darum gent. den $\mathrm{HaB}$ auf den Mitmenschen zu rechtfertigen (siehe "Brief aus dem Jahre 1920", "Wesire und Konsuln", u.a.).

${ }^{1}$ Die Liebe eines intellektuellen Paares, das von der Hauptstadt in das Hochgebirge reist, geht dadurch in Brüche. "Ein winziger Kontakt mit diesem schrecklichen Mechanismus hatte genügt, ihm die Frau zu nehmen, sie in eine Sklavin oder, im günstigen Fall, eine Fee der Berge zu verwandeln... Sie war ganz fremd, völlig veränder, nur noch körperliche Gestalt, während die Seele dort oben geblieben war." ("Der zerrissene April", überetzt von Joachim Röhm. Salzburg 1989, S.195). 
Wie in vielen anderen Fragen erhebt sich der Schriftsteller auch hier über die Ereignisse, Vorurteile, Glaubenskonflikte, er steht abseits von Leidenschaften und ergreift für niemanden Partei. Trotz alledem sind christliche Motive hin und wieder im Diskurs beteiligt, so wie z.B. in den Szenen der Hinrichtung und "Erhebung" Radisaws.

Noch weniger ist Religion ein Thema oder ein gewichtiges Motiv bei Kadare. Am meisten nahm, wie angeführt, eine Glaubensdiskussion im Roman "Wer hat Doruntina zurückgebracht" Platz ein; der Autor stellte hier einen eigenen Glauben der Albaner, auf Kanun und Besa gestützt, als in Konflikt mit der christlichen Kirche und den vom Grabe auferstandenen Konstantin als eine mögliche Gefährdung der Einmaligkeit Christi dar. Dies war jedoch nur in den essayistischen Erläuterungen als ein ideologisches Schutzmittel und nicht als integriertes Motiv im eigentlichen literarischen Text von Interesse.

Literarisch-stilistische Profile. Vorerst das Gemeinsame: jeder Autor schafft eine neue Realität. In der Analyse ging ich von dieser Voraussetzung aus, und nicht etwa von der Frage: "Wie ähullich ist das Werk zur Realität (beziehungsweise zu einem Mythos, einer Volksballade)?", um dadurch eventuelle Mißverständnisse in Zusammenhang mit Begriffen wie "Realismus", "Mimesis", usw. zu vermeiden.

"Wir schaffen Formen wie eine zweite Natur", so drückt Andric diese allgemeingültige Eigenschaft der Kunst und der Literatur in dem Essay über Goya aus. Kazantzakis hat eine ähnliche Definition: "Ich bemühe mich darum, soviel Materie wie möglich zu Geist zu machen". Und Kadare antwortete auf die Frage, ob er in einer Neubearbeitung seines Romans "Der große Winter" auf die gegen ihn geübte Kritiken weitgehend reagieren würde: "Das literarische Werk, mit seinen Mängeln und seinen Vorzügen, ist keine Hypothese, sondem eine Realität"1.

So sehr diese Schriftsteller in diesem Punkt auch übereinstimmen, so unterschiedlich sind doch die Wege, die sie zur Gestaltung der "zweiten Realität" einschlagen.

In der Sekundärliteratur über die drei Autoren wird der Terminus Realismus am meisten für Andrić,verwendet. Er selber meint dazu: "Ich weiß nicht, ob meine Werke Realismus sind, aber ich glaube, sie sind - Realität" 2 . Den Eindruck des realistischen Schriftstellers, dessen Bilder den Bildern und Gegebenheiten der realen Welt sehr ähnlich sehen, vermitteln bei Andrić die historische Genauigkeit, die leidenschaftslose Objektivität, der Naturalismus und verallgemeinemde Aussagen, bzw. Weisheiten und Sprüche. Jede dieser Eigenschaften ist relativ und beginnt bei einer näheren Betrachtung unter der Oberfläche zu "wackeln". Die Geschichte wird so weit respektiert, wie sie allgemein bekannt ist; eine wenig bekannte Vergangenheit, wie die Zeit des Brückenbaus in der "Brücke über die Drina" bleibt auch in der Literatur wenig bestimmt

l"Vepra letrare", Bd.12, S.315.

2Zitien nach Grubaćić, Kritisches Lexikon zur fremdsprachigen Gegenwartsliteratur. 
und unüberprüfbar; sie stimmt ungefähr, in Jahrhunderteinheiten, und vielleicht auch in ein Paar Tatsachen, z.B. daß die Brücke auf Anordnung eines bosnischen Wesirs errichtet wurde. Die Leidenschaftlosigkeit erreicht der Autor, indem er sich den Ton eines überparteilichen Volkserzählers aneignet; rein objektiv ist er dennoch nicht, schon allein dadurch, daß er in seinem "objektiven" Bericht, z.B. über den Bau der Brücke, bestimmte Charaktere, Ereignisse und Gegenstände übermässig fokusiert, wie die Pfählung Radisaws. Auch die erwähnte Grundstimmung seiner Prosa spricht gegen diese Objektivităt. Der Naturalismus betrifft nur bestimmte Szenen, wie jene der Hinrichtung. Dort, wo der Autor ganze Zeiträume überspringt, ersetzt er diesen Vorgang durch den konzentrierten typisierenden Ausdruck und mittels Verallgemeinerungen; keines von beiden spricht also für den überparteilichen Erzähler.

Kazantzakis kann durchaus auch als "realistischer" Schriftsteller gelten, wenn damit die Respektierung von bekannten Tatsachen gemeint ist. "Kapitän Michalis" stuitzt sich beispielsweise auf mehrere historische Tatsachen, und in seinen Grundzügen berücksichtigt dieser Roman vollständig den Ablauf der Befreiungskämpfe im Kreta des vorigen Jahrhunderts. Das Verschweigen realer Koordinaten scheint dagegen in der "Griechischen Passion" geradezu beabsichtigt: der Autor will die immer wiederkehrende Geschichte der Kreuzigung offensichtlich nicht an eine bestimmte Zeit und an einen bestimmten Ort anknüpfen, um damit ihre universale Bedeutung nicht zu verringern.

Bei Kadare wurde eine besondere Vorliebe für die Vergangenheit, die wenig beweisbar ist, festgestellt. Er berücksichtigt nicht einmal allgemein bekannte geschichtliche Ereignisse; man hör z.B von großen Banken, von Dividenden und Aktien, von Zeitungen und militärischen Stützpunkten im Albanien des 14. Jahrhunderts ("Die Brücke mit drei Bogen"), oder von modernen Entnationalisierungsmethoden und vom raffinierten bürokratischen System im Osmanischen Reich ("Die großen Paschaliks", "Der Angestellte der Traumbehörde"). Im Themenkreis Albanien - Türkei baut der Autor ein eigenes Reich auf, das mehreren Reichen und zugleich keinem ähnelt.

Für den Stil Andrić' wurde die Bezeichnung meditativ-philosophisch vorgezogen. Dabei stellte sich die Tendenz als wichtig heraus, die Zeit zu verlangsamen oder einfrieren zu lassen, auch wenn sie Spannen von Jahrhunderten umfasst. In der "Brücke über die Drina" wird dieser Effekt durch zwei "Kunstgriffe" erzielt: durch die Darstellung eines guten Teils der Handlungen als sich wiederholende, sowie durch das Bild und Symbol der Brücke. Die Bruicke lebt vom Augenblick ihrer Entstehung an in einer verlangsamten oder eingefrorenen, am Schluß plötzlich in einer auf den Kopf gestellten Zeit.

Die Sprache Kazantzakis ließe sich wohl am wenigsten als leidenschaftslos einordnen; sie ist im Gegenteil so oft schwungvoll, besonders in der ersten Phase seines Schaffens (siehe "Der Baumeister" oder "Askitiki"). In "O Protomastoras" waren noch romantische und klassische Enflüsse zu bemerken, später kristallisierte sich der eigentliche Stil Kazantzakis' mit der sinnlichen 
Darstellung, der Einbeziehung der Natur und der farbenreichen griechischen Landschaft, mit den scharf konturierten Charakteren heraus.

Seiner temperamentvollen Sprache war sich Kazantzakis immer bewußt, er selbst stellte sie als Aufforderung für seine Kunst auf: "Die Sprache muß von den Nieren kommen", "der Gedanke muß zu einem plastischen Bilde werden", "das Wort mußt du wie eine Granate explodieren lassen", "das Wort muß zu pulsierendem Fleisch werden", usw.

Stichwortartig könnte neben der Andrić'schen philosophischen Meditation und Kazantzakis' plastischen Bildern die assoziative Metaphorik als der charakteristischste Zug in der Literatur von I. Kadare gelten. Die Metaphorik, einst dominierendes Prinzip seiner Lyrik, blieb ebenso wichtig, vielleicht der natürlichste Ausdruck seiner Kreativität auch in der Prosa. Sie besteht aus Parallelismen, Symbolen, Vergleichen, absurden, drolligen Phantasien (des Typs "als ob"), u.a. Oft überraschen diese Tropen, da sie völlig unerwartet, bizarr oder rein assoziativ auftreten. Bereits der erste Roman "Der General der toten Armee", aus dem mehrere Beispiele gebracht wurden, war dadurch geprägt; besonders intensiv ist die Metaphorik in der autobiographischen Prosa, aber auch in Werken wie "Die Brücke mit drei Bogen". Die Bildung einer bestimmten Atmosphäre ist für Kadare ebenfalls typisches Prinzip, das in "General der toten Armee", "Chronik in Stein", oder "Brücke mit drei Bogen" mit trübem, regnerischen Wetter gleichgesetzt wird. Neben wetterbezogenen Beschreibungen kommt diese Atmosphäre anhand von stark konnotierten Worten zustande ; im "General der toten Armee" war sehr oft von Gebeinen, Knochen, Ausgrabungen, Schlamm, usw. die Rede, in "Brücke mit drei Bogen" bereiteten eine Reihe von verhängnisvollen Zeichen (Epileptiker, Krüppel, verstummte Sprache, Sarg über den Fluß, u.a.) das grausame Geschehen am Briickenpfeiler vor.

\subsection{Das Motiv im Vergleich}

Die ausgedehnte Präsentation der Autoren in dieser Untersuchung hat hoffentlich zum Verständis der Art, wie jeder von ihnen den Bauopfer-Mythos behandelt hat, mitgeholfen. Die Analyse der einschlägigen und einiger verwandter Werke beschäftigte sich darüber hinaus ausführlich mit der Handhabung der Mythologie bei jedem Schriftsteller. Zusammenfassend zeige ich noch einmal einige Stichwörter dieser Untersuchung vergleichsweise auf:

Vorlage: Jeder Autor gestaltet den Stoff der Ballade von der eingemauerten Frau frei und schöpferisch für sich Wenn vor allem das Datum der Entstehung des Werkes und dic Charal iika eines jeden Schriftstellers berück- 
sichtigt werden, dann wäre zu erwarten, daß "Der Baumeister", ein 1908 entstandenes Stück eines jungen Autors, der zu dieser Zeit romantisch-nationalistische Auffasssungen vertrat, der hergebrachten Vorlage am nächsten steht. Das ist tatsächlich der Fall, wenn man sich die Kulisse des Geschehens, die handelnden Personen, die schematische Handlung, etc. anschaut (siehe den Vergleich der einzelnen Motive): Andric führt die Ballade in seinem Roman nur als zweitrangige und nur als ethnographische Episode an; Kadare "vergewaltigt" die herkömmliche Handlung mit jedem Schritt seines Sujets. Anders stellt es sich jedoch bei einer näheren Betrachtung heraus, die vor allem dem tieferen Sinn des Mythos Rechnung trägt. Kazantzakis verwandelt die ursprüngliche Begründung des Mythos ${ }^{1}$, bzw. das Dilemma der Ballade, das ein BewuBtsein zwischen mythischer Notwendigkeit und Verlust des geliebten Menschen zeigt, in einen Liebe-Askese-Konflikt, und die Aufopferung in Strafe für die Unzucht des Baumeisters und seiner Freundin Smaragda.

Andrić integriert das Motiv des Bauopfers in realistischen, ja naturalistischen Szenen, nachdem er die herkömmliche Legende als Erfindung und Kindergeschichte abgetan hat. Und trotzdem, obwohl Abidaga, die Sejmen, Radisaw u.a. kaum mit dem Balladenstoff zu tun haben, steht er einer tieferen Interpretation des Mythos näher, einfach darum, weil er Dimensionen wie das Bauen als eine schwere, schmerzhafte Geburt, die Notwendigkeit des Opfers, die "weiße Kraft der Fundamente", die Harmonie des Bauwerkes mit Erde, Fluß, Natur vom Mythos übernimmt und völlig in seine Vision aufnimmt.

Kadare gebraucht den Mythos auf eine andere Art, indem er ihn demontiert und seine einzelnen Mythologeme verzerrt und auf ihre Kehrseite bringt. In diesem Sinne steht er ihm wiederum näher als Kazantzakis, denn eine umgekehrte Form des Mythos setzt diesen schon voraus, und die widerwärtige Realităt, die Kadare aufzeigt, eine Realität, die den Mythos vergewaltigt, hat sicherlich ein helleres, nämlich sein mythisches Gegenstück.

Opfer: Das Opfer entspricht bei Kazantzakis mehr dem traditionellen Opfer der Legende. In "Baumeister" ist dies noch einmal eine Frau jung, mutig und unschuldig. Die Geopferten am Pfeiler der Brücken über die Drina und über die Ujana e Keqe sind hingegen grobe Bauern, die dieses große, zukunftsträchtige Bauwerk nicht mögen, es sogar sabotieren. Nichtdestoweniger bewirken sie das, was auch das hergebrachte Bauopfer bewirkt: die Erlösung und Errichtung der Brücke. Hier sehe ich bei Andrić und Kadare eine größere Neigung zum Experimentieren auch im Vergleich zum Opfer in Kazantzakis' "Griechischer Passion".

Gefangensein im Dunkeln: Das Bauopfer geschieht bei Andrić nicht in den Fundamenten der Brücke, der Geopferte verwandelt sich im Gegenteil zum Heiligen, zum sacrum, anhand von ikonischen Zeichen der Geschichte Christi. Das bedeutet keine geringe Umformung des Mythos, im Sinne der Teilung mythischer Mächte in chthonische und in olympische; noch verzerrter zeigte

${ }^{1} \operatorname{Im}$ Sinne Kerényis. 
sich jedoch die Aufopferung, aus den genannten Gründen, bei Kadare. Die Szene an der Drei-Bogen-Brücke war beeindruckend (der Mann wurde nicht einmal im Pfeiler der Brücke eingemauert, die Offnung wurde im Bereich der Augen vorgenommen) und so "verfolgen seine offenen Augen" unabläßig den Chronisten der Brücke und den Leser. Dieses Beispiel der Abweichung von einer Schlüsselsituation des Mythos bezeugt den Schockeffekt, den ein pervertiertes Mythologem ausüben kann.

Die Brücke als Symbol beinhaltet bei Kadare keine positiven Konnotationen. $\mathrm{Zu}$ wenig bedeutet sie Verbindung zwischen den Menschen und Harmonie mit der Natur, wie bei Andrić. Dies hängt zu einem Großteil mit dem thematisierten Zeitpunkt zusammen, als Albanien dabei war, "die Zeit um 600 Jahre zurïckzudrehen". Aber nicht nur das bestimmte die Symbolik der Brücke, auch psychologische Muster und Grundstimmungen erwiesen sich als mitbestimmend. In "O Protomastoras" kam der Brücke als Symbol und Mittelpunkt der Dichtung keine besondere Bedeutung zu, u.a., weil sich hier die Aufmerksamkeit des Autors vorwiegend auf das Liebesverhältnis des Baumeisters konzentrierte.

Die Bearbeitung einer mythischen Vorlage wurde auch in einem breiteren Rahmen analysiert. Im Roman "Griechische Passion" trafen wir auf einen Schriftsteller, der sich in mancher Hinsicht vom Kazantzakis des "Baumeisters" distanzien hatte, vor allem durch den Verzicht auf eine romantische und idealisierende Sichtweise der mythischen Wirklichkeit. Hier gab es einerseits rein transplantierte Episoden der Passion Christi, andererseits aber originelle, vielschichtige Interpretationen eines altbekannten und wiederkehrenden Motivs. Ähnliche Freiheit in der Gestaltung war auch in Kadares Roman "Wer hat Doruntina zurückgebracht" festzustellen. Kadare unterscheidet sich hier aber von den anderen zwei Autoren z’ sehr durch seine eigenwillige, einfallsreiche Prosa. Gegenüber den glaubhaft - realistischen Bildem Andrić und Kazantzakis' etwa in "Brücke über die Drina" und "Griechische Passion" steht hier eine moderne kriminalistische Geschichte, die ihre Handlung von einer alten europäischen Ballade borgt und, vor dem angeblichen Hintergrund des mittelalterlichen Albaniens, modeme Charaktere in zeitlosen Zuständen durch aktuelle Stimmungen des Erzählers vermittelt. Bei den zwei Romanen von Kadare wurde noch bemerkt, daß er in publizistischen, ja sogar außerliterarischen Erklärungen (die albanische besa rief die Auferstehung Konstantins hervor, die albanische Ballade ist die älteste, weil unsere Vorfahren, die Pelasger, die ersten Maurer der Welt waren, usw.) etwas Anderes beteuen, als der Prosaduktus eigentlich mitteilt. Dem Literaturkritiker wird es in der Zukunft sicherlich nicht leicht fallen, den rein literarischen und aufrichtigen Teil seines Werkes vom propagandistischen zu trennen.

Die Beschäftigung mit den Schriftstellem war eine geradezu spannende Arbeit; ich versuchte dabei, so weit ich konnte, statistische oder trocken-analytische 
Wege zu vermeiden, um diese Autoren im kreativen Prozeß, als ganzheitliche Persönlichkeiten und ihr Werk als offenen "Gegenstand" zu beobachten. Daher möchte ich den Sinn dieser Arbeit nicht in einem schematischen Vergleich von zusammengestellten Ideen aus drei Werken sehen, die das Motiv des chthonischen Bauopfers zum Mittelpunkt machen, sondern vielmehr als Begegnung mit drei bedeutenden Schriftstellem aus Südosteuropa, unter dem besonderen Schwerpunkt Mythologie. Ich hoffe, daß die Arbeit auf diesem Weg war. 


\section{LITERATURVERZEICHNIS}

Andric, Ivo, Die Brücke über die Drina. Übersetzung von E.E. Jonas. Frankfurt a.M. 1960.

Der verdammte Hof. München 1957.

Francisco de Goya. Übersetzung von J. Schütz. München 1962.

Omer Pascha L.atas. München 1976.

Sabrana dela Ive Andrica. Bd. 10. Beograd, 3.A. 1967.

Sämtliche Erzählungen. (in 3 Bänden). Übersetzt von M. Dor, R. Federmann, A.

Schmaus. München 1962 - 64.

Wesire und Konsuln. Übersetzung: H. Thurn. München 1978.

Bechofen, Johan Jakob, Mutterrecht und Religion. Stuttgart 1984.

Baladadhe legjenda. Prishtinë 1980.

Bandic, Miloš, Ivo Andric - Zagonetka vedrine. Novi Sad 1963.

Bartl, Peter, Anmerkungen zu einigen Problemen der albanischen Geschichte. In: Südosteuropa $36,1987,676-689$.

Bergman, Gun, Turkisms in Ivo Andric's Na Drini Cuprija. Uppsala 1969.

Bien, Peter, Kazantzakis and the Linguistic Revolution in Greek Literature. Princeton, N.J. 1972.

Bürger, Gottfried August, Gedichte. Leipzig und Wien 1928.

Burkert, W., Griechische Religion der archaischen und der klassischen Epoche. Stuttgart 1977.

Cabej, Eqrem, Sitten und Bräuche der Albaner. In: Südost-Forschungen XXV. München 1966, S. 333-387.

Catapano, Giuseppe. Constantino e Garentina, Roma 1947.

Cocchiara,Giuseppe. Il ponte di Arta e i sacrifici di costruzione. In: Annali del Museo Pitré 1, 1950. 
Detienne, Marcel, Die skandalöse Mythologie. In: Faszination des Mythos. Studien zu antiken und modemen Interpretationen. Hrsg. Renate Schlesier. Basel, Frankfurt/M. 1985, S. 13-34.

Diplich Hnns, Das Bauopfer als dichterisches Motiv in Südosteuropa. München 1976.

Duden.DasgroBe Worterbuch derdeutschen Sprache.Mannheim 1981.

Džadžic,Petar, Hrastova greda u kamenoj kapiji. In: Delo Ive Andrića u kontekstu evropske književnosti i kulture. Hrsg. Dragan Nedeljković. Beograd 1981, S. 211-218.

Ivo Andric, Beograd 1957.

Eliade, Mircen,Geschichte der religiősen Ideen. Freiburg 1981.

Mythen, Träume und Mysterien. Salzburg 1961.

Engels, Friedrich, Der Ursprung der Familie, des Privateigentums und des Staates. Stuttgart 1892.

Fiction and Drama in Eastern Europe. Columbia, Ohio 1980.

Gavazzi, M, Die Kulturzonen Südosteuropas. In: Südosteuropa-Jahrbuch 2. München 1958, S. 11-23.

Gesemann, Gerhard, Gesammelte Abhandlungen. Neuried 1981.

Grubečic,Slobodan, Ivo Andric: In: Kritisches Lexikon zur fremdsprachigen Gegenwartsliteratur. 10. Nachtragslieferung. München 1986

Hawkesworth, Celia, Ivo Andric: Bridge between East and West. London 1984.

Homer, Odyssee. Übersetzt von J. H. Voss. 1. Ausgabe. Hamburg 1781.

Habner, Kurt, Die Wahrheit des Mythos. München 1985.

Isakovid, Antonije, Hrsg., Zbornik radova o Ivi Andricu. Srpska akademija nauka i umetnosti. Posebna izdanja 30. Beograd 1979.

Janiaud-Lust, Colette, Nikos Kazantzakis - sa vie - son oeuvre. Paris 1970.

Kadare, Ismail, Kronikë në gur, Tirana 1971. Dt. Ausgabe: Chronik in Stein. Übersetzung: J. Röhm. Salzburg 1988.

Koha e shkrimeve. Tirana 1986.

Përse mendohen këto male. Tirana 1964.

Motive me diell. Prishtina 1978.

Koha, Tirana 1976.

Kështjella, Tirana 1970. Dt. Ausgabe: Die Festung. Kiel 1989.

Gjenerali i ushtrisë së vdekur, Tirana 1964. Dt. Ausgabe: Der General der toten Armee. Übersetzung: O. Buchholz und W. Fiedler. Kiel 1988. 
Dimri i vetmisë së madhe, Tirana 1973. Überarbeitete Fassung: Dimri i madh, Tirana 1976. Dt. Ausgabe: Der große Winter. Kiel 1987.

Nëntori i një kryeqyteti. Tirana 1974.

Emblema e dikurshme. Tirana 1977. 2.A. Tirana 1981

Ura me tri harqe. In: Ura me tri harqe. Tirana 1978.

Pashallëqet e mëdha In: Ura me tri harqe, Tirana 1978. Dt. Ausgabe: Der Schandkasten. Übersetzt von J. Röhm, Salzburg 1990.

Muzgu i perëndive të stepës. In: Ura me tri harqe. Tirana 1978.

Kush e solli Doruntinën. In: Gjakftohtësia. Tirana 1980.

Prilli i thyer. In: Gjakftohtësia, Tirana 1980. Dt. Ausgabe: Der zerrissene April. Übersetzt von J. Röhm. Salzburg 1989.

Autobiografia e popullit në vargje, 1975. Dt. Ausgabe: Autobiogıaphie des Volkes in Versen. Tirana 1989.

Nëpunësi i Pallatit të Endrrave. In: Vepra letrare 9. Tirana 1989.

Komisioni i festës. In: Ura me tri harqe, Tirana 1978. Dt. Ausgabe: Die Festkommission. In: Die Schleierkarawane. Kiel 1989.

Sjellësi i fatkeqësisë. In: Nëntori 4,1984. Dt. Ausgabe: Die Schleierkarawane. In: Die Schleierkarawane. Kiel 1989.

Karaulac, Miroslav, Rani Andric. Beograd 1980.

Kavafis - Seferis. Gedichte. Athen o.J.

Kazantzakis, Nikos, Alexis Sorbas. Übersetzung: A. Steinmetz. Hamburg 1955.

Einsame Freiheit. Biographie aus Briefen und Aufzeichnungen. Hrsg. von Eleni Kazantzakis. München 1972

Freiheit oder Tod. Berlin 1954.

Griechische Passion. Übersetzt von W. Krebs. Berlin 1963.

Komödie. Tragödie in einem Akt. Zürich 1969.

Rechenschaft vor El Greco. Übersetzt von I. Rosenthal-Kamarinea. Berlin 1964.

Rettet Gott! Übersetzt von K. A. Horst. Wien 1953.

Kengae popullit. Tiranë 1955.

Këng̈̌popullorelegjendare. Tiranë 1955.

Kerenyi, Karl, Einführung in das Wesen der Mythologie. Amsterdam 1941. 
Konstantinovic,Zoran, Burgten Burg drey Brüder eines Leibes. Ein Beitrag zur vergleichenden deutsch - südslawischen Symbolbetrachtung. In: Orbis Litterarum 3-4. Odense 1987, S- 262270. (Festschrift für Bengt Algot Sorensen).

Neueste jugoslawische Beiträge zur Erforschung der deutsch-südslawischen Kulturbeziehungen. In: Die Kultur Südosteuropas. Ihre Geschichte und ihre Ausdrucksformen. München 1964, S. 119-160 (Südosteuropaschriften, Bd. 6).

Korac, Stanko, Andricevi romani ili svijet bez boga. Zagreb 1966.

Levi-Strauss, Claude, Mythologica, I. Das Rohe und das Gekochte. Frankfurt a.M. 1971.

Liebrocht, Felix, Zur Volkskunde. Heilbronn 1879.

Lukic, Radomir, Hrsg., Ivo Andric. Bibliografija dela, prevoda i literature. Beograd 1974.

Malinowski,Borislaw, Myth in primitive Psychology. London 1926.

Markovic, Marko S., Tausend und eine Nacht des Ivo Andric. München 1962.

Matl, Joseph, Sprache und Dichtung als Schicksalsspiegel der südosteuropäischen Völker. In: Die Kultur Südosteuropas, ihre Geschichte und ihre Ausdrucksformen. München 1964, S. 171-188 (Südosteuropa-Schriften, Bd. 6).

Megas, Georgios A., Die Ballade von der Ara-Brücke. Thessaloniki 1976.

Milanovic, Branko, Ivo Andric. Zagreb 1966.

Minde, Regina, Ivo Andric. Studien über seine Erzählkunst. München 1962.

Nedeljkovic, Dragan, Hrsg., Delo Ive Andrica u kontekstu evropeske književnosti i kulture. Beograd 1981.

Negoši - Petrovic, M, Ivo Andric. L'homme et l'oeuvre. Ottawa 1969.

Neumann, Erich, Amor und Psyche. Freiburg 1984.

Neues Testament. In der Übersetzung von Martin Luther. Berlin 1912.

Ranke - Graves, Robert, Griechische Mythologie. Reinbeck bei Hamburg 1984.

Rohde, Erwin, Psyche. Tübingen 1983.

Sainean, L., Les rites de la construction d'après la poésie de l'Europe Orientale. In: Revue de l'Histoire des réligions. Bd. 45, 1902, S. 359-396.

Schiephacke, Bruno, Bildersprache der Seele. Kleines Lexikon zur Symbolpsychologie. Berlin 1970.

Schladebach,Kristian. Die aromunische Ballade von der Ara-Brücke. In: Jahresbericht des Instituts für rumänische Sprache, Bd. 1. Leipzig 1894, S. 79-121.

Schmaus, Alois, Gesammelte Abhandlungen. München 1973. 
Storm, Theodor, Der Schimmelreiter. Novelle. 1888.

Subotic, Dragan, Yougoslav Popular Ballads. Cambridge, Mass., 1932.

Tartalja, Ivo, Pripovedaceva estetika. Beograd 1979.

Trousson, Raymond, Le Thème de Prométhée dans la Littératures Européenne. Genève 1964.

Vargyas, Lajos, Die Herkunft der ungarischen Ballade von der eingemauerten Frau. In: Acta ethnographica Academiae scientiarum Hungaricae. Tom.IX, fasc.1-2. Budapest 1960.

Volkslieder der Serben. Metrisch übersetzt und historisch eingeleitet. Leiprig 1853.

Vučkovic, Radovan, Velika sinteza o Ivi Andricu. Sarajevo 1974.

Wahrig.DeutschesWorterbuch. München 1986.

Wierzbicki, Jan, Ivo Andrić. Warszawa 1965.

Worterbuch derMythologie.I.Die alten Kulturvollker, Bd. 2: Götter und Mythen im Alten Europa. Stuttgant 1973.

Wundt, Wilhelm, Völkerpsychologie. II: Mythos und Religion. Leipzig 1909.

Wattke, Adolf, Der deutsche Aberglaube der Gegenwart. Leipzig 1925. 
- it:

$=0 \begin{array}{ll}1 \\ 0\end{array}$

ant. 10

$$
\text { (1) }
$$

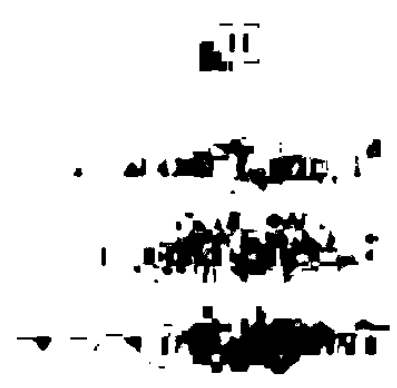

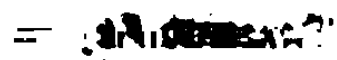

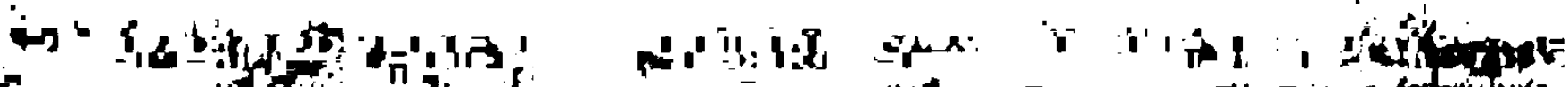

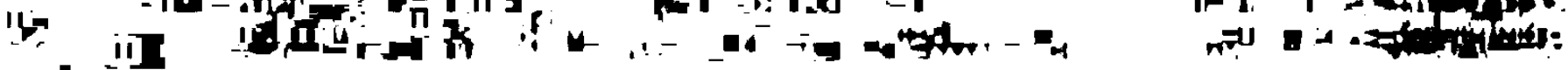
and

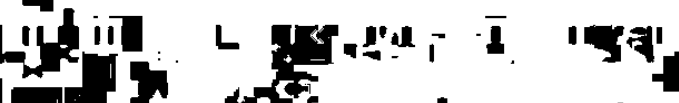

.

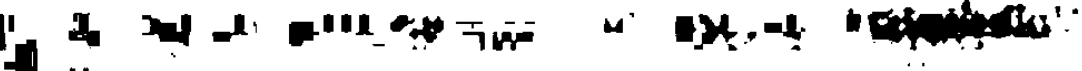
-

1'

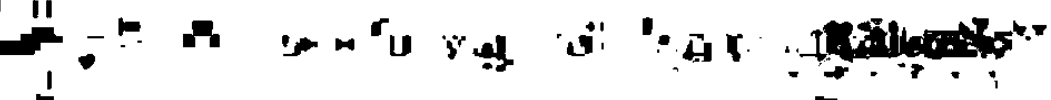

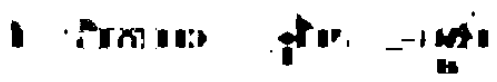

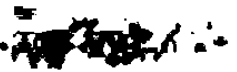

Atilimparito

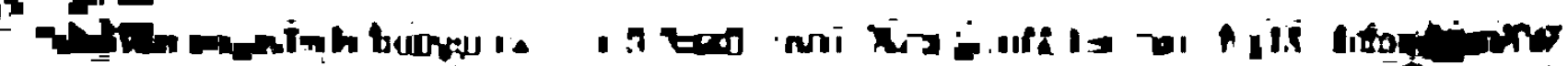
i.

$r+11$.

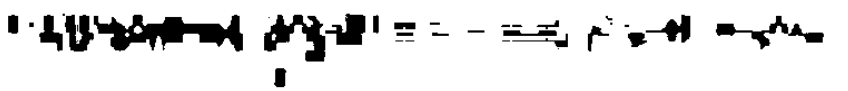

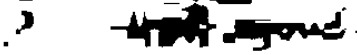

$\checkmark$

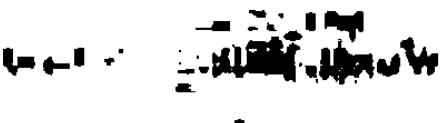

onds, whentor

1

11

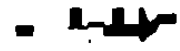

10

ip

$\mathbf{0}$

rorne

I. $x^{4} \frac{1}{4}$

1.

L._-

$+.45$

I m

$x \rightarrow \cos c$

I

ine

Ardian Klosi - 9783.954791729

r. 


\title{
ANHANG 1: Varianten der Ballade
}

\author{
Griechische Variante (Epirus)
}

Eintausend Meister waren einst am Bau der Arta-Brücke.

Was sie den ganzen Tag gebaut, es stürzt des Nachts zusammen.

Die Meister klagen bitterlich, die Baugesellen weinen.

Ein Vöglein flog herbei und setzt sich auf den mittleren Bogen;

Es sang nicht wie ein Vogel sonst, wie alle Vöglein singen,

Es sang vielmehr und redete mit Menschenstimm' und -sprache:

"Ihr Meister, laßt die Mühsal sein und plagt euch auch nicht weiter,

Grabt ihr hier keinen Menschen ein, wird grundfest nie die Brücke.

Ein Waisenkind soll es nicht sein, nicht Kindlein einer Witwe,

Vielmehr des Obermeisters Frau, die Frau des Meister Jannis".

Er trug dem Baugesellen auf, er solle sie ihm holen.

"Schön guten Tag, Frau Meisterin". - "Willkommen, Baugeselle!"

- "Spute dich, spute dich, Muisterin, der Meister will dich haben".

- "Kamst du fúr Gutes, Baugesell', komm ich so wie ich jetzt bin,

Kamst du für Böses, Baugeselle, nehm' ich die schwarzen Kleider".

- "Spute dich, Meisterin, und sei's so wie du jetzt bist".

"Wünsch' guten Tag, mein Jannis, dir". - "Willkommen, liebe Gattin".

- "Jannis, was riefst du mich herbei, was ließest du mich holen?"

- "Mein Fingerring fiel mir hinab, am mittler'n Brückenbogen,

Wer steigt hinab, wer steigt hinauf, den Ring wer wird ihn holen?"

- "Ich steig' hinab, ich steig' hinauf, den Ring, ich werd' ihn holen".

Hinab, hinauf war sie noch kaum, schon war sie eingemauert.

Mit heller Stimme rief sie laut, so laut wie sie nur konnte:

"Drei Schwestern mußten wir, die drei, als Bauopfer verenden,

Die Donaubrücke eine stützt, die and're stützt Avlona,

Die dritte, Allerjüngste, hält und stützt die Arta-Brücke.

So wie mir bebt mein armes Herz, so soll die Brücke beben,

Wie meine T:änen strömen jetzt, sollen die Wanderer stürzen

Und wie mein Kindlein heult, so soll der Strom auch widerhallen".

(Ütersetzt von V. Xanthaki-Kalopissi aus: G.Megas, Die Ballade von der Ara Brücke, S.183) 


\section{Ungarische Variante}

Einst des Weges zogen weit ins Land zwollf Maurer, Gingen immer... gingen... bis zur Festung Deva, Sollten dort die hohe stolze Burg erbauen;

Doch was tags sie bauten, stürzte nachts zusammen, Was bei Nacht sie bauten, stürt am Tag zusammen.

Maurer Klemens endlich stellte dies Gesetz auf:

Welche Frau als Erste ihnen Essen brächte, Mittagbrot im Korbe,

Sollte zwischen Steinen eingemauert werden,

Sollt' verbannt im Mauerwerk der stolzen Feste werden:

So nur wünd' es ihnen endlich denn gelingen,

Aufzubau'n die hohe stolze Burg von Deva.

Sieh! Da schritt heran das junge Weib des Klemens,

Auf dem Haupt den Korb trug sie, das Mittagbrot

Und im Arm ihr Kindlein, rund und wangenrot.

Voll Entsetzen sieht sie Klemens, der Gefährte:

"Gott, mein Gott! o laß vor ihr erstehen

Wilde Tiere, daß sie heimwärts flüchte!"

Ach! umsonst sein Flehen,

Gott, der Herr, erhörte nicht die Bitte,

Naher kam sein Weib mit jedem Schritte.

"Gott, mein Gott! o laß vor inr erstehen

Schwarze Wetterwolken, laß es Steine hageln,

Daß den Weg sie aufgibt!"

Ach, umsonst sein Flehen.-

Gott, der Herr, erhörte nicht die Bitte,

Näher kam sein Weib mit jedem Schritte.

"Guten Tag, ihr Zwollfe!... Guten Tag, ihr Maurer!...

- Lieber Gott, was habt ihr! - laßt mich dreimal grüßen

Und nicht einmal, nein, nicht einmal gebt ihr Antwort." 
"Ach, wir würden schon, wir würden Antwort geben,

Kämst du Arme nicht hierher zu deinem Tode;

Sieh, dein eigner Gatte stellte dies Gesetz auf:

Welche Frau als Erste uns das Essen brächte,

Mittagbrot im Korbe,

Sollte zwischen Steinen eingemauert werden,

Sollt' verbrannt im Mauerwerk der stolzen Feste werden.

So nur kann es endlich uns gelingen,

Auf dem Hügel aufzubau'n die Burg von Deva."

"Tu es denn, und komme was da muß,

Ward das Leben dir mit mir zum Überdruß!"

...Als den Korb sie ihr vom Haupt genommen haben

Und aus ihrem Arm den kleinen Knaben,

Dachte sie, es sei ein Scherz des Gatten...

Erst als bis zur Brust sie eingemauert war.

Wurde ihr die grause Wahrheit klar.

"Weine nicht, mein Söhnlein!

noch gibt's gute Frauen hier auf Erden,

Die die Brust dir geme reichen werden,

Noch gibt's gute Kinder, die dich wiegen,

Und die Vöglein, die von Ast zu Aste fliegen,

Werden Schlummerlieder für dich singen."

...Weiter bauten sie die hohe Burg von Deva;

Was bei Tag sie bauten, blieb bestehn am Tage.

...Hoch empor, hoch empor wuchs die Burg von Deva.

Eingebaut in ihre Mauem aber

Hatten sie des Klemens Lebensfreude

Und sein Glück auf Erden,

Ging nicht aus dem Haus mehr, sehen wollt er keinen,

Nachts trieb ihn vom Lager seines Kindes Weinen.

(Aus dem Ungarischen übertragen von Hedwig Lüdeke; in H. Diplich, Das Bauopfer als dicherisches Motiv in Südosteuropa, S.11-13) 


\section{RumanischeVariante}

I.

An des Argesch Strand

Talwärts in das Land

Wode Negru reitet

Von zehn Mann begleitet.

Meister waren neune,

Maurer wie sonst keine,

Doch niemand im Reich

War dem zehnten gleich.

Zogen also fort...

Einen heiligen Ort

Für den Klosterdom

Suchten sie am Strom.

Sieh, an jenem Pfad

Trafen sie gerad

Einen Hirten am Hang.

Der die Doine sang.

Als der Fürst inn sah,

Rief der Herr ihm da:

"Hirte stolz und frei,

Spielst auf der Schalmei,

Sag, den Fluß entlang

Geht der Herde Gang

Und auch weit hinauf

Gegen Stromes Lauf:

Hast du nicht gesehn

Im vorïbergehn

Eine Mauer alt,

Die verlassen, kalt,

Auf der Anhobh steht,

Wo's durch Haseln weht?"

"Ja, Herr, wo ich war,

Sah ich alle Jahr

Eine Mauer alt

Die verlassen, kalt.

MeineSchăfertunde

Heulten in der Runde,

Fielen wütend dann

Das Gemăuer an." 
Als der Fürst ihn so

Hörte, zog er froh

Zu der Mauer hin.

Und mit stolzem Sinn

Meister folgten, neune,

Mauer wie sonst keine,

Manol, der zehnte, war

Der beste seiner Schar.

"Seht die Maurer mein!

Hier will ich allein

Auf den Herm vertrauen

Und mein Kloster bauen!

Meister und Gesellen

Flink mit Lot und Kellen.

Große Meister ihr

Strebt getreulich mir

Macht die Arbeit gut,

Schafft mit gleichem Mut,

Baut ein Kloster da

Wie's noch keiner sah,

Dann mach ich euch gleich

Zu Bojaren reich,

Schafft ihr's nicht, sodann

Höret mich nur an,

Lebend in den Stein

Maure ich euch ein!"

II.

Meister und Gesellen

Maßen gleich die Stellen,

Und in großer Eil

Spannten Schnur und Seil;

Gruben breite Gräben,

Mauem zu erheben.

Was sie tags vollbracht

Stürzte in der Nacht.

So am zweiten Tag,

So am dritten Tag,

So am vierten Tag:

Fruchtlos Müh und Plag.

Kam der Fürst erstaunt,

Schalt sie schlecht gelaunt

Und rief dann im Zorn:

"Fanget an von vorn,

Sonst maur ich euch ein

Lebend in den Stein!" 
Maurer und Gesellen

Hoben Lot und Kellen, Schufen so in Not

Wie's der Herr gebot,

Bangten vor dem Tod

Bis zum Abendrot.

Doch Manole stand,

Ruihrte keine Hand,

Schlief dann tiefen Schlaf,

Bis ein Traum inn traf.

Stand zur Morgenstund

Auf und tat ihn kund:

"Meister, euer neune,

Maurer wie sonst keine,

WiBt ihr, was im Schlaf

Für ein Traum mich traf?

Hab die Stimm vernommen,

Ist von oben kommen,

Sagt, was wir vollbracht,

Stïrzt in jeder Nacht.

Und dies wăhr, Genossen

Bis wir fest entschlossen

Mauem in den Bau

Jene erste Frau,

Die ums Morgenrot

Bringt das täglich Brot,

Trägt das Mahl heran

Dem Bruder oder Mann.

Soll es denn gelingen,

Wollt ihrs fertig bringen

Und mit Gottvertrauen

Dieses Kloster bauen,

Bleibt uns keine Wahl.

Schwört mir allzumal,

$\mathrm{DaB}$ der Eid euch binde

Und uns einig finde:

Wessen Gattin traut,

Schwester oder Braut

Bringt im Morgenrot

Uns zuerst das Brot,

Muß geopfert sein,

Mauem wir sie ein!

III.

Kaum entfloh die Nacht, War Manol erwacht.

Früh, im Morgentau'n

Stieg er auf den Zaun,

Trat zur selben Frist

Auf das Baugerüst.

Sah ins Feld hinab,

Sucht die Wege ab. 
Weh! Was mußt er schaun,

Wollt dem Aug nicht traun,

Die schönste der Fraun

Bracht inm Wein und Brot

Früh im Morgenrot.

Sein geliebtes Weib,

$O$, der junge Leib!

Als er sie gesehn.

Blieb das Herz ihm stehn.

Stürzend auf die Knie

Weinte er und schrie:

"Herr, send einen Regen

Meinem Weib entgegen,

$\mathrm{Daß}$ er schăume, fließe,

Strömend sich ergieße;

$\mathrm{Da}$ die Fluten schwellen,

Sichentgegenstellen;

Herr, den Weg ihr wehre,

$\mathrm{DaB}$ sie heim mir kehre.

Gott war voll Erbarmen,

Hörr' die Bitt des Armen,

Zog viel Wolken bei.

Gab die Tropfen frei,

Und dann strömte Regen,

Schäumte allerwegen.

$\mathrm{Ob}$ auch Winde brausen,

Regen niedersausen,

Und die Fluten schwellen,

Sich entgegenstellen,

Ach, sie kommt heran.

Ist schon nah dem Mann;

Doch Manoles Herz

Weint vor jähem Schmerz,

Wieder zum Gebet

Stürzt er hin und fleht:

"Gon, erhör den Schrei,

Gib die Stürme frei,

Sollen Tannen wiegen

Und den Ahom biegen,

Berge wirf herum.

$\mathrm{Da} B$ sie kehre um.

Lenke, Herr, ich bitt,

Heimwärts ihren Schritt."

Gott war voll Erbarmen,

Hört das Flehn des Armen,

Ließ die Stürme los.

Auf die Erde groß.

Ließ die Tannen wiegen

Und den Ahom biegen,

Warf die Berge um,

$\mathrm{Da} B$ sie kehre um. 
Doch Manoles Weib

Hielt den schwanken Leib

Jedem Sturm entgegen,

Kam auf wüsten Wegen,

Ach, schon war sie nah,

Und nun stand sie da!

\section{IV.}

Als die Meister sahen

Manes Gattin nahen,

War die Freude gro $B$;

I h n traf so das Los.

Gleich faßt er sein Weib

Um den schlanken Leib

Rasend er sie küBt'

Schwang sie aufs Gerüst,

Lachend sprach sodann

Dergequalite Mann:

"Liebste, hör mich an,

Sollst nicht ăngstlich sein,

Denn zum Scherz und Schein

Mauem wir dich ein!"

Ana lacht und schaut,

Freudig ihm vertraut,

Doch Manol, ihr Mann,

Hebt nun seufzend an,

Baut in herber Qual

Wie der Traum befahl.

Baut die Gattin ein,

Und es schloß der Stein

Knie und Knöchel ein.

Also wuchs die Wand

Um das teuere Pfand.

Ach, das ărmste Blut

Weinte bald: "Nicht tut

Wohl dein Übermut.

Manole, Manole.

Meister mein, Manole,

Hier ist kein Verbleib

Für dein armes Weib."

Doch Manole schwieg.

Und die Mauer stieg,

Mauerte sie ein,

Und schon reicht der Stein

An die Knöchel klein,

An die Knie fein,

An die Lenden schmal,

Brüste allzumal.

Doch das arme Blut

Weinte fort: Nicht tut

Wohl dein Übermut! 
Manole, Manole,

Meister mein, Manole,

Mauer tut mich engen,

Und mein Kindlein zwängen!"

Doch Manole schwieg,

Und die Mauer stieg...

Denn er schwang den Stein

Hüllte gleich sie ein,

Ihre Lenden rein,

Brïste klein und rund,

Dann den lieben Mund

Und die Augen schön -

War nicht mehr zu sehn.

Doch er hört sie klagen,

Aus der Mauer sagen:

"Weh, ich muß es tragen,

Manole, Manole.

Meister mein, Manole,

Sieh, dies dunkle Haus

Löscht mein Leben aus."

V.

Den Argesch entlang

An dem schönen Hang

Wode Negru geht

Fürchtig zum Gebet,.

Seinem Kloster gleicht

- Stolz und unerreicht -

- So weit ihm bekannt -

Keins im garızen Land.

Als der Fürst es schaut

Herrlich auferbaut

Ruft er freudig laut:

"Maurermeister, ihr,

Sagt es ehrlich mir,

Weit und breit bekannt,

Größte in dem Land,

Habt ihr noch mehr Kraft,

Kunst und Meisterschaft,

Prächtig uns zu bauen,

Herrlicher zu schauen,

Noch ein Heiligtum

$\mathrm{Zu}$ weit höh'rem Ruhm?

Und die Meisterschar

Auf dem Dache war

Hochgemut und froh,

Brüsteten sich so: 
"Wo bleibt bis zur Frist

Einer, der sich mißt

Mit uns Meistern allen,

Mehr noch zu gefallen?

Niemand kommt uns gleich,

Fürst, in deinem Reich!

Dies sei allen kund,

$\mathrm{DaB}$ zu jeder Stund

Prächtiger wir bauen,

Herrlicher zu schauen,

Noch ein Heiligtum

Zu weit hoh'rem Ruhm?"

Negru horn sie an,

Finsteres er sann,

Gab Befehle dann:

"Brecht Gerüst und Stab,

Stang und Leiter ab!

Und die Maurermeister,

Alle großen Meister

Werden im Gebälk

Auf dem Dache welk

Sollen so verlassen

Faulen und verblassen!"

Doch die Meister dachten...

Und alsbald sie machten

Aus Schindeln gar klug

Flügel für den Flug.

Breiteten die Schwingen,

In die Luft zu springen.

Es wollte nicht gelingen.

Tot nach Sturz und Fall

Warn die Meister all.

Nur Meister Manole,

Der arme Manole,

Während er zu springen

Breitete die Schwingen,

Laute zu ihm dringen

Aus der hohlen Wand,

Stimme wohlbekannt,

Liebevolles Klagen,

Seufzer hingetragen,

Die nur immer sagen:

"Manole, Manole,

Meister mein, Manole!

Maver tut mich engen

Und mein Kindlein zwängen,

Weh, dies dunkle Haus

Löscht mein Leben aus!" 
Wohl sieht Mane hin

Mit verstörten Sinn,

Doch er kann nichts sehen...

Welt und Wolken drehen

Vor den Augen heiß

Rasend sich im Kreis;

Von Gebälk und Dach

Tot hinstürzt er jach.

Wo der Meister lag,

Fließt seit jenem Tag

An der gleichen Stelle

Eine sanfte Quelle,

Salzge Wellen leuchten,

Tränen sie befeuchten.

(Aus dem Rumänischen übertragen von Hans Diplich, in: Das Bauopfer als dicherisches Motiv in Südosteuropa" S.21-31) 


\section{Serbische Variante}

\section{Erbauung Skadars}

Eine Fest' erbauten die drei Brüder, Die drei Brüder, drei Merljawtschewitschen. Einer war Herr Wukaschin, der König. Und der zweite der Woiwod Ugljescha, Und der dritte war der jüngste Gojko. Schon drei Jahre baun sie an der Feste, An Skadar, der Fest' an der Bojana, Schon drei Jahre baun dreihundert Meister, Können nicht einmal den Grund ausheben, Minder noch die Feste selbst erbauen. Was am Tage aufgebaut die Meister, Alles reißet nächtlich ein die Wila.

Aber als das vierte Jahr begann nun, Rief die Wila aus dem Waldgebirge:

"KÖnig Wukaschin, du quälst umsonst dich! Quälst umsonst dich, all dein Gut verlierst du! Nicht den Grund vermagst du auszuheben, Wie willst du die Feste selber bauen! Findest du nicht zwei gleichnamige Wesen, Findest du nicht Stojan und Stojana Und die beiden leiblichen Geschwister, Sie im Fundamente zu vermauern;

So nur, Konig, wird der Grundstein halten, So nur kannst du deine Feste bauen!"

Als dies der König Wukaschin vernomnen, Rief er zu sich Dessimir, den Diener: "Höre, Dessimir, mein liebes Söhnchen! Treuer Diener warst du mir bis heute, Doch von heute an, mein liebes Söhnchen, Spanne, Kind, die Rosse vor den Wagen, Lade auf sechs Saumeslasten Goldes, Ziehe in der weißen Welt umher, Sohn! Suche mir zwei gleichbenannte Wesen, Suche mir zwei leibliche Geschwister, Welche Stojan und Stojana heißen!

Raub sie oder kauf sie mit Golde;

Bring sie nach Skadar an der Bojana, $\mathrm{DaB}$ wir in des Turmes Grund sie mauern; Denn nur also wird der Grundstein halten, Daß die Feste wir erbauen können." 
Als dies Diener Dessimir vernommen, Eilt er zu den Rossen und dem Wagen, Lud darauf sechs Saumeslasten Goldes; Und die weiße Welt durchzog der Diener, Zwei der gleichbenannten Wesen suchend, Zwei Geschwister, Stojan und Stojana! Suchte wohl drei Jahre lang der Diener, Nirgends fand er die gleichnamigen Wesen, Nirgends fand er Stojan und Stojana.

Drauf kehri' er zu seinem Herrn zurücke, Übergab dem König Ross' und Wagen, Gab ihm auch die sechs Saumlasten Goldes:

"Hier, mein König, hast du Ross' und Wagen, Hier hast du zurück die Lasten Goldes! Nirgends find ich die gleichnamigen Wesen, Nirgends find ich Stojan und Stojana."

Als dies König Wukaschin vernomnen, Da berief er wieder Rad, den Bauherrn; Aber Rad rief die dreihundert Meister. Und sie baun Skadar an der Bojana; Was sie bauen, reißet um die Wila, Gibt nicht zu, daß sie den Grund ausheben, Drauf die weiße Feste zu erbauen. Und sie ruft aus ihrem Waldgebirge:

"Hore, König Wukaschin, vernimm mich!

Was doch quälst du dich? Dein Geld verlierst du!

Nicht den Grund vermagst du auszuheben, Wie willst du die Feste selber bauen!

Doch vernimm: Ein jeder von euch Brüdern

Hat ein treues Ehgemahl zu Hause;

Die, so morgen kommt an die Bojana

Und den Meistern überbringı die Mahlzeit,

Diese mauert ein im Fundamente!

Dann nur, König, wird der Grundstein halten, $\mathrm{Daß}$ die Feste ihr erbauen könnet."

Als dies König Wukaschin vernommen, Rief er zu sich seine beiden Brüder:

"Höret meine Worte, meine Bruider!

Mir rief zu des Waldgebirges Wila,

Nicht mehr sollten wir das Geld vergeuden,

Nicht gestattet sie's, den Grund zu legen,

Drauf die weiße Feste zu erbauen.

Und es spricht des Waldgebirges Wila:

Jeglicher von uns drei Briddern hätte

Ein getreues Ehegemahl zu Hause;

Die, so morgen käm an die Bojana

Und den Meistem ihre Mahlzeit brächte,

Diese sollten wir im Grund einmauern,

So nur werde unser Grundstein halten,

$\mathrm{DaB}$ darauf wir unsre Fest' erbauen.

Laßt uns, Brüder, es bei Gott beschwören,

$\mathrm{Daß}$ dem Glück wir's überlassen wollen, 
Welche morgen geht an die Bojana."

Und bei Gott beschworen es die Brüder,

Keiner woll es seiner Gattin sagen.

Aber als die Nacht sich niedersenkte, Gingen sie nach ihren weißen Hofen, Und nachdem sie herrlich Mahl gehaiten, Ging ein jeder nach dem Schlafgemache.

Siehe, da geschah ein großes Wunder! Wukaschin trat erst den Eid mit Füßen, Er war's, der zuerst der Gattin sagte: "Hüte dich, du meine treue Liebe! Gehe morgen nicht nach der Bojana! Bringe nicht den Meistern ihre Mahlzeit! Dir dein junges Leben würd es kosten, Eingemauert in des Turmes Grunde."

Auch Ugljescha trat den Eid mit Füßen; Warnend sprach er zu der treuen Gattin: "Tausche dich nicht, meine treue Liebe! Gehe morgen nicht nach der Bojana! Bringe nicht den Meistern ihre Mahlzeit! In der Jugend wärest du verloren, Eingemauert in des Turmes Grunde."

Nur der junge Gojko hielt den Eidschwur, Sagte nichts zu seiner treuen Gattin.

Als der Morgen nun des Morgens anbrach, In der Früh erhoben sich die Brüder, Gingen nach dem Bau an der Bojana. Sieh, da gehn zwei edle junge Frauen, Von den Schwägerinnen, die zwei ältesten, Eine trägt ihr weißgebleichtes Linnen, Will's noch einmal auf die Bleiche bringen, Gehet mit dem Linnen auf den Bleichplatz. Trägt es dorthin, aber geht nicht weiter. Schöne rote Krüge bringt die zweite. Bringt die Krüge nach dem kalten Wasser, Spricht am Fluß daselbst mit andren Frauen Săumet dorten, aber geht nicht weiter.

Noch daheim ist Gojkos junge Gattin, Denn sie hat ein Kindlein in der Wiege. Einen Säugling, einen Monat alt erst.

Naht die Zeit zum herrschaftlichen Mahle.

Es erhebt sich ihre alte Mutter, Will die jungen Dienerinnen rufen, $\mathrm{DaB}$ das $\mathrm{Mahl}$ sie zur Bojana bringen.

Da beginnet Gojkos junge Gattin:

"Bleibe ruhig sitzen, meine Mutter!

Schaukle mir das Kindlein in der Wiege, $\mathrm{DaB}$ ich selbst das Mahl den Herren bringe; Wär es doch vor Gott gar große Sünde 
Und vor allen Leuten Schimpf und Schande,

Wenn statt unsrer dreie du es brächtest."

Und es blieb daheim die alte Mutter,

Schaukelte das Kindlein in der Wiege;

Auf stand Gojkos junge Ehegemahlin,

Rief die jugendlichen Dienerinnen,

Um das herrschaftliche Mahl zu tragen.

Als sie kamen ans Bojanawasser,

Sah sie der Merljawtschewitsche Gojko.

Drauf der Gattin stürzt er sich entgegen,

Und sie mit dem rechten Arm umschlingend,

Küßt er tausendmal ihr weißes Antlitz.

Heiße Tränen strömen aus dem Aug ihm,

Als die Wort er redete zur Gattin:

"Meine Gattin, du mein großes Herzleid!

Siehst du nicht, daß du hier sterben sollest?

Wem hast du Johannes überlassen?

Wer wird den Johannes heute baden?

Wer die Brust dem lieben Säugling reichen?"

Und er will ihr mehr und mehr noch sagen.

Doch nicht duldet's Wukaschin, der König.

Bei der Hand ergreift er sie und führ sie

Und ruft Rad herbei, des Baues Meister,

Aber Rad ruft die dreihundert Meister,

Láchelnd hört's die schlanke Neuvermählte,

Denkt bei sich, daß sie im Scherze jubeln.

Nun, daß sie die Feste endlich gründen,

Werfen hurtig die dreihunder Meister

Stein und Bäume um sie her in Menge,

Bis zum Gürtel also sie ummauernd.

So umtürmt von Steinen und von Bäumen.

Sieht die Arme, welch Geschick ihr werde;

Schmerzlich zürnend schreit sie in Verzweiflung,

Und sie flehet zu den lieben Schwägem:

"Duldet ihr's nicht, wenn ihr Gott erkennet,

Daß sie ein mich mauem, jung und blühend!"

Aber unerhöret blieb ihr Flehen.

Wendeten sich von ihr fort die Schwäger.

Drauf bezwinget Scham und Furcht vor Tadel,

Sprach sie flehend so zu ihrem Herren:

"Gib's nicht zu, mein guter Herr und Gatte,

Daß so jung sie grausam mich einmauem!

Laß uns gehen zu meiner alten Mutter!

Hat genug des Geldes ja die Mutter,

Kauft dir einen Sklaven oder Sklavin,

Sie im Fundamente einzumauern!"

Aber unerhöret blieb ihr Flehen

Als dies sah die schlanke Neuvermahlte,

Daß ihr keiner half auf ihre Bitten.

Flehte Rad sie an, des Baues Meister:

"Du, in Gott mein Bruder, lieber Meister! 
Laß ein Fensterlein an meiner Brust mich halten,

Wenn mein Säugling kommt, das Kind Johannes,

Wenn er kommt, daß ich ihm Nahrung reiche!"

Und um Gott erbarmte sich der Meister,

Ließ ein Fensterlein an ihrer Brust ihr,

Um hinaus aufs Feld die Brust zu haiten,

$\mathrm{DaB}$ sie ihrem Säuglinge Johannes,

Wenn er komme, Nahrung reichen könne.

Und noch einmal flehte sie zum Meister:

"Ich beschwöre dich, in Gott mein Bruder!

Laß ein Fensterlein mir an den Augen,

$\mathrm{DaB}$ ich schau nach meinem weißen Hofe,

Wenn sie mir das Kind Johannes bringen

Und wenn nach Hause man ihn wieder trägt."

Briderlich erbarmte sich der Meister,

Ließ ein Fensterlein ihr an den Augen,

$\mathrm{DaB}$ sie schau nach ihrem weißen Hofe,

Wenn man ihr das Kind Johannes bringe

Und wenn nach Hause man es wieder trägt.

Dieserweis erbauten sie die Feste.

Doch zur Stelle brachte man das Kindlein,

Und sie stillt es eine ganze Woche,

Eine Woche, dann ging ihr die Stimm aus.

Doch noch immer Nahrung blieb dem Knaben,

Und sie stillte ihn ein ganzes Jahr lang.

So wie damals, also ist es heute!

Frauen, die der Muttermilch ermangeln,

Um des Wunders, um der Heilung willen

Kommen hierher sie, ihr Kind zu stillen.

(Übersetzt von Therese Albertine Luise von Jakob. Aus: Volkslieder der Serben. Leipzig 1853) 


\section{Albanische Variante}

Der Nebel zog über die Bojana,

Da blieb er drei Tag' und drei Nächte lang;

Und dann kam eine leichte, kühle Brise,

Zerriß den Nebel und hob ihn hinauf,

Hinauf bis zum Valdanuz 1 ,

Hier waren nun drei Meister, drei Brüder,

Christen alle drei, gute Arbeiter,

Was sie am Tage immer erbauten,

Das fiel ihnen in der Nacht zusammen!

Da geht ein Heiliger des Weges vorbei:

"Guten Tag und viel Erfolg, ihr Meister!"

"Danke sehr, du guter Heiliger,

Woran siehst du denn unsren Erfolg?

Was wir am Tag erbauen.

Das fält in der Nacht zusammen.

Sei uns gnädig, o guter Heiliger,

Kannst du uns einen Ausweg sagen?".

"Wohl kann ich, nur fällt's mir schwer."

"Laß uns diese Last selbst tragen."

"Seid ihr alle drei vermählt?

Habt ihr alle drei eine Braut?"

"Alle drei sind wir vermählt,

Jeder hat daheim eine Braut;

Sag uns dann, was ist zu tun,

Wie soll'n wir die Burg aufbauen."

"Hör nun, wenn ihr sie errichten wollt,

Geht am Sonntag nicht arbeiten;

Leistet Schwur und gebt das Wort ${ }^{2}$,

Und zuhause verratet nichts,

Euren Frauen sagt ihr nichts!

Und den Tag darauf am Morgen,

MüBt ihr jene Braut, die kommt,

Um das Brot zu euch zu bringen,

In die Mauem der Burg einmauerr.

Und dann werdet ihr zusehen

Wie die Burg bald Wurzeln schlägt."

$O$ weh! der äiteste von den Brüdem

Brach das Wort, den Glauben brach

Und zuhaus erzählte er alles,

Verriet alles an seine Braut.

${ }^{1}$ Hafen- und Hügelname bei Ulcinj; hier befinden sich die Ruinen einer alten Festung.

2"lidhni besë e lidhni fe" 
Tat das Gleiche der zweite Bruder,

Vergaß alles, was der Heilige riet,

Brach das Wort, den Glauben brach er,

Verriet alles seiner Braut.

Der jüngste aber war auch der beste,

Er hielt das Wort, bewahrte den Glauben

Und niemandem erzăhlte er etwas daneim,

Kein Wort verriet er seiner Braut.

Am năchsten Tag gleich in der Früh,

Behauen sie Steine mit pochendem Herzen.

Rief die Mutter nach den Bräuten:

"Du erste Schwiegertochter!

Die Meister brauchen Brot,

Die Meister brauchen Wasser."

"Ich kann heute leider nicht dahin,

Ich hab' schlecht geschlafen, ich fühl' mich krank."

"Du zweite Schwiegertochter,

Die Meister brauchen Brot,

Die Meister brauchen Wasser.

Sie möchten haben ihr FåBchen mit Wein."

"Ich kann aber leider nicht dahin,

Zu meinen Leuten muß ich heut gehen."

"Du jüngste Schwiegertochter!"

"Was wünscht Ihr, meine liebe Mutter."

"Die Meister brauchen Brot,

Die Meister brauchen Wasser,

Sie möchten haben ihr Fäßchen mit Wein."

"Ich würde gem hingehen, Mutter,

Ich habe aber leider den Săugling daheim."

"Mach dir keine Sorgen, du liebe Tochter,

Wir werden uns um den Kleinen kümmern,

Ruhig wird er sein, weinen wird er nicht."

Sie nahm das Essen, Wasser und Wein,

Und ging darauf in die Stadt

Und näherte sich den Mauem der Burg.

Da blieben die Hămmer stehen.

Da standen die Herzen still,

Und alle erblaßten vor Schreck.

Als der eigene Mann sie sah,

Fiel ihm der Hammer von der Hand,

Einen Fluch stieß er verbittert aus.

"Warum fluchst du, teurer Mann,

Was für einen Fluch an den Mauern der Burg?"

"Jetzt sieht es schlecht für dich aus,

Wir müssen dich in der Burg einmauem!"

"Lebt wohl, mein Mann und ihr Brüder!

Ich habe für euch einen letzten Willen,

Wenn ihr mich in den Mauern einmauen,

Laßr eine Öffnung für mein rechtes Aug.

Laßt eine Öffnung für meine rechte Hand,

Laßt eine Öffnung für mein rechtes Bein,

Laßt eine Offnung für meine rechte Brust,

Weil mein Junge noch ein Säugling ist,

Und ich muB ihn, wenn er weint,

Mit einem Auge sehen können, 
Mit einer Hand zärtlich streicheln,

Mit einem Bein muß ich ihn wiegen,

An eine Brust werde ich ihn legen.

Und möge meine Brust erstarren

Und fest und stark möge die Burg werden

Für meinen Sohn, daß er eines Tages

König werde und drinnen kämpft!"

(Übersetzt von Ardian Klosi. Texi aus: Këngë popullore legjendare, S. 5-8) 


\section{-}

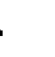

,

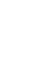




\section{ANHHANG 2:}

\section{Nikos Kazantzakis}

\section{DER BAUMEISTER}

Eine Tragödie

Ins Deutsche übersetzt von:

Augusta Dimou, Panos Korovessis und

Ardian Klosi 1

lOhnne das freundliche, unentbehrliche Korrekturlesen von Prof. Dr. Hermann Ölberg zu verggessen. Bei der Übersetzung wurde vor allem auf die inhaltliche und weniger auf eine künsstlerische Wiedergabe des Originals wert gelegt. 
Personen: Der Baumeister - Smaragda - Die Mutter - Der Sänger - Der Fürst

Chor der Măher (Männer und Frauen)

Chor der Bauarbeiter (Zigeuner und Zigeunerinnen)

Szene: Ebene, ein breiter Fluß, der sich im Hintergrund verlien, wo man eine wilde Landschaft mit bedrohlichen Bergspitzen sicht. In der Nachmittagssonne schimmert weiß die Brücke. Bei ihren Pfeilern tanzen fröhlich die Maurer, darunter auch Zigeuner, die auf ihren Trommeln und Tamburinen spielen. Sie schlagen den Rhythmus mit hochgehobenen Händen. Ihre wilde Musik ist bereits hörbar, bevor sich der Vorhang hebt.

Der Baumeister tritt aus der Grupppe der anderen Maurer hervor und geht auf Smaragda zu. Bald darauf erscheint der Chor der Măher, der langsam und ängstlich über die Brücke geht. Sobald die Mäher das andere Ufer erreicht haben, beschleunigen sie ihren Schritt, als wären sie knapp einem Unglück entkommen. Sie füllen den Schauplatz; braun und aufgeregt sind ihre Gesichter, Empörung kann man in ihren Bewegungen bemerken. Sie erinnern an eine durch Falken verscheuchte Vogelschar. Sie sprechen miteinander mit gedämpften, geheimnisvollen Stimmen. Im Hintergrund hör man noch immer wilde Zigeunermusik. 


\section{Tanz der Mäher}

- Stark wie Eisen ist die Brücke! Wie Eisen ist die Brücke!

- Hast du gesehen, hast du gesehen! Sie ist stark und unerschütterlich wie ein Felsen! Wir sind alle über sie gegangen, und sie hat sich kaum bewegt!

- Wie weiß und stolz schimmert sie in der Sonne! Wieviel Durst und wieviel Verlangen strahlen die eingerammten Pfeiler aus!

- Als wäre sie lebendig und verlangte nach Wasser!

EIN ALTER MÄHER: Jetzt wird sie zittern und beben und in der Nacht wieder in sich zusammenbrechen! Von ihr wird nur ein Haufen von Stein, Holz und Mörtel bleiben.

- Haha, wie eine alte Frau wird sie zusammenbrechen und auf dem Boden liegen, als wäre sie bis zu den Knochen vermorscht!

(Lachen, ein gehässiges, schadenfrohes Lachen).

EINE FRAU: Wie lacht ihr! Habt ihr keine Angst!?

EINE ANDERE FRAU: Das Böse jetzt nicht erwähnen, sonst kommt es wieder über uns! Da sind die Wolken, bald werden sie ihren Zorn auf uns ergießen. (Die Frauen schauen verängstigt die Wolken an und lauschen dem aufkommenden Beben.)

- O Du, allmächtige Jungfrau, rette uns!

EIN ALTER MANN: Dreimal wurde die Brücke am Tag erbaut, und dreimal trat am Abend, als die Zigeuner wie jetzt tanzten und jubelten, der Fluß wie eine Furie über die Ufer und überschwemmte unser Dorf. Wo war denn damals deine allmächtige Jungfrau, warum hat sie uns im Stich gelassen?

- Sei still jetzt! Denk nicht an jene schrecklichen Nächte.

EINE BLASSE FRAU: Meine Knie zittem immer noch. Was für eine Nacht war diese Nacht des dritten Zusammenbruchs! Ich war zu Hause und hatte gerade mein Kind gestillt, und da höre ich plötzlich vor meiner Türschwelle das Rauschen des Flußes. Das ganze Haus bebt und zittern als wäre es ein zarter junger Baum, den mächtige Hände an den Wurzeln packen und herausreißen wollen. Ich springe auf, mit dem Klcinen in meinen Armen, und laufe hinaus auf den Berg zu; da rasen die Wasser hinter mir, ich lache und weine wie eine Verriuckte. Mein Kind hätte ich beinahe erwürgt, so kräftig habe ich ihn gegen meine Brust gepresst.

- Sei still, still nun! Du flößt mir Angst ein.

(Ein atemloser, blaßer Bauer kommt).

- Dimitris wird uns erzählen, was die Mutter gesagt hat.

- Sprich! Neues Unglück teilen uns deine Augen mit! 
- Was prophezeit die Mutter schon wieder?

DIMITRIS: Zerstörung und Untergang prophezeit sie! Sie sitzt am Ufer und weint und schlägt die Hände auf die Brust und verflucht den Schuldigen aus tiefstem Herzen. (Er stürzt niedergeschlagen zu Boden).

CHOR (alle beängstigt): $O$ weh, $o$ weh!

(Ein Mädchen stürmt hinaus): Ich muß jetzt meine Sachen packen!

EIN ALTER MANN (hindert sie): Wohin willst du gehen, wohin willst du gehen? Hades ist ein starker kräftiger Mann, er wird dich fasssen.

-O weh!

- O du,allmächtige Jungfrau, strecke deine Hände über uns und nimm uns in deinen Schutz!

DER ALTE MANN: Was schreit ihr, was schreit ihr? Dreimal haben sich bis jetzt die Prophezeiungen der Mutter erfüllt. Wie Sterne am klaren Himmel leuchten ihre Wahrsagungen. Noch bevor die Nacht anbricht, wird der Fluß über die Ufer treten, alle Zäune wird er niederreißen; wütend wird der Fürst ihn zügeln wollen, aber der Fluß wird trotz alledem wieder unsere Kinder und unsere Herden ertuänken und unsere Emte vernichten.

- Ach, sag das nicht, ich habe Angst!

(Alle kommen zitternd und angsterfüllt wieder herein)

DREI MÄDCHEN (treten hervor, die Hände auf die Brust gepresst und leise flüsternd): Mein Goth, mein Gott!

ALLE (sie umringend): Was ist los? Was ist los? Wer ist hinter euch her?

DIE DREI MÄDCHEN: Der, der!

- Wer denn, wer? (Plötzlich haben sie verstanden; alle ziehen sich erschrocken zurück) Oooh!

DIE DREI MÄDCHEN: Der Fluß.

DAS ERSTE MÄDCHEN: Er tobt und brüllt! Als wäre er ein gefanges Ungeheuer.

DAS ZWEITE MÄDCHEN: Gerade sind wir über die Brïcke gegangen und haben auf ihn hinunter geschaut.

DAS DRITTE MÄDCHEN: Mein Gott, wie zittert mein Herz noch in Angst!

DAS ERSTE MÄDCHEN: Wild ist er über die Ufer getreten und hat wütend mit der Brücke gekämpft. Er hat in ihre Wurzeln hineingebissen, Schaum ist hochgekommen, schwer hat er gekeucht.

DAS ZWEITE MÄDCHEN: Er hat uns gesehen, wie wir über ihm standen; tief und voll Schmerz hat er geseufzt, wie ein Ochse, den man schlachtet.

- Oooh!

DAS ERSTE MÄDCHEN: Die Zigeuner haben gelacht, die Mutter neben ihnen klagte und verfluchte den Schuldigen.

DER ALTE (Er schüttelt traurig den Kopf und sagt:) 
- Ich bin alt, und meine Augen haben viel gesehen. Blut braucht der Fluß, um sich zu beruhigen und sich unser zu erbarmen!

- Blut! (Alle bekommen eine Gänsehaut vor Schrecken).

DER ALTE: Er hat Hunger. Hört ihr nicht, wie er brüllt, als wäre er ein hungriges Ungeheuer? Ihm verlangt nach einem menschlichen Körper, hört ihr das nicht?

(Alle lauern voller Angst auf das Brodeln und Rasen des Flusses. Die Zigeunermusik mit ihrem Kastagnettenspiel nähert sich. Verängstigt, schreiend und mit gestreckten Händen laufen die Frauen davon:)

- Wo soll ich hingehen, was wird aus mir werden! Hilfe!

- Vor welchem Heiligen soll ich meine Seele zu Boden werfen!

- Wessen teure Kerze soll ich zuerst anzünden?

- Ich habe Angst. O Du, Jungfrau, hilf uns!

- Mutter, Mutter, warum erbarmst du dich unser nicht!

DER ALTE MANN (Er sammelt die Männer rund um sich und spricht leise zu ihnen):

- Hort, kommt näher (zu den Frauen) Ihr aber bleibt stehen...

(Die Anwesenden teilen sich in zwei Chöre, Chor der Männer und der Frauen).

DER ALTE (Spricht zum Chor der Männer, gedämpft, atemlos und zornig)

- Hơrt Jetzt wird der Fürst kommen und den Baumeister belohnen, weil er die Brücke so gut gebaut hat. In der Nacht aber, wenn er gegangen ist, werden wir lauem... (der Chor schaudert) Ah! Habt ihr nicht gespürt, daß der Fluß den Baumeister als Opfer verlangt?

CHOR DER FRAUEN (versucht zuzuhören; hat eine böse Vorahnung): Ich habe Angst, ich habe Angst!

CHOR DER MÄNNER (flüsternd) Ja ja! Schwarz ist die Stunde, wo der Baumeister mit in unser Dorf gekommen ist!

- Niemand wird uns sehen.

- Es wird Nacht sein, wir werden im Busch am Ufer versteckt sein... Nicht einmal der Mond wird unsre grausige Tat sehen.

- Einen schweren Stein werden wir an den Hals des Baumeisters hängen und ihn wie ein Stück Fleisch dem alten Fluß, der vor Hunger stöhnt und brüllt, in den Rachen werfen.

- Ah, wenn er sich an seinem Körper nur satt fressen und uns sich unser und unsrer Kinder erbarmen würde!

CHOR DER FRAUEN (Argwöhnisch horchen sie auf die Verschwörung der Männer. Voller Angst heben sie die Hände über ihre Köpfe, als wollten sie jemanden vertreiben. In diesem Augenblick fliegen krächzend Rabenschwärme über die Brücke. Der Chor hört dem Krähen zu): 
- O weh! Sieh wie sie fliegen: wozu diese Eile!

- Als hätten sie einen Toten gerochen.

- Sie sind die Boten des Schicksals; sie sind die Totenvögel: sie fliegen voraus und das schwarz gekleidete Schicksal folgt ihnen.

(Ein junger Mann kommt fröhlich her. Es ist der Sänger, der seine Flöte nimmt und beim Mähen spielt. Seine Augen leuchten vor überschwenglicher Freude.)

EINE FRAU: Da ist der Sänger, da ist der Sänger! Er hat sicher Smaragda gesehen und ist wieder von ihr verblendet.

DER SÄNGER (Ohne seine Freude verstecken zu können): Sie kommt, sie kommt! CHOR: Wer kommt denn, wer?

DER ALTE: Der Fürst. Kommt, laßt uns so tun, als ob wir beim Tanzen wären, damit er nicht böse auf uns wird.

DER SÄNGER: Smaragda, Smaragda!

CHOR DER FRAUEN (trotzig und neidisch ): Ah, die Tochter des Fürsten. Hast du sie wieder gesehen und hat sie dich schon wieder berauscht?

- Sie verdreht ja deinen Kopf!

- Die Neraiden haben dich noch einmal getroffen!

DER SÄNGER: Ich sah sie, da kamen in meiner Flöte Tausende von Liedern und viel Leiden hoch, sie zwitscherten süß wie kleine Vögel im Käfig. Sie flatterten und wolletn ihre Flügel ausbreiten, und sich vor ihren Füssen niederwerfen, um sie willkommen zu heißen.

CHOR: Hahaha! Hör auf, halt den Mund, du Verrückter! Hast du wohl wieder einen Sonnenstich?

- Du bist von ihr und von Smaragda getroffen.

- Und jetzt redest du mit dir selbst.

- Was findest du denn so Besonderes an ihr? Sie ist keine fleißige Hausfrau, den ganzen Tag spaziert sie auf den Felderm und in der Sonne umher. Auf uns schaut sie von oben herab.

EIN BAUER: Hört auf, hört auf! Sie kommt! Voll mit Blumen ist ihr Schoß. Da ist sie, unsere Freude und unser Stolz!

(Man sieht Smaragda von ferne in grünem Kleid).

DER SÄNGER (sieht sie freudig an).: Von dort kommt der Frühling her (er zeigt auf Smaragda). Ihre Augen, ihre Lippen, ihre Wangen, wenn sie lacht! Alles an ihr strahlt Lieder aus.

CHOR: Hör doch endlich auf, du Faulpelz! Den ganzen Tag stopfst du mit deiner Flöte unsere Ohren voll, das reicht nun! Hör auf, du Leichtsinniger, den wir zu Unrecht so großzügig erhalten! (sie drängen ihn in eine Ecke, zu den Frauen).

DER SÄNGER: Das ist mir einerlei; schweige ich, so singe ich um so schöner und süßer! 
(Er sitzt am Boden und richtet seine Flöte her. In dem Wirrwart der Gespräche hör man zarte Noten, eine unerwartete arkadische Ruhe strömt aus der Flöte.)

(Es kommt die schöne Smaragda. Zwei Mädchen tragen in den Händen Geschenke: Tücher, Schmuck, Bänder, usw., Smaragda begrüßt lächelnd die Mädchen).

SMARAGDA: Seid willkommen, seid willkommen!

CHOR DER FRAUEN: Sei willkommen, du Prinzessin, sei willkommen!

CHOR DER FRAUEN (unter sich): Wie sie sich doch emiedrigt, daß sie uns willkommen heißt!

SMARAGDA: Warum sitzt ihr, bald wird mein Vater kommen. Ihr habt mit dem Tanz noch nicht begonnen. Seht, die Brücke steht schon da!

DER ALTE MANN (bösartig): Wir warten, meine Prinzessin, wir warten, daß sie wieder zusammenbricht.

CHOR DER FRAUEN: Deswegen ist auch unser Herz befangen.

SMARAGDA: Mein Herz zittert vor Freude; und jetzt, da die Brücke fest gebaut ist, bringe ich euch Gaben und Geschenke. Kommt, lacht ein bißchen; wenn wir der Freude gedenken, dann kommt sie zu uns.

DER SÄNGER: Was ist diese Freude, die aus deinen Augen strahlt, Smaragda? Ein Feuer ist das, keine einfache Freude!

SMARAGDA: Sei still, mein Sänger! Sei still! Ich habe auch meine Geheimnisse. (Zu einem Mădchen, das hinter ihr steht). Komm, meine Maria, bring die Geschenke her.

(Maria nähert sich und macht ein Bündel, das sie in der Hand hält, auf; alle können so die Geschenke sehen.)

SMARAGDA (nimmt eines von den Geschenken und sagt zu einer Frau vom Chor): Komm, Eleni, nimm das, damit die Sonne deine Schönheit schont.

ELENI (nähert sich): Danke, meine Prinzessin, Freude sei immer mit dir (nimmt die Gabe entgegen).

SMARAGDA (geheimnisvoll lächelnd zu Eleni): Was willst du, daß ich Andreas schenke? (Eleni beugt sich, rot im Gesicht. Lauter): Und du, Andreas, nimm dieses rotc seidene Tuch, trag es an Feiertagen, geh an einem vergitterten Fenster vorbei und sing von den Leidenschaften der Liebe (alle lachen; ein junger Mann, rot im Gesicht, kommt und nimmt das Tuch entgegen). SMARAGDA: Vorgestern hörte ich, wie du, Marigitza, zu deinen Freundinen sagtest, da $B$ die Ohrringe, die ich trug, dir sehr gut gefielen. Heute bringe ich sie dir, damit du sie tragen und an mich denken kannst.

MARIGITZA (läuft voller Freude hin und nimmı die Ohrringe): $O$, wie gütig bist du, wie gütig bist du! 
SMARAGDA: Und für dich, meine Tassula, hier ıst ein schönes Armband. Komm her, ich werde es dir selbst anziehen, damit du dir nicht weh tust (es kommt ein kleines blasses Mădchen, sie legt ihr das Armband um die Hand). Wo ist dein Vater? (Tassula zeigt auf einen alten Mann, der neben dem Chor sitzt und wütend um sich blickt). Da ist Onkel Tassos. Sei nicht traurig, ich habe dich nicht vergessen. Ich habe dir ein Fäßchen Wein nach Hause schicken lassen (Sie lacht). Der Schlaf nährt das Kind, der Wein den alten Mann...

DER ALTE MANN (etwas trotzig): Sei gegrüßt, meine Prinzessin.

SMARAGDA (verteilt die Gaben; alle laufen zu ihr und nehmen die Hüte, Schals und Tücher entgegen; Smaragda schmückt Hals und Haar der Mädchen mit bunten Fäden. Große Freude und festliche Stimmung hat den ganzen Chor verwandelt).

DER SÄNGER (schaut Smaragda verzückt an): Freude verteilst du, wie warmes Brot.

SMARAGDA: Und was möchtest du, mein Sänger, daß ich dir schenke?

DER SÄNGER: Eine Rose, eine Rose von deinen Händen und mein Leben wird für immer duften.

SMARAGDA (lacht): Wie leicht ist es, dein kleines Leben mit Freude zu füllen, mein Sänger. Ich habe aber eine ganz neue Flöte für dich aufbewahrt (nimmt aus ihrer Brust eine kleine Flöte und reicht sie ihm).

DER SÄNGER (nimmt ihre Hände in die seinen und liebkost sie):

- Ach! Deine wunderbaren Hände, sie kennen alle Tore der Freude und sie können sie öffnen!

CHOR DER FRAUEN: Still! Da kommt der Baumeister! Da kommt er!

SMARAGDA (erhebt sich, bla B im Gesicht): Der Baumeister!

DER SÄNGER (zu sich selbst nachdenklich): Sobald sie ihn sah, hat Smaragda Gesang und Tanz vergessen; ihre Beine und ihr Herz haben sich beflügelt, um ihm entgegen zu fliegen.

DER ALTE MANN (steht auf): Lachend kommst du her, weinend aber wirst du von uns weggehen.

DIE BAUARBEITER (von weit weg): Baumeister, Baumeister!

(Musik und Tanz hören auf. Die Bauarbeiter stellen sich in einem Halbkreis auf und beginnen im Hintergrund des Plateaus neben der Brücke zu tanzen; mit zurückgehaltener Verzweiflung rufen sie den Baumeister, der sich von ihnen entfernt hat).

SMARAGDA (langsam, indem sie versucht, sich zu fassen): $O$ du, Freude, bleib ruhig in mir, du darfst mich nicht ersticken!

DER SÄNGER (schaut sie an; langsam): Wie blaß ist sie, wie blaß! Als wäre sie durch eine große Sünde verwundet.

DIE BAUARBEITER (aus der Feme mahnend und mit Verbitterung): Baumeister! Baumeister! 
DER SÄNGER (tritt hervor, streckt seine Hände voller Freude aus und ruft nach dem Baumeister, der gerade gekommen ist): Sei begrüßt, o guter Mensch!

(Smaragda tritt ebenfalls hervor und streckt ihre Hände ihm liebevoll zu).

DER BAUMEISTER (strahlt vor Glück): Was hast du für mich, was hast du mitgebracht, Smaragda?

SMARAGDA: Rosen, Rosen! (Sie bedeckt ihr überall mit Rosen, auf den Haaren, auf den Schultern und an den Füßen).

DER BAUMEISTER (Er küßt ihre Hände voller Liebe): O, wie ich deinen Schoß und deine Hănde liebe, die mir Zärtlichkeiten und Rosen schenken!

(Sie kommen beide hervor und flüstern leidenschaftlich miteinander, während die Mäher die übrigen Tücher und andere Geschenke verteilen).

DER BAUMEISTER: Meine Liebe! Wie ich dich heute den ganzen Tag vermißt habe! Meine Hände zittern vor Verlangen, wenn sie sich an deinen Körper erinnem!

SMARAGDA (fast ohnmächtig vor Liebe): Wann wird es nur Abend...

DER BAUMEISTER: Oh, schau mich nicht so an! Ich weiß es nicht. Ich will dich vor all diesen Leuten fest umarmen und deine Lippen küssen!

SMARAGDA: Schweig, sie können uns hören. Schweig! Und die Nacht kommt bald, der Abendstern steht schon am Himmel.

DER BAUMEISTER: Wirklich, da ist der Abendstern. Bald wird es dunkel werden. Ich weiß nicht warum: jetzt, da die Briicke fertig ist, wünsche ich dich doppelt so sehr in meiner Nähe; doch für einen kurzen Augenblick hatte ich Angst.

SMARAGDA (wird plötzlich traurig): Nicht einmal du weißt, Baumeister, was du am meisten liebst, deine Kunst oder mich!

DER BAUMEISTER (betroffen will er das Thema wechseln): Schweige, Smaragda, schweige! Kindliche Sorgen lasten auf deiner Seele. (Er dreht sich in die Richtung der Brücke und spricht lauter). Was für ein Tag war heute! Ehern wie mein Wille wurde die Brücke! He, ihr Mäher!

SMARAGDA (verängstigt): Still, sprich leiser, Baumeister! Wenn wir sagen wollen, daß wir glücklich sind, dürfen wir es nur in unserem Innersten aussprechen, sonst kann es das böse Schicksalmitbekommen!

CHOR DER MÄNNER (unbeherrscht): Senke deine Flügel, Baumeister, nimm dich zusammen und erinnere dich: dreimal bis jetzt ist deine Brücke zusammengebrochen, dreimal! Du hast es zu schnell vergessen!

DER BAUMEISTER (in stiller Verachtung): Schreit nicht so, meine lieben Leute. So zitter immer der Sieg und leistet Widerstand, wenn wir ihn mit unseren Händen fangen wollen, um ihm die Flügel abzuschneiden.

DER ALTE MANN: Du stolzer junger Mann: ohne Gefahr hat noch niemand den Willen und die Gesetze Gottes mißachtet. 
- Gott hat unseren alten FluB auf dieser Welt frei und ohne Brücke erschaffen. Wer bist du, woher kommst du, der du es wagst, ihn zu knechten und zu unterjochen?

SMARAGDA (stürzt sich voller Angst zwischen die beiden): Seid still! Seid still! DER ALTE MANN: Sei verflucht du, deine Gehilfen und die Werke deiner Hände!

DER BAUMEISTER: Du Alter solltest dich besser zur Erde beugen und säen und mähen; du solltest den Schafherden auf dem Pfade folgen. Trage deine Nase nicht so hoch und sei am besten still!

DER ALTE MANN: Ja, ich bin alt, das Leben hat mir beigebracht, mich zu beugen und die Augen zu senken, meine Hände zu kreuzen und vor dem Schicksal Angst zu haben.

CHOR DER MÄNNER: Hast du keine Angst vor dem Schicksal? Hast du keine Angst?

DER BAUMEISTER: Schicksal, o Frauen und Kinder, ist ein weicher Teig in den Händen von Männern.

\section{CHOR DER FRAUEN UND DER MÄNNER: Oooh!}

SMARAGDA (sieht ihn ängstlich und zärtlich an): Du darfst nicht so reden: Ich habe Angst. Das Schicksal lauscht und hört alles.

DER ALTE MANN (drohend schüttelt er seine Sichel): Das Schicksal hat eine Sichel und kommt jeden Tag her, um die Seelen zu mähen.

DER BAUMEISTER (zu Smaragda): Wovor hast du denn Angst? Diesen Knechten und Rajas hörst du zu?! Sie sind doppelzüngig und unbedeutend. Kannst du dich nicht erinnern, wieviel Ärger und Schwierigkeiten sie mir schon bereitet haben, damit ich die Brücke nicht erbauen kann? Und jetzt können sie nichts als Lärmen und Jammern.

CHOR DER MÄNNER (immer heftiger und bedrohlicher): Du wirst sie nicht erbauen, nein! DER BAUMEISTER (lacht): Nicht erbauen?! Hahaha!

CHOR DER FRAUEN: Lach nicht! Gott steht über uns und sieht zu.

CHOR DER MÄNNER: Diese Nacht wird sie wieder zusammenbrechen, und du wirst lernen, dich zu beugen und zu gehorchen!

DER BAUMEISTER (geht stolz umher und sieht die Brücke an): Nein, sie wird nicht zusammenbrechen. Sie ist nicht die erste Brücke, die diese Hände fest gebaut haben. Fragt nur. Alle Städte und alle Brücken kennen mich; sie nennen mich Vater. Und nun sollte ich vor dieser kleinen Brücke Angst haben? Hahaha! Wer immer über uns stehen möge, sie wird nie zusammenbrechen!

DER ALTE MANN : Aah, junger Mann! All die Jahre und all die Fehlschläge haben dir nichts beigebracht, keine Geduld und keine Bescheidenheit!

- Wozu schreist du so! Du bist doch kein Gott!

DER BAUMEISTER: Ich bin ein Mensch und mehr will ich nicht sein.

CHOR DER MÄNNER UND DER FRAUEN (ängstlich): Wo sind deine Blitze, o Himmel! SMARAGDA (zittert vor Angst, fasst aber zugleich Mutt): Sprich noch! Sprich noch! 
DER SÄNGER (zu Smaragda): Hör auf, Smaragda, hör auf! Hast du keine Angst?

SMARAGDA: Ich weiß es nicht... ich weiß es nicht... meine Knie zittern, aber mein Herz...

(Die Wolken türmen sich. Aus der Ferne Donnergrollen).

BEIDE CHÖRE (gehen angstvoll auseinander): Hast du gehört, hast du gehört? Es donnert! (Entfernen sich vom Baumeister) Du Gesetzesbrecher!

- Oh, was wird mit uns werden; er wird uns alle auf dem Gewissen haben!

DER BAUMEISTER: Jetzt habt ihr vor dem Donner Angst!

SMARAGDA: Mein Gott, wie stark und schön ist er!

CHOR DER FRAUEN: Feuer wird sich über uns ergießen und euch beide verbrennen!

DER BAUMEISTER: Ihr Schwächlinge und Schreihälse!

DER ALTE MANN: Schimpf nicht! In kleine Teile werde ich dich zerstückeln!

(Der alte Mann stürzt mit der Sichel in der Hand vor. Man hält ihn zurück... Auch die Bauarbeiter laufen im allgemeinen Durcheinander herein).

DER BAUMEISTER: Faßt mich nicht an! Macht meine Hände nicht schmutzig! DER SÄNGER: Hilfe! Hilfe!

SMARAGDA: Weg mit euch, Rajas!

(Man hörn Trompeten. Alle erschrecken. Sie nehmen eine andere Haltung ein und stehen gleichgültig da. Aus der Feme kann man den Fürsten erkennen, der jetzt über die Brücke geht).

- Der Fürst! Der Fürst!

SMARAGDA: Mein Vater! Kommt jetzt, ihr Volk, und verbeugt euch!

CHOR DER MÄNNER UND FRAUEN (lehnen sich ängstlich aneinander): Der Fürst!

DER FÜRST: Was ist hier los?

SMARAGDA (umarmt ihn zärtlich):: Mein Vater! Mein Vater!

DER FÜRST (streichelt sie): Mein liebes Kind! Hast du die Geschenke schon verteilt? Ja ja (streichelt sie weiter).

CHOR DER MÄNNER: Willkommen, unser Herr! Möge Gott unsere Tage kürzen um dir Jahre zu geben!

DER FÜRST: Was gibt es hier? Warum steht ihr so verlegen da? Heute möchte ich feiern, ihr sollt singen und tanzen, da die Brücke fest gebaut ist. Ich habe euch heute frei gegeben. Sprich, du Alter, warum tanzt ihr nicht?

DER ALTE MANN: O Herr, wir sind müde; wir wollten trotzdem, um den Tag zu feiern, ein Lied anstimmen und einen Tanz beginnen, gerade jetzt, als Ihr kommt. 
DER FÜRST: Wo ist der Baumeister? (Die Chöre gehen auseinander und er erblickt ihn. Er geht zu ihm und nimmt ihn bei der Hand). Komm zu mir, ich bin heute sehr zufrieden mit dir, Baumeister. Ich war auf der Brücke und als ich zu ihrer Mitte kam, blieb ich stehen und sah in den FluB hinunter (Er dreht sich nach dem FluB und hebt seinen Arm hoch). Ah, er brültt und schreit wie ein Ungeheuer hinter eisernen Gittern! Er tobt wie ein ungezähmtes Pferd, das zum erstenmal die Zügel in seinem Maul fühlt. Von jener Nacht an, wo du meinen Sohn ertränkt hast, habe ich einen Eid geschworen: dich zu unterjochen, damit alle zarten Frauen, meine Schafherden und die Herden der Rajas dich überqueren können; du wirst in Ohnmacht heulen und du wirst weinen, weil du ohnmächtig bist! Ah! Brüll nur, du kannst deine Zähne und deine Krallen in die Steine fressen, die Brücke aber steht und herrscht über dir, sie ist unerschütterlich wie Gott!

CHOR DER FRAUEN: Ehre und Ruhm für Euch, o Fürst, der Ihr den Fluß überbrückt habt! Die kommenden Generationen werden es sehen und Euch segnen!

SMARAGDA (zu sich): Oh, ihr widerwärtige Sklaven!

DER FÜRST: Was hast du gesagt, meine Smaragda?

SMARAGDA: Nichts, mein Vater, nichts.

DER FÜRST (klopft dem Baumeister auf die Schulter): Nun, was wünschst du, Baumeister, daß ich dir schenke? Verlange, was du willst, du wirst es erhalten.

DER BAUMEISTER: Ich möchte, mein Fürst, ein großes Haus in der Mitte des Dorfes bauen, um in ihm die Frau, die ich erwählt habe, zur Braut zu machen.

DER FÜRST: Eine Kleinigkeit hast du von mir als Belohnung verlangt; du wirst sie haben.

(Die Bauarbeiter kommen in die Nähe und hören beunruhigt dem Wunsch des Baumeisters zu).

DIE BAUARBEITER: Heiraten willst du und in deinem Haus wohnen! Willst du uns dann verlassen?

- Wie kann eine solche Seele wie deine die vier Wände des Hauses in sich aufnehmen, Baumeister!?

DER BAUMEISTER: Seid still! Hier wollen wir uns nur ein wenig ausruhen, dann aber uns wieder auf den Weg machen!

DIE BAUARBEITER-Baumeister, Baumeister, hat dir ein Gespenst den Verstand verwirt?

- Die Werke deiner Hände zitterm hier und fallen in sich zusammen, wir sehen es. Wo immer du anderswo gebaut hast, konnte selbst Gott deine Bauten nicht erschüttern.

DER BAUMEISTER (schaut besorgt und hört, was seine Arbeiter sagen).

DER SÄNGER (zum Baumeister): Hör' ihnen nicht zu, bleib' bei uns. Eigener Herd ist Goldes wert. Es gibt nichts Schöneres, als wenn jeden Abend, da du nach Hause kommst, deine Frau auf dich wartet und du in ihrem Schoß die Freude findest. 
DER FÜRST: Bleib bei uns, Baumeister. Ich werde dir so ein großes Haus bauen lassen, wie du es dir wünschst; ich selbst werde dich trauen, Baumeister.

SMARAGDA (zu sich, zitternd): Ich höre mein Herz, wie es vor Freude fast zerspringt! DER FÜRST (zum Baumeister): Alles Gute wünsche ich dir. Und wer ist die glückliche Frau, die dein Herz erober hat?

(In dem Augenblick, als der Baumeister die Frau zeigen will, die er erwählt hat, fängt es zu donnem an; die Brücke bebt; ein Mädchen, das gerade die Brücke überquerte, beginnt zu schreien, kommt ganz blaß heran und fällt auf den Boden. Der Himmel wird dunkler, das sich aufziehende Gewitter wilder).

DAS MÄDCHEN: Oh, heilige Mutter, sie bebte! Gerade, als ich sie überquerte, kämpften Fluß und Brïcke miteinander.

(Alle haben sich versammelt. Man hört Schreien aus dem Chor, während sich der Donner năher und stärker wird. Ein Stück reißt sich krachend von der Brücke los und fält in den Fluß. Die Bauarbeiter laufen verzweifelt zur Brücke...)

DER BAUMEISTER (springt ärgerlich und wütend auf. Smaragda eilt $\mathrm{zu}$ ihm, als wolle sie ihn trơsten. Er hält sie zurück und sieht zur Brücke). Ah! Bist du wieder zusammengebrochen?!

DIE BAUARBEITER: $O$ weh, all unsere Mühe umsonst!

- Tagsüber bauen wir, und in der Nacht bricht die Brücke zusammen!

(Sie rennen zur Brïcke. Der Baumeister will mit, bleibt aber wie gelähmt vor Wut und Erschütterung stehen).

CHOR DER FRAUEN: Heilige Mutter! Jetzt bricht die ganze Brücke zusammen! EIN ARBEITER (kommt näher): Die ganze rechte Seite ist zusammengestürzt! CHOR DER FRAUEN: Mein Gott, die ganze Welt bebt, wir sind verloren!

DER BAUMEISTER (nähert sich nachdenklich dem erschütterten Chor): Still! Schreit nicht! Auch wenn sie zusammenbricht, wird man sie wieder errichten: (Es donnert gewaltig. Der ganze Chor schreit, der Fürst will den Baumeister zum Schweigen bringen, der aber spricht stolz weiter): Sie wird sich erheben und auf festen Fundamenten stehen, gleichgültig ob Er dort oben donnert und tobt!

DIE CHÖRE (mahnend): Oh! 
(Ängstlich gehen sie weg und wollen sich zerstreuen; aus der Ruine auf der rechten Seite kommt empört die alte Mutter hervor, die Heilige des Dorfes, die in einer Grotte am Ufer des Flußes wie ein Geist lebt. Sie ist alt, mit schneeweißen Haaren, düster und imponierend. Ein kleines, blasses Mädchen führt sie an der Hand).

DIE CHÖRE (umkreisen sie mit Angst und Hof fnung): Die Mutter! Die Mutter! DER FÜRST: Sei begrüBt, Mutter! Du bist der einzige Trost für mein Volk! (Alle strecken die Hände aus und flehen sie inständig an).

- Mutter, du weißt alles. Du kennst die Heilpflanzen, und jede von ihnen zeigt dir, wie sie heilen kann. Du fragst sie um Mitternacht, und sie verraten dir zitternd das Schicksal eines jeden von uns.

DER SÄNGER: Du weißt alles. In einer Hand hältst du den Tod und in der anderen das Leben, wie zwei zitternde Vöglein. Öffne deine rechte Hand und schenke uns, o Mutter, das süße, süße Leben.

DER FÜRST: Es ist deine Pflicht zu sprechen, Mutter, und unser Dorf zu retten, es ist deine Pflicht!

DER BAUMEISTER (kommt voller Stolz einige Schritte näher): Schreit nicht, wovor habt ihr Angst? Ich bin noch immer hier. Wahrscheinlich gab es eine Nachlässigkeit beim Bauen. Schämt ihr euch nicht? Wollt ihr auf eine Hexe hören?

(Die Mutter geht auf den Baumeister zu und stellt sich ihm gegenüber; links und rechts steht der Chor. Smaragda bleibt traurig stehen. Der Sänger ist vor ihren Füßen niedergefallen).

DIE MUTTER (mit Anmut und in heiliger Empörung): Wer bist du, Mann, der du so kindisch und unbedacht die Verantwortung für die Seelen so vieler Menschen übernimmst? Dreimal hast du bis jetzt mein Dorf in schwarz gekleidet; die, die über deine schlecht gebaute Brücke gingen, sind ertrunken. Wer bist du?

DER BAUMEISTER: Wer bin ich? (Schweigt. Plötzlich bricht er in Zorn aus.) Ich bin der blonde stolze Mann, der jeden Tag hier erschient... woher ich komme, weiß ich selbst nicht. Ich bin kein Rajah; meine gute Alte, du kannst mir keine Angst einjagen. Ich wurde von Zigeunern in Lumpen und in Zelten voll der Löcher großgezogen, wo die Sterne und der Regen hineinschauten; ich fühle in mir, o Mutter, die Seele von Frauen und Kindern der Zigeuner groß wie das Meer, ich habe keine Angst. Vergebens willst du mir, Hexe, Angst bereiten, ich habe keine Angst!

DER FÜRST (gebieterisch): Schweige, Baumeister! Als ob es nicht genug wäre, daß du die Brücke nicht bauen kannst; jetzt brüstest du dich auch noch! 
SMARAGDA (scheu): Schweige. Du sollst nicht der Mutter widersprechen. Sie hat in ihren Händen die Schlüssel unseres Schicksals.

DIE MUTTER (mit Kraft und Bitterkeit): Ich eine Hexe! Ich bin keine Hexe, du leichtsinniger Mann! Der Schmerz hat mich alle Geheimnisse des Lebens gelehrt. Die Jahre voller Tränen haben aus mir eine Steinsäule gemacht, einen Stalaktit der Sklaverei, den du mit deinen Worten nicht im geringsten beschädigen kannst!

DER BAUMEISTER: In mir steigt ein Olymp voll von Göttern der Verachtung. (Er geht verächtlich von der Mutter weg und wendet sich zur Brücke).

CHOR DER FRAUEN (man hört Donner): Es donnert! Es donnert! Hörst du das? Der Sturm wird bald losbrechen!

EIN MÄDCHEN: O du, gute Mutter! All unsere Hoffnungen liegen zu deinen Füßen!

DER FÜRST: Mutter, wir warten. Es ist deine Pflicht, uns zu sagen, was zu tun ist, damit wir uns retten können. Wer ist daran Schuld, Mutter, daß die Brücke nicht bleibt, wer ist der Schuldige? Wer zerstörn die Brücke jedes Mal, wenn sie errichtet wird?

DIE MUTTER: Der Baumeister, er ist der Schuldige. Das ist derjenige, der an der Zerstörung der Brïcke die Schuld trägt.

DER FÜRST: Der Baumeister?! (Der ganze Chor schreit freudig auf).

SMARAGDA: Lüge! Du bist eine Lügnerin!

DER FÜRST (verblüfft): Smaragda! Wie kannst du so sprechen! Die Mutter erzählt nie Lügen, sie belugt niemanden.

DER BAUMEISTER (dreht sich plötzlich um und geht zur Mutter; ironisch:) Ich bin der Schuldige? Ich zerstöre die Brücke?! Hahaha!

DIE MUTTER: Ja, du, der du mit sieben Falten den ehernen Gürtel des Schmerzes an deinem Mieder festgebunden hast, der du herunterkommst und im blutigen Gehäuse des Lebens kämpfen möchtest.

DER FÜRST: Voll Finsternis sind deine Worte, Mutter! Warum ist er schuldig? Wie ist es möglich, daß er tagsüber baut und in der Nacht dann selbst zerstört? Sprich, Mutter!

DIE MUTTER: Sein Kreuz biegt das Glück, seine Hände zittern vor fleischlichem Verlangen, sie sind nicht keusch genug für große Werke. Die Zärtlichkeiten der Frau weben eine Verwirrung aus Rosen vor seinen Augen und iassen ihn nicht klar und nüchtern sehen.

SMARAGDA (zu sich): Du sollst nicht brechen, mein Herz! (Sie umarmt den Fürsten und will, daß er nicht zuhören mochte): Nein, nein, Lügen! Du sollst nicht darauf hören, Vater!

DER BAUMEISTER (zomig wie jemand, der plötzlich die Wahrheit erfährt): Schweige, du Lügnerin!

DIE MUTTER (in unbeherrschter Empörung): Lügnerin! (zu dem Chor, verachtend und ironisch) Seht ihn an, den Helden, den blonden! So ist der, der seine Arme ausstreckt, um den Sieg einzufangen! Und doch sind sie lahm und fallen in Sinnlichkeit auf das Liebeslager. Seht 
ihn an; der Körper der Frau schillert vor ihm wie ein Schloß aus Elfenbein; sobald es dunkel wird, stolpert sein Körper vor Verlangen ihr entgegen; jeden Tag, wenn er herkommt und die Arbeit beginnt, sind seine Augen dunkel und seine Gedanken schweifen weit ab. Seht ihn an, genießt diesen Blick. Und trotzdem möchte er Brücken bauen! (zum Baumeister). Du sollst vorher auf starken Beinen stehen; erst dann darfst du dich mit großen Werken beschäftigen!

SMARAGDA (Stürzt zu Boden und weint).

DER FÜRST: Warum weinst du? Was betrifft es dich, mein Kind? Hast du Mitleid mit ihm?

DER BAUMEISTER (gequält): Es ist nicht das erste Mal, daß ich eine Brücke errichtet habe... es ist nicht das erste Mal...

DIE MUTTER: Ja, aber es ist wohl das erste Mal, daß sich der Schoß einer Frau, der Hafen der Vernichtung, dir öffnete.

DER BAUMEISTER (besorgt): Schweige! Schweige! Es ist nicht wahr, schweige!

DIE MUTTER (mit bitterer Ironie): Ist es nicht wahr? (langsam und schmerzvoll) Wer große Straßen anlegt, Berge zerteilt und Meere verbindet, der geht immer nach vorne und schaut nicht nach hinten; er vergißt den engen, süßen und schattigen Pfad des Glücks, auf dem nur zwei gehen können...

DER BAUMEISTER (phantasiert): Schweige... Schweige... (dann plötzlich, als ob ihm ein Licht aufgegangen wäre) Oh! Du hast recht!

SMARAGDA (weinend): Du darfst nicht auf sie hören, du darfst nicht auf sie hören, Baumeister!

DER BAUMEISTER (abwesend): Und wie hat sie doch recht! Und wie hat sie doch recht!

DIE BAUARBEITER (aus der Ferne, über die Ruinen der Brücke gebeugt): $O$ weh, o Schmerz! Schade um unsere ganze Arbeit; Schande über dich, Baumeister, was für eine Schande!...

DIE MUTTER: Höre, der du einst der berühmte Baumeister warst; wenn die Flüsse dich sahen, bekamen sie Angst, wie die stolzen Pferde, wenn sie den Reiter erblicken. Und siehe jetzt, was aus dir geworden ist! (Sie zeigt auf die zusammengebrochene Brücke und auf die anderen Bauarbeiter). Deine Arbeiter treiben ihren Spott mit dir!

(Es donnert wieder. Die Brücke bebt. Der Sturm ist losgebrochen).

DER FÜRST: Mutter, was sollen wir jetzt tun, um gerettet zu werden? Sag es! Der Sturm ist gekommen und wütet über uns. Sprich!

SMARAGDA: Erbarme dich unser, o Mutter!

DIE MUTTER: Ein großes Opfer wird verlangt, damit die Brücke stehen bleibt!

CHOR DER FRAUEN: O weh! Was haben unsere Ohren gehör!

DER BAUMEISTER: Sprich, Mutter, es ist einerlei, was für ein Opfer verlangt wird. Ich lasse mich nicht verspotten. 
DIE MUTTER: Einer muß hier getötet werden.

CHOR DER MÄNNER UND DER FRAUEN: O weh!

DER FÜRST: Sprich klar und deutlich, Mutter! Wen sollen wir opfern, damit das Volk gerettet wird?

DIE MUTTER: Fürst, das Schicksal verlangt ein großes Opfer von dir...

DER FÜRST: Ich schwöre: Wer immer das Opfer sein soll, ich werde ihm den Tod mit meinen eigenen Händen bringen, damit unser Dorf gerettet wird. Es ist recht, daß einer verloren geht, um Tausende zu retten. Es soll ihm eine Freude sein, sich für ein ganzes Volk zu opfern. Sobald der Tod ihn ermeicht, macht er ihn unsterblich. Sprich seinen Namen aus, Mutter, hab' keine Angst. Ich schwöre es beim Kopf meiner Smaragda, hier vor allen, daß ich mich dir nie widersetzen werde, gleichgültig wer es sein soll. Sprich, Mutter! Wer muß sterben, damit wir gerettetwerden?

(Einige Augenblicke ist es still. Man wagt nicht einmal zu atmen...)

DER SÄNGER: Mein Gott, mein Gott! Wie schwer ist mein Herz! Sprich! Was immer deine Lippen auch aussprechen, es ist besser als dein Schweigen!

DIE MUTTER (spricht leise und traurig): Die Frau, die der Baumeister liebt...

DER BAUMEISTER (außer sich, unterbricht sie): Schweige! Schweige!

DIE MUTTER: Die Frau, die ihn bezaubert und in der Nacht um den Schlaf gebracht hat. Sie muß sterben, damit die Hände des Baumeisters wieder frei sind und nicht mehr zittern, wenn er eine Brücke entwirft.

DER SÄNGER: O, sei uns gnädig, Mutter! Hart sind deine Worte wie das blinde Schicksal! DIE MUTTER: Heute noch, bevor die Sonne untergeht, muß sie sterben! Sonst werden wir noch einmal Verwüstungen und Katastrophen in der Nacht haben; und nicht irgendwo, sonderm auf den Fundamenten der Brücke muß ein Pfeiler erbaut werden... Über ihrem Körper, nur über ihrem Körper muß die Brücke errichtet werden!

SMARAGDA (Ganz blaß tritt sie einen Schritt hervor und spricht mit matter Stimme): Nur auf ihrem Körper wird die Brücke fest, Mutter?

DIF. MUTTFR (mit tiefer Betrübnis): Ja, mein Kind.

CHOR DER FRAUEN (empört): Wer ist sie? Wer ist sie?

- An wessen Blut werden die Pfeiler sich erfreien?

DER FÜRST: Sag uns ihren Namen, Mutter!

SMARAGDA: Du sollst nicht auf sie hören, Vater!

DER FÜRST (löst sich von der Umarmung Smaragdas und spricht befehlend): Sag ihren Namen!

DIE MUTTER: Ich darf es nicht sagen. Der Baumeister oder sie allein müssen es eröffnen. Damit es von Wert ist, muß sie sich selbst aus freiem Willen als Opfer darbringen. (Das kleine 
Mädchen zieht sie an der Hand). Gehen wir, mein Kind (Sie dreht sich plötzlich um und sagt zum Baumeister:) Ach, Baumeister! Zerreiß deine Brust, nimm dein Herz heraus und leg es an die Fundamente der Brücke, wenn du willst, daß sie fest wird! Ich habe nichts mehr zu sagen (zu den Chören:) Ich habe nichts mehr zu sagen (geht).

(Eine grauenhafte Stille. Der Fürst geht auf die Frauen zu und beobachtet sie wie ein Adler die Tauben.

Alle treten zitternd zurück).

CHOR DER FRAUEN: Oh! Das Schicksal breitet über unseren Häupten seine Flügel aus, die Flügel eines Raubvogels!

- Das Schicksal, das Schicksal ist über uns und wählt!

DER FÜRST: Wer ist sie? Sie muß hier sein. Wer zittert am meisten?

(Der Fürst geht hin und her, dann schaut er plotzlich den Baumeister an).

DER FÜRST: Baumeister (Stille). Sprichst du nicht? Möchtest du nicht gestehen? (Schweigt, dann, als hätte er eine Entscheidung getroffen, wendet er sich zu den Mähern). Einer von euch soll ins Dorf gehen und allen Mädchen kundtun, sie mögen hierher kommen; er soll ihnen sagen, daß wir hier ein großes Fest bereiten (ein Mäher macht sich auf den Weg); und schnell, bevor die Sonne untergeht. Hast du die Mutter nicht gehört? Die Tötung muß erfolgen, bevor die Nacht anbricht. (Der Mäher läuft weg. Der Fürst spricht drohend zum Baumeister): Baumeister, denke daran: wenn du die Schuldige nicht nennst, werde ich das Fundament auf dir selbst errichten. Denk' daran! (zu den Chören) Denkt daran; bis ich von der Brücke zurückkomme, müsst ihr euch entschieden haben, sie mir zu nennen. Ah! Wir und unsere Kinder wollen nicht wegen einer Unzüchtigen zugrunde gehen. Nein! (Er dreht sich um und sagt zu Smaragda:) Un du, meine Smaragda, geh nach Hause.

SMARAGDA: Nein, mein Vater, ich will bleiben. Laß mich bleiben.

DER SÄNGER (verzweifelt): Smaragda, Smaragda, willst du nicht weggehen?...

INTERMEZZO

(Der Vorhang fällt nicht. Zwischen dem ersten und dem zweiten Teil findet ein Intermezzo statt. Es kommen Zigeunertänzerinnen mit Tamburinen und anderen Instrumenten. Zwei Chöre). 


\section{ERSTER CHOR (singt Lieder und Klagen).}

- O weh! O weh! Deine Hände, Baumeister, deine starken Hände, die das Schicksal rühren, fallen schlaff wie eine weiche Kerze, so sie sich an die Brüste jener süßen Frau erinnem. $O$ weh, o weh!

\section{ZWEITER CHOR (in einem schnellen, fröhlichen Tanz)}

- Fest legen sich die Flügel der Liebe an unsere Körper, und alle Bitterkeiten und Besorgnisse werden wie Samen verstreut, um Kinder zu gebären, die, wenn erwachsen. an unserem Herzen nagen. Wir sterben vor Schmerzen, wir beugen uns und rufen: (Der Chor hält an, als wäre er der Freude überdrüssig). Es gibt nichts Schöneres als die Welt!

\section{ERSTER CHOR (steht auf und tanzt)}

- Hör nicht darauf, Baumeister! Schnalle los dein Mieder, den Gürtel der Krankheit! Reisse dich los von den Händen der Frau um deinen Hals, die dich süß in den Abgrund zieht! Du bist der Baumeister, du lebst nicht um zu genießen, sondern um zu bauen.

\section{ZWEITERCHOR}

- Hahaha! All die Brücken sind keinen Kuß auf den Mund wern! Meine Hände strecke ich aus und ich segne die Schande; heiße sie willkommen, die uns fest umarmt und zu Boden wirft, und sich am warmen Bett erfreut.

(DIE MÄDCHEN des Dorfes, die den Zigeunerinnen zuhören, staunen und werden rot im Gesicht).

- O, sag' das nicht, sag' das nicht! Wie süß ist die Liebe, wenn die Gnade Gottes über ihr steht. Sie erfüllt unsren Körper wie der erste Regen die dürstende Erde. So eine Liebe schenke uns, Jungfrau!

(Die Männer, unter ihnen einige neue, kommen von der Brücke zurück) 


\section{CHOR DER MÄNNER (triumphierend)}

- Ich bin erleichtert! Für einen Augenblick hatte ich Angst und sagte zu mir: ich bin größer als du! Ich bin erleichtert! Wir alle -ich sehe es ein - neigen uns ohnmächtig wie Gerstenhalme vor der Sichel des Schicksals.

\section{CHOR DER FRAUEN}

- Und wir alle, kleine und große, fallen, wie von einer Sichel gemäht, in die dunklen Räume unseres Herren, den Hades.

\section{CHOR DER MÄNNER}

- Das Schicksal zieht über uns und wir zittem alle wie Halme in der Dämmerung!

\section{CHOR DER FRAUEN}

- Das Schicksal zieht unter, vor und hinter uns wie ein stürmisches Meer um Mitternacht; wir sind Boote ohne Licht, ohne Steuer und ohne Ruder.

\section{DER SÄNGER}

- O Sonne, du schwebst nieder, blutend, und hie und da stürzst du herunter; o Sonne, was für schreckliche Taten wirst du heute vergolden?!

\section{II}

(Alle Mädchen des Dorfes sind, feierlich angezogen, gekommen; über den Frauen und Männern schwebt Schrecken; die Mädchen flüstern einander zitternd zu, da sie von der Brücke herkommen. Der Sänger ist wieder vor Smaragdas Füßen zusammengebrochen).

DER SÄNGER (leise und flehend): Smaragda! Smaragda! (Smaragda sieht auf die Brücke und spricht nicht). 
EIN MÄHER: Mein Gott! Was für eine tiefe Finsternis hat sich über den Berg gelegt! EIN MÄDCHEN (von denen, die an den Fluß gekommen sind): Heilige Frau! Der Tod lädt uns heute zu seinem Feste ein!

DER SÄNGER (der Baumeister nähert sich nachdenklich): $O$ weh! Wie habt euch, du und das Schicksal, an der Kreuzung getroffen?

DER ALTE MANN (schadenfroh): Gib auf, ob du willst oder nicht, und nimm die Hand des Schicksals!

(Die anderen kommen atemlos und schreien in Angst:)

- Der Fürst! Der Fürst!

$$
\text { (eine bedrückende Stille) }
$$

DER FÜRST (spricht langsam und feierlich): Gott hat unser ganzes Dorf meinen Händen anvertraut, und am morgigen Tag muß ich ihm über das Leben des Volkes Rechenschaft ablegen. Das Böse, ein unbeschriebenes Blatt, das auf eurer Brust wächst, wird Wurzeln auf meiner Brust schlagen und meine Eingeweide fressen. Darum tut es mir doppelt weh, ich muß die Schuldige finden, die die Ursache der Verwüstung unseres Dorfes ist. Wer es von euch weiB, wer sie ist, der hat das Verhängnis unseres Dorfes auf seinem Haupt und dem seiner Kinder. Tausendmal sei der verflucht, falls er ihren Namen nicht verrät, wer immer sie sein sollte: Frau oder Schwester!

DER ALTE MANN: Wir, unser Fürst, schwören bei unseren Kindern: wir wissen es nicht, wer die Schuldige ist. Und wie könnte sie selbst gestehen? Es ist süß das Leben auf der Welt, Fürst. Frag' den Baumeister. Nur er kann es gestehen, um sein Leben zu retten.

DER FÜRST (zum Baumeister, der nachdenklich dasteht): Baumeister!

(Der Baumeister antwortet nicht; er schaut nur auf die Brücke und schweigt)

DER SÄNGER: Erbarme dich unser, o Gott! Hab' mit dem Körper der schönen Verführerin Mitleid!

DER FÜRST: Es gibt kein Mitleid. Schweige, Sänger! Es gibt kein Mitleid. Es ist besser, einen einzigen zu töten, um Tausende zu retten. (Er geht auf ein blasses Mädchen zu, daß mehr als alle anderen zittert). Bist du diejenige, da du wie ein Halm zitterst? Deinetwegen scheint der Baumeister den Kopf verloren zu haben!

DIE JUNGE FRAU (weint und wirft sich zu Boden): Nein! Nein! Ich schwöre es bei meiner Seele, Fürst!

VIELE: Nein, sie ist es nicht, Fürst!

DAS JUNGE MÄDCHEN: Ich bin erst zwanzig Jahre alt und habe Angst vor dem Tod...

DER FÜRST: Es kann aber nicht anders sein, sie muß hier mitten unter euch stehen... Hier sind die besten Mädchen des Dorfes, hier ist sie versteckt und weint.

CHOR DER FRAUEN (angstvoll): Oh! 
DIE BAUARBEITER (kommen mit Kellen in der Hand): Die Sonne geht unter, die Sonne geht unter! Wir haben keine Zeit!

DER FÜRST (wütend und hartnäckig): Erschlagt den Baumeister und mauert ihn ein... wenn ihr sie nicht verraten wollt! Ich werde dich zwingen, Baumeister, ob du willst oder nicht; du wirst dich beugen und sprechen!

DER BAUMEISTER (geht langsam auf die Mäher zu, die ihn anfassen wollen): Faßt mich nicht an!

CHOR DER MÄNNER: Er ist schuldig, er hat unser Dorf ruiniert!

DER ALTE MANN: Dich verlangt der Fluß als Opfer.

DER BAUMEISTER: Faßt mich nicht an!

DER FÜRST: Nenne die Frau, deren Körper deinen Verstand verwirt hat und so die Brücke nicht bauen läßt. Nenne sie, wenn du leben willst!

DIE BAUARBEITER (kommen näher und bilden einen Halbkreis hinter den Mähern): Nenne sie, nenne sie!

- Ein Führer kann über sein Leben nicht bestimmen, Baumeister!

- Reiß dein Herz heraus, wirf' es in den Fluß, und dann gehen wir.

DER BAUMEISTER (zu sich, betrübt): Gib auf, mein Herz, und schreie nicht!

DER FÜRST (wütend): Schleppt inn weg, er soll eingemauer werden! (zu den Meistern, die murmeln und sich bedrohlich bewegen) Wozu klagt ihr und warum schreit ihr so? Ich bin hier der Fürst. Nehmt ihn fort! Ah, du willst sie nicht verraten!

(Smaragda kann sich nicht mehr zurïckhalten. Angstvoll hat sie hin und wieder den Baumeister beobachtet, sie ist aufgesprungen, um zu sprechen. Sie tritt einen Schritt vor, bleibt dann aber plötzlich stehen. Sie will schreien, hält sich dann aber zurück. Jetzt kann sie sich doch nicht mehr halten. Sie stürzt vor und hält die Männer, die den Baumeister wegschleppen wollen; mit einem triumphierenden Ausbruch ihres ganzen Körpers schreit sie).

SMARAGDA: Haltet ein, haltet ein. Ich bin es, die ihn liebt!

(Alle halten überrascht an. Der Fürst, verzweifelt, läuft zu Smaragda, umarmt sie und sagt ăngstlich zu ihr)

DER FÜRST: Mein Kind, mein Kind! Meine Smaragda! Was ist mit dir, was hast du?

DER BAUMEISTER:Smaragda!

DER SÄNGER (umarmt Smargdas' Knie): Hör' auf! Schweige, schweige!... 
SMARAGDA (löst sich unbeherrscht aus der Umarmung los): Ich liebe ihn, wirklich und ohne Zweifel! Über alles. Laß das alle hören! (heftig zu den Meistern:) Kommt nun, kommt! Ich liebe den Baumeister.

DER FÜRST (in Angst): Smaragda!

DIE BAUARBEITER (triumphierend): Sie hat gestanden, sie hat gestanden! Vergessen Sie Ihren Eid nicht, Fürst!

SMARAGDA: Vergiß deinen Eid nicht, Vater. Ich bin es, die ihn verführt und behext ihm die Kraft zum Bau der Brücke genommen hat. Die Mutter hat recht: ich bin es, die nicht mehr hier sein darf. So ist es... Wenn man sich für den opfert, den man liebt, dann ist das Sterben süß. (Die Baumeister nähem sich, um sie zu holen). Gehen wir!

DER FÜRST: Haltet ein! Nein, nein! Es wäre nicht genug, ihn nur zu lieben. Die Mutter hat gesagt, daß sich der Baumeister die ganze Nacht an ihrem Körper erfreut, meine Smaragda ist aber rein!

SMARAGDA (drückt die Hände verzweifelt auf die Brüste): Mein Gott, mein Gott!

DER SÄNGER: Vielleicht ist es doch eine andere Frau. Ihr sollt kein unschuldiges Blut vergieBen!

DER FÜRST: Der Baumeister soll weggeschleppt und eingemauert werden, wenn er nicht gestehen will!

(Der Chor der Mäher jubelt wieder vor Freude und umkreist den Baumeister).

SMARAGDA: Halt! Halt! (Sie stehen. Sie spricht gedämpft, als wäre sie verwundet). Der Baumeister hat sich in der Tat die ganze Nacht an mir und an meinem Körper erfreut.

DER FÜRST (voller Angst): Smaragda!

SMARAGDA: Schau mich nicht so an, Vater, schau mich nicht so an! (Sie neigt sich und weint). Es ist wahr.

DER BAUMEISTER: Es sind Lügen. Hören Sie nicht auf sie, Fürst! Sie lügt.

SMARAGDA: Seht ihr? Wenn er mich nicht liebte, würde er so sprechen? Nein, er würde schweigen und mich sterben lassen, um sein Leben und das Leben seiner geliebten Frau zu retten.

DER FÜRST (Außer sich geht er hin und her und weiß nicht, was tun. Mit Angst und einem Schimmer Hoffnung schaut er Smaragda direkt in die Augen): Mein Kind, hab Mitleid mit mir...

SMARAGDA: Mein Vater, mein Vater, du zerbrichst mein Herz...

DER FÜRST: Sag' mir, daß es nicht wahr ist, daß es nur ein Traum ist, ein schrecklicher Traum, den ich jetzt habe!

SMARAGDA: Das kann ich nicht, es ist wahr... Erinnerst du dich, wie oft du mir in der Früh sagtest, da $\mathrm{B}$ ich müde und blaß aussähe...

DER FÜRST (verzweifelt hält er die Hand vor ihren Mund): Sei still! 
CHOR DER FRAUEN (außer sich geratend und brüllend): Ah! Es waren seine Küsse! Ich habe sie oft gesehen, um Mittemacht, mit ihm beim Fluß...

- Ja, ich auch: Ich auch: Ich auch!

SMARAGDA: Jetzt schreit und brüllt ihr wie ein Bluthund auf dem sterbenden Hirsch! Ja, alle habt ihr mich gesehen; na, und? Ich habe bis jetzt meine Schönheit in seine Hände gegeben; ihr habt mich gehaßt; jetzt werfe ich auch meine Liebe weg. Ihr braucht nicht zu schreien. Er kennt alle Male meines Körpers. Und was, wenn ich sterbe?! Auch der ganze Fluß kann seine Küsse nie von meinem Körper waschen!

CHOR DER FRAUEN: Selbst der ganze Fluß kann die Schande von deinem Körper nie waschen!

DER SÄNGER: Mein Gott, wie süß ist die Schande, wie süß!

CHOR DER FRAUEN: Du hast wohl deinen Verstand verloren!: Du Buhlende der Nacht! Du Unverschämte!

SMARAGDA: Schreit nur, so viel ihr wollt. Was kümmert es mich? (Sie streckt die Hände aus und geht auf den Chor zu). Kommt näher, schimpft nur auf mich, fasst mich an, nehmt meine Hände in eure Hände, haltet eure Wangen an meine Wangen, presst eure Lippen auf meine Lippen. Das kümmert mich nicht: greift mich an, wie ihr wollt, ihr könnt meinen Körper nie beschmutzen! Mein Körper duftet wie eine blühende Wiese.

(Der Fürst stürzt sich verzweifelt auf sie, um sie zu schlagen und zum Schweigen zu bringen).

DER FÜRST: Noch schwerer als die Brücke möge der Beil meines Fluchs auf dir sein, Smaragda!

SMARAGDA (bricht zusammen und schlägt auf den Boden, als hätte sie ein Beil getroffen): Ah! (Sie kriecht, um die Hand ihres Vaters zu fassen).

DER FÜRST (zieht sich zurück): Faß' mich nicht an! Du hast mein Haus, mein Ansehen und meinen Namen entehrt. Wie Asche hast du meine Ehre in die vier Winde zerstreut! Wo soll ich nun bleiben, wo soll ich hingehen?

SMARAGDA: Schweig. Vater! Hab Mitleid mit mir!

DER BAUMEISTER (kann es nicht mehr ertragen): Schweig', Smaragda, schweig und wein nicht! Erst jetzt fühle ich, wie tief und grenzenlos ich dich liebe! Ich habe Straßen gelegt, Berge und Meere aufgerissen, Flüsse überbrückt, ich bin auf meinem Traum geritten auf der Suche nach dir. Wieso tretet ihr zwischen uns? Ich liebe sie und sie liebt mich! Wir brauchen nicht eure Genehmigung, um uns die ganze Nacht aneinander zu erfreuen.

SMARAGDA (Mut fassend ist sie jetzt für die Aufopferung bereit): O! Danke, danke!

DER FÜRST (zum Baumeister): Es war eine schwarze Stunde, da dein Schatten die Schwelle meines Hauses beschmuzte. Verführer und Genießer: so hast du dich gezeigt; wie ein Korsar bist du hereingeschlichen und hast mich um meine Ehre gebracht! (zu Smaragda, die ihn anfleht zu schweigen) $\mathrm{FaB}$ mich nicht an, ich habe keine Tochter mehr! (Er schlägt sich verzweifelt auf 
die Brust, als wolle er sie in zwei Teilezerreißen). Verzweiflung, wie kannst du schlaffen?! Nehmt sie, ich möchte sie niemehr sehen! Meine Augen verdunkeln sich. Wach auf, Verzweiflung, du bist jetzt meine einzige Tochter!

(Weint. Einige Mäher holen ihn, um ihn nach Hause zu bringen, die Arbeiter nehmen Smaragda. Smaragda dreht sich um und sieht ihren Vater an; im gleichen Augenblick hat auch er sich gewendet, um Smaragda zu sehen; Smaragda stürzt sich auf ihren Vater, der seine Arme ausgestreckt hat, beide weinen).

SMARAGDA: Mein Vater! Gib mir den letzten süßen Kuß und tröste mich auf meiner Reise ohne Rückkehr.

DER FÜRST: Mein Kind, mein Kind! (Er küßt sie und weint).

DIE BAUARBEITER- Die Sonne geht unter, die Sonne geht unter! Beeilen wir uns!

(Sie werden nur mit Mühe getrennt. Der Fürst geht ab. Smaragda bewegt sich zum Fluß langsam wie eine Braut. Der Baumeister geht nachdenklich und entschlossen an ihrer Seite).

DER BAUMEISTER: Wein nicht, mein Liebling (Er nimmt sie am Arm und hilft ihr beim Gehen).

SMARAGDA: Komm näher zu mir, noch näher! Ich will dich in meinem Herzen spüren; so kann ich gleichsam jetzt als deine Braut gehen... (Sie entsinnt sich plötzlich und stößt einen Schrei aus) Oh! Der Fluß ist mein Bräutigam, die Erde das Brautbett meiner Ehe, und die blutigen Beile sind mein Schleier.

DER SÄNGER: Tut es dir nicht leid um deinen schönen Körper?!

SMARAGDA: Ich bin stolz, da $B$ ich einen schönen Körper habe, und da $B$ ich demjenigen meinen Körper schenke, den ich liebe.

DER SÄNGER: Smaragda, Smaragda! Du weinst! Denke, wie schwarz und finster die Unterwelt ist; ohne Feiern, ohne Sonne. Die schönen Jünglinge sind zerrissene Bäume und die schlanken Mädchen zertrümmerte Tore, die kleinen Kinder verfaulte Äpfel in der Unterwelt!

SMARAGDA (mit Angst) Schweig', schweig' Du flößt mir Angst ein, ich habe Angst vor dem Tod (Sie läßt ihre Tränen fließen und steht still. Zu den Meistern, die sie holen): Habt ihr es eilig? Lasst mich noch einen Tag leben, einen einzigen Tag. Ich habe noch nicht einmal richtig gesehen, wie die Berge rot werden, sobald die Sonne aufgeht. Ich habe mir auch noch nicht gemerkt, welcher Vogel als erster beim Tagesanbruch zwitschert. Ich habe noch nicht genug gesehen. Nur einen Tag, nur einen Tag!

DER BAUMEISTER: Schweig, Smaragda, und weine nicht. Wir haben in einer einzigen Nacht Tausende und Tausende von Jahren ehelichen Glückes und auch ganz normale Jahre wie die von ihnen erlebt. Das ganze Leben haben wir uns auf den Mund geküßt, so sterben wir jetzt ruhig und erfüllt. 
SMARAGDA (lächelt mit Bitterkeit, als spräche sie vor sich hin).

"Wie ruhig sind die Berge, wie ruhig die Wiesen; sie warten auf keinen Tod, und werden nicht alt!".

(Ein Arbeiter kommt laufend von der Brücke, mit Kelle und Hammer in der Hand).

- Beeilt euch, beeilt euch! Die Sonne geht unter. (Zeigt mit der Kelle auf den schönen Sonnenuntergang hinten).

SMARAGDA (Springt voll Körper auf): Die Sonne!

DER BAUMEISTER: Meine Smaragda! Meine Smaragda!

DER SÄNGER: Wie eilig hast du es, Baumeister! Laß sie doch noch für einen Augenblick Freude an der Sonne haben.

SMARAGDA (Streckt ihre Arme hungrig der Sonne zu. Die Sonne durchtränkt ihre Augen, Haare, Hände, so wie sie es mit der dürstenden Erde macht).

- O Sonne! Jetzt, in der Stunde der Trennung spüre ich dich noch schwerer und süßer, gleich wie den Körper des Liebhabers auf mir. Du füllst meine Handflächen meine Haare, meine Augen und die Falten meiner Kleider, und ich fühle, wie du meinen warmen Hals fest umarmst. Du gehst wie ein goldenes Kreuz zwischen meinen Brüsten unter: o Sonne!

(Sie kann die Tränen nicht mehr zurückhalten, die langsam und lautlos über ihre Wangen rollen).

DER BAUMEISTER: Komm jetzt, nicht zittern. Wie zitterst du, meine Smaragda!

DER SÄNGER (springt wütend auf) Ah! Was willst du denn? Daß sie nicht zittere? Daß sie, zum Tode geschleppt, lache und dir sage 'danke!' Verflucht sollen deine Brücken sein, Baumeister! Was wird nun aus uns werden, ohne Smaragda, verwaist? Ein einziges ihrer Haare ist viel wervoller als all deine Brücken zusammen! Lieber sitze ich am Ufer, ohne den Fluß überqueren zu müssen, und Smaragda kommt zu mir und lächelt mir zu, um mich zu heilen, viel lieber als eiserne Brücken zu haben, und über sie zu reiten. (Zu Smaragda) Meine Smaragda! Ich zerbreche meine Flöte und werfe sie in den Fluß! (Er zerbricht die Flöte auf seinen Knien) O du von allen bewunderte Schönheit! Nur ich kann dich erfühlen und beweinen! Smaragda! Smaragda! Du bist nur für einen kurzen Augenblick über uns wie ein fallender Stem erschienen.

SMARAGDA: Schweige, mein Sänger, schweige! O Sonne und Berge, o Bäume und Meere, ich habe euch so geliebt. Lebt wohl! Niemand wird mir den rosigen Günel meiner zwanzig Jahre dort unten in der schwarzen Erde umschnallen (Sie bleibt stehen und zittert).

DER BAUMEISTER: Meine Liebe, meine Liebe! (Sie sind bei der Brücke).

SMARAGDA: Oh! (Der Baumeister beugt sich, um sie zu küssen. Angstvoll streckt Smaragda ihre Hände aus, um ihn zu halten). Küß mich nicht, nein! Ich werde nicht mehr die Kraft haben 
zu sterben. (zu den Meistern:) Gehen wir. Macht schnell. (Sie führen sie langsam zu den Fundamenten der Brücke $a b)$.

DER SÄNGER: Schließe deine Augen, Smaragda, schließe deine Augen und schaue nicht auf die Schönheit der Welt.

DER BAUMEISTER (beugt sich über sie): Schweig' und weine nicht. Ich liebe dich. Schweig'!

DER SÄNGER (mit wehmütiger Stimme): Du, Schönheit, gehst weg, und wo läßt du mich? (Er stürzt sich auf die Steine).

DER BAUMEISTER ( schiebt den Sänger, der ihm den Weg versperrt hat, zur Seite): Geh auf die Seite und schreie nicht! (zu den Meistem, die Steine und Kalk herantragen:) Stठ̋sst vier Pfeiler ein statt zwei (Seine Stimme ist laut und zugleich gerührt). Mauert sie mit Blei und Eisen ein!

SMARAGDA (von unten): Och!

DER BAUMEISTER: Meine Liebe, meine Liebe! Du darfst nicht zittern (Er redet mit ihr, über sie gebeugt).

DIE BAUARBEITER (fröhlich, da die Brücke fest und stark wird): Sei gegrüßt, auf dein Wohl, Baumeister!

DER BAUMEISTER (dreht sich zornig um): Haltet den Mund!

(Die Meister arbeiten. Man hört nur das Hämmem der Arbeiter und das Schluchzen des Sängers. Es dauert eine Weile. Niemand spricht. Plötzlich kommt aus den Fundamenten der Brücke die erstickte Stimme Smaragdas empor).

SMARAGDA: Langsam, langsam! Es tut mir weh!

EIN ARBEITER- O! Was wäre wenn die Brücke so wie ihr kleines Herz und ihre Stimme zittert?

EIN ANDERER (beugt sich, schaut hinunter und sagt): Sie steht da, zusammengefaltet, und zieht ihre Knie an sich.

EIN ANDERER: thre Haare hängen frei und flattern wie Seetang im Meer, ihr ganzer Körper zittert.

DER BALMEISTER (beugt sich und ruft): Oh! Zittere nicht, meine Smaragda! Drück deine Knie fest mit den Händen zusammen, so daß sie sich nicht mehr bewegen, neine Liebe!

SMARAGDA:Ooh!

DIE BAUARBEITER: Die Brücke wird stark... Sie wird stark... Sie schwankt nicht mehr...

(Stille. Man hört noch immer die Meister beim Arbeiten und den Sänger weinen. Der Baumeister steht auf der Brücke, wankt und stöhnt).

DER BAUMFISTER: Meine Smaragda! Meine Smaragda! 
(Smaragda von unten mit halbtoter dünner Stimme:)

SMARAGDA: Schweig', mein Bester, schweig'. Hab' keine Angst. Aus meinem Herzen mache ich ein Stück Eisen, und eisenhart soll auch die Brücke werden. Meine Haare werden zu Eisen, und stark wie Eisen sollen die Menschen über die Brücke gehen, mein Liebling.

DER SÄNGER (nachdenklich): Mein Gott, mein Gott! Wieviel stärker ist die Liebe als der Tod!

DIE BAUARBEITER: Die Brücke schwankt nicht mehr! Sie schwankt nicht mehr! Sie wird eisenhart!

DER BAUMEISTER (schreit): Smaragda!

(Beklemmende Stille. Man vernimmt kaum ein Stöhnen. Der Baumeister ruft noch einmal verzweifelt).

DER BAUMEISTER: Smaragda!

(Alle werfen Steine hinunter. Der Sänger wirft seine zerbrochene Flöte weg und weint. Der Baumeister lässt einen großen Stein hinunter. Die Zigeuner arbeiten fröhlich, die Mäher werfen immer wieder Steine hinab. Das Wetter ist ruhig und friedlich geworden, der Sonnenuntergang vergoldet alles rundumher).

\section{DER GANZE CHOR: DIE ZIGEUNERINNEN}

- Auf dein Glück, Baumeister!

\section{DER ERSTE HALBCHOR}

- Als siegreicher Reiter gehst du durch die engen Gassen der Jugend, Baumeister, wo Frauen lauem und töten!

\section{DER ZWEITE HALBCHOR}

- Meine Hände strecke ich aus und segne dein Schicksal, Smaragda. Wie ein Adler schwebt dein Geheimnis über meinem Haupt. Ach! Wenn auch ich das Leben und den Tod so wie du entgegennehmenkönnte!

\section{DER GANZE CHOR: DIE BAUARBEITER}

- Sei gegrüßt, Baumeister!

- Wir sind die Krähen, die die Samen von Seele zu Seele und vom Berg zum Felde bringen, die schwarzen Schwalben der Jugend.

(Der Baumeister hör ihnen wehmütig und unbewegt zu. Plötzlich steht er auf).

- Steht auf! Unsere Arbeit hier ist beendet. Gehen wir). 
(Sie laufen umher, falten die Zelte zusammen und bereiten sich vor zu gehen... Die Zigeuner spielen auf ihren Kastagnetten und Tamburinen in einem wilden Wirbel. Jubelnd schreien sie):

- Auf dein Wohl und dein Glück, Baumeister!

(Petros Psiloritis - 1908) 